\title{
Expression und Funktion von Caveolin bei glialen Zellen, insbesondere Oligodendrozyten
}

\author{
Dissertation \\ zur Erlangung des Doktorgrades \\ der Mathematisch-Naturwissenschaftlichen Fakultäten \\ der Georg-August-Universität zu Göttingen
}

vorgelegt von

Matthias Schmitz

aus Hamm

Göttingen 2006 
Referent: Prof. Dr. rer. nat. Hardeland Korreferent: Prof. Dr. rer. nat. Engel

Tag der mündlichen Prüfung: 04.05.2006 


\section{Einleitung}

$\begin{array}{ll}\text { Abkürzungsverzeichnis } & 1\end{array}$

1.1 Morphologie und Funktion glialer Zelltypen des ZNS 4

1.2 Entwicklung und Differenzierung von OL in vivo und in vitro 5

$\begin{array}{lll}1.3 & \text { Regulation der Fortsatzbildung von OL } & 6\end{array}$

$\begin{array}{lll}\text { 1.3.1 Neurotrophine } & 7\end{array}$

1.3.2 Neurotrophinrezeptoren und nachfolgende Signalkaskaden 8

1.4 Lipid Rafts oder Membran-Mikrodomänen 11

1.4.1 Cholesterin als Bestandteil von Mikrodomänen 12

$\begin{array}{ll}\text { 1.4.1.1 Cyclodextrine } & 13\end{array}$

1.4.2 Caveolae/Caveolin 14

1.4.2.1 Caveolin/CMD-Struktur 16

1.4.2.2 Interaktionen zwischen Caveolin und Cholesterin 18

1.4.3 Lipid Rafts/CMD und Signaltransduktion 19

1.4.3.1 Rolle der Lipid Rafts bei der Signaltransduktion 19

1.4.3.2 Caveolin/CMD bei der Signaltransduktion $\quad 21$

1.5 Fragestellung und Ziele dieser Arbeit 22

\section{Material und Methoden}

2.1 Verwendete Geräte und Reagentien 24

2.1 .1 Geräte 24

2.1.2 Verwendete Verbrauchsmaterialien und Reagentien 26

2.1.3 Verwendete Antikörper 30

2.1.4 Transfektionsreagentien/Transfektion 31

2.2 Zellkultur 31

2.2.1 Präparation von Schweine-OL 33

2.2.2 Anlegen einer Monolayer Zellkultur 34

2.2.3 Lebendzellfärbung 35

2.2.3.1 Trypanblau bzw. Ethidiumbromid-Färbung 35

2.2.3.2 MTT-Assay 35

2.2.4 Isolation von Myelin 36

$2.3 \quad$ Immuncytochemie 37

2.3.1 MOSP (Maus anti-Myelin Oligodendrocyte specific Protein)-Färbung 37

$\begin{array}{lll}\text { 2.3.2 Caveolin-1-Färbung } 38 & 38\end{array}$ 
$\begin{array}{lll}2.4 & \text { Proteinkonzentrationsbestimmungen } & 38\end{array}$

2.4.1 Bestimmung der Proteinkonzentration mit der Tüpfelprobe 38

2.4.2 Bestimmung der Proteinkonzentration mithilfe der Dot-Methode 39

2.4.3 Proteinbestimmung nach Bradford 40

2.4.4 Herstellung der Proteasehemmer 40

2.5 Isolation von CMD 41

2.5.1 Isolierung von $\mathrm{CMD}$ mittels Detergens-freier $\mathrm{NaCO}_{3}$-haltiger SaccharoseDichtegradientenzentrifugation $\quad 41$

2.5.2 Isolation von CMD mittels Triton X-100-haltiger SaccharoseDichtegradientzentrifugation

2.5.3 Anreicherung von CMD aus der Plasmamembran unter Anwendung von MACS (Magnetic Cell Sorting)-Technologie 43

2.6 Cholesterin-Bestimmung 45

2.7 Immunpräzipitation 46

$\begin{array}{lll}2.8 & \text { SDS-Polyacrylamidgel-Elelektrophorese } & 47\end{array}$

2.9 Western Blot/Immunoblot 50

2.9.1 Detektion des chemilumineszenten sekundären Antikörpers mithilfe eines Röntgenfilms $\quad 52$

2.10 Gelfärbungen 53

2.10.1 Coomassie-Färbung 53

2.10.2 Silberfärbung $\quad 54$

2.10.3 Gel-Konservierung 55

2.11 MAPK In-Gel Kinase Assay 55

Molekularbiologische Methoden

2.12 RNA-Isolierung 58

2.13 Herstellung von cDNA durch reverse Transkription 59

2.14 PCR (Polymerase-Kettenreaktion) 60

2.15 Klassische RT-PCR 62

$\begin{array}{lll}2.16 & \text { Agarosegelelektrophorese } & 63\end{array}$

$\begin{array}{lll}2.17 & \text { Transfektion mit siRNA } & 64\end{array}$

$\begin{array}{ll}\text { 2.17.1 Herstellung der siRNA } & 65\end{array}$ 


\section{Ergebnisse}

3.1 Charakterisierung von Schweine-OL unter Standardbedingungen

3.2 Immunzytochemischer Nachweis von Caveolin-1 bei Schweine-OL und deren spezifische Färbung durch anti-MOSP

3.3 Schweine-OL exprimieren von den drei Caveolin-Subtypen lediglich Caveolin-1

3.4 Detektion von Caveolin-1 innerhalb der Myelinmembran

3.5 Immunzytochemischer Nachweis von Caveolin-1 und TrkA mittels konfokaler Lasermikroskopie

3.6 Darstellung der Assoziation von Caveolin-1 und TrkA mittels

Coimmunpräzipitation 73

3.7 Elektronenmikroskopische Darstellung von Caveolae in Schweine-OL 74

3.8 Veränderungen der Caveolin-1 Expression und des Cholesterin-Levels mit zunehmender Kulturdauer von Schweine-OL $\quad 76$

$\begin{array}{lll}3.9 & \text { Isolation von CMD aus Schweine-OL }\end{array}$

3.9.1 Isolation von CMD nach der Methode von Lisanti mittels detergenshaltiger Saccharose-Dichtegradientzentrifugation

3.9.2 Isolierung von CMD mittels detergensfreier Saccharose-

$\begin{array}{ll}\text { Dichtegradientenzentrifugation } & 79\end{array}$

3.9.2.1 Verteilung des CMD-Markerproteins Flotillin 81

$\begin{array}{ll}\text { 3.9.2.2 Verteilung von Cholesterin } & 81\end{array}$

3.9.2.3 Nachweis der Neurotrophinrezeptoren TrkA, p75 ${ }^{\mathrm{NTR}}$ und von

Signalproteinen wie p21 Ras in den CMD-angereicherten Fraktionen 4-6 82

3.9.3 Isolation von CMD aus der Plasmamembran mithilfe von MACS 83

3.10 CMD/Caveolin-1-Interaktionen mit NGF/TrkA 86

3.10.1 Einfluss von NGF auf die Caveolin-1-Expression in Schweine-OL 86

3.10.1.1Untersuchung der Caveolin-1-spezifischen mRNA-Synthese in Schweine-OL nach Stimulation mit NGF 86

3.10.1.2 Beeinflussung der Caveolin-1-Proteinexpression durch NGF 87

3.11 Inhibitorische Einflüsse von Caveolin-1 auf die

$\begin{array}{ll}\text { NGF-Signaltransduktion } & 88\end{array}$

3.11.1 MAPK-Aktivität von 8 Tage kultivierten und von 30 Tage kultivierten

OL unter NGF $\quad 89$

3.11.2 Einfluss einer erhöhten Caveolin-1-Expression auf die MAPK-Aktivität 90 
3.11.3 Inhibition der MAPK-Aktivität durch Cavtratin 91

3.12 Transfektion von Schweine-OL mit siRNA 92

3.12.1 Aufnahme eines fluoreszierenden Transfektionsreagens 93

3.12.2 Test von verschiedenen Transfektionsreagentien auf ihre Zellverträglichkeit und Transfektionseffizienz 93

3.12.3 Untersuchung der Zellverträglichkeit von jetSI-Endo in einem MTTLebendzellassay 95

3.12.4 Transfektion von OL mit MAPK-spezifischer siRNA 96

3.13 Reduktion der Caveolin-1-Expression in Schweine-OL durch $\begin{array}{ll}\text { Transfektion mit Caveolin-1-spezifischer siRNA } & 97\end{array}$

3.13.1 Immunzytochemische Darstellung des durch Transfektion mit Caveolin-1-siRNA herbeigeführten Caveolin-1-Knock-downs 98

3.13.2 Nachweis des Caveolin-1-Knock-downs im Western Blot 99

3.13.3 Morphologische Auswirkungen eines Caveolin-1-Knock-downs 100

3.13.4 Auswirkung einer reduzierten Caveolin-1 Expression auf die MAPK$\begin{array}{ll}\text { Aktivität von Schweine-OL } & 102\end{array}$

3.1.4 Phosphorylierung von Caveolin-1 an Tyr.14 (Caveolin pY14) nach $\begin{array}{ll}\text { Stimulation von Schweine-OL mit NGF } & 104\end{array}$

$\begin{array}{ll}\text { 3.14.1 Immunzytochemischer Nachweis } & 104\end{array}$

3.14.2 Quantifizierung der Caveolin pY14 nach Stimulation von Schweine-OL $\begin{array}{ll}\text { mit NGF } & 105\end{array}$

3.14.3 Nachweis der NGF-induzierten Caveolin pY14 mittels Western Blot

3.14.4 Inhibition der NGF-induzierten Caveolin-1-Phosphorylierung durch $\begin{array}{ll}\text { PP2 und durch K252a } & 108\end{array}$

3.14.5 Anfärbung der Caveolin pY14 und der TrkA-Phosphorylierung 109

3.15 Einfluss von Cholesterin auf die Signalgebung in Schweine-OL unter NGF 111

$\begin{array}{ll}\text { 3.15.1 Aufnahme von Cholesterin } & 111\end{array}$

3.15.2 Morphologische Charakterisierung von Schweine-OL nach Gabe von PEG-600 Cholesterin 113

3.15.3 Kombination von PEG-600 Cholesterin und NGF 114

3.15.4 Wirkung von PEG-600 Cholesterin auf die Expression von Caveolin-1 115 
3.15.5 Einfluss der Kombination von Cholesterin und NGF auf die MAPK-

Aktivität

3.15.6 Reduzierung des Cholesterin-Levels mithilfe von Methyl-ß-Cyclodextrin 117

3.15.7 Morphologische Auswirkungen eines durch Methyl-ß-Cyclodextrin herbeigeführten Cholesterinmangels

3.15.8 Auswirkung eines Cholesterinmangels auf die MAPK-Aktivität nach

NGF-Stimulation

3.15.9 Bestimmung des Cholesterin-Levels von Schweine-OL, die mit NGF stimuliert wurden

3.15.10 Beeinflussung des Cholesterin-Levels durch einen mittels siRNA herbeigeführten Caveolin-1-Knock-down

\section{Diskussion}

4.1 Detektion von Caveolin in adulten Schweine-OL

4.1.1 Morphologische Erscheinungsformen von CMD

4.2 Isolationstechniken zur Isolierung von CMD

127

4.3 Regulation der NGF/TrkA-Signaltransduktion in CMD

4.3.1 Interaktion von Caveolin-1 und TrkA

129

4.3.2 CMD/Caveolin-1 als Plattform für die NGF/TrkA-Signalkaskade

130

4.4 NGF-bedingte Einflüsse auf Caveolin-1/CMD

4.4.1 Hochregulation der Caveolin-1-Expression durch NGF

4.4.2 NGF-induzierte Caveolin-1 Phosphorylierung an Tyrosin-14

4.4.2.1 Zusammenhang zwischen der Phosphorylierung von TrkA und der Caveolin pY14

4.5 Caveolin als Negativregulator: Treten altersbedingte Effekte auch in Schweine-OL-Kulturen auf?

4.5.1 Inhibition des NGF/TrkA-Signalweges durch die Caveolin-1-Gerüst (Scaffolding)-Domäne

4.6 Auswirkungen eines durch Transfektion mit Caveolin-1-spezifischer siRNA herbeigeführten Caveolin-1-Knock-downs auf die Fortsatzbildung von OL

4.6.1 Caveolin-1 als förderndes und hemmendes Regulativ der NGF/TrkA Signalkaskade? 
4.7 Regulation der NGF-Signalkaskade durch die CMD-Komponente Cholesterin

4.7.1 Erfolgt eine indirekte Modulation der NGF/TrkA Signalkaskade via Caveolin-1 über die Cholesterin Homöostase?

4.8 Quintessenz der Arbeit

4.9 Zusammenfassung der Arbeit

\section{Literaturverzeichnis}

5.1 Referenzen 


\section{Abkürzungsverzeichnis}

Abb.

Ak

APS

Aqua dest.

Ara-C

AS

BIS N,N'

bp

BSA

bzw.

$\mathrm{Ca}^{2+}$

$\mathrm{CaCl}_{2}$

Caveolin pY14

CB

cDNA

CMD

d.h.

DIV

DMSO

EDTA

$\mathrm{EtOH}$

FCS

FITC

g

h

$\mathrm{HCl}$

HP

Ig

$\mathrm{kDa}$

1

Lsg.

M
Abbildung

Antikörper

Ammoniumperoxodisulfat-Stammlösung

destilliertes Wasser

Cytosin-1-beta-D-Arabinofuranosid

Aminosäure

Methylenbisacrylamid

Basenpaare

Bovine Serum Albumin (Rinderserumalbumin)

beziehungsweise

Calcium

Calciumchlorid-Dihydrat

Caveolin Phosphorylierung an Tyrosin-14

Coomassie Brillant Blau G-250

copy DNA

caveolinhaltige Mikrodomänen

das heißt

Tage in Kultur (Days in vitro)

Dimethylsulfoxid

Ethylendiamintetraessigsäure

Ethanol

Fetal Calf Serum (Fetales Kälberserum)

Fluorescein Isothiocyanat

Gramm

Stunde

Chlorwasserstoff (Salzsäure)

Hexose-Phosphat-Puffer

Immunglobulin

Kilodalton

Liter

Lösung

Molar 


\begin{tabular}{|c|c|}
\hline $\mathrm{mA}$ & Milliampere \\
\hline MAPK & Mitogen-activated Protein Kinase \\
\hline MBP & Myelin Basic Protein \\
\hline $\mathrm{mCi}$ & Millicurie (radioaktive Einheit) \\
\hline MEM & Minimal Essential Medium-Earle \\
\hline MG & Molekulargewicht \\
\hline mg & Milligramm \\
\hline $\mathrm{MgCl}_{2}$ & Magnesiumchlorid \\
\hline $\min$ & Minuten \\
\hline$\mu g$ & Mikrogramm \\
\hline$\mu l$ & Mikroliter \\
\hline $\mathrm{ml}$ & Milliliter \\
\hline$\mu \mathrm{M}$ & Mikromolar \\
\hline $\mathrm{mM}$ & Millimolar \\
\hline $\mathrm{mm}$ & Millimeter \\
\hline mmol & Millimol \\
\hline mOs & Milliosmol \\
\hline mRNA & Messenger-Ribonucleinsäure \\
\hline $\mathrm{Na}$ & Natrium \\
\hline $\mathrm{Na}_{3} \mathrm{VO}_{4}$ & Natrium-Orthovanadat \\
\hline $\mathrm{nCi}$ & Nanocurie \\
\hline ng & Nanogramm \\
\hline NGF & Nerve Growth Factor \\
\hline NGFR & Nerve Growth Factor Receptor \\
\hline $\mathrm{nM}$ & Nanomolar \\
\hline $\mathrm{nm}$ & Nanometer \\
\hline NS & nicht-kodierend (nonsense) \\
\hline OL & Oligodendrozyten \\
\hline $\mathrm{p} 75^{\mathrm{NTR}}$ & Protein 75 Neurotrophin Rezeptor \\
\hline PBS & Phosphat-buffered Saline \\
\hline $\mathrm{pH}$ & Negativer dekadischer Logarithmus der $\mathrm{H}^{+}$Ionen Konzentration \\
\hline PMSF & Phenylmethan-sulfonylfluorid \\
\hline PNS & Peripheres Nervensystem \\
\hline P-TrkA & Phosphoryliertes TrkA \\
\hline
\end{tabular}




$\begin{array}{ll}\text { r.E. } & \text { relative Einheiten } \\ \text { RT } & \text { Raumtemperatur } \\ \text { sek } & \text { Sekunde } \\ \text { SDS } & \text { Natriumdodecylsulfat } \\ \text { SDS-PAGE } & \text { SDS-Polyacrylamid Gelelektrophorese } \\ \text { siRNA } & \text { short interference RNA } \\ \text { TBS } & \text { Tris-buffered Saline } \\ \text { TCA } & \text { Trichloressigsäure } \\ \text { TEM } & \text { Transmissionselektronenmikroskop } \\ \text { TEMED } & \text { N,N,N',N'-Tetramethylethyldiamin } \\ \text { Trk } & \text { Tyrosin Receptor Kinase } \\ \text { U } & \text { Units } \\ \text { UV } & \text { Ultraviolett } \\ \text { (v/v) } & \text { Volumen bezogen auf Volumen } \\ \text { (w/v) } & \text { Einwaage bezogen auf Volumen } \\ \text { z.B. } & \text { zum Beispiel } \\ \text { ZNS } & \text { Zentrales Nervensystem } \\ {\left[\gamma^{-33}\right]-A T P} & \text { ATP mit radioaktiv markiertem Phosphat }\end{array}$




\section{Einleitung}

\subsection{Morphologie und Funktion glialer Zelltypen des ZNS}

Die früher als Stützzellen oder Kittzellen bezeichneten Gliazellen (vom griechischen Wort glia für "Leim, Kitt“) kommen überall im zentralen (ZNS), aber auch im peripheren Nervensystem (PNS) vor. Sie füllen fast den ganzen “nichtneuralen“ Raum aus. Heute weiß man, dass ihre Funktion weit über die seiner Zeit angenommene Rolle einer Kittsubstanz hinausgeht.

Gliazellen werden in Makro- und Mikroglia unterteilt. Mikroglia sind Makrophagenähnliche "Fresszellen“ des Gehirns (BRUCE-KELLER et al., 1999). Zu den makroglialen Zellen gehören Astrozyten und Oligodendrozyten (OL).

Astrozyten lassen sich in Typ I und Typ II unterteilen. Typ I Astrozyten haben eine Fibroblasten-ähnliche Morphologie, dagegen sind Typ II Astrozyten sternförmige Zellen mit vielen Verästelungen und Fortsätzen. Astrozyten haben sehr vielseitige physiologische Funktionen und sind sowohl mit Axonen, als auch mit NervenZellkörpern assoziiert. Darüber hinaus gehen sie enge Verbindungen mit Blutkapillaren ein und sind an der Ausbildung der Blut-Hirn-Schranke, am Metabolismus von Neurotransmittern und an der Aufrechterhaltung des extrazellulären Milieus beteiligt. Sie versorgen Neurone mit Sauerstoff und Nährstoffen, speichern Nährstoffe wie Glykogen und transportieren neuronale Stoffwechselprodukte wie $\mathrm{CO}_{2}$ und $\mathrm{NH}_{4}$ ab.

OL bilden eine isolierende Markscheide (Myelin) um Axone des ZNS, indem sich ihre Fortsätze in mehrfachen spiraligen Schichten um die Axone herumwickeln. Während der Myelinaufbauphase produzieren OL ein Mehrfaches ihres eigenen Gewichtes. Beim Myelin handelt es sich um eine spezialisierte Plasmamembran der OL, die zu etwa 70\% aus Phospholipiden, Glykolipiden und Cholesterin sowie zu etwa 30\% aus Membranproteinen besteht. Darüber hinaus fehlen im kompakten Myelin Ionenkanäle fast vollständig, weshalb Axone von Myelin gut elektrisch isoliert werden. Ein Oligodendrozyt kann bis zu 50 Axonsegmente myelinisieren (PETERS 1964), eine Schwannzelle, die im PNS Axone myelinisiert, dagegen in der Regel nur eines (PFEIFFER et al., 1993). Ein Axon ist nicht durchgängig myelinisiert, sondern weist auch myelinfreie Stellen auf, die Ranvierschen Schnürringe. Ranviersche Schnürringe bzw. Knoten (nicht-myelinisierte Axonabschnitte von ca. $0.5 \mu \mathrm{m}$ Länge) und Internodien (bemarkte Axonabschnitte bis $\mathrm{zu} 1 \mathrm{~mm}$ Länge) ermöglichen eine 
saltatorische und damit raschere Erregungsleitung, d.h. bis zu 100-200 ms. Je dicker die Faser und je größer die Schnürringabstände, desto schneller die Weiterleitung des elektrischen Signals. Bei marklosen Nervenfasern erfolgt die Erregungsleitung um bis zu 100mal langsamer (LEMKE 1988).

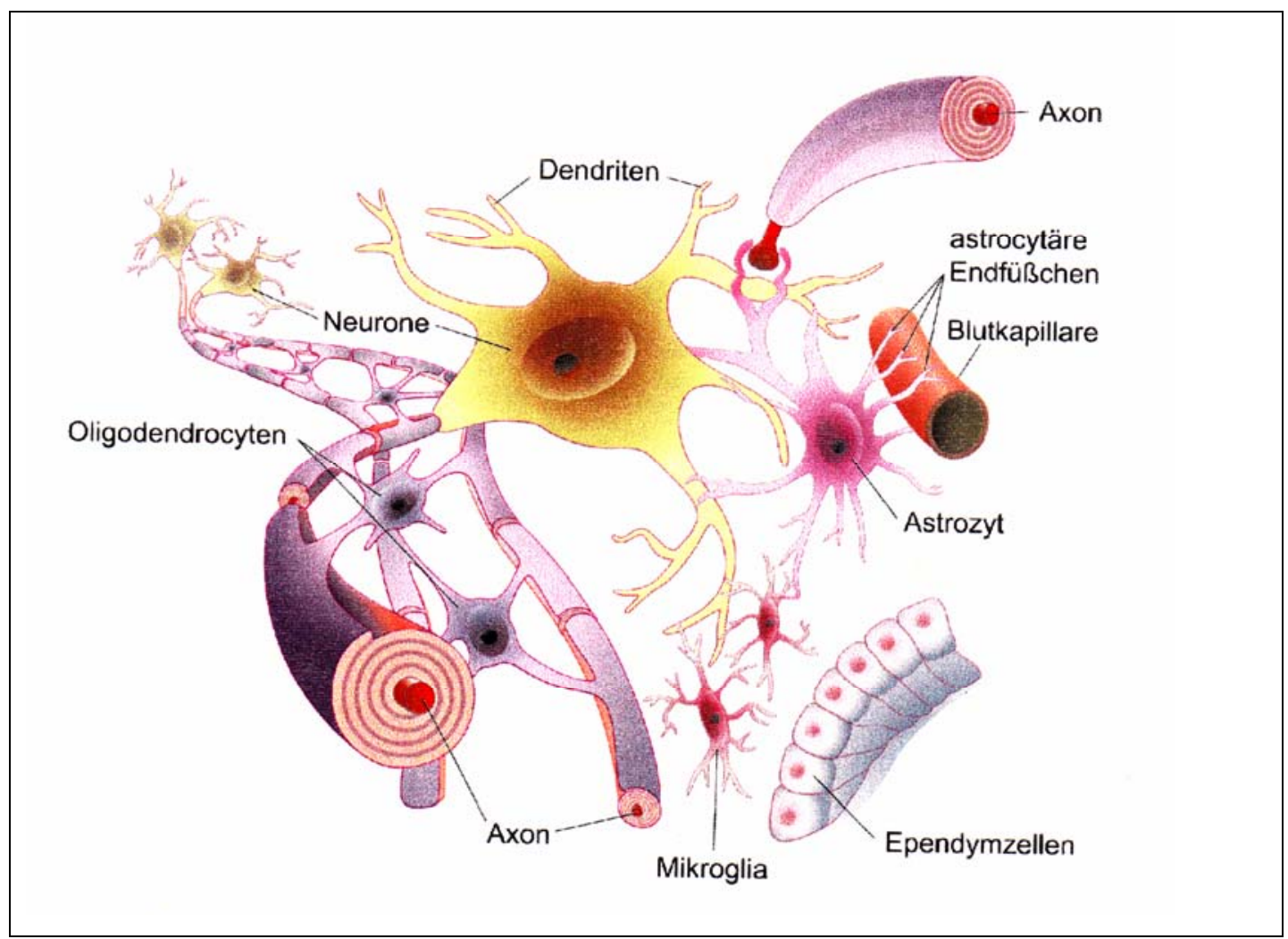

Abb. 1: Schematische Darstellung der verschiedenen Zelltypen im ZNS in ihrer anatomische Anordnung (modifiziert nach www.shydrager.com).

\subsection{Entwicklung und Differenzierung von OL in vivo und in vitro}

OL stammen von neuroepithelialen Vorläuferzellen des ventralen Neuralrohrs ab (ORENTAS et al., 1998; RICHARDSON et al., 2000). Zur Myelinisierung befähigte reife OL durchlaufen verschiedene Entwicklungsstadien, die morphologisch und immunzytochemisch charakterisiert worden sind (GARD et al., 1990; DUBOISDALCQ and ARMSTRONG 1992; HARDY et al., 1993) (Abb. 2). Die sehr frühen Vorläuferzellen, die auch als Pro-OL-Vorläufer bezeichnet werden, exprimieren das neurale Zelladhäsionsmolekül NCAM. Ihre Morphologie ist monopolar und sie besitzen die Fähigkeit zu proliferieren und zu migrieren. In vivo wandern die OL in diesem 
Stadium zu ihren Zielorten (PRINGLE et al., 1989). Im nächsten Entwicklungsstadium, den OL-Vorläufer (O-2A)-Zellen, findet man eine bipolare Morphologie. Immunzytochemisch sind sie zu diesem Zeitpunkt mit dem monoklonalen Antikörper A2B5 anfärbbar. Im nächsten Stadium können sich O-2A-Zellen in vitro entweder zu OL oder Typ2 Astrozyten differenzieren (NOBLE et al., 1989). O-2A-Vorläuferzellen durchlaufen weitere Differenzierungsphasen, die zunächst durch eine tripolare Morphologie und immunzytochemisch als $\mathrm{O}^{+}$gekennzeichnet sind, bevor sie in unreife OL (Netzwerk von Fortsätzen, immunzytochemisch $\mathrm{O}^{+}{ }^{+}$) übergehen.

Die terminale Differenzierung zu reifen OL ist durch die Ausbildung von membranösen Flächen gekennzeichnet. Charakterisieren lassen sich diese Zellen durch die Expression der beiden Myelinproteine PLP (Proteolipid Protein) und MBP (Myelin Basisches Protein).

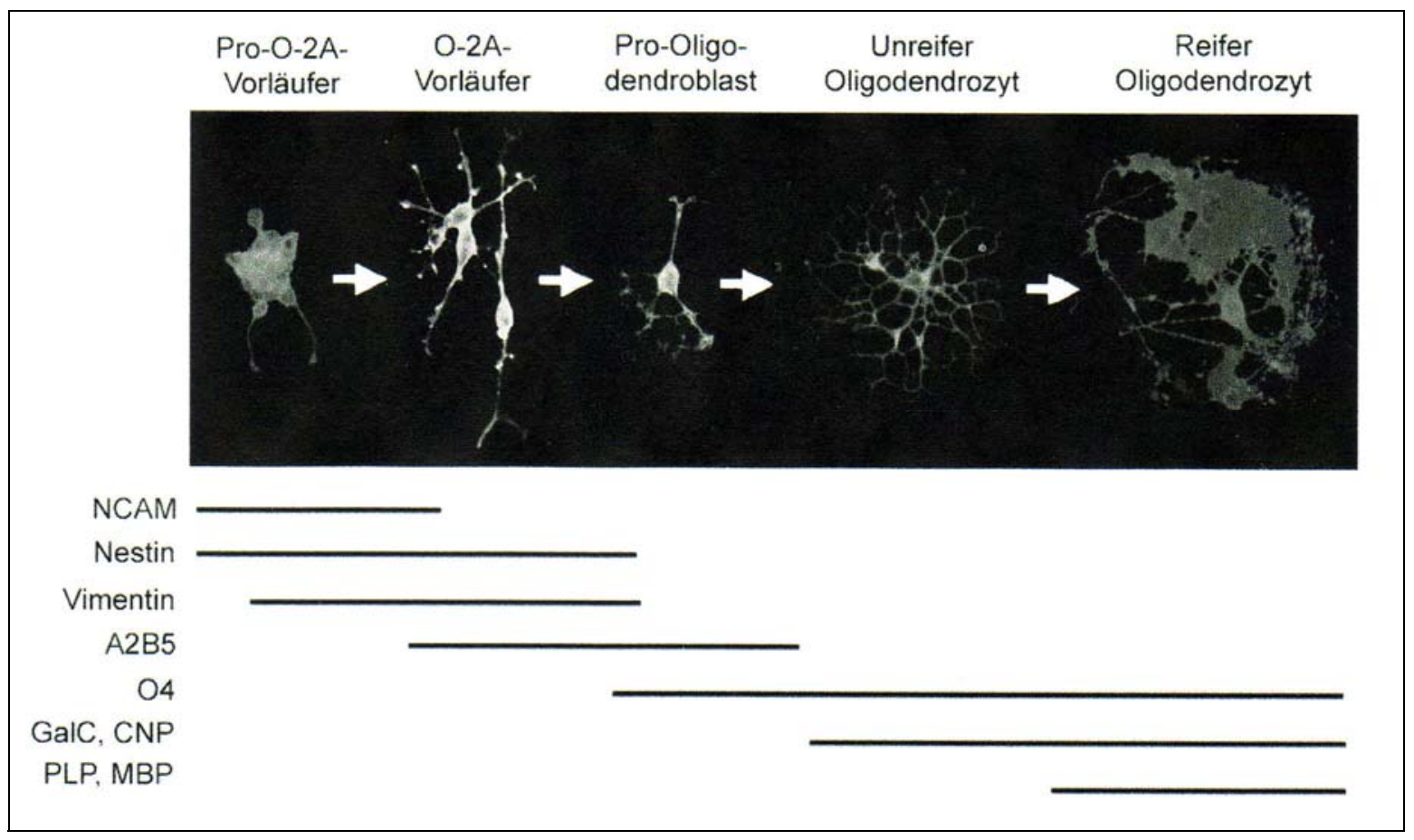

Abb. 2: Darstellung der Differenzierungsstadien von $\mathrm{OL}$ in vitro. Die Linien zeigen die zeitlich determinierte Expression von Markern während der Entwicklung an (modifiziert nach ARMSTRONG 1998).

\subsection{Regulation der Fortsatzbildung von OL}

Die Myelinmembran kann als Subdomäne der Plasmamembran von OL angesehen werden (KRAMER et al., 2001). Prinzipiell lassen sich bei der Myelinbildung, wie auch 
bei der Remyelinisierung 5 Phasen unterscheiden: OL müssen Fortsätze bilden, die Kontakt zu Axonen finden; anschließend werden die Axone von OL-Fortsätzen umwickelt, es erfolgt eine Lateralisierung und abschließend eine Kompaktierung der spiralig umwickelten Fortsätze zu kompaktem Myelin. Dieser Prozess ist insofern von großem Interesse, weil die Zerstörung des "schützenden“ Myelins mit einem Funktionsverlust des betroffenen Axons enden kann. Gelänge es demyelinisierte Axone im ZNS wieder zu remyelinisieren bzw. geschädigte OL wieder zu regenerieren, so wäre dies ein wichtiger Therapieansatz zur Behandlung der Multiplen Sklerose, die durch demyelinisierte Plaques gekennzeichnet ist.

Einen ersten Hinweis, dass die Regeneration der OL-Fortsätze von Kinasen gesteuert sein könnte, lieferte der Befund, dass unter Stimulation von Proteinkinase C mithilfe von 12-O-Tetradecanoylphorbol-13-Acetat (TPA) OL bereits nach 24 h ein Netzwerk von stabilen und verzweigten Fortsätzen regenerierten (ALTHAUS et al., 1991). Dagegen formten OL nach Stimulation von Proteinkinase A eine Art “Teppich" von Fortsätzen. Ein weiterer Weg die Fortsatzbildung von OL und damit den ersten Schritt der Myelinbildung zu beeinflussen, läuft über Rezeptor-gesteuerte Tyrosinkinasen. Bei der Regeneration von oligodendrogliären Fortsätzen und bei der Remyelinisierung von demyelinisierten Arealen erwies sich insbesondere die Cytokinfamilie der Neurotrophine (NT) als effektiv, was NT als Therapeutikum für demyelinisierende Erkrankungen interessant machte (ALTHAUS et al., 1992; COHEN et al., 1996; ALTHAUS et al., 1997a; ROHDE et al., 1998; McTIGUE et al., 1998; ALTHAUS, 2004). Eine wichtige Station innerhalb der NT-Signalkaskade stellen die MAPK Erk1 und Erk2 dar, deren Inhibition zu einer Hemmung des oligodendroglialen Fortsatzwachstums führt (STARIHA et al., 1997).

\subsubsection{Neurotrophine}

Die zu der Familie der Wachstumsfaktoren gehörenden Neurotrophine bestehen im Wesentlichen aus sechs Mitgliedern:

NGF (Nerve Growth Factor), BDNF (Brain Derived Neurotrophic Factor), Neurotrophin (NT)-3, NT-4/5, NT-6 und NT-7 (BARBACID et al., 1995). Sie spielen bei Differenzierung, Überleben und Regeneration glialer Zellen eine wesentliche Rolle (ALTHAUS et al., 1992, 2000; HUTTON et al., 1992, 1995; COHEN et al., 1996; KUMAR et al., 1996). Anhand von in vitro Versuchen konnte nachgewiesen werden, dass von den genannten Neurotrophinen lediglich NGF die Fortsatzbildung von 
Schweine-OL deutlich verbessert sowie in einer Subpopulation adulter OL die Proliferation für 3-4 Zyklen anregt; Schweineastrozyten hingegen antworten nicht auf NGF (ALTHAUS et al., 1992, 1997a,b). Die Synthese des Wachstumsfaktors NGF konnte in Nager-OL nachgewiesen werden; ob auch Schweine-OL NGF synthetisieren, ist noch nicht abschließend geklärt (GONZALEZ et al., 1990; BYRAVAN et al., 1994; ALTHAUS et al., 2000). Weitere NGF-Quellen sind mikrogliale Zellen und Astrozyten (GRADIENT et al., 1990; BOUTROS et al., 1997; HEESE et al., 1998).

Zunächst entsteht NGF als sog. Vorläufer oder Pro-NGF, das je nach Glykosylierung ein Molekulargewicht von 32 kDa oder höher aufweisen kann. Diese Pro-Form wird intrazellulär proteolytisch von Furin zum reifen NGF (13,5-14 kDa) gespalten. NGF bindet an einen Tyrosinkinase kompetenten Rezeptor, TrkA und an p75 ${ }^{\mathrm{NTR}}$.

\subsubsection{Neurotrophinrezeptoren und nachfolgende Signalkaskaden}

Bei den Neurotrophinrezeptoren lassen sich im Prinzip zwei Typen unterscheiden: Einen höhermolekularen (140 kDa), dessen intrazellulärer Anteil enzymatische Tyrosinkinase-Aktivität entwickelt, so genannte Trks, und einen p75Neurotrophinrezeptor $\left(\mathrm{p} 75^{\mathrm{NTR}}\right)$, der nur einen relativ kurzen zytoplasmatischen Schwanz ohne enzymatische Aktivität besitzt (Abb. 3). Trks gehören aufgrund ihrer ähnlichen molekularen Topologie der Familie der Rezeptor-Tyrosinkinasen (RTKs) an, deren Proteinstruktur sich aus drei Hauptdomänen zusammensetzt. Die erste Domäne befindet sich extrazellulär und ist für die Bindung des Liganden verantwortlich. Diese ist über eine hydrophobe membrandurchgängige Region an die intrazelluläre Domäne gekoppelt. Die intrazelluläre Domäne kann in eine Tyrosinkinase-Domäne mit katalytischer Aktivität und einen carboxyterminalen Schwanz unterteilt werden (ULLRICH et al., 1990; SCHLESSINGER et al., 1992; FRIEDMAN et al., 1996). Es lassen sich TrkA, TrkB und TrkC unterscheiden, zu denen die verschiedenen Neurotrophine unterschiedliche Affinität besitzen. Prinzipieller Ligand für TrkA ist NGF, doch kann auch NT-3 in hohen Konzentrationen eine TrkA-Antwort hervorrufen (BARBACID et al., 1995; BOTHWELL 1995; LEWIN et al., 1996) (Abb. 3). Im Gegensatz zu TrkA existieren von TrkB und TrkC trunkierte Formen, die katalytisch inaktiv sind. 


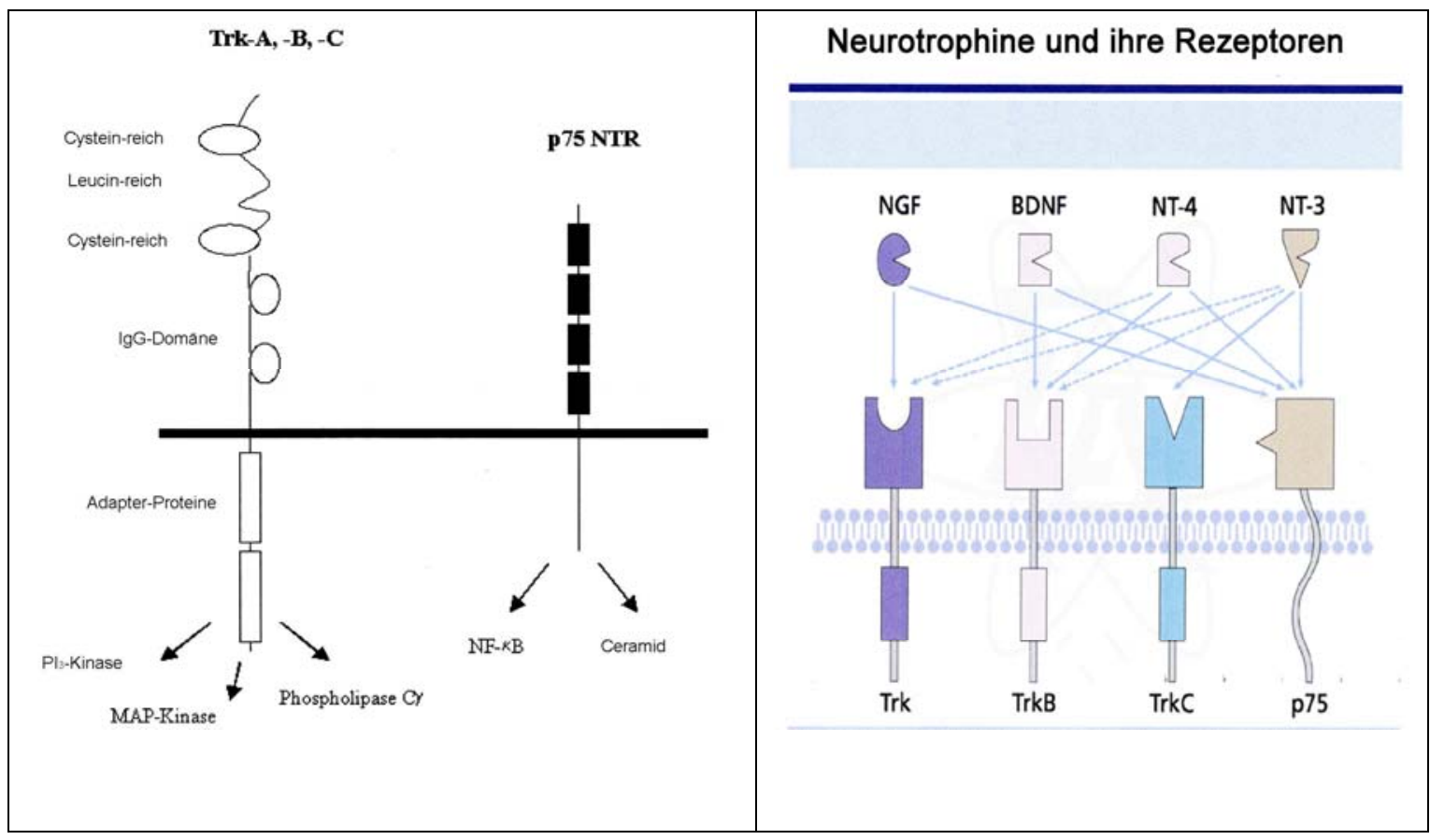

Abb. 3: a) Schematische Darstellung der Neurotrophinrezeptoren TrkA, -B, -C. b) Bindung der Neurotrophine NGF, BDNF, NT-4 und NT-3 an die korrespondierenden Rezeptoren. (modifiziert nach Sigma-Aldrich)

Im Gegensatz zu den G-Protein gekoppelten 7-Transmembranrezeptoren (7TMRezeptoren), bei denen die Bindung des Liganden eine Veränderung der Tertiärstruktur des Rezeptors auslöst, führt die Bindung von NGF an seinen hochaffinen TrkARezeptor, der im inaktiven Zustand als Monomer vorkommt, zu einer Veränderung seiner Quartärstruktur, d.h. die Rezeptoren bilden im aktivierten Zustand Dimere aus. Bei dieser Dimerbildung, die mit einer Konformationsänderung des Rezeptors verbunden ist, werden die Proteinkinasedomänen so in Kontakt gebracht, dass die Tyrosinreste der einen Kette im aktiven Zentrum der anderen liegen und sich gegenseitig phosphorylieren können (Autophosphorylierung). Diese gegenseitige Kreuzphosphorylierung initiiert die Weiterleitung von Signalen, wobei Phosphotyrosine im phosphorylierten TrkA-Rezeptor als “Anheftungsstellen“ fungieren. PI3-Kinase, Phospholipase C sowie das Adapterprotein Shc docken über SH2-, PTB-Domänen an die Tyrosin-phosphorylierten Stellen an. Shc assoziiert mit Grb2, das mit SOS über zwei SH3-Domänen wechselwirkt.

Diese Domänen binden an prolinreiche Abschnitte von Polypeptiden (COHEN et al., 1995). Der Guanosin Diphosphat/Triphosphat-Austauschfaktor SOS bindet seinerseits an das Protein p21 Ras und aktiviert es. Dieses aktivierte p21 Ras mit GTPase-Funktion gehört zur Familie der kleinen G-Proteine, bei dessen Aktivierung sich GDP ablöst und 
durch GTP ersetzt wird. Für die funktionale Kompetenz von p21 Ras ist zudem wichtig, dass es über eine Farnesylierung mit der Plasmamembraninnenseite assoziiert ist. Obwohl die Aktivierung von Raf1 über p21 Ras noch nicht genau geklärt ist, so zeigen bisherige Ergebnisse, dass Raf1 durch p21 Ras zur Membraninnenseite rekrutiert wird und, dass bei der Phosphorylierung von Raf1 möglicherweise Src oder Proteinkinase C$\alpha$ (PKC- $\alpha$ ) eine Rolle spielen könnten (DAUM et al., 1994; MARAIS et al., 1995).

Eine wichtige Rolle in der Kaskadenreaktion nehmen die mitogenaktivierten Proteinkinasen (MAP-Kinasen) ein, die als extrazellulär regulierte Kinasen (ERK) bezeichnet werden. MAP-Kinasen müssen, um ihre volle Aktivität zu erlangen, an einem Threoninund an einem Tyrosinrest phosphoryliert werden. Die Proteinkinase, die beide Phosphorylierungen katalysiert, ist die MAP-Kinase-Kinase, welche wiederum von Raf1, einer MAP-Kinase-Kinase-Kinase (MAPKKK), phosphoryliert und damit aktiviert wird. Einmal aktiviert wandert die MAPK aus dem Zytosol in den Zellkern und phosphoryliert Transkriptionsfaktoren wie z.B. Elk-1, welches zur TCF-Familie (ternary complex factor) gehört und beispielsweise die Transkription des c-fos-Gens anschaltet. Hierbei handelt es sich um ein genregulatorisches Protein, das Zellwachstum und die Fortsatzbildung anregt (KUKUSHKIN et al., 2002). Neben der Aktivierung von MAPK spielen Trk-Rezeptor aktivierte Signalkaskaden, die über den Phosphatidylinositol-3-Kinase- und den Phospholipase C $\gamma$-Weg laufen (HEUMANN 1994; CROWDER and FREEMEN 1998), eine wichtige Rolle, z.B. für das Überleben von neuralen Zellen. Alle Neurotrophine (u.a. NGF, BDNF, NT-3, NT 4/5) binden neben ihrem Kinase-kompetenten Rezeptor auch an $\mathrm{p}^{\mathrm{NTR}}$, einem $75 \mathrm{kDa}$ Glykoprotein (RODRIGUEZ-TEBAR et al., 1990; 1992) (Abb.2). Der p75 ${ }^{\text {NTR }}$ zählt zur Tumor-Nekrose-Faktor-Rezeptor Superfamilie (Abb. 2) (CHAO 1994). Man hat zum einen zeigen können, dass $\mathrm{p} 75^{\mathrm{NTR}}$ mit TrkA interagiert, wodurch entweder die Bindungsaffinität von NGF zu TrkA oder aber die Autophosphorylierung nach Bindung von NGF moduliert wird (HEMPSTEAD et al., 1991; BARKER and SHOOTER, 1994; HANTZOPOULOS et al., 1994; VERDI et al., 1994; GREENE and KAPLAN 1995; EPA et al., 2004). Auf der anderen Seite gibt es Hypothesen, nach denen $p 75^{\text {NTR }}$ signalunabhängig von Trk fungiert und für einen programmierten Zelltod (Apoptose) verantwortlich ist (RABIZADEH et al., 1993). Dabei dürften Ceramid und an $\mathrm{p}^{\mathrm{NTR}}$ assoziierende Proteine eine Rolle spielen (DOBROWSKY et al., 1994, 1998; HEMPSTEAD 2002). 


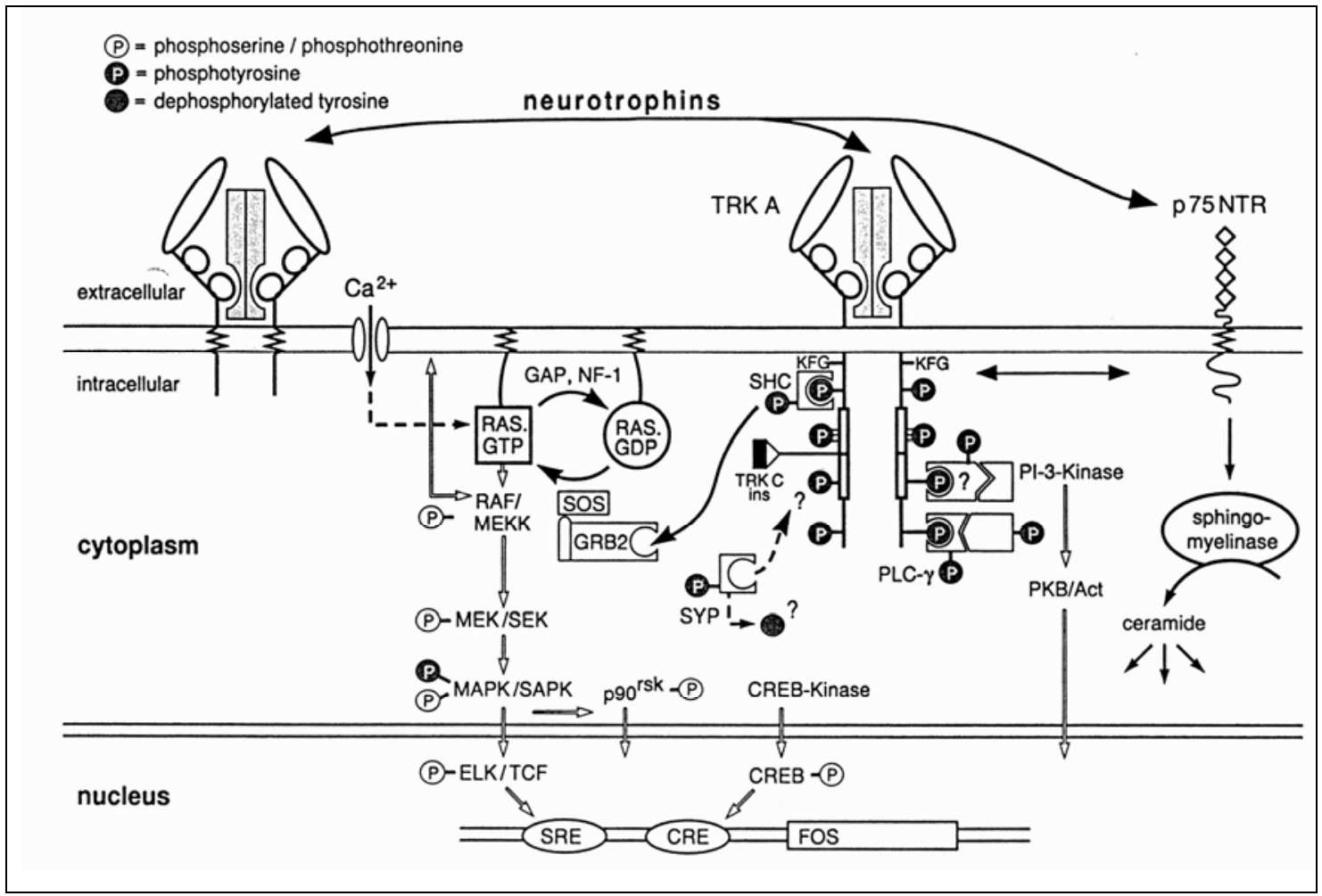

Abb. 4: Neurotrophin-Signalkaskade in OL. Die Bindung eines Neurotrophins an Trk (z.B. die Bindung von NGF an TrkA) führt zur Aktivierung dieser RezeptorTyrosinkinase-gesteuerten Signalkaskade, die in Schweine-OL letztlich zum Fortsatzwachstum bzw. zur Myelinsynthese führt (modifiziert nach HEUMANN et al., 1994).

\subsection{Lipid Rafts oder Membran-Mikrodomänen}

Das ursprüngliche Modell der Plasmamembran mit einer relativ gleichmäßigen Verteilung von Lipiden und Proteinen wurde in den letzten Jahrzehnten modifiziert. Heute ist bekannt, dass sich innerhalb der Plasmamembran und in intrazellulären Membranen Mikrodomänen mit einem höheren Anteil an Glykosphingolipiden, Glykosylphosphatidylinositol (GPI)-verankerten Proteinen und Cholesterin ausbilden können (SIMONS and IKONEN 1997; HARDER and SIMONS 1997) (Abb.5). Wegen ihrer eingeschränkten lateralen Beweglichkeit werden diese Mikrodomänen als “Lipid Rafts“ bezeichnet (KURZCHALIA and PARTON 1999). Lipid Rafts sind in der Regel flache Domänen innerhalb der Plasmamembran. Sie sind an einer ganzen Reihe verschiedener zellulärer Prozesse beteiligt, zu denen u.a. Transport von Proteinen und Lipiden (HELMS et al., 2004), Aufnahme von Viren (PARTON 2003) und Weiterleitung von Signalen (SIMONS et al., 2000) gehören. 


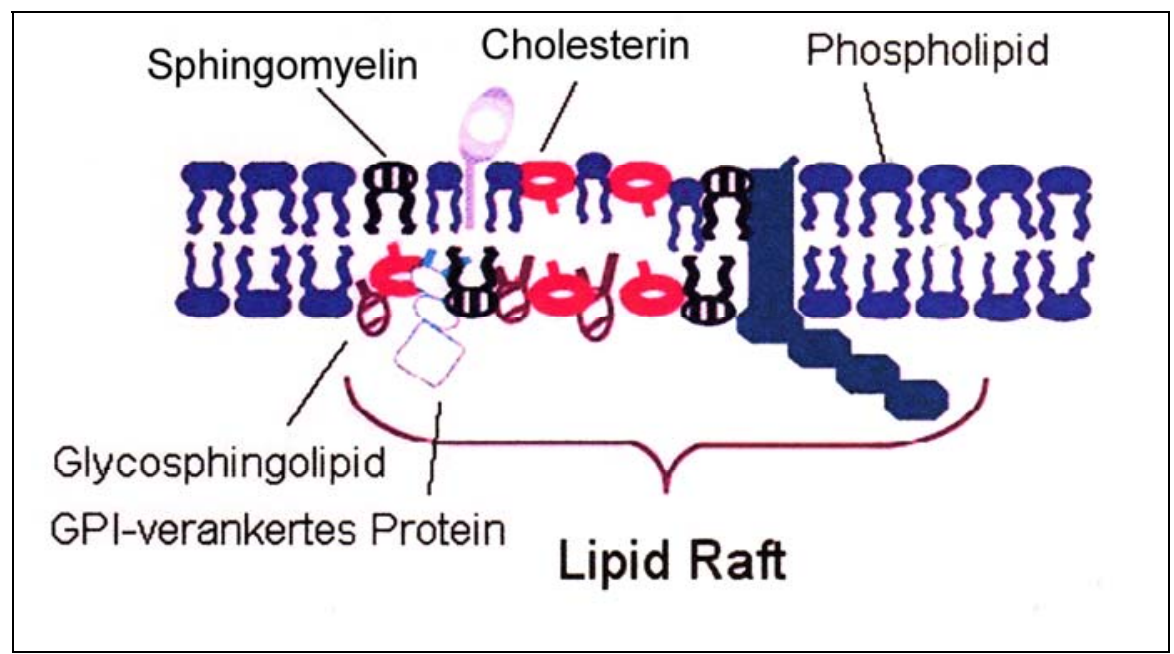

Abb. 5: Schematische Darstellung eines Lipid Raft innerhalb der Plasmamembran. Diese Mikrodomänen enthalten vor allem Cholesterin, Sphingomyelin, Glykosphingolipide und GPI-verankerte Proteine (www.biophys.uni-linz.ac.at).

\subsubsection{Cholesterin als Bestandteil von Mikrodomänen}

Cholesterin wurde von Pouletier de la Salle im Jahre 1769 entdeckt und erhielt von Michel Chevreul 1815 seinen Namen (VANCE et al., 2000). Es gehört zu den Steroiden. Diese bestehen aus einem tetracyclischen Ringsystem. Cholesterin ist das wichtigste Sterol und besitzt einen kleinen hydrophilen Part in Form einer Hydroxyl (OH)-Gruppe am C3-Atom sowie einen hydrophoben und lipophilen Acyl-Rest am entgegengesetzten Ende.

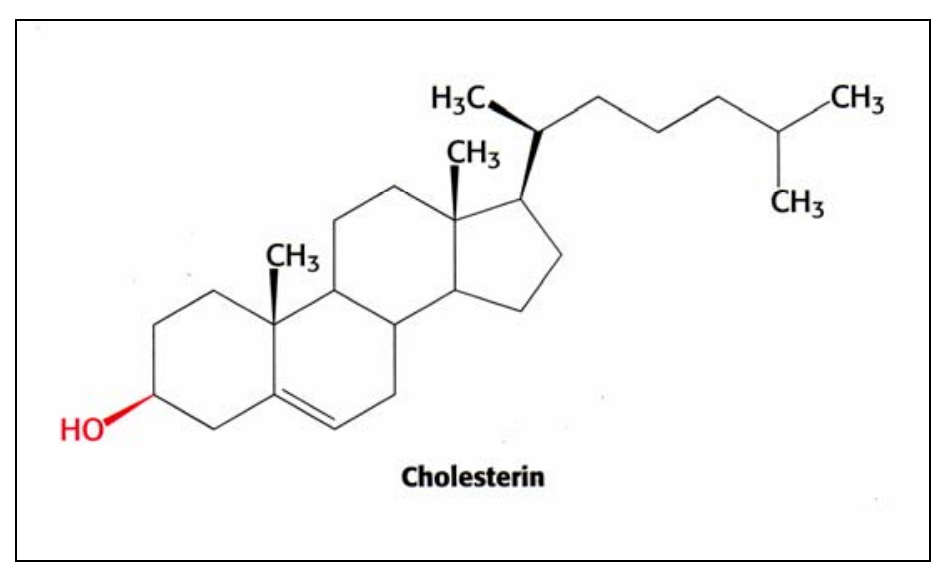

Abb. 6: Strukturformel des Cholesterins (Biochemie L. Stryer 5. Auflage).

Cholesterin tritt in allen Geweben auf, besonders reichlich im Gehirn und Rückenmark. Es ist eine sehr wichtige Komponente aller Membranen (PFEIFFER et al., 1993; 
CALDERON et al., 1997) und macht etwa 26\% des Gesamtlipidgehaltes von Myelinmembranen aus. Seine Esterform ist im normalen Gehirn nicht vorhanden, tritt aber bei demyelinisierenden Erkrankungen auf. In biologischen Membranen kann Cholesterin aufgrund hydrophober Wechselwirkungen eine Cluster-Bildung von Sphingolipiden und Membranproteinen verursachen, sodass es zum Phänomen “Lipid Rafts“ kommt, die sich wie "Inseln von höherer Dichte“ in biologischen Membranen bewegen können (SIMONS and IKONEN 1997). Nach Peiro sind 80-90\% des Plasmamembran-Cholesterins in diesen Rafts enthalten (PEIRO et al., 2000). Eine Wechselwirkung von Cholesterin mit Phospholipiden ist für die Regulation der Fluidität und Stabilität von Membranen von wesentlicher Bedeutung. Bei niedrigen Temperaturen "verflüssigt“ es, bei höheren Temperaturen dagegen "versteift“ es die Membran (OHVO-REKLIA et al., 2002).

Im Gehirn findet die Synthese von Cholesterin gebunden an Lipoproteine endogen statt, d.h. es kann kein Cholesterin aus dem Blutsystem aufgenommen werden, da Cholesterin im adulten Hirn nicht die Blut-Hirn-Schranke überqueren kann. Daher sind alle neuralen Zellen auf die eigene Synthese von Cholesterin angewiesen. Da Neurone selber kaum Cholesterin synthetisieren, wird diese Aufgabe vorwiegend von Gliazellen übernommen. Im Gehirn gehören neben den OL vor allem Astrozyten zu den Cholesterinproduzenten (SAITO et al., 1987; TABERNERO et al., 1993; PFRIEGER 2003).

\subsubsection{Cyclodextrine}

Um die physiologische Funktion von Cholesterin innerhalb von Lipid Rafts besser verstehen zu können, bedient man sich der Cyclodextrine (Abbauprodukt von Amylose). Methyl-ß-Cyclodextrin und Hydroxypropyl-Cyclodextrin sind geeignet, Cholesterin aus der Plasmamembran herauszulösen (NEUFELD et al., 1996; YANCEY et al., 1996; CHRISTIAN et al., 1997; ATGER et al., 1997), was zu einer Zerstörung der cholesterinhaltigen Lipid Rafts innerhalb der Plasmamembran (FURUCHI et al., 1998; PEIRO et al., 2000; CHEN et al., 2001) führt. Die Fähigkeit Cholesterin in einer Gleichgewichtsreaktion zu binden, verdankt Cyclodextrin seiner speziellen Struktur: Cyclodextrine bestehen aus mehreren Glukoseeinheiten (D-(+)- Glukopyranosen), die $\alpha$-1,4-glykosidisch miteinander verknüpft sind. Dabei lagern sich die D-(+)Glukopyranosen in "Sessel-Form" an, sodass die "Sitzflächen des Sessels" in etwa parallel zur Achse des Cyclodextrins stehen (Abb. 7). Durch die spezielle Anordung der 
primären Hydroxylgruppen ergibt sich eine konusförmige Gesamtstruktur des Cyclodextrins, wodurch im Inneren ein hydrophober Hohlraum und außen ein hydrophiler Bereich entsteht. Das Molekül ist damit endolipophil und exolipophob, was dazu führt, dass im Inneren dieser ringförmigen Moleküle hydrophobe Gastmoleküle wie z.B. Cholesterin eingeschlossen und über van-der-Waals-Kräfte gebunden werden können. Die zusätzliche Methylgruppe beim Methyl-ß-Cyclodextrin dient dem Anstieg der Wasserlöslichkeit.

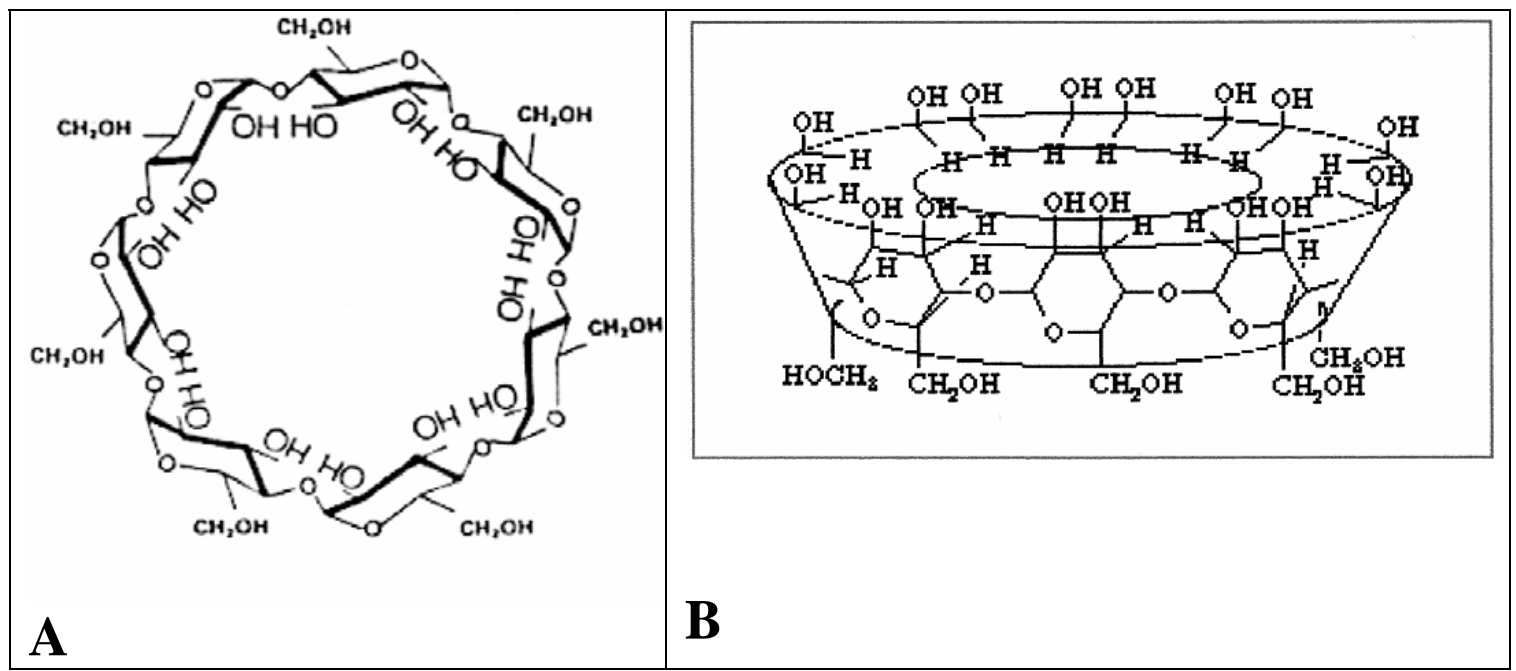

Abb. 7: Struktur von Cyclodextrin. (A) Ringförmige Anordnung mehrerer Glukoseeinheiten (D-(+)- Glukopyranosen), die $\alpha$-1,4-glykosidisch miteinander verknüpft sind. (B) Räumliche Darstellung der konusförmigen Gesamtstruktur des Cyclodextrins, wodurch im Inneren ein hydrophober Hohlraum und außen ein hydrophiler Bereich entsteht.

\subsubsection{Caveolae/Caveolin}

Mikrodomänen, die Caveolin enthalten, sind quasi eine Spezialform dieser Lipid Rafts. Sie können dabei von flach bis eingestülpt verschiedene Formen annehmen (MATVEEV et al., 2000). Letztere Form wurde als Caveolae erstmals 1953 mittels Elektronenmikroskopie von Palade entdeckt und als Plasmamembran-Vesikel beschrieben (PALADE 1953). Zwei Jahre später wurde für diese PlasmamembranEinstülpungen von Yamada die Bezeichnung Caveolae eingeführt (YAMADA 1955). Caveolae werden in der englischsprachigen Literatur aufgrund ihrer kolbenförmigen Erscheinung im Elektronenmikroskop häufig mit den Worten "little caves“ (kleine Höhlen) umschrieben (Abb. 8). Ende der 80er Jahre wurde Caveolin erstmals von zwei 
unabhängigen Arbeitsgruppen entdeckt und im Jahre 1992 als solches beschrieben. Die eine Gruppe fand Caveolin als Substrat für das Rous Sarcoma Virusprotein innerhalb von Caveolae (GLENNEY et al., 1989, 1992; ROTHBERG et al., 1992). Das andere Forscherteam identifizierte Caveolin als VIP21 und gleichzeitig als Hauptkomponente in der "low density“ Fraktion, nachdem es ihnen zuvor gelungen war, Caveolae in selbiger zu isolieren (KURZCHALIA et al., 1992). Caveolin und Caveolae wurden eine Reihe von physiologischen Aufgaben zugeschrieben, wie Endozytose, Pinozytose, Phagozytose, Transzytose, Kalziumtransport und Modulation der Signaltransduktion.

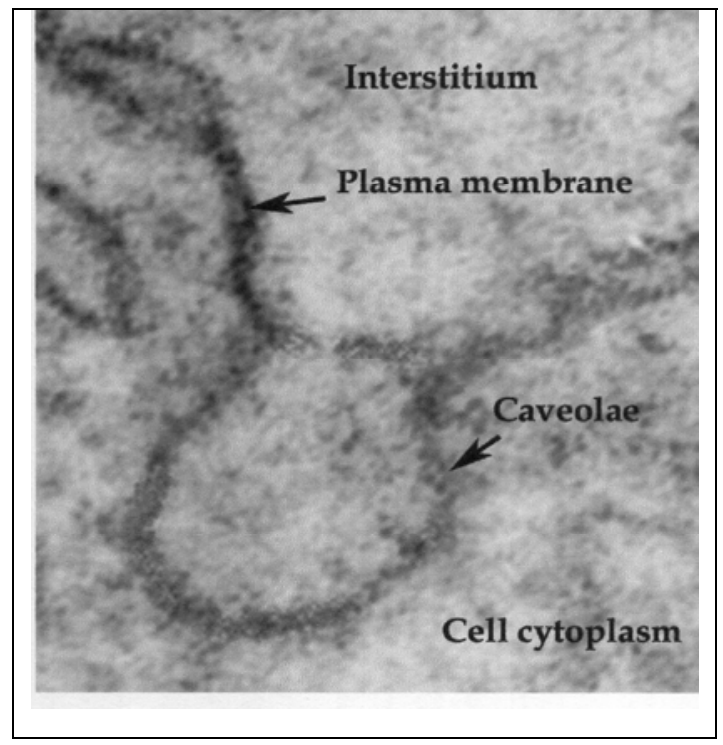

Abb. 8: Elektronenmikroskopische Darstellung der kolbenförmigen Morphologie von Caveolae.

Caveolinhaltige Mikrodomänen (CMD), ein Oberbegriff, der unabhängig von dem morphologischen Erscheinungsbild ob z.B. flach oder für Caveolae klassisch kolbenförmig gewählt wird, sind ebenfalls reich an Cholesterin, Sphingomyelin und Gangliosiden; sie sind wie Lipid Rafts in Detergentien wie Triton X-100 bei $4^{\circ} \mathrm{C}$ unlöslich (KURZCHALIA et al., 1992; ROTHBERG et al., 1992; SARGIAKOMO et al., 1993). Abgesehen von Caveolin, einem 21-24 kDa großen und charakteristischen Markerprotein für CMD, ist die biochemische Zusammensetzung von Lipid Rafts und CMD sehr ähnlich, aber nicht vollkommen gleich (LIU et al. 1997; COHEN et al., 2003). Ein weiteres für CMD spezifisches Marker- und Strukturprotein ist Flotillin (BICKEL et al., 1997; EVANS et al., 2003), anhand dessen man CMD identifizieren kann. 
Insgesamt existieren drei Caveolin-Subtypen, von denen die Caveoline 1 und 2 noch verschiedene Isoformen besitzen. Man unterscheidet Caveolin-1 $\alpha$ (24 kDa) und Caveolin-1 $\beta$ (21 kDa, entspricht Caveolin-1 $\alpha$ ohne die ersten 30 AS) sowie Caveolin$2 \alpha, \beta, \gamma$ und Caveolin-3 (LI et al., 1996; SCHERER et al., 1995; PIKE 2005). Dabei werden die Gene für Caveolin-1 und -2 ubiquitär exprimiert, d.h. in fast allen Geweben (SCHERER et al., 1994); besonders hoch ist die Expression in Endothelzellen, Fibroblasten und Fettzellen. Dagegen wird Caveolin-3 häufig muskelspezifisch (Zwerchfell, Herz) exprimiert (TANG et al., 1996; WAY et al., 1995; DAS et al., 1999), aber auch in Astrozyten und Chondrozyten (NISHIYAMA et al., 1999; SCHWAB et al., 1999).

\subsubsection{Caveolin/CMD-Struktur}

Bezüglich der Caveolin-Struktur ist bekannt, dass Caveolin durch eine integrale hydrophobe 33 Aminosäure (AS) lange "Hairpin-Domäne“ (AS 102-145) in der Plasmamembran verankert ist (Abb. 9, 10). Sowohl der Amino-, als auch der Carboxylterminus ragen frei ins Zytosol (KUZCHALIA et al., 1994). Im Aminoterminus sind zwei Hauptdomänen für die meisten strukturellen und regulatorischen Funktionen des Caveolins verantwortlich. Die erste Domäne (von AS 61-101) ist für die Eigenschaft des Caveolins mit sich selbst zu interagieren, d.h. Homooligomere auszubilden, zuständig (Abb. 9). Aufgrund von Oligomer-Oligomer Interaktionen können dabei Komplexe von 14-16 Untereinheiten entstehen (MONIER et al., 1995; SARGIAKOMO et al., 1995; Song et al., 1997), wodurch Caveolin-1 seine Fähigkeit als Gerüstprotein in CMD erhält, die im Golgi-Apparat ausgebildet wird (MACHLEIDT et al., 2000).

Innerhalb dieser Oligomerisierungsdomäne existiert eine weitere funktionelle Domäne von AS 82-101 (Abb. 9). Diese wird als Caveolin-Gerüst-Domäne (CSD) bezeichnet und ist an der Interaktion von Caveolin mit sich selbst sowie mit anderen Molekülen, z.B. Signalmolekülen, beteiligt (LI et al., 1995; COUET et al., 1997, 2001). In vivo wurde zudem nachgewiesen, dass Caveolin-1 und -2 auch heterooligomere Komplexe bilden können (SCHERER et al., 1997; GALBIATI et al., 1998; DAS et al., 1999). Eine weitere Domäne (66-71 AS) von Caveolin-1 wird aufgrund ihres hohen Spezies übergreifenden Konservierungsgrades als Erkennungs-Domäne (Signature-Domain) bezeichnet (Abb.9). Ohne sie könnte neu synthetisiertes Caveolin das ER nicht verlassen. (MACHLEIDT et al., 2000). 


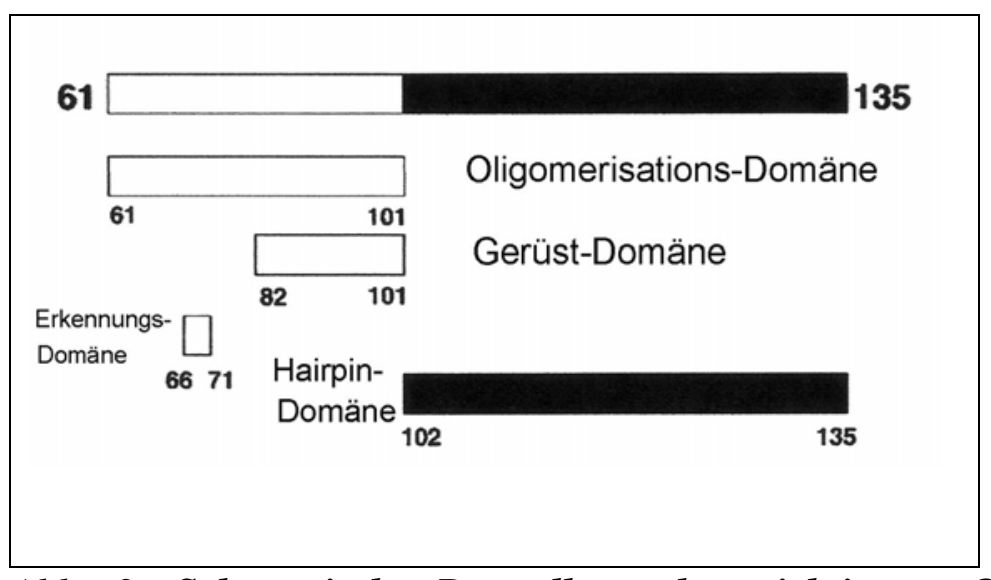

Abb. 9: Schematische Darstellung der wichtigsten Caveolin-1 Strukturdomänen (COUET et al., 2001).

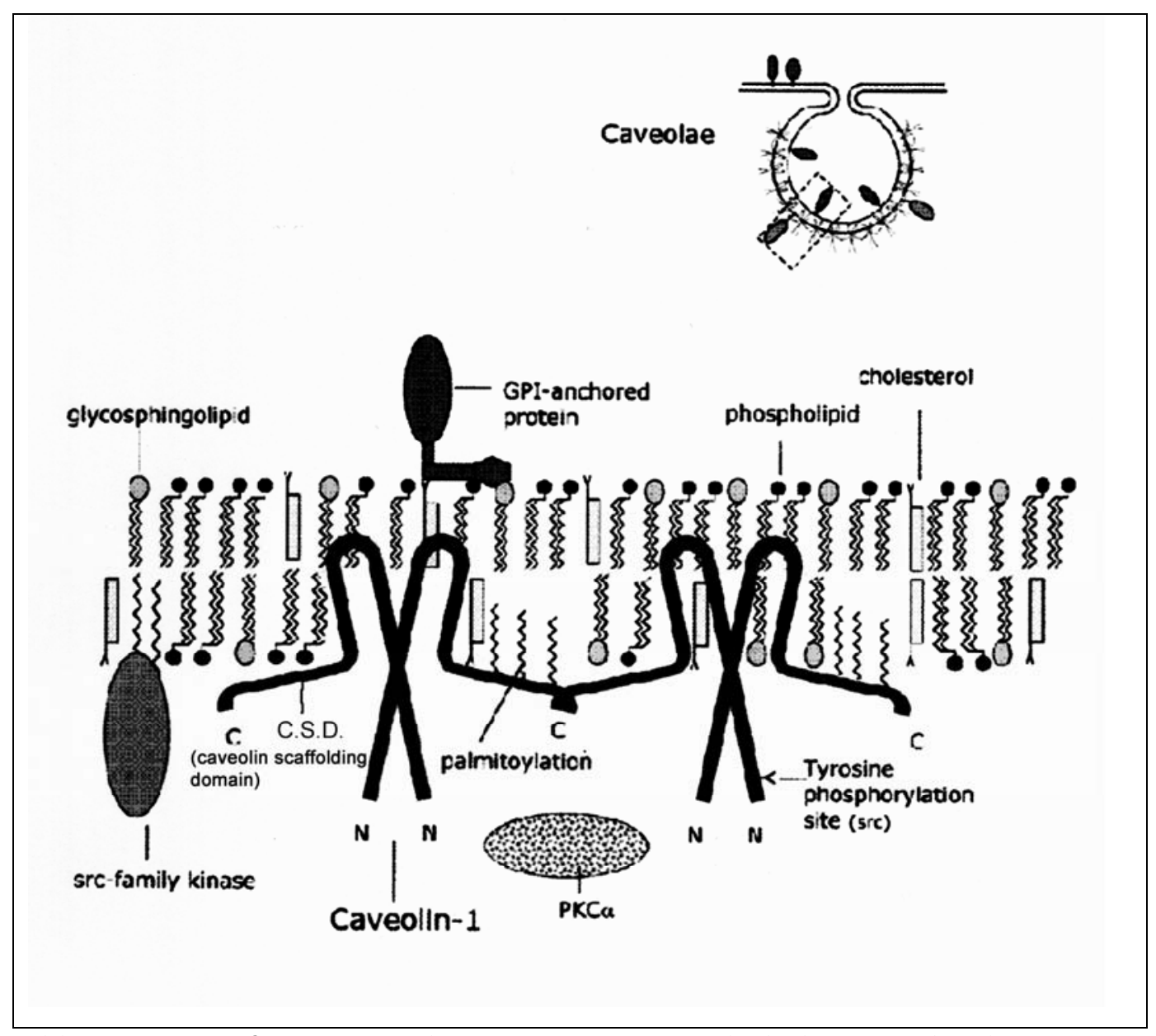

Abb. 10: Vergrößerter Ausschnitt aus einer caveolinhaltigen Mikrodomäne: Caveolin besitzt eine integrale Hairpin-Domäne und einen $C$ - und $N$-terminalen intrazellulären Bereich. Durch seine Fähigkeit Homooligomere auszubilden, trägt Caveolin im erheblichen Maße zur Stabilisierung von CMD bei (BENDER et al., 2002). 


\subsubsection{Interaktionen zwischen Caveolin und Cholesterin}

Für eine Wechselwirkung von Caveolin-1 und Cholesterin in vivo ist neben der räumlichen Nähe innerhalb von CMD, die erhöhte Bindungsaffinität von Caveolin-1 zu Cholesterin von Bedeutung (FRA et al., 1995; MURATA et al., 1995; THIELE et al., 2000). Es wurde gezeigt, dass Caveolin-1 den zellulären Cholesterin Ein- und Ausstrom moduliert. Caveolin-1 dient gewissermaßen als Cholesterin-Carrier, welcher neu synthetisiertes Cholesterin aus dem Endoplasmatischen Reticulum oder Golgi-Apparat zur Plasmamembran transportiert, wo es schließlich an HDL (High Density Lipoprotein) gebunden wird (Abb.11) (SMART et al., 1996; FIELDING et al., 1997b, 2001a,b; UITTENBOGAARD et al., 1998; COHEN et al., 2004). Ein weiterer Hinweis für eine Involvierung von CMD in den Cholesterintransport ist die Lokalisation des HDL-Rezeptors (scavenger receptor SR-B1) innerhalb von CMD (GRAF et al., 1999; MATVEEV et al., 1999; FRANK et al., 2002). CMD stellen somit eine Art Plattform dar, wo ein Austausch zwischen Cholesterin aus der Zellmembran und HDL stattfindet (COHEN et al., 2003). Das Fehlen von Caveolin-1 würde die Cholesterin Homöostase im erheblichen Maße beeinflussen. Anscheinend kann in einigen Zellen sogar der intrazelluläre Cholesterinspiegel die Transkription des Caveolin-1-Gens regulieren. Während ein Erniedrigen des Cholesterinspiegels die Caveolin-1-spezifische mRNA abnehmen lässt, hat eine Cholesterinzugabe den umgekehrten Effekt (BIST et al., 1997; FIELDING et al., 1997a; HEILSTONES et al., 1998; COHEN et al., 2003).

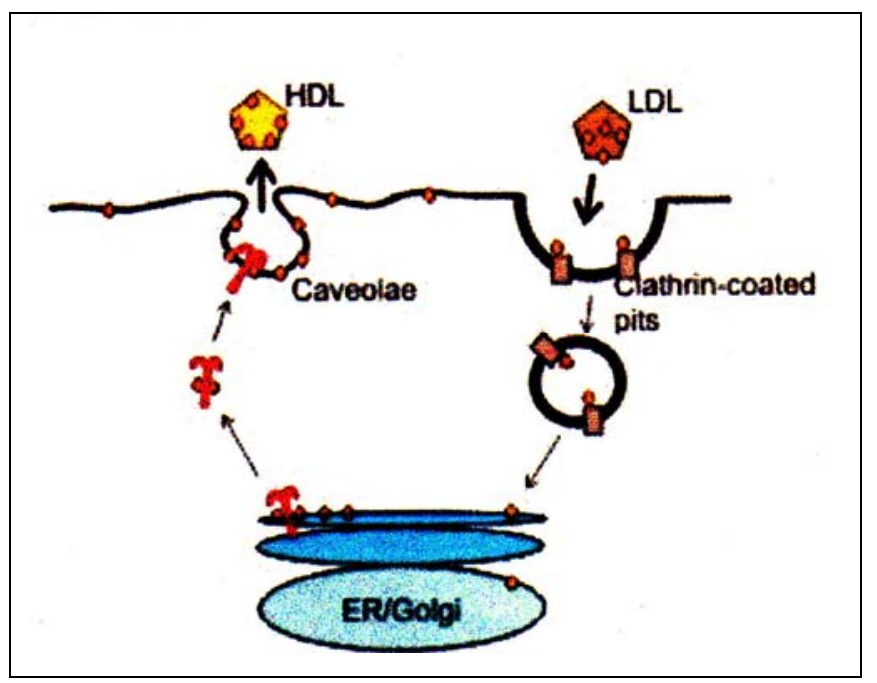

Abb. 11: Involvierung von CMD und Caveolin in den Cholesterintransport. Intrazelluläres Cholesterin wird an Caveolin gebunden und vom Endoplasmatischen Reticulum/Golgi-Apparat zur Plasmamembran transportiert (nach RAZANI and LISANTI 2001a). 
Eine relevante Voraussetzung, um innerhalb von CMD an Cholesterin binden zu können, ist die Lipidmodifizierung von Caveolin-1. Dabei wird im Zuge der Palmitoylierung Palmitinsäure über S-Acylierung von Cysteinen an Caveolin-1 gebunden.

Dies geschieht beim Caveolin-1 posttranslational an verschiedenen Cysteinresten (DIETZEN et al., 1995; MONIER et al., 1996; TANG et al., 1996). Die Palmitoylierung erhöht die Membranassoziierung von Caveolin und ist absolut essentiell für die Bindung an Cholesterin (SONG, et al., 1997; MACHLEIDT, et al. 2000; UITTENBOGAARD et al., 2000). Nicht notwendig ist die Palmitoylierung dagegen für die Verankerung von Caveolin in CMD (DIETZEN et al., 1995).

\subsubsection{Lipid Rafts/CMD und Signaltransduktion}

\subsubsection{Rolle der Lipid Rafts bei der Signaltransduktion}

Lipid Rafts werden wegen ihrer Detergens-Unlöslichkeit (Triton X-100 bei $4^{\circ} \mathrm{C}$ ) auch als "Detergent resistent membranes“ (DRMs) bezeichnet. Anhand dieser chemischen Eigenschaft gelang es DRMs zu isolieren. Bei der Untersuchung der isolierten DRMs wurde gezeigt, dass diese Mikrodomänen Signalmoleküle wie u.a. G-Proteine und Mitglieder der Src-Familie enthalten. Basierend auf diesem Befund konnte schließlich gezeigt werden, dass eine wichtige Funktion dieser spezialisierten Membranplattformen die Signalweiterleitung in Zellen ist. Je nach Signalkaskade existieren dabei eine Reihe unterschiedlicher Möglichkeiten Signale weiterzuleiten:

Abb. 12 zeigt vier verschiedene Wege, wie Lipid Rafts in der neuronalen Rezeptorgekoppelten Signaltransduktion involviert sein können (PARATCHA et al., 2002). In Abb. 12A ist der Rezeptor zusammen mit Scr-Kinasen, kleinen Adaptermolekülen, Ceramiden und anderen für die Signalgebung relevanten Molekülen permanent mit den Lipid Rafts assoziiert. Wird der Rezeptor durch die Bindung eines Liganden an seine extrazelluläre Domäne aktiviert, so resultiert daraus im Zuge der Signalweiterleitung eine Dimerisierung und Phosphorylierung des Rezeptors. Beispiele für diesen membranassoziierten Rezeptortyp sind die beiden Neurotrophinrezeptoren TrkA und p75 ${ }^{\text {NTR }}$ (BILDERBACK et al., 1997, 1999). Ein weiterer Weg der Signaltransduktion unter Beteiligung von Lipid Rafts ist die Verlagerung des Rezeptors aus der umliegenden Plasmamembran in die Lipid Rafts (Abb. 12B). Diese Arten von Rezeptoren haben in ihrer inaktiven Form eine geringe oder gar keine Affinität zu Lipid 
Rafts. Bindet ein Ligand an solch einen Rezeptor, so steigt dadurch seine Affinität zu den Lipid Rafts an, und es kommt zur Translokation des Rezeptors, die entweder extrazellulär (cis) wie beim GPI-verankerten Corezeptor oder intrazellulär (trans) wie bei Lipid verankerten Adaptermolekülen erfolgen kann. Ein Beispiel hierfür wäre der Tyrosinkinase-Rezeptor c-Ret. Den umgekehrten Weg, dass ein Rezeptor nach der Anlagerung seines Liganden und der damit verbundenen Aktivierung die Lipid Rafts verlässt, findet man beim EGF (Epidermal-Growth-Factor)-Rezeptor (Abb. 12C). Außerdem gibt es Rezeptoren, die sich permanent außerhalb von Lipid Rafts befinden (Abb. 12D). Nach Aktivierung dieser Rezeptoren verlagern sich lediglich die Signalmoleküle in die Lipid Rafts, von wo aus eine sekundäre Signalweiterleitung erfolgt. Diese Art der Signalweiterleitung findet man beispielsweise bei FGFRezeptoren.

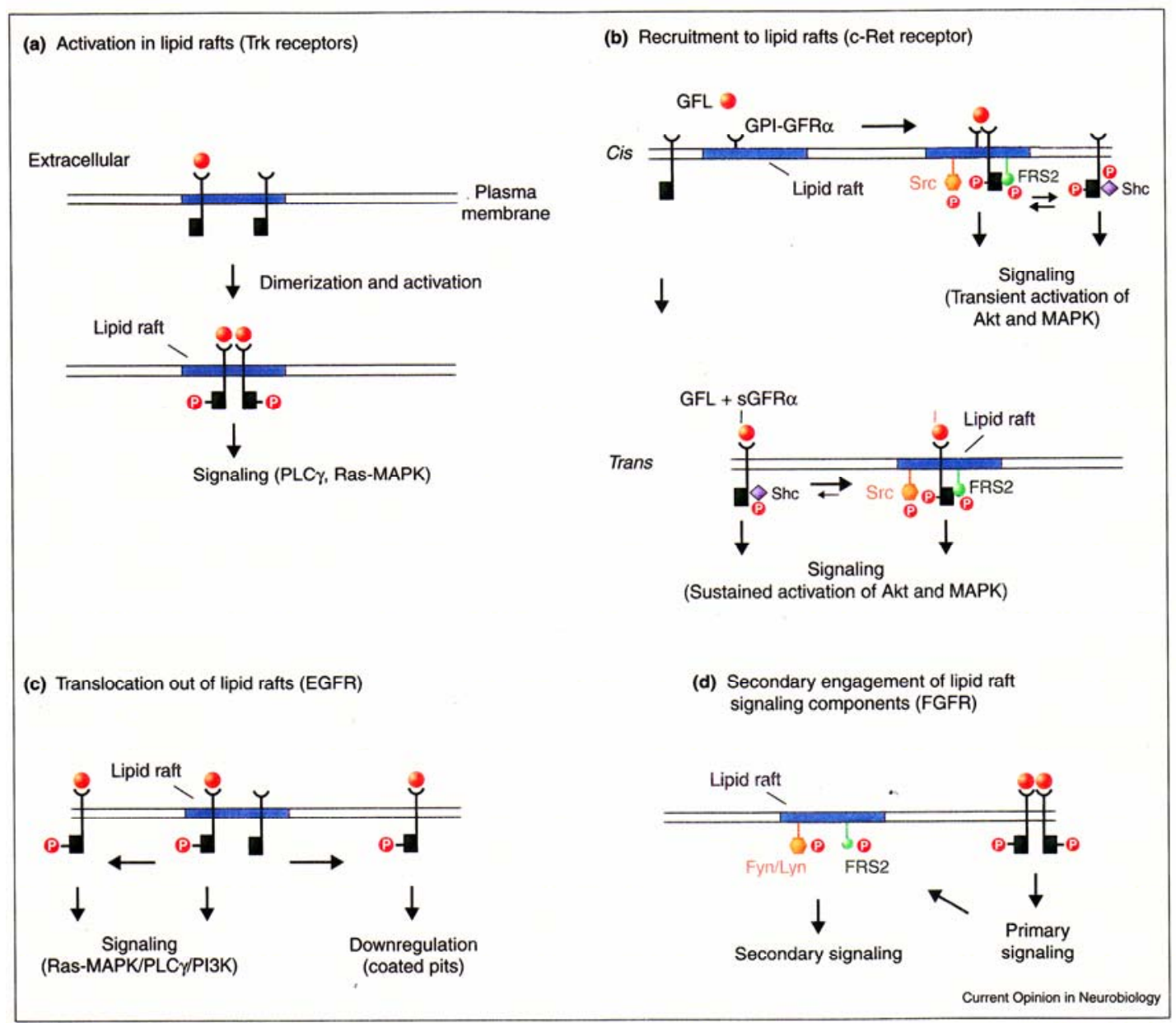

Abb. 12: Signaltransduktion unter Einbeziehung von Lipid Rafts. Dargestellt sind vier Möglichkeiten der Signalweiterleitung in Lipid Rafts. Dabei sind eine permanente Lokalisation des Rezeptor innerhalb von Lipid Rafts (A), eine Verlagerung des Rezeptors aus der umliegenden Plasmamembran in die Lipid Rafts (B), eine mit der 
Aktivierung verbundene Translokation des Rezeptor aus den Lipid Rafts heraus und eine permanente Expression des Rezeptor außerhalb von Lipid Rafts (D) mögliche Beispiele, wie Lipid Rafts in die neuronale Rezeptor-gekoppelte Signaltransduktion involviert sein können (PARATCHA and IBANEZ 2002).

All diese Beispiele zeigen, wie vielseitig die Signaltransduktion unter Beteiligung von Lipid Rafts sein kann. Bei der Aktivierung von TrkA spielt aller Voraussicht nach Caveolin eine wichtige Rolle.

\subsubsection{Caveolin/CMD bei der Signaltransduktion}

Die erste Arbeitsgruppe, die in einer mit Caveolin-Membranen angereicherten Fraktion Proteine, die bei der Signalgebung eine Rolle spielen, entdeckte und in der Literatur beschrieben hat, waren Lisanti und seine Kollegen (LISANTI et al., 1993; 1994a). Sie entdeckten in den von ihnen aufgereinigten Mikrodomänen eine Fülle von Signalmolekülen wie z.B. Src-ähnliche Tyrosinkinasen und heterotrimere G-Proteine. Das Gerüstprotein Caveolin-1 könnte bei der Signalgebung als eine Art Andockstelle für zahlreiche Zelloberflächenrezeptoren und Signalproteine dienen. Im weiteren Verlauf der Signalgebung kommt es dann innerhalb von CMD zur Interaktion mit weiteren CMD-assoziierten Signalkomponenten. Ein Beispiel hierfür ist die Aktivierung des Insulin-Rezeptors (YAMAMOTO et al., 1998; GUSTAVSSON et al., 1999; NYSTROM et al., 1999). Heute ist klar, dass die Signalgebung unter Beteiligung von Caveolin/CMD nicht auf einen Rezeptor-Typ begrenzt ist. Neben den G-ProteinRezeptoren sind Tyrosinkinase-Rezeptoren bekannte Beispiele für Rezeptoren, die mit CMD assoziiert sind. Zu solchen Tyrosinkinase-Rezeptoren gehören der EGF-Rezeptor, Insulin-Rezeptor, PDGF-Rezeptor, VEGF-Rezeptor und der TrkA-Rezeptor. Die Involvierung von CMD in die Signaltransduktion beschränkt sich nicht allein darauf, dass CMD als eine Art "Plattform“ genutzt werden, sondern bestimmte Domänen von Caveolin-1 können per se oder im phosphorylierten Zustand Signalwege auch direkt beeinflussen. Ein wichtiger Schritt, um auf die Signalgebung einwirken zu können, ist die Phosphorylierung von Caveolin-1. Dieses besitzt mehrere Phosphorylierungsstellen, die von verschiedenen Enzymen phosphoryliert werden können: Caveolin-1 kann von Proteinkinase C entweder an Serin oder an Threonin phosphoryliert werden. Daneben wird Caveolin-1 vorzugsweise von c-Src-Kinase an Tyrosin 14 phosphoryliert (CASELLI et al., 2001; STAN 2002; LEE et al., 2005). Durch das Anheften der 
Phosphatgruppe können diverse Signalmoleküle, wie beispielsweise Grb7 (HYANGKYU et al., 2005) oder Enzyme, wie die Phosphotyrosin-Protein-Phosphatase (CASELLI et al., 2001) an Caveolin-1 andocken und einen Signalweg einleiten bzw. inhibieren. Hierfür wäre der Befund, dass der Insulin-Rezeptor infolge einer Insulinstimulation in 3T3L1-Adipozyten die Phosphorylierung von Caveolin-1 katalysiert ein Beispiel (KIMURA et al., 2002).

Auf der anderen Seite wurde in einigen Studien ein inhibitorischer Einfluss, den Caveolin-1 über seine CSD auf einige Signalkaskaden ausübt, beschrieben. Beispielsweise kann Caveolin-1 die Nitrit-Oxid-Synthase (NOS) (JU et al., 1997; VENEMA et al., 1997; FERON et al., 1998), die Tyrosinkinasen c-Src (LI et al., 1996) und Fyn sowie Proteinkinase A, -C $\alpha$ und MEK1 (COUET et al., 1997; OKA et al., 1997; ENGELMAN et al., 1998) inaktivieren bzw. inhibieren.

\subsection{Fragestellung und Ziele dieser Arbeit}

Ausgangspunkt für diese Arbeit waren zwei Publikationen, die die Frage aufwarfen, ob eine altersbedingte Abschwächung der NGF/TrkA-Signalkaskade in OL mit einer erhöhten Caveolin-Expression einhergehen könnte. In der einen Arbeit war gezeigt worden, dass zwar humane OL ebenfalls auf NGF mit einer verbesserten Fortsatzbildung antworteten, jedoch gegenüber der Reaktion von Schweine-OL deutlich verzögert (ALTHAUS et al., 2001). Ein wesentlicher Unterschied beider OLPräparationen bestand darin, dass Schweine-OL von jungen Tieren (einem Jünglingsalter im humanen Bereich entsprechend) isoliert wurden, während die humanen OL bei Operationen von 40-50 jährigen Patienten mit Temporallappenepilepsie gewonnen wurden. In der zweiten Arbeit wurde gezeigt, dass eine Überexpression von Caveolin-1 in gealterten Fibroblasten zu einer Abschwächung der EGF-Signalkaskade führte, obgleich die Expression vom EGF-Rezeptor und Erks nicht vom normalen abwich (PARK et al., 2000).

Aus diesen beiden Ansätzen entwickelte sich eine vom Alter zunächst unabhängige Fragestellung, nämlich ob eine Interaktion von NGF/TrkA mit Caveolin bzw. CMD erfolgt, und ob dadurch eine Modulation der NGF/TrkA-Signalkaskade erkennbar wird. Um dieser komplexen Fragestellung nachgehen zu können, ergab sich ein Aufgabenkatalog von unterschiedlich aufwändigen Untersuchungsschritten: 
1) Während die Expression von TrkA/p75 ${ }^{\text {NTR }}$ bei Schweine-OL bekannt war, war unbekannt, ob Schweine-OL auch Caveolin exprimieren, sodass zunächst ein Nachweis von Caveolin erfolgen musste.

2) Zudem sollte das Vorkommen von CMD in ihrer charakteristischen kolbenförmigen Erscheinung in Schweine-OL mittels TEM dokumentiert werden.

3) Als nächstes sollte eine Isolationstechnik etabliert werden, mit der sich CMD aus der Plasmamembran anreichern lassen.

4) Außerdem sollte gezeigt werden, dass Caveolin und TrkA in Schweine-OL miteinander assoziiert sind sowie, dass TrkA und andere Signalproteine der unter (1.3.2) aufgeführten Signalkaskade in CMD enthalten sind.

5) Durch Inhibition der Caveolin-Expression, indem Schweine-OL mit Caveolin-1spezifischer siRNA transfiziert werden, sollte herausgefunden werden, wie sich das Fehlen von Caveolin auf die Fortsatzbildung von Schweine-OL und die NGF/TrkA-Signalkaskade auswirkt.

6) Ebenfalls war von Interesse, ob sich eine inhibitorische Beeinflussung der NGF/TrkA-Signalkaskade durch Cavtratin, einem zellpermeablen Caveolin-1 Scaffolding-Domänen Peptid, detektieren lässt.

7) Aufgrund der Tatsachen, dass Caveolin und Cholesterin innerhalb von Mikrodomänen vorkommen und Caveolin mit Cholesterin interagiert, ist ein weiteres Ziel dieser Arbeit, eine eventuelle Beeinflussung der NGF/TrkASignalkaskade durch Cholesterin zu zeigen. Die Frage, wie sich die Gabe von exogenem Cholesterin bzw. die Reduktion von Cholesterin durch Methyl-ßCyclodextrin auf die Fortsatzbildung von Schweine-OL auswirkt, stand dabei im Vordergrund. 


\section{Material und Methoden}

Alle in dieser Arbeit durchgeführten Versuche wurden als Triplikate oder zumindest als Duplikate durchgeführt.

\subsection{Verwendete Geräte und Reagentien}

\subsubsection{Geräte}

\begin{tabular}{|c|c|}
\hline Geräte & Hersteller \\
\hline $\begin{array}{l}\text { Ultrazentrifuge L8-60 u } \\
\text { SW } 28 \text { Rotor Beckmann Zentrifuge } \\
\text { SW } 41 \text { Rotor } \\
\text { SW } 52 \text { Rotor }\end{array}$ & Beckman, USA \\
\hline $\begin{array}{l}\text { Mini-Twin-Gelelektrophoresekammer } \\
\text { Trio Thermoblock (PC-Gerät) }\end{array}$ & Biometra, Göttingen \\
\hline Mini-TransBlot Cell & Bio-Rad, München \\
\hline Vakuum Zentrifuge Jota RVC & Christ, Göttingen \\
\hline Coulter Counter & Coulter Electronics, Krefeld \\
\hline $\begin{array}{l}\text { Superspeed Zentrifuge Servall RC -5B } \\
\text { Refrigerated }\end{array}$ & Du Pont Instuments, USA \\
\hline Schüttler und Wasserbad & Gebr. Rettberg, Göttingen \\
\hline Glashomogenisator & Heidolph, Deutschland \\
\hline $\begin{array}{l}\text { Zentrifuge: Omega } 70000 \text { mit Rotor SW } 30 \\
\text { Brutschrank Cyperm } \\
\text { Biofuge } 13\end{array}$ & Heraeus, Hanau \\
\hline Slap Gel Trockner Model SE 1160 & Hoffer Scientific Instruments \\
\hline pH-Meter & Knick, Deutschland \\
\hline Autoradiogramm Kassette & Kodak Industrie, Paris (Frankreich) \\
\hline Schüttler & Krannich, Göttingen \\
\hline MACS-Separator & Miltenyi Biotec, Bergisch Gladbach \\
\hline $\begin{array}{l}\text { Mikroplatten-Reader zur } \\
\text { Cholesterinbestimmung }\end{array}$ & Molecular Devices \\
\hline Nalgene Röhrchen Ultra Plus & Nalge Company Rochester (USA) \\
\hline
\end{tabular}




\begin{tabular}{|c|c|}
\hline $\begin{array}{l}\text { Gelkammern } \\
\text { Elektrophorese Konstant Power ECPS } 3000\end{array}$ & Pharmacia, Schweden \\
\hline Sterilarbeitsbank & Process Techniques, Hannover \\
\hline $\begin{array}{l}\text { Edelstahlfiltrationsvorsatz (SM } 162 \text { 14) } \\
\text { Sterilfilter (0,2 } \mu \mathrm{M} \text { Porendurchmesser) }\end{array}$ & Sartorius, Göttingen \\
\hline Kühlzentrifuge 2 KD mit Swing-out-Rotor & Sigma, München \\
\hline $\begin{array}{l}12 \mathrm{~cm} \text { lange Metallkanülen } \\
\text { (Innendurchmesser } 1 \mathrm{~mm}) \\
\text { anatomische Pinzette } \\
\text { Präparierpinzetten } \\
\text { Skalpellhalter und Rasierklingen } \\
\text { Arterienklinge } \\
\text { Magnetrührer } \\
\text { Ultraschall } \\
\text { Ultraschallbad }\end{array}$ & Schütt, Göttingen \\
\hline Feinwaage Mettler & Spoerhase AG, Gießen \\
\hline Shimadzu UV-160A-Spektralphotometer & Shimadzu Corporation, Kyoto (Japan) \\
\hline Dampfsterilisator Typ 300 & Varioklav, München \\
\hline UV-Kontaktlampe Typ Chromen & Vetter GmbH, Wiesloch \\
\hline Osmometer & Schlag, Bergisch Gladbach \\
\hline $\begin{array}{l}\text { Axioskop für Durchlicht und } \\
\text { Auflichtfluoreszenz (Anxiovert 200) } \\
\text { mit UV-Lampe, Temperaturkontrolle, } \\
\text { Digitalkamera und Notebook } \\
\text { IM35 Phasenkontrastmikroskop } \\
\text { Novascan } 30 \text { Elektronenmikroskop }\end{array}$ & Zeiss, Göttingen \\
\hline
\end{tabular}




\subsubsection{Verwendete Verbrauchsmaterialien und Reagentien}

\begin{tabular}{|c|c|}
\hline Produkt & Hersteller \\
\hline $\begin{array}{l}\text { ECL Western Blotting Detection Reagents } \\
1 \text { und } 2 \\
\text { ECL plus Western Blotting Detection } \\
\text { Hybond-ECL-Nitrozellulose Membran mit } \\
45 \mu \mathrm{m} \text { Porengröße } \\
\text { Trockenmilch } \\
{\left[\gamma^{33} \mathrm{P}\right] \text { ATP }}\end{array}$ & Amersham Buchler, Braunschweig \\
\hline Methanol & Baker, Deventer (Niederlande) \\
\hline $\begin{array}{l}\text { Baypen } \\
\text { Trasylol } 100000 \mathrm{KIE}\end{array}$ & Bayer, Leverkusen \\
\hline $\begin{array}{l}\text { Beckman Ultra-Clear Tube } \\
5 \text { × } 20 \mathrm{~mm} ; 5 \text { x } 41 \mathrm{~mm} ; 14 \text { x } 89 \mathrm{~mm}\end{array}$ & Beckman Coulter, USA \\
\hline $\begin{array}{l}\text { Fetales Kälberserum (Fetal Calf Serum) } \\
\text { Ham’s F-10 } \\
\text { Leucin } \\
\text { Methionin } \\
\text { Minimal Essential Medium-Earle } \\
\text { Minimal Essential Medium-Earle ohne } \\
\text { Leucin und Methionin } \\
\text { Penicillin/Streptomycin }(10000 \text { g/ml })\end{array}$ & Biochrom KG, Berlin \\
\hline $\begin{array}{l}\text { Rinderserumalbumin (BSA) } \\
\text { Coomassie Brillant Blau G-250 } \\
\text { Dithiothreitol (DTT) } \\
\text { N,N'-Methylenbisacrylamid (BIS) }\end{array}$ & Biomol, Hamburg \\
\hline $\begin{array}{l}\text { Bio-Rad Protein Assay } \\
\text { (Bradford Reagens) }\end{array}$ & Bio Rad Laboratories GmbH, München \\
\hline $\begin{array}{l}\text { Caveolin-1 Gerüst-Domäne-Peptid } \\
\text { (Cavtratin) + negative Kontrolle } \\
\text { K252a }\end{array}$ & Calbiochem Merk, Darmstadt \\
\hline
\end{tabular}




\begin{tabular}{|c|c|}
\hline $\begin{array}{l}\text { Ethanol (EtOH) 95\% } \\
\text { Isopropanol }\end{array}$ & Chemie-Vertrieb, Hannover \\
\hline Isotone II Lösung & Coulter Diagnostics GmbH, Krefeld \\
\hline Aquasol & DuPont, Boston (USA) \\
\hline Protein DOT-Metric Assay-Kit & Geno-Tech, St Louis (USA) \\
\hline Kulturschalen $32 \mathrm{~mm}\left(8,8 \mathrm{~cm}^{2}\right)$ & Greiner Bio-one GmbH, Frickenhausen \\
\hline $\begin{array}{l}\text { B-Mercaptoethanol } \\
\text { Nonidet-P40 (NP-40) } \\
\text { D(+)-Glukose Monohydrat } \\
\text { D(-)-Fruktose }\end{array}$ & Fluka, Buchs (Schweiz) \\
\hline RX Fuji Medical X-ray Film & Fuji, Tokio (Japan) \\
\hline Acrylamid & Gerbu, Gailberg \\
\hline Lipofektamin & Invitrogen, Karlsruhe \\
\hline Röntgenfilm Entwickler und Fixierer & Kodak Industrie, Paris (Frankreich) \\
\hline $\begin{array}{l}\text { Amidoschwarz } \\
\text { Ammoniaklösung } \\
\text { Ammoniumperoxodisulfat }\left(\mathrm{NH}_{2}\right)_{2} \mathrm{~S}_{2} \mathrm{O}_{8} \\
\text { (APS) } \\
\text { Bromphenolblau } \\
\text { Borsäure } \\
\text { Calciumchlorid-Dihydrat }\left(\mathrm{CaCl}_{2} * 2 \mathrm{H}_{2} \mathrm{O}\right) \\
\text { Coomassie Brillant Blau G-250 } \\
\text { Dimethylsulfoxid (DMSO) } \\
\text { Dinatriumhydrogenphosphat }\left(\mathrm{Na}_{2} \mathrm{HPO}_{4}\right) \\
\text { Ethanol reinst. } \\
\text { Ethanol vergällt } \\
\text { Ethylendiamintetraessigsäure }(\mathrm{EDTA}) \\
\text { Essigsäure konz. (Eisessig) } \\
\text { Fruktose } \\
\text { Glukose } \\
\text { Glycerin } \\
\text { Glycin }\end{array}$ & Merck, Darmstadt \\
\hline
\end{tabular}




\begin{tabular}{|c|c|}
\hline $\begin{array}{l}\text { Harnstoff } \\
\text { Kaliumchlorid } \\
\text { Kaliumdihydrogenphosphat }\left(\mathrm{KH}_{2} \mathrm{PO}_{4}\right) \\
\text { Kaliumhydroxid } \\
\text { Lithiumchlorid } \\
\text { Magnesiumchlorid } \\
\text { Natriumchlorid } \\
\text { Natriumdihydrogenphosphat }\left(\mathrm{NaH}_{2} \mathrm{PO}_{4}\right) \\
\text { Natriumhydrogencarbonat }\left(\mathrm{NaHCO}_{3}\right) \\
\text { Natriumhydroxid (NaOH) } \\
\text { Natriumhydroxid-Lösung }(1 \mathrm{~N}) \\
\text { Phenylmethan-sulfonylfluorid }(\mathrm{PMSF}) \\
\text { Phosphorsäure } \\
\text { Saccharose } \\
\text { Salzsäure konz. } \\
\text { Salzsäure 1N } \\
\text { Trichloressigsäure (TCA) }\end{array}$ & \\
\hline Amplex Red Cholesterol Assay Kit & $\begin{array}{l}\text { Molecular Probes (Invitrogen), } \\
\text { Eugene, Oregon (USA) }\end{array}$ \\
\hline Sterilfilter Millex $22 \mu \mathrm{M}$ & Millipore, Cork (Irland) \\
\hline $\begin{array}{l}\text { TC-Dish } 35 \times 10 \\
\text { 24-, 48-, 96-Lochplatten }\end{array}$ & Nunc, Roskilde Dänemark \\
\hline $\begin{array}{l}\text { Percoll } \\
\text { Agarose }\end{array}$ & Pharmacia Biotech GmbH, Freiburg \\
\hline $\begin{array}{l}\text { RNeasy Mini Kit (50) } \\
\text { Qiashredder (50) }\end{array}$ & Qiagen $\mathrm{GmbH}$, Hilden \\
\hline Dialysier-Folie, flach 1000 x $1200 \mathrm{~mm}$ & Reichelt Chemietechnik, Heidelberg \\
\hline Zell Scraper $25 \mathrm{~cm}$ & Sarstedt, Newton (USA) \\
\hline Zelluloseacetet-Folie & Sartorius, Göttingen \\
\hline $5951 / 2$ Faltenfilter $270 \mathrm{~mm}$ & Schleicher\&Schuell, Feldbach (Schweiz) \\
\hline $\begin{array}{l}\text { Nylonnetze der Porengrößen } 300,150 \text { und } \\
70 \mu \mathrm{m}\end{array}$ & Schütt, Göttingen \\
\hline
\end{tabular}




\begin{tabular}{|c|c|}
\hline $\begin{array}{l}\text { Albumin aus Rinderserum (BSA), krist. } \\
\text { reinst } \\
\text { Ethylenglycolbis(2-aminoethylether)- } \\
\text { N',N',N',N'-tetraessigsäure (EGTA) } \\
\text { N,N,N',N'-Tetramethylethyldiamin } \\
\text { (TEMED) } \\
\text { Paraformaldehyd } \\
\text { Triton X-100 }\end{array}$ & Serva, Heidelberg \\
\hline $\begin{array}{l}\text { Aprotinin } \\
\text { Adenosintriphosphat (ATP) } \\
\text { Alkalische Phosphatase } \\
\text { Cholestrin-PEG } 600 \\
\text { Cytosin-1-beta-D-Arabinofuranosid (Ara- } \\
\text { C) } \\
\text { Guanidium-HCl } \\
\text { (2-Hydroxypropyl)-B-Cyclodextrin } \\
\text { Imidazol-HCl } \\
\text { Insulin } \\
\text { Lumunol sodium salt } \\
\text { Methyl-beta-Cyclodextrin } \\
\text { MTT (Thiazolyl blue) } \\
\text { Myelin Basic Protein (MBP) } \\
\text { Natrium-Dodecylsulfat (SDS) } \\
\text { Natrium-Orthovanadat (Na } \mathrm{VO}_{4} \text { ) } \\
\text { Tween } 20 \\
\text { Tween } 40 \\
\text { Nerrium-Pyrophosphat } \\
\text { p-Coumaric acid } \\
\text { Polyethylenglycol } 600 \text { (PEG 600) }\end{array}$ & Sigma, Deisenhofen \\
\hline
\end{tabular}


\begin{tabular}{|l|l} 
Catch and Release v2.0 & Upstate Biomol, Hamburg
\end{tabular}

(reversible Immunoprecipitation System)

\subsubsection{Verwendete Antikörper}

\begin{tabular}{|c|c|}
\hline $\begin{array}{l}\text { Human Brain-Lysat } \\
\text { polyklonaler anti-Disulfid Isomerase (ER- } \\
\text { Marker) Kaninchen IgG }\end{array}$ & Abcam, Eching \\
\hline $\begin{array}{l}\text { ECL anti-Kaninchen IgG Horseradish } \\
\text { Peroxidase linked } \\
\text { ECL anti-Maus IgG Horseradish } \\
\text { Peroxidase linked } \\
\text { ECL anti-Ratte IgG Horseradish } \\
\text { Peroxidase linked }\end{array}$ & Amersham, Bioscience, England \\
\hline anti-p21 Ras (monoklonaler Maus IgG) & $\begin{array}{l}\text { Calbiochem kooperiert mit Merk, } \\
\text { Darmstadt }\end{array}$ \\
\hline $\begin{array}{l}\text { anti-MOSP (Myelin-Oligodendroglia- } \\
\text { specific-Protein), (monoklonaler Maus } \\
\text { IgM) }\end{array}$ & Chemicon, Hofheim \\
\hline Ratte Anti-Maus IgM Micro Beads & Miltenyi Biotec, Bergisch Gladbach \\
\hline $\begin{array}{l}\text { Alexa Fluor } 488 \text { Ziege anti-Maus IgG } \\
\text { Alexa Fluor } 488 \text { Ziege anti-Kaninchen IgG } \\
\text { Alexa Fluor } 488 \text { Kaninchen anti-Ziege IgG } \\
\text { Alexa Fluor } 546 \text { Ziege anti-Maus IgG } \\
\text { Alexa Fluor } 488 \text { Ziege anti-Maus IgM } \\
\text { Alexa Fluor } 546 \text { Ziege anti-Maus IgM }\end{array}$ & Molecular Probes (Invitrogen), Leiden \\
\hline $\begin{array}{l}\text { anti-TrkA (polyklonaler Kaninchen IgG) } \\
\text { Anti-P-TrkA (polyklonaler Kaninchen } \\
\text { IgG) } \\
\text { anti-Caveolin-1 (polyklonaler Kaninchen } \\
\text { IgG) } \\
\text { anti-Caveolin-2 (polyklonaler Kaninchen } \\
\text { IgG) }\end{array}$ & $\begin{array}{l}\text { Santa Cruz Biotechnology Inc., Santa } \\
\text { Cruz (USA) }\end{array}$ \\
\hline
\end{tabular}




\begin{tabular}{|l|l|}
\hline $\begin{array}{l}\text { anti-Caveolin-3 (polyklonaler Kaninchen } \\
\text { IgG) }\end{array}$ & \\
\hline anti-ß-Aktin (polyklonaler Kaninchen IgG) & Spring Bioscience, USA \\
\hline $\begin{array}{l}\text { anti-Caveolin (polyklonaler Kaninchen } \\
\text { IgG Antikörper) } \\
\text { anti-Phosphor Caveolin Tyr.14 (pY14) } \\
\text { (monoklonaler Maus IgG1 Antikörper) } \\
\text { anti Flotillin-1 } \\
\text { (Maus IgG1 Antikörper) }\end{array}$ \\
\hline $\begin{array}{l}\text { anti-MAPK Erk1+Erk2 (polyklonaler } \\
\text { Kaninchen IgG) } \\
\text { anti p75 }\end{array}$ \\
\hline
\end{tabular}

\subsubsection{Transfektionsreagentien/Transfektion}

\begin{tabular}{|l|l|}
\hline $\begin{array}{l}\text { jetSI-Endo } \\
\text { siRNA-Fluor }\end{array}$ & Biomol, Hamburg \\
\hline $\begin{array}{l}\text { Lipofectamin } 2000 \\
\text { Oligofectamin }\end{array}$ & Invitrogen, Karlsruhe \\
\hline Gene Silencer & PEQ Lab Biotechnologie, Erlangen \\
\hline $\begin{array}{l}\text { RNAiFect } \\
\text { Caveolin-1 siRNA } \\
\text { MAPK-siRNA }\end{array}$ & Qiagen GmbH, Hilden \\
\hline
\end{tabular}

\subsection{Zellkultur}

\section{Lösungen und Puffer:}

Hexose-Phosphat (HP)-Puffer:

$5 \%(\mathrm{w} / \mathrm{v})(=277,5 \mathrm{mM})$ Fruktose

$5,5 \%(\mathrm{w} / \mathrm{v})(=277,5 \mathrm{mM})$ Glukose

$10 \mathrm{mM} \mathrm{KH}_{2} \mathrm{PO}_{4}$

$20 \mathrm{mM}(4,77 \mathrm{~g})$ HEPES 
in wässriger Lösung

pH 7,3 mit $1 \mathrm{~N} \mathrm{KOH}$ einstellen

$630 \mathrm{mOsm}+/-15$

Transportpuffer :

$300 \mathrm{ml}$ HP-Puffer mit $400 \mathrm{U} / \mathrm{ml}$ Penicillin und $400 \mu \mathrm{g} / \mathrm{ml}$ Streptomycin

\section{$\underline{\text { Fötales Kälberserum (FCS- Fetal Calf Serum) }}$}

Dieses wurde nach 30 min Hitzeinaktivierung bei $56^{\circ} \mathrm{C}$ zwecks Lagerung in $60 \mathrm{ml}$ Portionen eingefroren. Vor Gebrauch wurde das Serum aufgetaut, sterilfiltriert und für die Zellkultur verwendet.

Cytosin-1-beta-D-Arabinofuranosid (Ara-C)-Medium:

4,805 g/1 Minimal Essential Medium-Earle (MEM)

4,945 g/1 Ham's F-10

$1,7 \mathrm{~g} / 1 \mathrm{NaHCO}_{3}$

$10 \mathrm{mg} / 1$ Transferin

$5 \mathrm{mg} / \mathrm{l}$ Insulin

$40 \mathrm{mg} / 1(400 \mathrm{U} / \mathrm{ml})$ Mezlocyclin fertig in $-20^{\circ} \mathrm{C}$ Portionen

4 mg/l Cytosin-1-beta-D-Arabinofuranosid (Ara-C)

in wässriger Lösung

pH 7,3 mit $1 \mathrm{~N} \mathrm{HCl}$

$300 \mathrm{mOsm}+/-10$

Cytosin-1-beta-D-Arabinofuranosid (Ara-C)- freies Medium (MEM):

4,805 g/1 Minimal Essential Medium-Earle (MEM)

4,945 g/1 Ham's F-10

$1,7 \mathrm{~g} / 1 \mathrm{NaHCO}_{3}$

$10 \mathrm{mg} / 1$ Transferin

$5 \mathrm{mg} / \mathrm{l}$ Insulin

15 mM HEPES

$40 \mathrm{mg} / 1(400 \mathrm{U} / \mathrm{ml})$ Mezlocyclin fertig in $-20^{\circ} \mathrm{C}$ Portionen

in wässriger Lösung, $\mathrm{pH}$ 7,3 mit $1 \mathrm{~N} \mathrm{HCl}$

$300 \mathrm{mOsm}+/-10$ 
$\underline{\text { Kulturmedium : }}$

Ara-C-Medium mit 5\% (v/v) Fötales Kälberserum (FCS)

Percoll :

Am Tage der Präparation frisch auf pH 7,3 mit $1 \mathrm{~N} \mathrm{HCl}$ einstellen (ca. 6 Tropfen auf 45 $\mathrm{ml})$

Poly-D-Lysin:

$2 \mathrm{mg} / 100 \mathrm{ml}$ Poly-D-Lysin auf der Feinwaage einwiegen, wird immer frisch am Präparationstag in wässriger Lösung hergestellt.

\subsubsection{Präparation von Schweineoligodendrozyten (Schweine-OL)}

Die Präparation und Isolierung von OL erfolgte nach der Methode von Gebicke-Härter (GEBICKE-HÄRTER et al., 1984). Als Ausgangsmaterial dienten Gehirne von sechs bis acht Monate alten Hausschweinen (Sus scrofa), die von einem ortsansässigen Schlachtbetrieb sowie vom Institut für Tierzucht der Universität Göttingen bezogen wurden. Die Betäubung der Tiere erfolgte mittels Elektrozange, im Anschluss wurden die Schweine durch Eröffnen der Halsschlagader getötet. Auf ein intensives Abflammen der Köpfe wurde verzichtet, um eine Schädigung der Gehirnzellen zu verhindern. Nach einem Zeitraum von höchstens 20 min wurden die Gehirne entnommen und in einem Transportpuffer $\left(4^{\circ} \mathrm{C}\right)$ überführt. Die Präparation der $\mathrm{OL}$ erfolgte unter sterilen Bedingungen auf Eis. Ebenfalls wurden alle verwendeten Lösungen und Puffer stets eisgekühlt eingesetzt. Zur Präparation wurden die Schweinegehirne aus dem Transportgefäß in eine Petrischale überführt und Rückenmarkrest (Medulla spinalis) sowie Kleinhirn (Cerebellum) entfernt. Als nächstes wurden die Gehirnhälften in der Frontalebene in 2-3 mm dicke Scheiben geschnitten. Diese wurden in eine neue mit eisgekühltem HP-Puffer gefüllte Petrischale gegeben, um sie von Blutverunreinigungen zu befreien. Danach wurde mithilfe eines Skalpells aus den Frontalschnitten die weiße Hirnsubstanz von der grauen getrennt. Ebenfalls nicht verwendet wurde das ventrikelauskleidende Ependym. Nach zweimaligem Waschen in HP-Puffer wurde das Gewicht der weißen Substanz bestimmt. An jedem Präparationstag wurden zwei Dichtegradienten mit je $14 \mathrm{~g}$ weißer Substanz eingesetzt. Diese wurde zunächst mit einer Rasierklinge grob zerkleinert und im Anschluss in ca. $15 \mathrm{ml}$ HP-Puffer 
suspendiert und auf ein Endvolumen von $30 \mathrm{ml}$ gebracht. Um die weiße Substanz noch weiter zu zerkleinern, wurde die Zellsuspension nacheinander luftblasenfrei mit möglichst geringem Druckaufwand durch einen zwischen zwei Spritzen befindlichen Edelstahlfilter gepresst. Im Inneren dieser Edelstahlfilter befand sich ein Nylonnetz, dass je nach Größe eine Maschenweite von 300, 150 und $70 \mu \mathrm{m}$ hatte. Um eine möglichst sanfte Zerkleinerung der weißen Hirnsubstanz zu erreichen, wurde die Suspension nacheinander in der obigen Reihenfolge beginnend mit dem $300 \mu \mathrm{m}$ Nylonnetz filtriert. Anschließend wurde die Suspension mit HP-Puffer auf ein Volumen von $30 \mathrm{ml}$ eingestellt. Zum Aufbau eines diskontinuierlichen Drei-Stufen PercollDichtegradienten wurde die Suspension wie folgt fraktioniert:

1. $25 \mathrm{ml} \mathrm{HP}-P u f f e r+5 \mathrm{ml}$ Percoll (Verhältnis 5:1)

2. $30 \mathrm{ml}$ Zellsuspension $+10 \mathrm{ml}$ Percoll (Verhältnis 3:1)

3. $12 \mathrm{ml} \mathrm{HP-Puffer}+6 \mathrm{ml}$ Percoll (Verhältnis 2:1)

Diese drei Fraktionen wurden auf drei Plastikröhrchen der Marke Nalgene Röhrchen Ultra Plus verteilt, die $10 \mathrm{ml}$ aus Fraktion 1, $13 \mathrm{ml}$ aus Fraktion 2 und $5 \mathrm{ml}$ aus Fraktion 3 enthielten. Die Zentrifugation des Dichtegradienten erfolgte bei $10000 \mathrm{rpm}$ und $4^{\circ} \mathrm{C}$ für 30 min in einem SW 41 Swing-out-Rotor. Nach der Zentrifugation befanden sich die OL direkt über den sedimentierten Erythrozyten und wurden mit einer $10 \mathrm{ml}$ Spritze entnommen. Um die Percollreste zu entfernen und die Osmolarität zu senken, wurden die OL zweimal mit MEM-Medium gewaschen. Dazu wurden die OL zunächst für 10 min bei $4^{\circ} \mathrm{C}$ und bei $500 \mathrm{x}$ g pelletiert. Der zweite Waschschritt erfolgte bei $130 \mathrm{x} g$ ebenfalls für 10 min bei $4^{\circ} \mathrm{C}$. Zum Schluss wurde das Pellet in Ara-C-Medium aufgenommen und die Zellzahl mithilfe eines Coulter Zell-Counters bestimmt. Pro Schale wurden ca. $5 \times 10^{5}$ Zellen $/ 2$ ml Medium ausgesät.

\subsubsection{Anlegen einer Monolayer Zellkultur}

Für das Anlegen einer Monolayer Zellkultur wurden Zellkulturschalen mit einem Durchmesser von $35 \mathrm{~mm}$ verwendet. Diese wurden entweder über Nacht oder aber mindestens für $30 \mathrm{~min}$ mit Poly-D-Lysin $(2 \mathrm{mg} / 100 \mathrm{ml})$ beschichtet und anschließend ein bis zweimal mit sterilem Wasser gewaschen. Die Kultivierung erfolgte im Inkubator bei einer Temperatur von $37^{\circ} \mathrm{C}, 5 \% \mathrm{CO}_{2}$ und $90 \%$ Luftfeuchtigkeit (ALTHAUS et al., 1984; BÜRGISSER et al., 1988). Ca. 18 - 22 Stunden nach Ende der Präparation wurde das Ara-C-Medium in den Schalen gegen Kulturmedium, welches zusätzlich 5\% FCS 
(Fötales-Kälber-Serum) enthielt, ausgetauscht. Im weiteren Verlauf der Kultivierung wurde das Kulturmedium alle 3-4 Tage gewechselt. Für langzeitkultivierte Zellen galt: Nachdem die Zellen dreimal hintereinander mit Ara-C-haltigem MEM-Medium kultiviert worden sind, wurde ab dem vierten Mediumwechsel nur noch MEM-Medium verwendet. Bei allen Stimulationsexperimenten, wo die Zellen nach acht Tagen Kultivierung mit verschiedenen Substanzen (z.B. NGF) stimuliert wurden, wurde das Ara-C-Medium gegen MEM-Medium ausgetauscht.

\subsubsection{Lebendzellfärbung}

\subsubsection{Trypanblau bzw. Ethidiumbromid-Färbung}

Hierzu wurde Trypanblau bzw. Ethidiumbromid auf die Zellen gegeben, gemischt und für 2 min bei Raumtemperatur inkubiert. Da Trypanblau nur die Zellmembran von toten Zellen durchdringen kann, bleiben die lebenden Zellen farblos. Im Regelfall wurde eine Überlebensrate von mehr als $85 \%$ beobachtet.

\subsubsection{MTT-Assay}

Der MTT-Lebendzell-Assay misst die mitochondriale Dehydrogenase-Aktivität (MOSMANN, 1983). Von der lebenden Zelle wird MTT (3-(4,5-dimethylthiazol-2-yl)2,5-diphenyl tetrazolium bromid, Sigma) aufgenommen und in den Mitochondrien zu schwarz-blauem Formazan umgesetzt (CHENG et al., 1998).

\section{MTT-Lösung}

$5 \mathrm{mg} / \mathrm{ml}$ MTT in PBS lösen und in einem 0,22- $\mu \mathrm{m}$ Filter sterilfiltrieren

\section{Lyse-Puffer}

$1 \mathrm{~g}$ SDS

9,4 ml DMSO

$30 \mu 1$ Essigsäure (konz.)

Zur Bestimmung der Lebendzellzahl wurde die MTT-Lösung in einer 1:10 Verdünnung (200 $\mu \mathrm{l} / 2 \mathrm{ml}$ Medium) direkt ins Medium zu den Zellen gegeben. Danach wurden die Zellen für 30-60 min im Brutschrank bei $37^{\circ} \mathrm{C}$ inkubiert. Die Auswertung erfolgte zum einen visuell unter dem Phasenkontrastmikroskop und zum anderen photometrisch. Dazu wurden die Zellen mit einem Spatel vom Plattenboden gelöst, in einer Zentrifuge 
pelletiert und in $200 \mu$ Lyse-Puffer für $10 \mathrm{~min}$ gerührt. Schließlich wurde in einem Photometer die optische Dichte der lysierten Zellen bei $570 \mathrm{~nm}$ gemessen.

\subsubsection{Isolation von Myelin}

Die Methodik erfolgte nach dem Versuchsprotokoll von Agrawal zur Subfraktionierung von Myelin (AGRAWAL et al., 1973). Dazu wurden 3 g weiße Hirnsubstanz präpariert und in $16 \mathrm{ml}$ 0,88 M Saccharoselösung im Glashomogenisator homogenisiert. Danach wurde diese Lösung in ein $40 \mathrm{ml}$ Tube gegeben und mit 0,32 M Saccharose überschichtet. Zentrifugiert wurde in einem SW 28-Rotor für $1 \mathrm{~h}$ bei $24000 \mathrm{rpm}$. Das Myelin wurde nun aus der Interphase abgenommen, in 9 Volumeneinheiten eiskaltem Wasser erneut im Glashomogenisator vermischt und für 20 min auf Eis gestellt. Nun wurde für $15 \mathrm{~min}$ bei $24000 \mathrm{rpm}$ zentrifugiert, das Pellet im eiskalten Wasser dispergiert und für $10 \mathrm{~min}$ bei $10000 \mathrm{rpm}$ abzentrifugiert. Dieser Schritt wurde einmal wiederholt, danach wurde das Pellet in 0,32 M Saccharose homogenisiert und auf $30 \mathrm{ml}$ mit 0,32 M Saccharose aufgefüllt. Daraus wurden sechs $5 \mathrm{ml}$ Portionen über einen diskontinuierlich Saccharosegradienten aufgetrennt, der vorher für mindestens $3 \mathrm{~h}$ auf Eis gestanden haben muss, bevor das Myelin eingefüllt wird. Dabei erfolgte der stufenweise Aufbau des Gradienten nach folgendem Schema von unten nach oben:

$5 \mathrm{ml}$ Myelin in 0,32 $\mathrm{M}$ Saccharose

$12 \mathrm{ml} \mathrm{0,55} \mathrm{M}$ Saccharose

$9 \mathrm{ml} \mathrm{0,75} \mathrm{M} \mathrm{Saccharose}$

$6 \mathrm{ml} \mathrm{0,85} \mathrm{M} \mathrm{Saccharose}$

$6 \mathrm{ml} \mathrm{0,88}$ M Saccharose

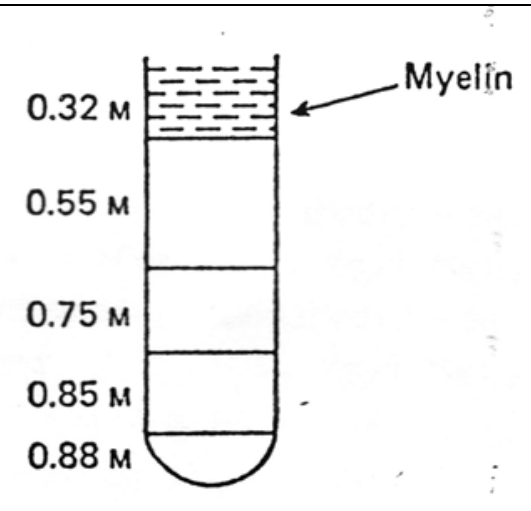

Die Zentrifugation lief bei $24000 \mathrm{rpm}$ und dauerte $1 \mathrm{~h}$. Am Ende erhielt man 3 verschiedene Banden: 
Fraktion 1: leichtes Myelin

Fraktion 2: schweres Myelin

Fraktion 3: Membran

Fraktion 4: Pellet

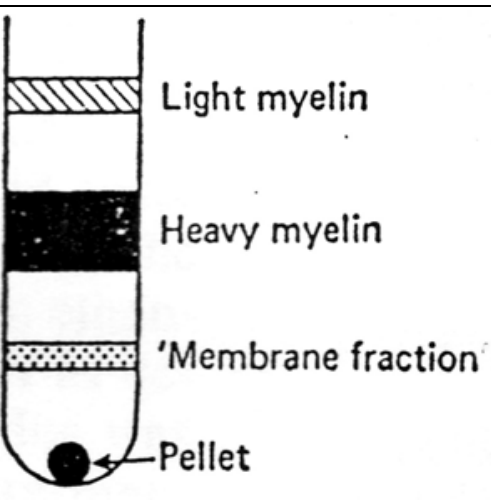

Zum Schluss wurden die vier Fraktionen einzeln abgenommen, homogenisiert, dann auf $100 \mathrm{ml}$ mit kaltem $\mathrm{H}_{2} \mathrm{O}$ aufgefüllt und für 30 min bei $30000 \mathrm{rpm}$ pelletiert. Der letzte Schritt war einmal zu wiederholen.

\subsection{Immuncytochemie}

\subsubsection{MOSP (Maus anti-Myelin Oligodendrocyte specific Protein)- Färbung}

\section{HEPES-BSA-Medium}

$20 \mathrm{mM}(0,47 \mathrm{~g} / 100 \mathrm{ml})$ HEPES

0,5\% (v/w) (50 mg / $10 \mathrm{ml})$ BSA (Bovine-Serum-Albumin)

in MEM-Medium

$\mathrm{pH} 7,4$

Zunächst wurden die Zellen nach mindestens 8 DIV dreimal in PBS gewaschen. Im Anschluss folgte die Inkubation mit Maus anti-MOSP IgM bei RT auf dem Schüttler. Der Antikörper wurde in einer Konzentration von 1:5000 in HEPES-BSA-Medium auf die Zellen gegeben. Nach 30 min wurden überschüssige MOSP-Antikörper entfernt und die Zellen dreimal mit PBS gewaschen. Danach wurden die Zellen in Methanol/Eisessig $(95 / 5)$ für $15 \mathrm{~min}$ im Kühlschrank fixiert. Zur Detektion von MOSP im Fluoreszenzmikroskop wurden die Zellen mit einem fluoreszierenden sekundären antiMaus IgM behandelt. Dieser wurde in einer Konzentration von 1:1000 eingesetzt. Die Zellen wurden für 30 min bei RT geschaukelt. Am Ende wurde erneut dreimal mit PBS 
gewaschen, ehe die Zellen im Fluoreszenzmikroskop betrachtet und im Kühlschrank aufbewahrt werden konnten.

\subsubsection{Caveolin-1-Färbung}

Genutzt wurden ein monoklonaler Maus anti-Caveolin IgM, welcher wegen seiner Größe lediglich Caveolin-1 in der Plasmamembran markiert und ein polyklonaler Kaninchen anti-Caveolin IgG. Die Zellen wurden nach mindestens $8 \mathrm{DIV}$ zunächst dreimal mit PBS gewaschen, ehe sie mit Methanol/Eisessig (95:5) für $30 \mathrm{~min}$ im Kühlschrank fixiert wurden. Nach abermaligem Waschen mit PBS wurden die Zellen mit 0,1\%-igem Triton für 10 min auf dem Schüttler bei RT inkubiert. Im Anschluss folgten wieder drei Waschschritte mit PBS. Schließlich konnte der monoklonale Maus anti-Caveolin $\operatorname{IgM}$ (1:1000 in MEM-Medium) für $30 \mathrm{~min}$ auf die Zellen gegeben werden. Nachdem der erste Antikörper durch dreimaliges Waschen der Zellen vollständig entfernt wurde, wurden die Zellen mit einem Fluoreszenz-gekoppelten sekundären Antikörper (Alexa fluor 488 Ziege anti-Maus IgM) in einer Konzentration von 1:1000 für 30 min bei RT inkubiert. Nach finaler Waschung konnten die Zellen unter UV-Licht betrachtet werden.

\subsection{Proteinkonzentrationsbestimmungen}

\subsubsection{Bestimmung der Proteinkonzentration mit der Tüpfelprobe}

Lösungen:

NaCl-Lösung

$0,9 \% \mathrm{NaCl}(\mathrm{w} / \mathrm{v})$ in Aqua bidest.

Amidoschwarz Färbelösung

0,5\% (w/v) Amidoschwarz 10 B in Methanol/Eisessig im Verhältnis 9:1

Entfärbelösung

Methanol/Eisessig im Verhältnis 9:1 
Besondere Verbrauchsmaterialien:

Zelluloseacetat-Folie

BSA (krist. reinst)

Die Tüpfelprobe wurde nach dem Protokoll von (NEUHOFF et al. 1979) durchgeführt. Zunächst wurde BSA in unterschiedlichen Konzentrationen von $0,5-5 \mathrm{mg} / \mathrm{ml}$ in $\mathrm{NaCl}$ gelöst, um eine zuverlässige Eichreihe zu erstellen. Von jeder $\mathrm{zu}$ eichenden Konzentration wurden nun $2 \mu \mathrm{l}$ auf ein kleines viereckiges Stückchen ZelluloseacetatFolie getüpfelt und für $5 \mathrm{~min}$ in einer Amidoschwarz-Färbelösung inkubiert. Mithilfe dieser Lösung wurden die Proteine gleichzeitig gefärbt und fixiert. Der überflüssige Farbstoff wurde durch Waschung der Zelluloseacetat-Folien in einer Entfärbelösung entfernt. In gleicher Weise wurde mit den zu untersuchenden Proben verfahren. Zur Auswertung wurden die Proben visuell mit den Werten der Eichreihe verglichen.

\subsubsection{Bestimmung der Proteinkonzentration mithilfe der Dot-Methode}

Zur Bestimmung der Proteinkonzentration wurde bei dieser Methode ein Protein AssayKit der Firma Geno Technology verwendet.

Zunächst wurde $1 \mu \mathrm{l}$ der Probe mit $5 \mu$ l Dilution Puffer verdünnt und ein Teststreifen zwischen zwei Magneten auf einer Magnetplatte befestigt. Nun wurden $2 \mu 1$ von der verdünnten Proteinprobe mithilfe einer Kapillare, die in eine Plastikvorrichtung gesetzt wurde, punktförmig und gleichmäßig auf den Teststreifen aufgetragen. Als nächstes wurde der Teststreifen in einem Fixierbad (0,4 ml Fixierer $+3,5 \mathrm{ml}$ Wasser) für $2 \mathrm{~min}$ bei RT inkubiert und dabei leicht geschwenkt. Im Anschluss wurde der Teststreifen in ein Entwicklerbad (0,4 $\mathrm{ml}$ Entwickler $+3,5 \mathrm{ml}$ Wasser) überführt, für ca. $30 \mathrm{sek}$ geschwenkt und für 2-4 min inkubiert. Am Ende wurde die Proteinkonzentration mithilfe einer Dot-Skala bestimmt, wobei die Proteinmenge mit dem Dot-Durchmesser korrelierte. 


\subsubsection{Proteinbestimmung nach Bradford}

\section{Lösungen:}

Bradford-Reagens der Firma BioRad

Die Proteinbestimmung nach Bradford (BRADFORD et al., 1976) wurde in dieser Arbeit hauptsächlich für die Umrechnung des Cholesterinwertes auf $1 \mathrm{mg}$ Protein bei den Cholesterinmessungen verwendet. Durch Bindung des Coomassie Brilliant BlueFarbstoffes an Proteine im sauren Milieu verschiebt sich das Absorptionsmaximum von 465 (rotbraun) auf $595 \mathrm{~nm}$ (blau). Die Absorptionszunahme bei $595 \mathrm{~nm}$ ist hierbei ein Maß für die Proteinkonzentration der Probe.

Die Stammlösung für den Bradford-Assay stammte von der Firma BioRad und setzt sich aus dem oben genannten Coomassie-Farbstoff, Ethanol und Phosphorsäure zusammen. Zunächst wurde eine Eichreihe im Bereich von 1-10 $\mu \mathrm{g} / \mu \mathrm{l}$ erstellt. Als nächstes wurden $200 \mu 1$ Stammlösung (verdünnte Bradford-Reagens) und $2 \mu 1$ Proteinlösung auf eine 96 Loch-Platte gegeben. Danach wurden die Proben für $10 \mathrm{~min}$ im Dunkeln bei RT inkubiert, ehe die Extinktion bei $595 \mathrm{~nm}$ Wellenlänge in einem Mikroplatten-Reader gemessen wurde. Nach Abzug des Leerwertes ließ sich der entsprechende Proteinwert ermitteln. In gleicher Weise wurde mit den zu vermessenden Proteinproben verfahren. Anhand der gemessenen Extinktion der Eichreihe konnte eine Eichkurve erstellt werden, die jedem Extinktionswert einen Proteinwert zuordnet, woraus sich ein Umrechnungsfaktor ermitteln ließ.

\subsubsection{Herstellung der Proteasehemmer}

\section{PMSF (100 mM):}

17,4 mg in $1 \mathrm{ml}$ Isopropanol bei RT lösen, 1:100 verdünnen

\section{$\underline{\mathrm{NaF}}(100 \mathrm{mM}):$}

4,2 $\mathrm{mg}$ in $1 \mathrm{ml} \mathrm{H}_{2} \mathrm{O}$ bei RT lösen, 1:100 verdünnen

Aprotinin $(1 \mathrm{mM})$ :

$1 \mathrm{mg} / \mathrm{ml}$ in $\mathrm{H}_{2} \mathrm{O}$ bei RT lösen, 1:1000 verdünnen 
Leupeptin $(1 \mathrm{mM})$ :

$1 \mathrm{mg} / \mathrm{ml}$ in $\mathrm{H}_{2} \mathrm{O}$ bei RT lösen, 1:1000 verdünnen

Natrium-Orthovanadat $(100 \mathrm{mM})$ :

Zur Herstellung einer 100 mM Natrium-Orthovanadatlösung wurden 184 mg NatriumOrthovanadat in $10 \mathrm{ml} \mathrm{H}_{2} \mathrm{O}$ gelöst. Der Ausgangs pH-Wert lag bei ungefähr 12,0. Mit 1 $\mathrm{N} \mathrm{NaOH}$ oder $1 \mathrm{~N} \mathrm{HCl}$ wurde der $\mathrm{pH}-$ Wert nun auf 10,0 eingestellt, wodurch sich die anfangs farblose Lösung gelb färbte. Nach kurzem Kochen wurde die Lösung wieder farblos. Danach wurde die Lösung auf Eis gestellt, bis sie wieder RT hatte. Insgesamt wurde dieser Vorgang dreimal wiederholt, bis die Lösung farblos und der pH-Wert stabil blieb. Durch diese Prozedur wird das Na-Orthovanadat depolymerisiert und in einen noch stärkeren Protein Tyrosin Phosphatase Inhibitor umgewandelt. Am Ende wurde das aktivierte Natrium-Orthovanadat portioniert und bei $-20^{\circ} \mathrm{C}$ eingefroren und so für mindestens $1 \frac{1}{2}$ Jahr konserviert.

\subsection{Isolation von CMD}

\subsubsection{Isolierung von $\mathrm{CMD}$ mittels Detergens-freier $\mathrm{NaCO}_{3}$-haltiger Saccharose-Dichtegradientenzentrifugation}

CMD wurden nach der folgenden leicht modifizierten Methode über einen SaccharoseDichtegradienten isoliert (SONG et al., 1996; SILVA et al., 1999).

\section{Verwendete Lösungen und Puffer:}

MBS-Puffer $(500 \mathrm{ml})$

2,45 g (25 mM) MES

$4,4 \mathrm{~g}(0,15 \mathrm{M}) \mathrm{NaCl}$

pH 6,5

MB-Puffer $(500 \mathrm{ml})$

$2,45 \mathrm{~g}(25 \mathrm{mM}) \mathrm{MES}$

pH 6,5 
Puffer A $(200 \mathrm{ml})$

$5,3 \mathrm{~g}(250 \mathrm{mM}) \mathrm{Na}_{2} \mathrm{CO}_{3}$ in $200 \mathrm{ml} \mathrm{MBS}$

$\mathrm{pH} 6,5$

Puffer B (100 ml)

$5,3 \mathrm{~g}(500 \mathrm{mM}) \mathrm{Na}_{2} \mathrm{CO}_{3}$

$1 \mathrm{mM}$ PMSF (Stammlösung $100 \mathrm{mM}, 17,4 \mathrm{mg} / \mathrm{ml}, 1: 100$ verdünnen)

pH 6,5

$\underline{90 \% \text { Saccharoselösung }(100 \mathrm{ml})}$

$90 \mathrm{~g}$ Saccharose in ca. $25 \mathrm{ml}$ MBS lösen

35\% und 5\% Saccharoselösung (100 ml)

35 g bzw. 5g Saccharose in Puffer A (MBS + $\left.250 \mathrm{mM} \mathrm{Na}_{2} \mathrm{CO}_{3}\right)$ lösen.

Nach 8-10 Tagen in Kultur werden pro Gradient etwa 50x10 $60^{6}$ Zellen (8-10 Platten) benötigt. Zuerst wurde das Medium entfernt und die Zellen wurden 2x in MBS-Puffer gewaschen. Danach wurden die Zellen pro Platte in $200 \mu 1$ Puffer B abgelöst. Als nächstes wurden die Zellen mittels Glashomogenisator mit 10-Stößen zum Platzen gebracht. Für eine postnukleäre-Fraktionierung wurde die Zellsuspension unter Zusatz von DNase I bei 1000 rpm zentrifugiert und der Überstand abgenommen. Schließlich folgte der Aufbau des Saccharose-Gradienten in einem Beckman Ultra-Clear Tube:

- untere Schicht: $2 \mathrm{ml}$ Zellsuspension + $2 \mathrm{ml}$ 90\%-iger Saccharoselösung vermischen

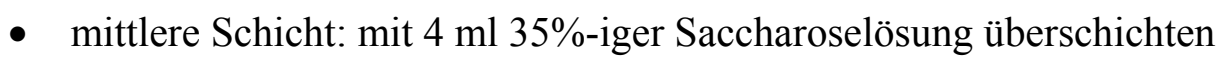

- obere Schicht: mit $4 \mathrm{ml}$ 5\%-iger Saccharoselösung überschichten

Nach erfolgtem Austarieren wurde der Gradient für $22 \mathrm{~h}$ bei $39000 \mathrm{rpm}$ und $4^{\circ} \mathrm{C}$ zentrifugiert (SW 41 Rotor Beckmann Zentrifuge). Am darauf folgenden Tag wurde mithilfe einer 1000er Pipette 12x $1 \mathrm{ml}$ Fraktionen vom Gradienten abgenommen und im Verhältnis 3:1 mit MB-Puffer verdünnt. Danach folgte ein 30-minütiges Zentrifugieren bei $10000 \mathrm{rpm}$ (SW 21 Rotor). Schließlich wurden die Proben in 2\%igem SDS gelöst und nach dem Zusatz von Mercaptoethanol-haltigem Probenpuffer bei $95^{\circ} \mathrm{C}$ denaturiert. Die Zelllysate der zwölf Fraktionen wurden nun auf einem 12\%-igen SDS- 
Polyacrylamidgel aufgetrennt und die Proteine auf eine PVDF-Folie übertragen. Zur Detektion von Caveolin-1 und TrkA im Immunoblot wurden die polyklonalen IgG Antikörper Caveolin-1 (Kaninchen) und TrkA (Kaninchen) an das Protein gebunden. Über einen an HRP-gekoppelten sekundären Antikörper konnten die entsprechenden Proteine mithilfe einer Detektionlösung auf einem Röntgenfilm sichtbar gemacht werden.

\title{
2.5.2 Isolation von CMD mittels Triton X-100-haltiger Saccharose- Dichtegradientzentrifugation
}

Triton X-100-Puffer $(200 \mathrm{ml})$

$2 \%$ Triton $\mathrm{X}-100$

$1 \mathrm{mM}$ PMSF

in MBS Puffer lösen

Diese Methode wurde ursprünglich von Lisanti und seinen Mitarbeitern entwickelt (SARGIACOMO et al., 1993; LISANTI et al., 1994b, 1995) und macht sich die charakteristische Eigenschaft von CMD zu Nutze, bei $4^{\circ} \mathrm{C}$ unlöslich in nicht-ionischen Detergentien (z.B. 1\%iges Triton X-100) zu sein. Zunächst wurde eine homogene OLZellsuspension aus 8-10 Kulturschalen mit jeweils etwa $5 \times 10^{6}$ Zellen in einem Triton X-100-haltigen Puffer hergestellt. Diese Suspension wird danach im Verhältnis 1:1 mit einer 80\%-igen Saccharoselösung vermengt, und danach mit 30\%-iger und 5\%-iger Saccharoselösung überschichtet, sodass ein Dichtegradient bestehend aus drei Schichten (jeweils $4 \mathrm{ml}$ ) mit 40\%-, 30\%- und 5\%-tigem Saccharoseanteil aufgebaut werden konnte. Nach 22-stündigem Zentrifugieren bei $39000 \mathrm{rpm}$ und $4{ }^{\circ} \mathrm{C}$ wurden schließlich zwölf 1 ml-Fraktionen abgenommen und mittels SDS-Page und Western Blot auf die Caveolin-Verteilung hin analysiert.

\subsubsection{Anreicherung von CMD aus der Plasmamembran unter Anwendung von MACS (Magnetic Cell-Sorting)-Technologie}

\author{
Puffer A \\ $20 \mathrm{ml}$ PBS \\ $2 \mathrm{mM}(14,9 \mathrm{mg})$ EDTA
}


$0,1 \%(\mathrm{v} / \mathrm{w}) \mathrm{BSA}$

zusätzlich wurden folgende Proteasehemmer dem Puffer zugesetzt:

100 mM PMSF (1:100)

$100 \mathrm{mM}$ Na-Orthovanadat (1:100)

$100 \mathrm{mM} \mathrm{NaF}$ (Natriumfluorid) (1:100)

$1 \mathrm{mM}$ Aprotinin (1:1000)

$1 \mathrm{mM}$ Leupeptin (1:1000)

\section{Triton X-100 Puffer}

1\% Triton $\mathrm{X}-100$

in MBS-Puffer lösen + Proteasehemmer

Um CMD aus der Plasmamembran anzureichern, wurden 8-10 Tage alte Zellkulturen mit anti-MOSP IgM markiert. Nach erfolgter Waschung in PBS wurden die Zellen in $700 \mu 1$ Puffer A abgespatelt, durch Ultraschall zerkleinert und unter Zusatz von DNase I für $10 \mathrm{~min}$ bei $1000 \mathrm{rpm}$ abzentrifugiert, um eine postnukleäre Fraktion zu erhalten. Das Zellpellet wurde nun in $80 \mu \mathrm{l}$ Puffer A resuspendiert. Als nächstes wurde an den primären IgM Antikörper ein mit magnetischen Beads gekoppelter sekundärer Antikörper angehängt. Dazu wurden $80 \mu 1$ der Zellsuspension mit $20 \mu 1$ eines anti-Maus IgM MicroBeads-gekoppelten Antikörper vermischt und für $15 \mathrm{~min}$ bei $10^{\circ} \mathrm{C}$ geschüttelt. Danach wurde $1 \mathrm{ml}$ von Puffer A zugegeben und für $10 \mathrm{~min}$ bei $3000 \mathrm{rpm}$ zentrifugiert. Dieser Waschschritt wurde 2x wiederholt, bevor das Zellpellet in $500 \mu 1$ Puffer A aufgenommen und auf eine spezielle MACS-Säule, die in einer Magnetapparatur (MACS-Separator) eingesetzt wurde, aufgetragen. Das Eluat mit dem Durchfluss wurde verworfen, da das Beads-gekoppelte Antigen durch das Magnetfeld im MACS-Separator in der Säule zurückgehalten wurde. Um das übrige Zellmaterial zu eluieren, wurde die Säule dreimal mit Puffer A beladen und der Durchfluss gesammelt. Zum Schluss wurde die Säule aus der Magnetapparatur entfernt, mit $1 \mathrm{ml}$ Puffer A beladen, und mithilfe eines Spritzenkolbens wurde das Beads-gekoppelte Material aus der Säule gedrückt. Zur Verringerung des Volumens folgte nun ein Zentrifugationsschritt in der Heraeus Zentrifuge. Dazu wurden die isolierten Plasmamembran-Fragmente in spezielle Beckman Röhrchen (Beckman Ultra-Clear Tube 5 x $20 \mathrm{~mm} ; 5 \times 41 \mathrm{~mm}$ ) pipettiert und für $30 \mathrm{~min}$ bei $35000 \mathrm{rpm}$ zentrifugiert. Der Überstand wurde verworfen, das Pellet im Triton X-100-Puffer durch Sonifizieren 
gelöst und für $45 \mathrm{~min}$ auf Eis inkubiert. Danach wurden Triton X-100-lösliche Bestandteile von den unlöslichen durch Zentrifugieren bei $35000 \mathrm{rpm}$ getrennt. Der Überstand enthielt Detergens-lösliches Material, das mit einer Pipette abgenommen und in einer Vakuum-Zentrifuge oder durch die Begasung mit Stickstoff eingedampft wurde. Beide Fraktionen wurden nun in 5\%-igem SDS für mindestens 45 min gelöst, für 2 min bei $95^{\circ} \mathrm{C}$ denaturiert und auf einem Polyacrylamidgel mit doppelter SDSMenge aufgetrennt.

\subsection{Cholesterin-Bestimmung}

Für alle Cholesterinmessungen wurde das Amplex Red Cholesterin Assay Kit der Firma Molecular Probes verwendet. Es besteht aus einem Reaktionspuffer, der 0,5 $\mathrm{M} \mathrm{K}_{2} \mathrm{PO}_{4}$, $0,25 \mathrm{M} \mathrm{NaCl}, 25 \mathrm{mM}$ Gallensäure und $0,5 \%$ Triton X-100 enthält sowie einer "Working-Solution" aus $300 \quad \mu \mathrm{M} \quad$ Amplex-Red-Reagens (10-Acetyl-3,7Dihydroxyphenoxazin), $2 \mathrm{U} / \mathrm{ml}$ Horseradish Peroxidase, $2 \mathrm{U} / \mathrm{ml}$ Cholesterin-Oxidase und 0,2 U Cholesterin-Esterase. Das Absorptions- und Fluoreszenz-Emissionsspektrum von Resorufin (Produkt der Amplex Red Reagens) liegt zwischen 560 und $590 \mathrm{~nm}$. Dieses wurde mit einem Platten-Reader der Firma Molecular Devices detektiert.

Testprinzip:

Cholesterinester $+\mathrm{H}_{2} \mathrm{O}$ Cholesterinester-Hydrolase $\rightarrow$ Cholesterin + Fettsäure

Cholesterin $+\mathrm{O}_{2} \underline{\text { Cholesterin-Oxidase }} \rightarrow$ Cholest-4-en-3-on $+\mathrm{H}_{2} \mathrm{O}_{2}$

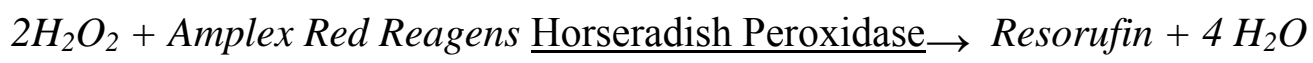

\section{Cholesterin Extraktion}

Zur Bestimmung des Cholesteringehaltes wurden die OL 3x in PBS gewaschen, mit einem Schaber in $800 \mu \mathrm{l}$ PBS abgelöst, bei $3000 \mathrm{rpm}$ abzentrifugiert und die Zellmembran mittels Ultraschall zerkleinert. Als nächstes wurde freies Cholesterin von den übrigen Zellbestandteilen getrennt. Dazu wurde Cholesterin in der Zellsuspension mit Chloroform/Methanol im Verhältnis 2:1 ausgeschüttelt (GAMBLE et al. 1978). In Chloroform gelöstes Cholesterin wurde in ein Eppendorfgefäß überführt und durch Vakuum-Zentrifugation wurde das Chloroform abgedampft. 


\section{Cholesterin-Bestimmung}

Mit einer Cholesterin-Referenz ( $2 \mathrm{mg} / \mathrm{ml}$ Cholesterin) wurde eine Eichgerade von 0 $20 \mu \mathrm{g} / \mathrm{ml}$ Cholesterin erstellt. Später konnte hiermit jeder Probe anhand ihrer gemessenen Fluoreszenz die jeweilige Cholesterinkonzentration zugewiesen werden. Zur Cholesterinmessung wurde die Probe in $50 \mu 1$ Reaktionspuffer gelöst, auf eine 48Loch-Platte überführt und mit $50 \mu 1$ Working-Solution vermischt. Anschließend folgte ein 30-minütiger Inkubationsschritt bei $37^{\circ} \mathrm{C}$ im Mikroplatten-Reader, ehe die Fluoreszenz bei 570-590 nm gemessen werden konnte.

\section{Immunzytochemische Detektion der Cholesterinaufnahme}

Verbrauchsmaterial:

Fluorescein-gekoppeltes PEG (Polyethylenglycol)-50 Cholesterin (zur Verfügung gestelt von Kobayashi)

Die eingesetzte Konzentration von $1 \mu \mathrm{M}$ Fluorescein-gekoppeltem PEG (Polyethylenglycol)-50 (FPEG)-Cholesterin stammte aus dem Protokoll von (ISHITSUKA et al., 2005). Um nachzuweisen, dass primäre OL in der Lage sind, exogenes Cholesterin aufzunehmen, wurde fluoreszierendes FPEG-Cholesterin $(1 \mu \mathrm{M})$ für $24 \mathrm{~h}$ auf OL-Kulturen gegeben. Die Cholesterin-Aufnahme konnte schließlich mittels Fluoreszenzmikroskopie nachvollzogen werden.

\subsection{Immunpräzipitation}

Für die Immunpräzipitation wurde ein "Catch and Release Kit" von Upstate verwendet. Die Zellen wurden in PBS gewaschen, mit einem Schaber vom Plattenboden abgelöst und pelletiert. Danach wurden die Zellpellets in $50 \mu 1$ Waschpuffer (1:10 verdünnt, da der Puffer 10x konzentriert ist), der Proteasehemmer enthalten sollte, für 30 min gelöst. Parallel konnte mit der Säulenvorbereitung begonnen werden. Dazu wurde der Säulenboden entfernt, die Säule in ein Eppendorfgefäß gestellt und für 30 sek bei 5000 rpm zentrifugiert. Es folgten zwei Waschschritte, in denen die Säulen mit $400 \mu 1$ Waschpuffer beladen und abzentrifugiert wurden. Als nächstes wurde der Immunpräzipitationsansatz in folgender Reihenfolge auf die Säule gegeben:

1) $415 \mu 1$ Waschpuffer

2) $50 \mu 1$ Zelllysat 
3) $5 \mu 1$ Antikörper

4) $10 \mu \mathrm{l}$ Affinitätsligand

Die Immunpräzipitation wurde bei RT unter Rotation der Säule oder bei $4^{\circ} \mathrm{C}$ über Nacht durchgeführt. Nach Beendigung wurde ungebundenes Material für 30 sek bei 5000 rpm abzentrifugiert. Nach drei Waschschritten mit je $400 \mu l$ Waschpuffer und anschließender Pelletierung bestanden zwei Möglichkeiten. Man konnte die Säule sowohl mit nativen als auch mit denaturierendem Probenpuffer $(50 \mu 1)$ eluieren. Dies hing vom jeweiligen Protein ab. Schließlich wurden die Proben noch bei $95^{\circ} \mathrm{C}$ gekocht und konnten danach direkt aufgetragen werden.

\subsection{SDS-Polyacrylamidgel-Elektrophorese}

Die SDS-Polyacrylamidgel-Elektrophorese wird zur Auftrennung von Proteingemischen verwendet. Dabei dient das Acrylamid als inerte Matrix mit variabler Porengröße. Das negativ geladene Detergens SDS bindet an die hydrophoben Bereiche der Proteine, umhüllt diese und verleiht ihnen dadurch eine negative Ladung. Auf diese Weise verhindert man eine potentielle Abhängigkeit der Wanderungsgeschwindigkeit von der Proteinladung. Die Wanderungsgeschwindigkeit ist einzig abhängig von dem Molekulargewicht des Proteins und somit der Fähigkeit des Proteins, sich durch die vorgegebenen Poren der Gelmatrix zu bewegen.

\section{Verwendete Lösungen und Puffer:}

Proben- Auftragspuffer $4 \mathrm{ml}$ :

$2 \mathrm{ml}$ Tris $\mathrm{HCl}(1,5 \mathrm{M}) \mathrm{pH} 8,8$

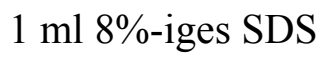

$1 \mathrm{ml}$ Glycerin

$80 \mu 1$ ß-Mercaptoethanol

$100 \mu \mathrm{g}$ Bromphenolblau

pH 6,8 
Acrylamid-Stammlösung:

$30 \%(\mathrm{w} / \mathrm{v})$ Acrylamid

$0,8 \%(\mathrm{w} / \mathrm{v}) \mathrm{N}, \mathrm{N}$ '-Methylenbisacrylamid (BIS)

in wässriger Lösung, mit Aktivkohle mindestens eine Stunde rühren und danach abfiltrieren

\section{Tris HCl-Puffer $\mathrm{pH} 8,8$}

1,5 M Tris $\mathrm{HCl}$ in wässriger Lösung

Tris HCl-Puffer $\mathrm{pH} \mathrm{6,6}$

$0,5 \mathrm{M}$ Tris $\mathrm{HCl}$

in wässriger Lösung

Ammoniumperoxodisulfat-Lösung (APS)

$10 \%(\mathrm{w} / \mathrm{v})(1 \mathrm{~g} / 10 \mathrm{ml})$ Ammoniumperoxodisulfat in wässriger Lösung

$\underline{\text { Sammelgel }}$

0,99 ml Acrylamid-Stammlösung

$1,5 \mathrm{ml}$ Tris $\mathrm{HCl} \mathrm{pH} 6,8$

$60 \mu 1$ 10\% SDS-Stammlösung

$3,45 \mathrm{ml} \mathrm{H}_{2} \mathrm{O}$

$50 \mu 1$ 10\%-iges APS

$10 \mu 1$ TEMED (N,N,N',N'-Tetramethylethyldiamin)

Trenngel:

Je nach Größe des nachzuweisenden Proteins wurde das Trenngel in unterschiedlichen Polyacrylamidkonzentrationen angesetzt. Allgemein werden Proteine mit einem hohen Molekulargewicht auf einem niedrigprozentigen und Proteine mit einem niedrigen Molekulargewicht auf einem höherprozentigen Polyacrylamidgel aufgetrennt. Da die Größe der zu untersuchenden Proteine in dieser Arbeit häufig zwischen 20 und 100 kDa lagen, wurden zumeist 10-12\%-ige Gele zur Auftrennung verwendet. Die Proteinproben erreichen innerhalb des Sammelgels eine einheitliche Startlinie, bevor sie im Trenngel nach ihrem Molekulargewicht aufgetrennt werden. 


\begin{tabular}{|l|l|l|l|l|l|l|}
\hline $\begin{array}{l}\text { Trenngel } \\
\text { (in } \\
\text { Prozent) }\end{array}$ & $\mathbf{5 \%}$ & $\mathbf{6 \%}$ & $\mathbf{7 , 5 \%}$ & $\mathbf{1 0 \%}$ & $\mathbf{1 2 \%}$ & $\mathbf{1 5 \%}$ \\
\hline $\begin{array}{l}\text { Acrylamid } \\
\text { Lösung }\end{array}$ & $1 \mathrm{ml}$ & $1,2 \mathrm{ml}$ & $1,5 \mathrm{ml}$ & $2 \mathrm{ml}$ & $2,4 \mathrm{ml}$ & $3 \mathrm{ml}$ \\
\hline $\begin{array}{l}\text { Tris HCl } \\
\text { Puffer pH } \\
\mathbf{8 , 8}\end{array}$ & $1,5 \mathrm{ml}$ & $1,5 \mathrm{ml}$ & $1,5 \mathrm{ml}$ & $1,5 \mathrm{ml}$ & $1,5 \mathrm{ml}$ & $1,5 \mathrm{ml}$ \\
\hline SDS 10\% & $60 \mu \mathrm{l}$ & $60 \mu \mathrm{l}$ & $60 \mu \mathrm{l}$ & $60 \mu \mathrm{l}$ & $60 \mu \mathrm{l}$ & $60 \mu \mathrm{l}$ \\
\hline H2O & $3,44 \mathrm{ml}$ & $3,24 \mathrm{ml}$ & $2,94 \mathrm{ml}$ & $2,44 \mathrm{ml}$ & $2,04 \mathrm{ml}$ & $1,44 \mathrm{ml}$ \\
\hline TEMED & $5 \mu \mathrm{l}$ & $5 \mu \mathrm{l}$ & $5 \mu \mathrm{l}$ & $5 \mu \mathrm{l}$ & $5 \mu \mathrm{l}$ & $5 \mu \mathrm{l}$ \\
\hline APS 10\% & $30 \mu \mathrm{l}$ & $30 \mu \mathrm{l}$ & $30 \mu \mathrm{l}$ & $30 \mu \mathrm{l}$ & $30 \mu \mathrm{l}$ & $30 \mu \mathrm{l}$ \\
\hline
\end{tabular}

Abb. 13 : Zusammensetzung der Trenngele verschiedener Konzentrationen.

\section{Laufpuffer (5 Liter)}

$30 \mathrm{~g}(49,5 \mathrm{mM})$ Tris

$144 \mathrm{~g}(383,6 \mathrm{mM})$ Glycin

$5 \mathrm{~g}(3,5 \mathrm{mM})$ SDS

in wässriger Lösung; pH 8,6

Die verwendete Apparatur bestand aus zwei durch Spacer getrennte Glasplatten, die nach Einlegen einer Gummidichtung mithilfe von drei Klammern zusammengehalten wurden.

Beim Gießen eines Gels musste das 10\%-tige APS immer frisch angesetzt werden; bzw. durfte es nicht älter als 1 Woche sein. Außerdem wurden APS und TEMED beim Gießen eines Gels immer als letztes dazugegeben. Der Abstand der beiden Glasplatten betrug $1 \mathrm{~mm}$. In diesen Zwischenraum wurde nun das flüssige Trenngel gegeben und mit einer 0,1\%-igen SDS-Lösung überschichtet, um einen glatten Abschluss des Trenngels zu erhalten. Nach einer Polymerisationsdauer von mindestens 20 min wurde die 0,1\%-ige SDS-Lösung wieder entfernt und das Sammelgel eingefüllt. Zur Taschenbildung wurde ein Kamm in das Sammelgel eingesetzt. Nach einer erneuten Polymerisationszeit von mindestens 20 min wurde das SDS-Gel in eine mit Laufpuffer gefüllte Mini-Twin-Gelelektrophoresekammer von Biometra eingesetzt und der Kamm vorsichtig entfernt. Nun wurden die Geltaschen mit Laufpuffer gespült, um überflüssige Gelreste zu entfernen und mit den zu untersuchenden Proben beladen. Um den Proben das Einwandern in das Sammelgel zu erleichtern, wurde zunächst eine Stromstärke von 10-15 mA / Gel angelegt. Nach etwa 10 min wurde der Gellauf bei $25 \mathrm{~mA} / \mathrm{Gel}$ fortgesetzt, bis die Lauffront das untere Ende vom Gel erreicht hatte. Als nächstes folgte 
die Übertragung der aufgetrennten Proteine vom Gel auf eine Nitrozellulosemembran (oder auf eine PVDF-Membran) mithilfe eines Western- oder Immunoblots.

\subsection{Western Blot / Immunoblot}

Der gebräuchliche Trivialname Western Blot geht auf den Namen des Erfinders der Blottingtechnik namens Southern zurück. In Anlehnung an seinen Namen wurde der Transfer von RNA-Fragmenten als Northern-, der Transfer von DNA-Fragmenten als Southern- und der Proteintransfer als Western Blotting bezeichnet. Demnach bezeichnet der Term Western Blot also das Proteinblotting mit anschließender Immundetektion.

\section{Lösungen:}

PBS-Tween Waschlösung (2 Liter)

$28,4 \mathrm{~g}(80 \mathrm{mM}) \mathrm{Na}_{2} \mathrm{HPO}_{4}$

$5,0 \mathrm{~g}(20 \mathrm{mM}) \mathrm{NaH}_{2} \mathrm{PO}_{4}$

$11,68 \mathrm{~g}(0,1 \mathrm{M}) \mathrm{NaCl}$

$1 \mathrm{ml}(0,1 \%)(\mathrm{v} / \mathrm{v})$ Tween 20

in wässriger Lösung

\section{$\underline{\text { Blot-Puffer }}$}

$3,03 \mathrm{~g} / 1$ (25 mM) Tris

14,4 g/l (192 mM) Glycin

$4 \mathrm{ml}$ 10\%iges $(0,1 \%)$ SDS

$200 \mathrm{ml}(20 \%)$ Methanol

mit Aqua bidest. auf 1 Liter auffüllen $(\sim 800 \mathrm{ml})$

Besondere Verbrauchsmaterialien:

Hybond $^{\mathrm{TM}}$-ECL-Nitrozellulosemembran mit einer Porengröße von $45 \mu \mathrm{m}$ oder Hybond $^{\mathrm{P}}$-ECL-PVDF-Membran mit einer Porengröße von $45 \mu \mathrm{m}$

Zur weiteren Untersuchung der durch SDS-Polyacrylamidgel-Elektrophorese aufgetrennten Proteine transferiert man die Proteine aus dem Gel auf eine feste Membran. Die fixierten Proteine können im Anschluss immunologisch mithilfe von 
Antikörpern oder durch Membranfärbung näher untersucht und charakterisiert werden. Der Transfer der Proteine auf die Membran kann auf verschiedene Weise erfolgen. Hauptsächlich wird zwischen Kapillarblotting, wo die Proteine durch Kapillarkräfte auf die Membran gelangen und Elektroblotting unterschieden. Beim Elektroblotting wandern die Proteine durch das Anlegen eines elektrischen Feldes auf die Membran, die auf der Anodenseite angebracht ist. In dieser Arbeit wurde das Elektroblotting in einem Puffertank (TOWBIN et al., 1979; BURNETTE, 1981) durchgeführt. Dazu wurden Acrylamidgel und Nitrozellulosemembran luftblasenfrei zwischen zwei Filterpapieren und Schwammtüchern in eine Gitterkassette geklemmt. Danach wurde diese Gitterkassette in einem mit Blot-Puffer gefüllten Tank eingesetzt. Zusätzlich wurden in den Tank ein Eis-Akku und ein Magnet gegeben. Der Transfer der Proteine auf die Membran erfolgte unter Rühren bei $350 \mathrm{~mA}$ für $1 \mathrm{~h}$. Im Anschluss konnte die Nitrozellulosemembran entweder bei $-20^{\circ} \mathrm{C}$ gelagert werden (bis $\mathrm{zu} 4$ Wochen sind möglich) oder es konnte direkt mit der Immundetektion begonnen werden.

\section{Lösungen und Puffer:}

Blockpuffer 100ml:

$5 \%(5 \mathrm{~g})$ Trockenmilch

mit PBS Tween-20 auf $100 \mathrm{ml}$ auffüllen

\section{Blockierungslösung:}

$5 \%(\mathrm{w} / \mathrm{v})$ BSA in PBS-Tween-20

Um unspezifische Bindungsstellen auf der Nitrozellulosemembran zu blockieren, wurde die Nitrozellulosemembran in Blockpuffer (alternativ: in Blockierungslösung) für mindestens $1 \mathrm{~h}$ bei Raumtemperatur (oder über Nacht im Kühlschrank) inkubiert. Danach wurde die Membran einmal für 15 min und zweimal für 5 min in PBS-Tween20 gewaschen. Im Anschluss folgte die Inkubation mit einem primären Antikörper in Blockpuffer für $1 \mathrm{~h}$ bei Raumtemperatur auf dem Schüttler oder über Nacht im Kühlschrank bei $4^{\circ} \mathrm{C}$. Die Konzentration des primären Antikörpers betrug in der Regel 1:1000 (falls nicht anders angegeben). Bei zu schwachem oder zu starkem Signal wurde die Konzentration entsprechend abgeändert. Nach erfolgter Inkubation wurde die Nitrozellulosemembran erneut einmal für $15 \mathrm{~min}$ und zweimal für $5 \mathrm{~min}$ in PBS- 
Tween-20 gewaschen. Als nächstes wurde an den C-Terminus des primären Antikörpers ein Hoseradish Peroxidase-gekoppelter sekundärer Antikörper von Amersham gekoppelt. Dazu wurde die Nitrozellulosemembran mit dem sekundären Antikörper in Blockpuffer entweder für mindestens $1 \mathrm{~h}$ bei Raumtemperatur oder über Nacht im Kühlschrank bei $4^{\circ} \mathrm{C}$ unter Schütteln inkubiert. Dabei lag die Konzentration des sekundären Antikörpers meist bei 1:1000 oder 1:2000. Bei zu starker Hintergrundfärbung wurde der sekundäre Antikörper weiter verdünnt. Nach Inkubationsende wurde die Nitrozellulosemembran einmal für 15 min und viermal für 5 min in PBS-Tween-20 gewaschen.

\subsubsection{Detektion des chemilumineszenten sekundären Antikörpers mithilfe einen Röntgenfilms}

Verbrauchsmaterial:

RX Fuji Medical X-ray Film

Detektionlösung I+II (Amersham)

Lösung A (im Kühlschrank bei $4^{\circ} \mathrm{C}$ lagern)

$200 \mathrm{ml} \mathrm{0,1} \mathrm{M} \mathrm{Tris} \mathrm{HCl}(\mathrm{pH} 8,6)$

$50 \mathrm{mg}$ Luminol

\section{Lösung B (immer frisch ansetzen)}

$11 \mathrm{mg}$ para-Hydroxycoumarinsäure

in $10 \mathrm{ml}$ DMSO lösen

Lösung A und B kommen als Alternativen in Betracht

Das Prinzip des ECL Western Blots beruht auf der Oxidation von Luminol durch das Enzym HRP (Hoseradish Peroxidase) in Anwesenheit des Verstärkers (Enhancers) Phenol. Auf diese Weise werden die Freisetzung von Licht und die Sensitivität um das 1000-fache gesteigert. Die Lichtproduktion dieser chemilumineszenten Reaktion erreicht ihr Maximum nach 5-20 min und nimmt danach wieder rasch ab, was bei der Röntgenfilmbelichtung zu berücksichtigen gilt. 


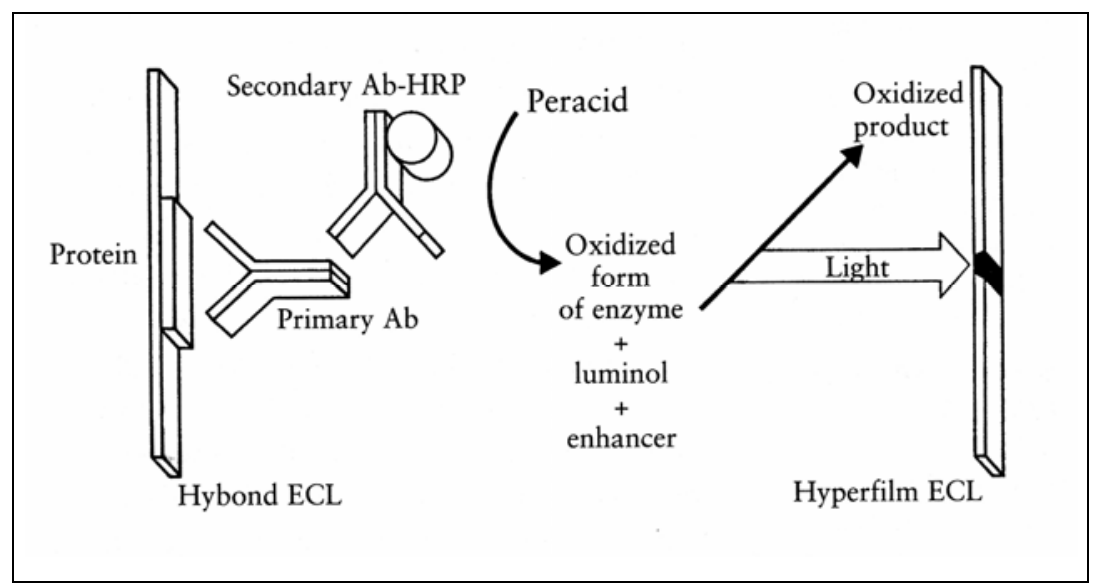

Abb. 14: Prinzip des ECL Western Blottings.(Amersham)

Das Sichtbarmachen der Proteinbande erfolgt durch einen Peroxidase-gekoppelten sekundären Antikörper, dessen Lichtfreisetzung mittels Röntgenfilms detektierbar ist. Dazu wurde die Nitrozellulosemembran zunächst für 2 min in einer Dektionslösung geschwenkt (alternativ $1 \mathrm{ml}$ Lösung $\mathrm{A}+0,3 \mu \mathrm{l} 30 \%$-iges $\mathrm{H}_{2} \mathrm{O}_{2}+100 \mu 1$ Lösung $\mathrm{B}$ ). Danach wurde die Nitrozellulosemembran in eine Klarsichthülle platziert und zusammen mit einem Röntgenfilm in einer Kodak X-Omatic Kassette exponiert. Die Belichtungszeit des Röntgenfilms konnte je nach Intensität der Proteinbande und des Hintergrundes auf der PVDF-Membran stark schwanken. Als nächstes wurde der belichtete Röntgenfilm im Entwicklerbad (100 ml Entwickler $+400 \mathrm{ml}$ Wasser) für etwa $3 \mathrm{~min}$ in einer Dunkelkammer entwickelt. Nach der Entwicklung wurde der Röntgenfilm kurz in ein Wasserbad getaucht, für mindestens 10 min im Fixierbad fixiert und nach erneuter Waschung getrocknet.

\subsection{Gelfärbungen}

Um Proteine direkt im Gel anzufärben wurden in dieser Arbeit die beiden geläufigsten Färbetechniken angewendet.

\subsubsection{Coomassie-Färbung}

Färbelösung

0,01\% (w/v) Coomassie-Brilliant-Blau R250

$7,5 \%(\mathrm{v} / \mathrm{v})$ Essigsäure

$50 \%(\mathrm{v} / \mathrm{v})$ Methanol

in wässriger Lösung 
Entfärbelösung (1 1)

7,5\% (v/v) Essigsäure

$5 \%(\mathrm{v} / \mathrm{v})$ Methanol

$5 \%$ (w/v) Glycerin (falls das Gel getrocknet werden soll)

in wässriger Lösung

Coomassie-Brilliant-Blau R250 ist ein Triphenylmethanfarbstoff. Zur Färbung wurde das Polyacrylamidgel in eine Färbelösung gelegt und für $1 \mathrm{~h}$ bei RT geschüttelt. Dabei diente das 50\%-ige Methanol zum Fixieren der Proteine im Gel. Die Enfärbung des Gels erfolgte in einer Entfärbelösung über Nacht bei Raumtemperatur (RT). Zum Aufsaugen des Coomassie-Brilliant-Blau-Farbstoffes wurden kleine Schwammstückchen direkt in die Entfärbelösung gelegt. Am Ende wurde das Gel luftfrei zwischen zwei Dialysier-Folien getrocknet. Man erreicht mit dieser Methode eine Nachweisempfindlichkeit je nach Farbstoffbindevermögen der Proteine von ca. 100 ng bis $1 \mu \mathrm{g}$.

\subsubsection{Silberfärbung}

Fixierlösung

$50 \%(\mathrm{v} / \mathrm{v})$ Ethanol

$10 \%$ (v/v) Essigsäure

$40 \%(\mathrm{v} / \mathrm{v})$ Wasser

Waschlösung

$5 \%(\mathrm{v} / \mathrm{v})$ Methanol

5\% (v/v) Essigsäure

in wässriger Lösung

Glutaraldehyd-Lösung

25\% (v/v) (40 ml) Glutaraldehyd

$75 \%(\mathrm{v} / \mathrm{v})(100 \mathrm{ml})$ Aqua bidest 
Silberlösung

$21 \mathrm{ml} \mathrm{NaOH}(0,1 \mathrm{~N})$

1,4 ml Ammoniak (Konz.)

$4 \mathrm{ml} \mathrm{AgNO}_{3}(20 \%)$

\section{Entwicklungslösung}

0,005\% Zitronensäure-1-hydrat

0,0019\% Formaldehyd (säurefrei)

Ein ebenfalls häufig eingesetzter Nachweis von Proteinen ist die Silberfärbung. Diese ist wesentlich empfindlicher als die Coomassie-Färbung und erreicht Nachweisgrenzen von Subnanogramm-Mengen von Proteinen. Nach erfolgter Proteinauftrennung wurde das Polyacrylamidgel zwischen $30 \mathrm{~min}$ und $2 \mathrm{~h}$ lang in der Fixierlösung inkubiert. Danach wurde das Gel über Nacht in einer Waschlösung geschüttelt. Am nächsten Tag wurde das Gel in die Glutaraldehyd-Lösung überführt und für 30 min inkubiert. Im Anschluss folgten vier Waschschritte mit $\mathrm{H}_{2} \mathrm{O}$ für jeweils $30 \mathrm{~min}$. Das Gel wurde nun unter Rühren für 10 min in die Silberlösung eingetaucht. Danach wurde das Gel für 2 min in $\mathrm{H}_{2} \mathrm{O}$ gewaschen. Als nächstes wurde das Gel entwickelt. Je nach Bandenintensität wurde das Gel für ca. 1 min in der Entwicklungslösung geschwenkt, ehe es mit $\mathrm{H}_{2} \mathrm{O}$ gewaschen und zu Dokumentationszwecken getrocknet wurde.

\subsubsection{Gel-Konservierung}

Um Polyacrylamidgele für längere Zeit zu konservieren, wurden diese luftblasenfrei in Dialysier-Folie, die zuvor mit Wasser befeuchtet wurde, gelegt. Das Trocken des Gels erfolgte mithilfe eines Gel-Dryers, wobei dem Gel unter Vakuum bei $42^{\circ} \mathrm{C}$ das Wasser entzogen wurde.

\subsection{MAPK In-Gel Kinase Assay}

Lösung $1(500 \mathrm{ml})$

$50 \mathrm{mM}(3,03 \mathrm{~g})$ Tris $\mathrm{HCl}$

$20 \%(100 \mathrm{ml})(\mathrm{v} / \mathrm{v})$ Isopropanol

in wässriger Lösung pH 8,0 
Lösung $2(500 \mathrm{ml})$

$50 \mathrm{mM}(3,03 \mathrm{~g})$ Tris $\mathrm{HCl}$

$5 \mathrm{mM}(175 \mu \mathrm{l})$ B-Mercaptoethanol

in wässriger Lösung pH 8,0

Lösung $3(200 \mathrm{ml})$

$50 \mathrm{mM}(1,21 \mathrm{~g})$ Tris $\mathrm{HCl}$

$5 \mathrm{mM}(70 \mu \mathrm{l})$ ß-Mercaptoethanol

$6 \mathrm{M}(114,64 \mathrm{~g})$ Guanidium- $\mathrm{HCl} \mathrm{HCl}$

in wässriger Lösung pH 8,0

Lösung 4 (1,5 1)

$50 \mathrm{mM}(9,09 \mathrm{~g})$ Tris $\mathrm{HCl}$

$5 \mathrm{mM}(525 \mu \mathrm{l})$ ß-Mercaptoethanol

0,04\% (60 $\mu \mathrm{l})(\mathrm{v} / \mathrm{v})$ Tween-40

in wässriger Lösung pH 8,0

Lösung 5 (2 1)

$5 \%(\mathrm{w} / \mathrm{v}) \mathrm{TCA}$

$1 \%$ (w/v) Na-Pyrophosphat

in wässriger Lösung

$\underline{\text { Reaktions-Puffer }(100 \mathrm{ml})}$

$50 \mathrm{mM}(6,06 \mathrm{~g})$ Tris $\mathrm{HCl}$

$5 \mathrm{mM}(0,102 \mathrm{~g}) \mathrm{MgCl}_{2}$

$1 \mathrm{mM}(0,038 \mathrm{~g})$ EGTA

$5 \mathrm{mM}(0,077 \mathrm{~g})$ Dithiothreitol (DTT)

in wässriger Lösung pH 8,0

\section{$\underline{\text { Heisser-Reaktions-Puffer }}$}

10 ml Reaktions-Puffer

$10 \mu 150 \mathrm{mM}(2,8 \mathrm{mg} / 100 \mu \mathrm{l})$ ATP

$50 \mu \mathrm{Ci}\left[\gamma^{-33} \mathrm{P}\right]$-ATP 


\section{MBP-Trenngel}

$1840 \mu 1 \mathrm{H}_{2} \mathrm{O}$ bidest

$600 \mu 1$ MBP (Myelin-Basic-Protein) (3 mg/600 $\mu 110$ mM Tris HCl; pH 7,4)

$1500 \mu \mathrm{l}$ 1,5 M Tris HCl, $\mathrm{pH} 8,8$

$2000 \mu 1$ 30\%-iges Acrylamid Mix

$60 \mu 110 \%$-ige SDS

$30 \mu 1$ 10\%-iges Ammoniumperoxodisulfat (APS)

$5 \mu 1$ TEMED

\section{$\underline{\text { Sammelgel }}$}

(s. Western Blot 2.9)

Der Aktivierungsstatus der p44 und p42 MAP-Kinase wurde hierbei durch den Einbau von $\mathrm{P}^{33}$ in MBP in einem In-Gel Kinase Assay gemessen. Vor dem Abernten wurden die Zellen dreimal in PBS gewaschen und in $600 \mu$ PBS mit einem Spatel vom Boden der Petrischale abgelöst. Nach dem Zentrifugieren (10 min bei $3000 \mathrm{rpm}$ ) wurde das Pellet in 2\%-igem SDS für $1 \mathrm{~h}$ vollständig gelöst und schließlich in $10 \mu 1$ Probenpuffer aufgenommen und für 90 sek auf $95^{\circ} \mathrm{C}$ erhitzt. Durch das im Probenpuffer enthaltene ß-Mercaptoethanol wurden die Protein-Disulfidbrücken gespalten, und das anschließende Erhitzen der Proben auf $95{ }^{\circ} \mathrm{C}$ diente zum Denaturieren. Nach Bestimmung des Proteingehalts mittels Tüpfelprobe (NEUHOFF et al. 1979) wurden von jeder Probe 20-80 $\mu \mathrm{g}$ Protein/Geltasche auf das MBP-Gel aufgetragen. Dieses enthielt im Vergleich zu normalen Polyacrylamidgelen 0,5 mg/ml MBP (Myelin-BasicProtein), welches als Substrat für die MAPK dient. Im Anschluss an die Gelelektrophorese wurde das SDS aus dem Gel entfernt und die MAPK wurden de/renaturiert. Dazu diente ein Protokoll von Kameshita (KAMESHITA et al., 1989). Der Nachweis der renaturierten MAPK-Aktivität erfolgte in leicht modifizierter Form nach einem Protokoll von Virdee (VIRDEE et al., 1995).

Die weitere Behandlung des Gels gestaltete sich wie folgt:

1) SDS-Entfernung: Gel wurde für $2 \mathrm{x} 1 \mathrm{~h}$ in je $250 \mathrm{ml}$ von Lösung 1 bei $\mathrm{RT}$ inkubiert und geschüttelt.

2) Äquilibrierung: Gel wurde für $2 \mathrm{x} 1 \mathrm{~h}$ in je $250 \mathrm{ml}$ von Lösung 2 bei RT inkubiert und geschüttelt. 
3) Denaturierung: Gel wurde für $2 \mathrm{x} 1 \mathrm{~h}$ in je $100 \mathrm{ml}$ von Lösung 3 bei RT inkubiert und geschüttelt.

4) Renaturierung: Gel wurde für $6 \mathrm{x} 1 \mathrm{~h}$ in je $250 \mathrm{ml}$ von Lösung 4 bei $4^{\circ} \mathrm{C}$ inkubiert und geschüttelt (auch über Nacht möglich).

Danach wurde das Gel für $45 \mathrm{~min}$ in $20 \mathrm{ml}$ Reaktionspuffer auf Eis äquilibriert. Als nächstes erfolgte die Inkubation in $10 \mathrm{ml}$ "heißem" Reaktionspuffer bei $30^{\circ} \mathrm{C}$ für 60 min. Anschließend wurde das Gel für 5x $60 \mathrm{~min}$ bei RT in je $500 \mathrm{ml}$ von Lösung 5 gewaschen, um überschüssige Radioaktivität zu entfernen, bzw. so lange bis keine Radioaktivität mehr im Waschpuffer messbar war und fixiert. Schließlich wurde das Gel in Dialysier-Folie eingepackt auf einer Absaugapparatur getrocknet. Der aufgelegte Röntgenfilm exponierte bei $-70^{\circ} \mathrm{C}$ für mindestens 3 Tage und wurde danach entwickelt.

\section{Molekularbiologische Methoden}

\subsection{RNA-Isolierung}

Besonderes Verbrauchsmaterial

Qiagen RNeasy Mini Kit (50)

Qiashredder (50) Säulen

Für die RNA-Isolierung wurde der RNeasy Mini Kit der Firma Qiagen verwendet. Die Zellen wurden zunächst in $2 \mathrm{ml}$ PBS gewaschen, ehe sie in $600 \mu$ RLT-Lysepuffer aufgenommen und mithilfe eines Schabers von der Platte abgelöst wurden. Um bei der Zelllyse die Disulfidbrücken von Proteinen (z.B. Membranproteine) zu spalten, wurde dem RLT-Lysepuffer ß-Mercaptoethanol im Verhältnis 1:100 zugegeben. Das oben eingesetzte Volumen an RLT-Lysepuffer richtete sich nach der Anzahl der Zellen auf der Platte, die bei ungefähr $5 \times 10^{6}$ liegen sollte. Nach erfolgter Zelllyse konnte man die Zellen entweder bei $-70^{\circ} \mathrm{C}$ einfrieren oder direkt weiterverarbeiten. Für die direkte Verarbeitung musste das Lysat für $10 \mathrm{~min}$ bei $37^{\circ} \mathrm{C}$ inkubiert werden. Erfahrungsgemäß brachten die eingefrorenen Proben eine höhere RNA-Ausbeute bei der Isolierung. Zur weiteren Verarbeitung wurde das Lysat auf eine DNA Shredder-Säule (Qiagen-RNeasy Mini Kit) gegeben und für $2 \mathrm{~min}$ bei $13000 \mathrm{rpm}$ in einer Tischzentrifuge zentrifugiert. Mit diesem Zentrifugationsschritt werden ungewünschte DNA und 
Zellmembranbestandteile aus den Proben entfernt. Im Anschluss wurde 1 Volumen (hier: $600 \mu$ l) 70\%-iger Ethanol zugegeben und gut durchgemischt. An dieser Stelle war darauf zu achten, dass das Lysat klar ist. Ausgefallene DNA sollte mit einer Pipettenspitze entfernt werden. Da die Säule mit maximal $700 \mu 1$ pro Ansatz befüllt werden konnte, wurde bei mehr als $700 \mu 1$ Volumen die RNeasy-Säule zweimal beladen und jeweils für 15 Sekunden bei 10000 rpm zentrifugiert. Die Eluate wurden verworfen und es folgten drei Waschschritte: Als erstes wurden die RNeasy-Säulen mit $700 \mu 1$ Waschpuffer RW1 (Qiagen-Kit) befüllt und erneut für 15 Sekunden bei 10000 rpm zentrifugiert. Auch hier wurde der Durchfluss verworfen. Nun wurde die Säule mit 500 $\mu 1$ RPE Waschpuffer beladen, welcher Ethanol enthalten musste und für 15 Sekunden bei 10000 rpm zentrifugiert. Der Durchfluss wurde erneut verworfen und die zweite Waschung (mit RPE-Puffer) wiederholt. Als nächstes wurden die Proben noch einmal gründlich für 2 min bei 13000 rpm abzentrifugiert. Die Membran in der Säule war nun "trocken" und sollte nur noch die RNA enthalten, die beim nächsten Schritt eluiert wurde. Dies geschah, indem $30 \mu 1$ RNase freies Wasser möglichst mittig auf die Säule gegeben und für 5 min bei Raumtemperatur inkubiert wurde. Im Anschluss wurde die Probe für $1 \mathrm{~min}$ bei $10000 \mathrm{rpm}$ zentrifugiert. Der Durchfluss enthielt die aufgereinigte RNA und wurde wegen der Instabilität der RNA sofort auf Eis gestellt. Die mRNA Konzentration wurde mithilfe eines Photometers bestimmt. Dazu wurde nach Verdünnung der RNA $\left(1: 100\right.$ in $\left.\mathrm{H}_{2} \mathrm{O}\right)$ die Absorption bei $260 \mathrm{~nm}$ in einer Quarzküvette gemessen. Durch die Subtraktion des Leerwertes konnte die RNA-Konzentration bestimmt werden. Nach Abschluss der RNA-Konzentrationsbestimmung wurden die Proben beschriftet und bei $-80^{\circ} \mathrm{C}$ gelagert.

\subsection{Herstellung von cDNA durch reverse Transkription}

\section{Besonderes Verbrauchsmaterial: GibcoBRL Preamplification Kit}

Zur reversen Transkription wurden $5 \mu \mathrm{g}$ mRNA eingesetzt. Diese wurde zunächst in ein 1,5 ml Eppendorfreaktionsgefäß pipettiert und mit $1 \mu$ Zufallshexameren (Random Hexamer) versehen. Diese Zufallsnukleotide binden an komplementäre Bereiche auf der mRNA und dienen bei der Umschreibung als Primer. Als nächstes wurde der Ansatz mit bidestilliertem Wasser auf ein einheitliches Reaktionsvolumen von $12 \mu 1$ aufgefüllt. Der Ansatz wurde nun für 10 min bei $70^{\circ} \mathrm{C}$ inkubiert und anschließend für 1 min auf Eis 
heruntergekühlt. Nun wurden pro Ansatz jeweils $2 \mu 1$ 10x PCR-Puffer, $2 \mu 125$ mM $\mathrm{MgCl}_{2}, 1 \mu 10$ mM dNTPs, $2 \mu 1$ 0,1 M DTT zugegeben und die Ansätze gut gemischt. Anschließend wurden die Proben für $5 \mathrm{~min}$ bei $25^{\circ} \mathrm{C}$ inkubiert. Jetzt wurde in jede Probe $1 \mu$ l SuperScript II reverse Transkriptase (50 Units) hinzugegeben und die Proben für $10 \mathrm{~min}$ bei $25^{\circ} \mathrm{C}$ inkubiert. Es folgten zwei weitere Inkubationen: 50 min bei $42^{\circ} \mathrm{C}$ und $15 \mathrm{~min}$ bei $70^{\circ} \mathrm{C}$. Das eigentliche Umschreiben war damit beendet. Um die Reste der ursprünglichen RNA-Vorlage zu verdauen, wurde nun $1 \mu 1$ RNase H zugegeben und der Ansatz für $20 \mathrm{~min}$ bei $37^{\circ} \mathrm{C}$ inkubiert. Dieser letzte Schritt musste nicht durchgeführt werden, wenn die Proben als Matrize für eine PCR dienten, bei welcher die hitzeempfindliche mRNA sowieso zerfällt. Die synthetisierte cDNA wurde zur Lagerung bei $-80^{\circ} \mathrm{C}$ eingefroren.

\subsection{PCR (Polymerase-Kettenreaktion)}

\section{Verwendete Primer:}

\begin{tabular}{|c|c|c|c|}
\hline $\begin{array}{ll}\text { Name des } \\
\text { Primers }\end{array}$ & $\begin{array}{l}\text { Nukleotid-Sequenz } \\
5^{\prime} \rightarrow 3^{\prime}\end{array}$ & $\begin{array}{l}\text { Größe des } \\
\text { Fragments } \\
\text { (in bp) }\end{array}$ & Accession \\
\hline Caveolin-1 FW & GGC AAC ATC TAC AAG CCC AAC & 546 & AY490204 \\
\hline Caveolin-1 RV & GGA ACT TGA AAT TGG CAC CAG & & \\
\hline GAPDH FW & CCA TCA CCA TCT TCC AGG AG & 610 & U48832 \\
\hline GAPDH RV & TCA AGG GCA TCC TGG GCT AC & & \\
\hline
\end{tabular}

Zuerst muss das zu untersuchende DNA Fragment durch die Wahl geeigneter Primer eingegrenzt werden. Man verwendet einen "sense" und einen "antisense" [Vorwärts (FW) und Rückwärts (RV)] Primer, die dafür sorgen, dass die Taq-Polymerase bindet und das gewünschte Fragment amplifiziert. Die Polymerase-Kettenreaktion besteht aus drei Schritten, die zyklisch wiederholt werden. Bei der Denaturierung (1) werden die Wasserstoff-Brücken zwischen den beiden Strängen gespalten, sodass die DNA einzelsträngig vorliegt. Der nächste Schritt ist die Anlagerung der Primer an die DNA (Annealing) (2). Hierbei ist die spezifische Annealingtemperatur des jeweiligen Primers von großer Relevanz, um sicherzustellen, dass nur die spezifische DNA amplifiziert wird. Sie hängt zum einen von der Länge und zum anderen vom GC-Gehalt des 
verwendeten Primers ab. Mit folgender Formel kann die Annealingtemperatur annähernd berechnet werden:

$69.3+0.41 \times$ (\% GC-Gehalt)-650/Länge des Primers.

Nach der Anlagerung der Primer wird der Einzelstrang mithilfe einer thermostabilen DNA-Polymerase wieder aufgefüllt (Elongation; Extension) (3). Dies geschieht bei $72^{\circ} \mathrm{C}$, weil die Polymerase-Aktivität bei dieser Temperatur am größten ist.

\section{Abfolge der PCR-Schritte:}

1. Denaturierung (Hot Start)

2. Denaturierung

3. Anlagerung der Primer

4. Elongation des Einzelstranges

Wiederholen der Schritte 2-4 in 35 Zyklen

5. Finales Auffüllen der restlichen Einzelstränge

6. Lagerung bei $10^{\circ} \mathrm{C}$
$5 \min$ bei $94^{\circ} \mathrm{C}$

50 sek bei $94^{\circ} \mathrm{C} *$ ]

1 min bei $\left.56^{\circ} \mathrm{C} *\right] 35$ Zyklen

$1.30 \min$ bei $\left.72^{\circ} \mathrm{C}^{*}\right]$

$10 \min$ bei $72^{\circ} \mathrm{C}$

Alle gewählten Primer wurden von der Firma IBA synthetisiert und nach folgenden Kriterien anhand der DNA-Sequenz des jeweiligen Proteins entworfen: FW und RV Primer lagen zwischen 500-800 Nukleotide auseinander. Die Primer sollten

a) keine Palindrome enthalten (z.B. ATTA): Die Primer könnten sonst auch in entgegengesetzter Richtung binden, weil die DNA-Sequenz von links nach rechts und von rechts nach links gelesen gleich ist.

b) nicht monoton sein (z.B. AAAAAA etc.).

c) ca. 18-30 Nukleotide lang sein.

d) die 3'Enden des FW- und RV-Primers dürfen nicht komplementär zueinander sein.

e) die FW- und die RV-Primer sollten einen ausgeglichenen AT und GC-Gehalt aufweisen.

f) pro PCR sollten 100 pmol Primer eingesetzt werden. 


\subsection{Klassische RT-PCR}

Die RT-PCR dient in der Molekularbiologie zur Analyse spezifischer mRNA, d.h. mit ihr kann eine spezielle Genexpression in Zellen untersucht werden. Für die Amplifikation ist es zunächst notwendig, die hitzeempfindliche mRNA in cDNA umzuschreiben. Erst die auf diese Weise gewonnene komplementäre cDNA dient als Matrize. Um zu überprüfen, ob in den aus unterschiedlich stimulierten Zellen extrahierten cDNA-Proben eine vergleichbare cDNA-Gesamtmenge vorliegt, wird ein Standard-Ansatz benötigt, welcher immer parallel zu der eigentlichen Matrizen-DNA amplifiziert wird. Für die Standart PCR muss eine cDNA verwendet werden, deren Expressionsrate in den Zellen permanent und auf einem relativ hohen Level erfolgt. Außerdem sollte die Expression nicht von anderen stimulierenden Substanzen beeinflusst werden. Ein möglicher Standard, der diese Anforderungen erfüllt, ist das ßAktin-Gen. Das ß-Aktin-Gen gehört zu den "Haushalts-Genen", die für die Synthese der Grundbausteine in der Zellstruktur zuständig sind. Diese Gene weisen eine weitgehend gleich bleibende Expressionsrate unter verschiedenen Kulturbedingungen des entsprechenden Zelltyps auf. Sind die Intensitäten der ß-Aktin Kontroll-Amplifikate nach der PCR identisch, so beweist dies, dass identische Mengen an mRNA isoliert und in cDNA umgeschrieben worden sind und anschließend als Matrize für die PCR zur Verfügung stehen. Den Experimenten lag folgender PCR-Standard-Ansatz zu Grunde:

- $\quad x \mu l$ cDNA (Matrize)

- 100 pmol Forward Primer von dem jeweiligen Protein

- 100 pmol Reverse Primer , , , , ,

- $1 \mu 1 \mathrm{dNTPs}$ (Oligonukleotidmix / $10 \mathrm{mM}$ )

- $1 \mu 1$ Red Taq-Polymerase

- $5 \mu 1$ PCR Reaktionspuffer

- Auffüllen mit bidestilliertem Wasser auf ein Endvolumen von $50 \mu 1$

Diese Ansätze wurden in das PCR-Gerät gegeben und über 35 Zyklen amplifiziert. Nachdem die PCR beendet war, wurden die Proben mit $10 \mu$ DNA-Auftragspuffer versetzt. Dieser dient dazu, die DNA zu beschweren, damit sie beim Auftragen besser in die Geltaschen gleitet. Für die Analyse der großen PCR-Produkte wurden immer 11,5\%-ige Agarosegele verwendet. 


\subsection{Agarosegelelektrophorese}

Ethidiumbromid-Stammlösung:

Ethidiumbromid 1\% (w/v) $(1 \mathrm{~g} / 100 \mathrm{ml})$

Die Lösung wurde in $\mathrm{H}_{2} \mathrm{O}$ hergestellt und bei Raumtemperatur aufbewahrt.

TBE-Puffer (10-fach konzentriert) (1 Liter)

Tris $\quad 89 \mathrm{mM}(108 \mathrm{~g})$

Borsäure $\quad 89 \mathrm{mM}(45 \mathrm{~g})$

EDTA-Na $2 \mathrm{mM}(8,32 \mathrm{~g})$

pH 8,6 in wässriger Lösung

10x DNA-Auftragspuffer $(100 \mathrm{ml})$

$20 \%(\mathrm{w} / \mathrm{v})(7,5 \mathrm{~g})$ Ficoll

$0,1 \mathrm{M}(3,7 \mathrm{~g})$ EDTA

$1 \%(1 \mathrm{~g}) \mathrm{SDS}$

$0,25 \%(\mathrm{w} / \mathrm{v})(0,25 \mathrm{~g})$ BPB (Bromphenolblau)

Im elektrischen Feld wandern DNA-Moleküle aufgrund ihres negativ geladenen Phosphatrückrades zur Anode. Die Wanderungsgeschwindigkeit wird dabei durch die unterschiedliche Größe der DNA-Fragmente bestimmt. Für die Auftrennung von 0,5-3 $\mathrm{kb}$ großen DNA-Fragmenten werden normalerweise 1-1,5\%-ige Agarosegele benutzt. Die DNA-Fragmente wurden durch die Einlagerung in die DNA (Interkalierung) von Ethidiumbromid (EtBr) im UV-Licht sichtbar gemacht. Beim Ethidiumbromid handelt es sich um einen planaren organischen Farbstoff, der aus aromatischen Ringen besteht und der zwischen die heteroaromatischen Ringe der DNA-Basen interkaliert. Ethidiumbromid kann durch UV-Licht angeregt werden und emittiert Licht im orangeroten Bereich. Nach Erstarren der Agarose wurde der Kamm entfernt, die Halterung zusammen mit dem Gel in die Elektrophoresekammer eingesetzt und das Agarosegel mit einfach konzentriertem TBE-Puffer überschichtet. Die PCR-Produkte wurden für etwa 40 min bei 130 Volt aufgetrennt. Nach Abschluss der Elektrophorese wurden die Gele auf einem UV-Transilluminator mit einer Wellenlänge von $250 \mathrm{~nm}$ gelegt und ausgewertet. 


\subsection{Transfektion mit siRNA}

Die RNA-Interferenz wird als universelles Werkzeug zum Stilllegen von Genen verwendet. Das Ausschalten eines bestimmten Gens dient der systematischen Analyse des jeweiligen Genproduktes, d.h. des kodierten Proteins. Auslöser der RNA-Interferenz sind kurze, doppelsträngige RNAs, die als siRNAs (small-interference RNA) bezeichnet werden und nur 21 Nucleotiden lang sein dürfen. Dieses Prinzip des Genstilllegens basiert möglicherweise auf einem natürlichen Abwehrmechanismus der Zelle, da einige Viren doppelsträngige RNA-Intermediate produzieren (VOINNET et al., 2005).

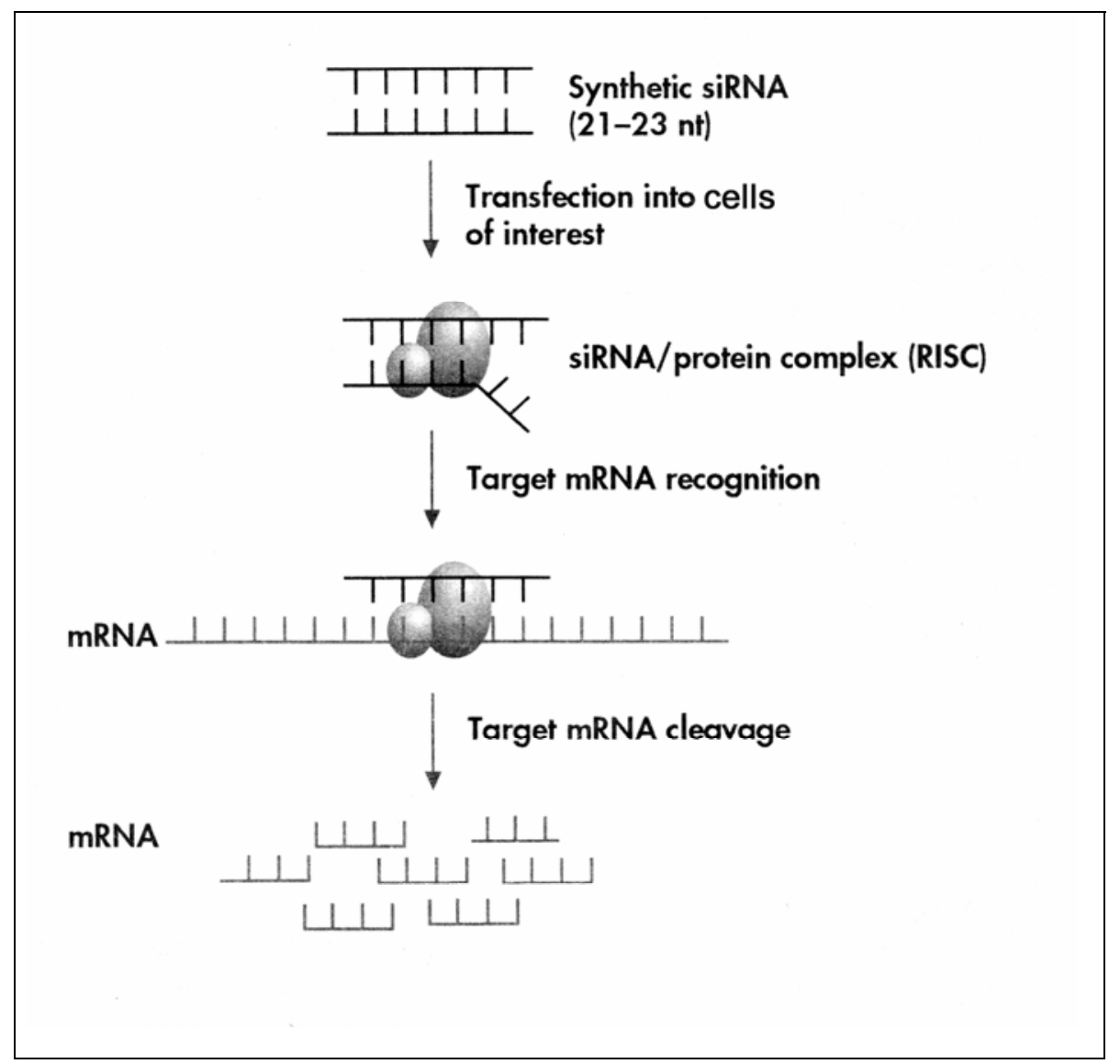

Abb. 15 : Mechanismus des “Gen-silencing" durch Transfektion der Zellen mit siRNA. Synthetische siRNAs werden in Verbindung mit einem Transfektionsreagens in die Zelle eingeschleust. Bevor es zum eigentlichen "Gen-silencing" kommt, wird die siRNA von RISC (RNA-induced-silencing-complex) gebunden. Aus der Trennung der beiden siRNA-Stränge resultiert eine Aktivierung von RISC. Als nächstes bindet RISC an die mRNA, deren Sequenz komplementär zur im RISC gebundenen siRNA ist. Die Target-mRNA wird gespalten und schließlich von der Zelle verdaut. (Qiagen Handbuch) 
Um die Expression eines bestimmten Gens zu unterdrücken, werden RNADoppelstränge aus 21-23 Nucleotidpaaren hergestellt, die mit der Gensequenz des abzuschaltenden Gens übereinstimmen müssen. Dabei wird die Genexpression auf PostTranskriptions-Ebene unterbunden. Im Zytosol verbindet sich die siRNA mit bestimmten Zelleiweißen zu einer Blockiereinheit namens RISC (RNA-inducedsilencing-complex). Dieser enthält eine Helikase und zwei Ribonukleasen. Dabei löst sich der eine siRNA-Strang ab (MARTINEZ et al., 2002). Als nächstes bindet RISC mit dem Passagier-RNA Einzelstrang an die komplementäre mRNA und spaltet sie. Dies führt zum Abbau der mRNA (HUTVAGNER 2005; LEUSCHNER et al., 2006). Ein RISC-Komplex mit einer siRNA ist in der Lage den Verdau mehrerer mRNA-Moleküle zu bedingen, wodurch der Einsatz selbst geringster siRNA-Mengen zu einer Hemmung der Expression des jeweiligen Gens führt.

\subsubsection{Herstellung der siRNA}

Auf der veröffentlichten Sequenz von Caveolin-1 basierend, wurden von der Firma Qiagen zwei verschiedene Caveolin-1-siRNAs angefertigt. Dabei galt es folgende Regeln einzuhalten:

1) Der G/C-Gehalt sollte zwischen 45 und 55\% liegen.

2) Die Länge der gesamten Sequenz sollte 19 Nucleotide betragen.

3) Die Target-cDNA Sequenz sollte zwischen 50 und 100 Nucleotide nach dem Start-Kodon beginnen.

\section{Caveolin-Sequenz (Pubmed Acessionnumber: AY490204)}

1 ccacggggcc agaatgtcgg ggggcaata cgtagactcg gagggacatc tctacaccgt

61 ccccatccgg gaacagggca acatctacaa gcccaacaac aaggccatgg cagaggaat

121 gaacgagaag caagtgtatg acgcgcacac caaggagata gacttggtca accgcgatcc

181 caagcatctc aacgacgacg ttgtcaagat tgattttgaa gatgtgattg cagaaccaga

241 agggacacac agtttcgatg gcatctggaa ggccagcttc accaccttca ctgtgacgaa

301 gtactggttt taccgtttgc tgtctgccet ctttggcatc ccaatggegc tcatctgggg

361 catttacttt gccattctct ccttcctgca catctgggcg gttgtaccet gcattaagag

421 tttcctgatt gagattcagt gcatcagcog tgtctattcc atctacgtcc acaccttctg

481 tgacccgctc tttgaggcta ttggcaaal attcagcaat atccgcatca acatgcagaa

541 agaatataa gtgacatttc aagggtataa gtatacccaa ttcttctttg tccctttaa 601 ttttcttggt $g$ 


\section{Caveolin-1-siRNA}

\section{Duplex 1}

Targetsequenz: CAC CTT CAC TGT GAC GAA GTA

Sense r(CCU UCA CUG UGA CGA AGU A)dTdT

Antisense r(UAC UUC GUC ACA GUG AAG G)dTdG

\section{Duplex 2}

Targetsequenz: AAC ATG CAG AAA GAA ATA TAA

Sense r(CAU GCA GAA AGA AAU AUA A)dTdT

Antisense r(UUA UAU UUC UUU CUG CAU G)dTdG

Mit Fluoreszenzfarbstoff-markierter siRNA wurden zunächst 5 verschiedene Tansfektionsreagentien hinsichtlich ihrer Transfektionseffizienz getestet. Dabei wurde nach dem folgenden für OL optimierten Tansfektionsprotokoll verfahren:

Zunächst wurden $8 \mu 1$ Transfektionsreagens in $200 \mu$ l Gibco Minimal Medium gegeben, 5 min bei RT inkubiert und mit der entsprechenden siRNA ( $50 \mathrm{nM})$ vermengt. Danach wurden siRNA und Transfektionsreagens für $15 \mathrm{~min}$ (höchstens $30 \mathrm{~min}$ ) bei RT zwecks membrangängiger Komplexbildung inkubiert, bevor man sie auf die Zellen geben konnte. Diese erhielten zuvor 2,8 ml frisches MEM-Medium. Der Transfektionsprozess erfolgte im Brutschrank bei $37^{\circ} \mathrm{C}$ und war nach etwa 5-8 Stunden abgeschlossen. Danach oder spätestens am darauf folgenden Tag wurde das MEM-Medium gegen AraC-Medium ausgetauscht. Die Protein-Herunterregulation war bereits nach $48 \mathrm{~h}$ im Western Blot nachweisbar. Innerhalb der Zelle war die siRNA für etwa 5-6 Tage stabil, ehe sie abgebaut wurde. Als Kontrolle dienten Zellen, die mit nicht kodierender NSsiRNA transfiziert wurden. Hierdurch konnte eine mögliche Beeinflussung der Ergebnisse durch den Transfektionsprozess ausgeschlossen werden. 


\section{Ergebnisse}

\subsection{Charakterisierung von Schweine-OL unter Standard- bedingungen}

OL wurden nach der Methode von Gebicke-Härter (GEBICKE-HÄRTER et al., 1984) aus den Hirnen von 6-9 Monate alten Hausschweinen (Sus scrofa) isoliert und in Primärkultur genommen. Etwa 30 min nach Aussaat hatten sich die frisch präparierten Schweine-OL bereits am Plattenboden abgesetzt; im Phasenkontrastmikroskop waren abgerundete Zellkörper zu sehen, denen die Zellfortsätze in Folge der Präparation fehlten. Wie frühere Untersuchungen im Labor gezeigt haben, befinden sich die OL in den ersten postpräparativen Tagen in einer Art Schockzustand. Erst nach etwa 4-7 Tagen beginnen die Zellen erneut mit der Fortsatzbildung. Nach 8 Tagen in Kultur (DIV) waren einige kurze Fortsätze zu erkennen. Mit Fortdauer der Kultivierung wurden lange faserförmige Fortsätze ausgebildet. Die Phase des Fortsatzwachstums war unter Normalbedingungen nach etwa 14-18 Tagen abgeschlossen. Der 7.-8. DIV bot sich als Zeitpunkt für diverse Versuche an, weil die OL erste kleine Fortsätze zeigten und die meisten Fremdzellen innerhalb dieser Woche abgestorben und weggewaschen waren. Die Reinheit der unter diesen Bedingungen kultivierten primären OL lag bei über 95\% (ALTHAUS et al., 1991). Bei den wenigen kontaminierenden Zellen handelte es sich meistens um flache, Astrozyten-ähnliche Zellen (ALTHAUS et al., 1984; GEBICKE-HÄRTER et al., 1984).

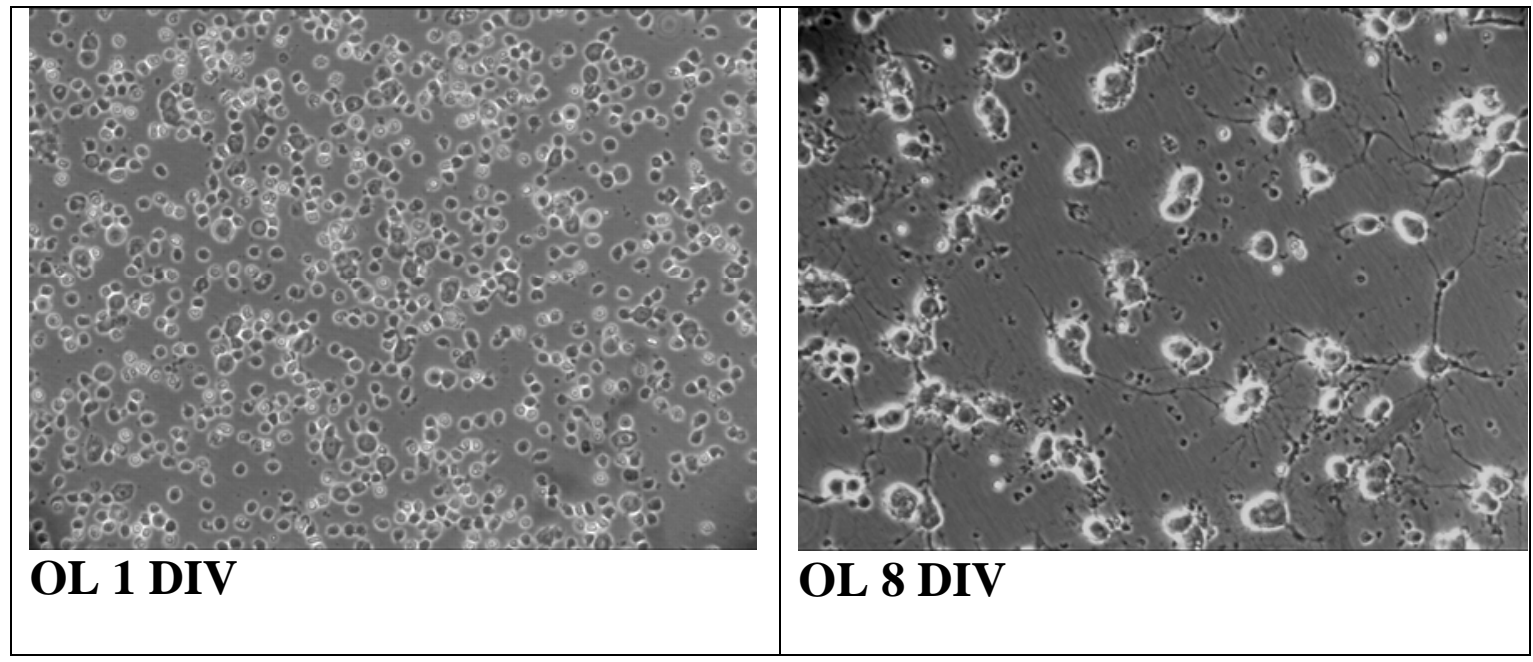




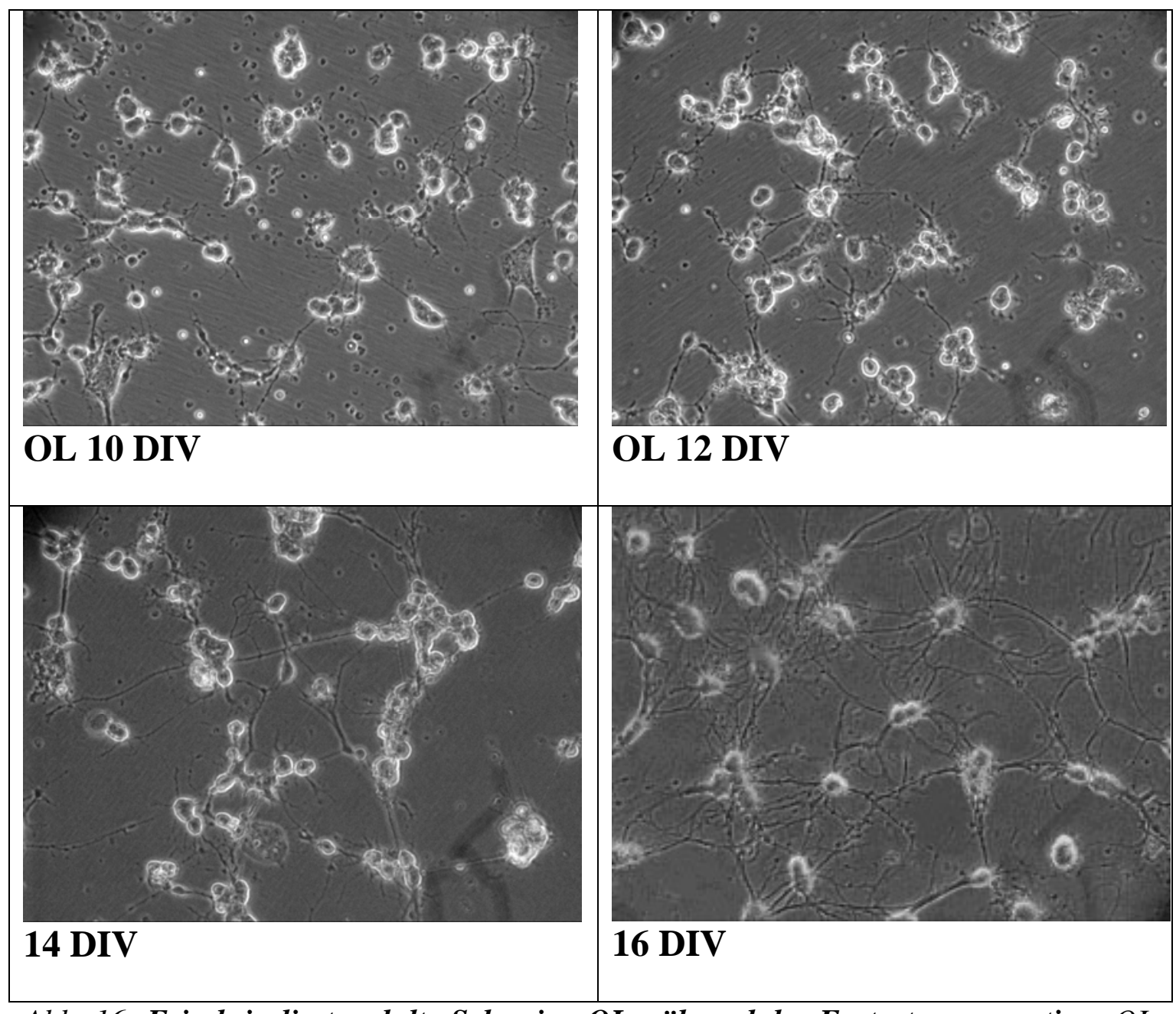

Abb. 16: Frisch isolierte adulte Schweine-OL während der Fortsatzregeneration. $O L$ beginnen nach 8 Tagen in Kultur mit der Entwicklung von Fortsätzen, was mit zunehmender Kulturdauer zu einem Netzwerk von Fortsätzen führt. (Phasenkontrastaufnahmen 200Fach vergrößert)

\subsection{Immunzytochemischer Nachweis von Caveolin-1 bei Schweine-OL und deren spezifische Färbung durch anti- MOSP}

Bei der Frage, ob caveolinhaltige Mikrodomänen (CMD) eine Rolle bei der NGF/TrkAgesteuerten Signalkaskade in Schweine-OL spielen, musste als erstes gezeigt werden, dass Schweine-OL Caveolin exprimieren. Dieses war zuvor nur an PC12-Zellen (BILDERBACK et al., 1998), Astrozyten (CAMERON et al., 1997) und im Verlauf dieser Arbeit an OL von Mäusen (ARVANITIS et al., 2004) gezeigt worden. 
Zwei Caveolin-1-spezifische Antikörper wurden für eine immunzytochemische Darstellung genutzt, nämlich ein monoklonaler Maus anti-Caveolin IgM und ein polyklonaler Kaninchen anti-Caveolin IgG. Letzterer wurde zusammen mit dem OLspezifischen Maus anti-MOSP IgM eingesetzt, um nachzuweisen, dass Caveolin tatsächlich von Schweine-OL exprimiert wird. Das an der oligodendroglialen Plasmamembran exprimierte Protein MOSP wurde durch einen grünfluoreszierenden Alexa Fluor 488 Ziege anti-Maus IgM als Sekundär Antikörper dargestellt (Abb. 17 A). Als Nebenaspekt ließ sich so der hohe Reinheitsgrad der primären OL-Kulturen zeigen, da Astrozyten und andere gliale Zellen MOSP nicht exprimieren (DYER et al., 1994).

Die Darstellung von Caveolin-1 erfolgte mithilfe eines polyklonalen Kaninchen antiCaveolin-1 IgG und einem rotfluoreszierenden Alexa Fluor 546 Ziege anti-Kaninchen IgG (17 B). In Abb. $17 \mathrm{C}$ wurden $17 \mathrm{~A}$ und $17 \mathrm{~B}$ übereinander gelegt und man erkennt die überlappenden Areale von MOSP und Caveolin-1. Im Gegensatz zur MOSPAnfärbung, die immunzytochemisch ein in der Plasmamembran gelegenes Protein nachweist, wird Caveolin-1 sowohl in der Plasmamembran, als auch im Zytoplasma detektiert. Beide Proteine lassen sich bis in feinere Fortsatzverästellungen darstellen.

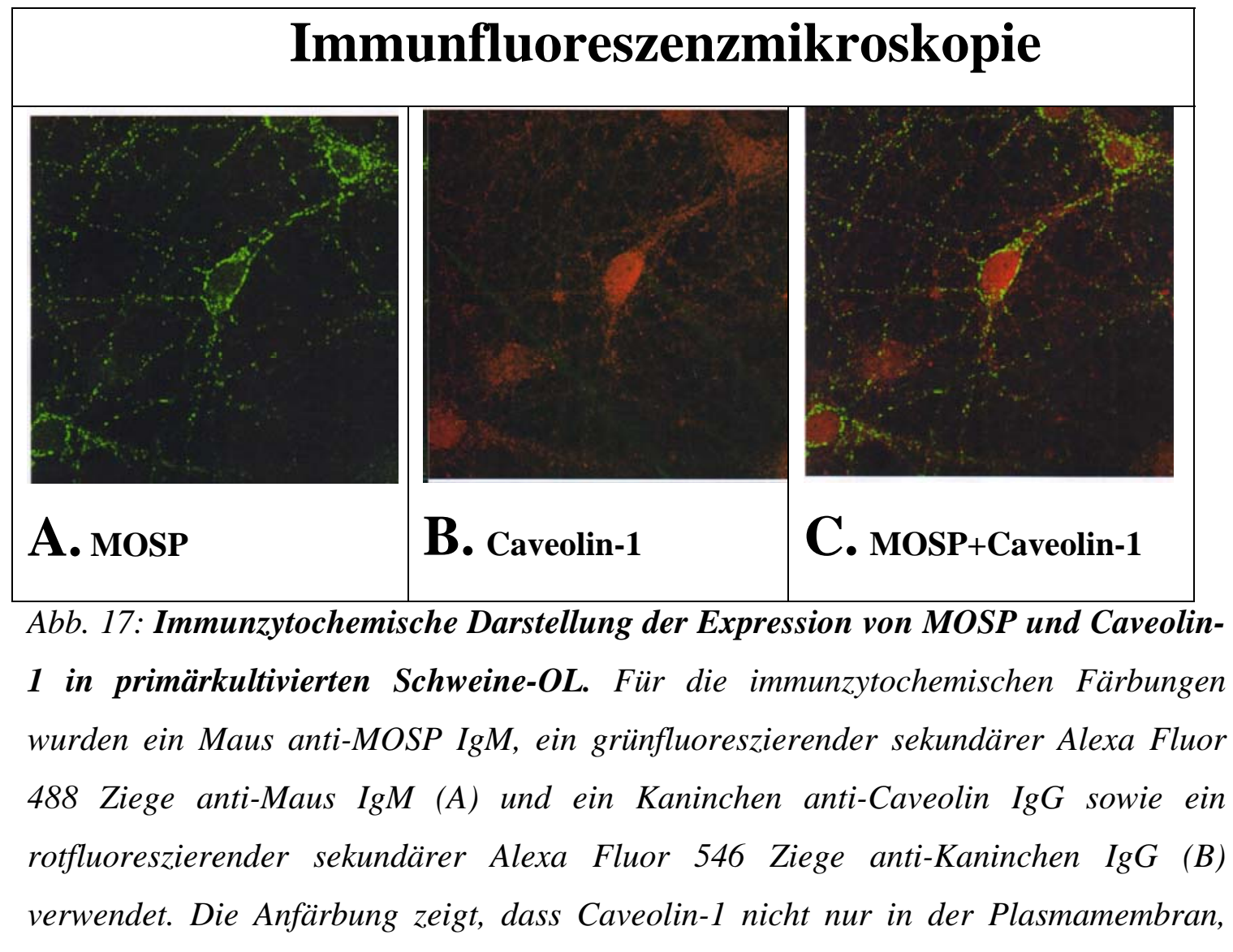


sondern auch im Zytoplasma exprimiert wird. (Aufnahmen bei 400facher Vergrößerung)

\subsection{OL exprimieren von den drei Caveolin-Subtypen lediglich}

\section{Caveolin-1}

Als nächstes wurde untersucht, welche der drei bekannten Caveolin-Subtypen in primärkultivierten Schweine-OL vorkommen. Dazu wurden Western Blots von Zelllysaten aus Schweine-OL angefertigt. Zur Anfärbung dienten drei polyklonale Kaninchen anti-Caveolin IgG: Und zwar von Caveolin-1, -2, -3. Um zu zeigen, dass die verwendeten Antikörper auch funktionstüchtig sind, wurde für Caveolin-1 und -2 neben dem OL-Zelllysat auch eine positive Kontrolle bestehend aus humanen Endothelzellen aufgetragen (Abb. 18 A1, B1).

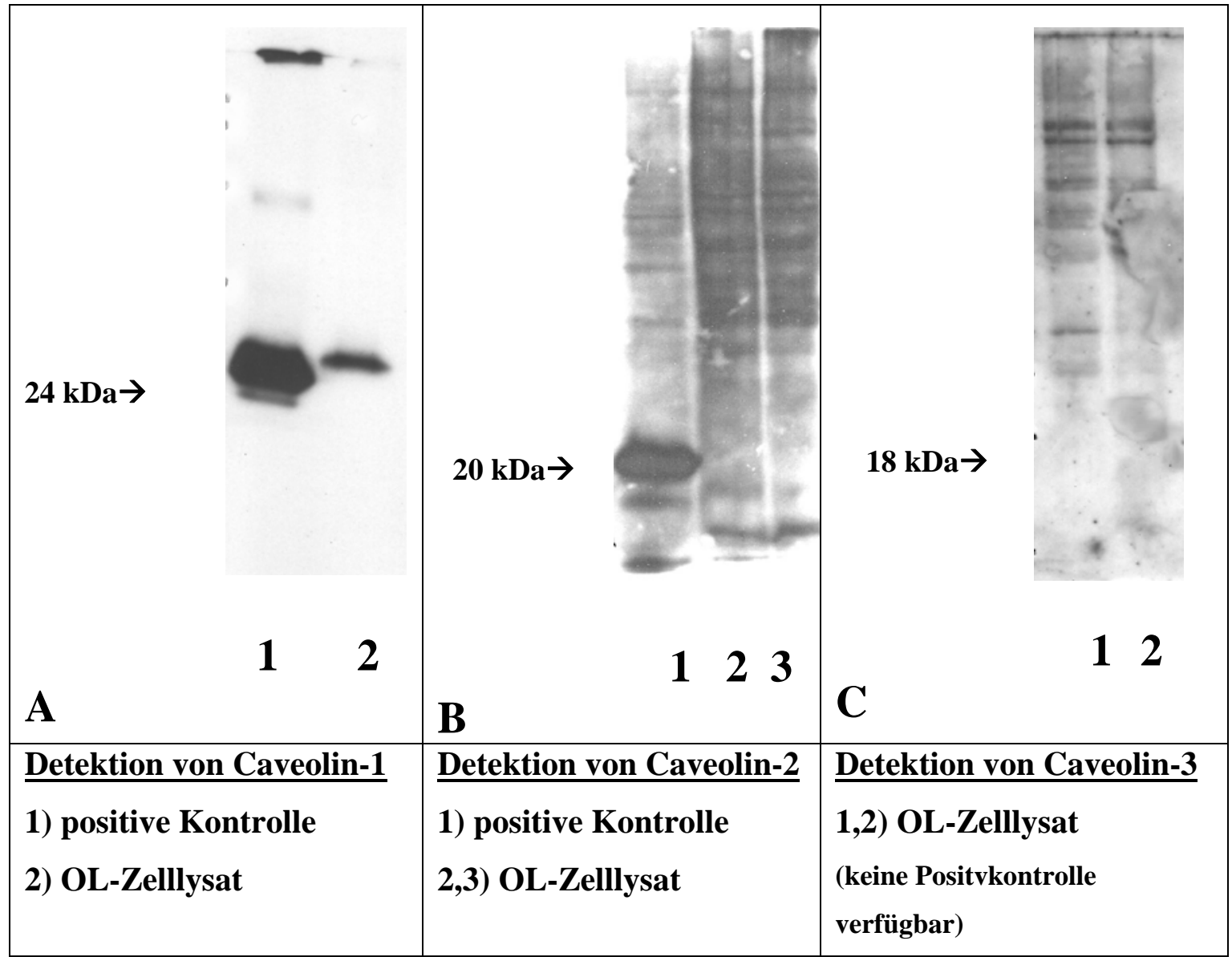

Abb.18: Untersuchung von primärkultivierten Schweine-OL auf die Expression der drei verschiedenen Caveolin-Subtypen. In A und B wurde in der ersten Spur jeweils eine positive Kontrolle bestehend aus dem Lysat humaner Endothelzellen aufgetragen 
(A1, B1); daneben befinden sich die OL-Zelllysate (A2, B2, C1+2). Von den drei bekannten Caveolinen konnte lediglich Caveolin-1 in Schweine-OL detektiert werden.

Von den drei untersuchten Subtypen exprimieren primärkultivierte Schweine-OL lediglich Caveolin-1 (Abb. 18). Als nächstes wurde der Frage nachgegangen, ob Schweine-OL beide Caveolin-1-Isoformen ( $\alpha$ und $\beta$ ) besitzen. Hierfür wurden die OLZelllysate auf einem 15\%-igen SDS-Polyacrylamidgel aufgetrennt und ein Immunoblot erstellt. Auf diese Weise waren Caveolin-1 $\alpha$ und das um 30 Aminosäuren kleinere Caveolin-1 $\beta$ detektierbar (Abb. 19).

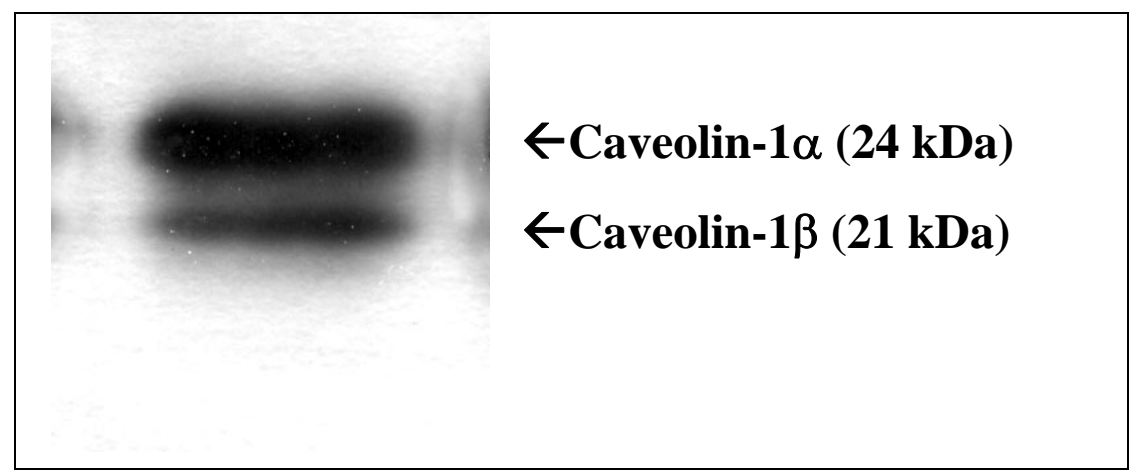

Abb. 19: Darstellung der beiden Caveolin-1-Isoformen $\alpha$ und $\boldsymbol{\beta}$ mittels Immunoblot.

\subsection{Detektion von Caveolin-1 innerhalb der Myelinmembran}

Die einzelnen Subfraktionen von Myelin wurden nach dem Versuchsprotokoll von Agrawal gewonnen (AGRAWAL et al., 1973). Dazu wurde die weiße Hirnsubstanz aufgereinigt und über einen diskontinuierlichen Saccharose-Dichtegradienten aufgetrennt. Die vier erhaltenen Subfraktionen, die aus leichten Myelin, schweren Myelin, Membranen und Pellet bestehen, wurden danach in einem Western Blot analysiert. Caveolin-1 konnte in allen vier Fraktionen als Bestandteil von Myelin abgebildet werden (Abb. 20). Der größte Teil von Caveolin-1 befand sich allerdings im Pellet, das vorwiegend aus einem Gemisch zellulärer Organellen bestand (AGRAWAL et al., 1973). 


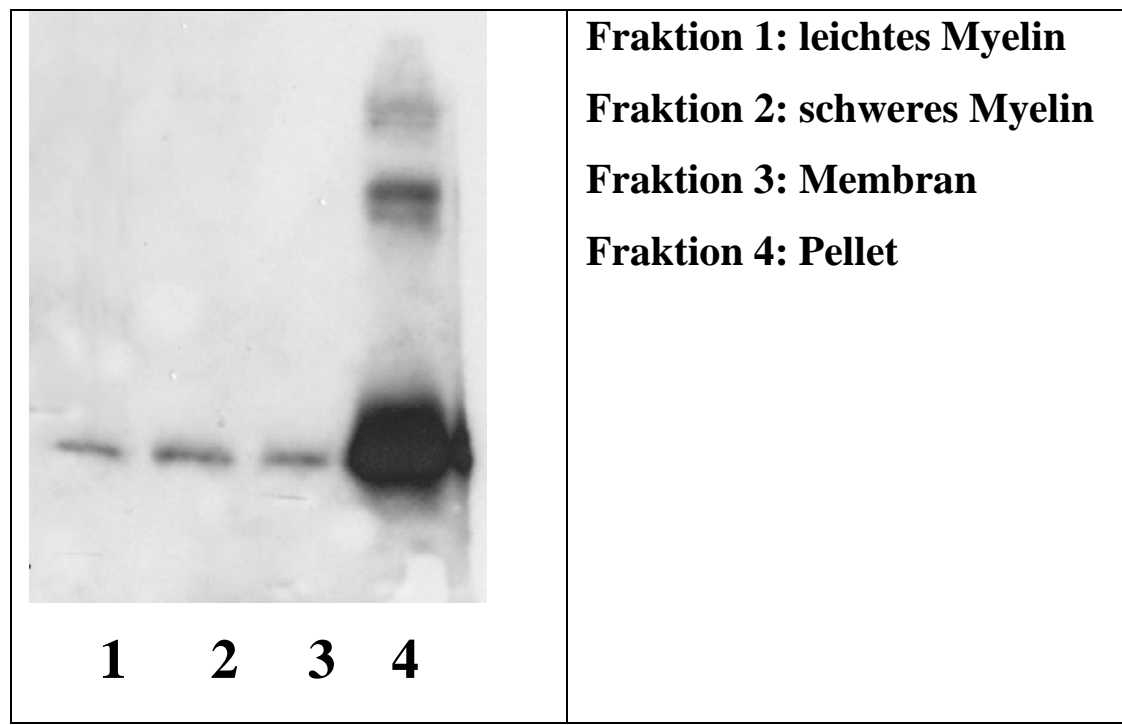

Abb. 20: Caveolin-1 als Bestandteil von Myelin. Alle vier Subfraktionen waren Caveolin-1-haltig; der größte Teil befand sich allerdings in der Pellet-Fraktion.

\subsection{Immunzytochemischer Nachweis von Caveolin-1 und TrkA mittels konfokaler Lasermikroskopie}

Um Einfluss auf die NGF/TrkA-Signalkaskade ausüben zu können, ist eine räumliche Nähe von Caveolin-1 und TrkA innerhalb der Plasmamembran vorauszusetzen. Dafür wurden Schweine-OL mit einem polyklonalen Kaninchen anti-TrkA IgG sowie einem grünfluoreszierendne Alexa Fluor 488 anti-Kaninchen IgG immunzytochemisch angefärbt. Caveolin-1 wurde dagegen mit einem monoklonalen Maus anti-Caveolin-1 IgM sowie einem rotfluoreszierenden sekundären Alexa Fluor 546 anti-Maus IgM detektiert. Aufgrund seiner Größe kann dieser Antikörper nicht ins Zellinnere gelangen und färbt somit lediglich Caveolin-1 in der Plasmamembran an. Mittels konfokaler Lasermikroskopie konnte eine Colokalisation von TrkA (Abb. 21 A) und Caveolin-1 (Abb. 21 B) im Bereich der oligodendroglialen Plasmamembran detektiert werden. Areale, in denen TrkA und Caveolin-1 sich überlappen, konnten besonders gut durch das Übereinanderlegen der beiden Einzelfärbungen in Abb. $21 \mathrm{C}$ gezeigt werden. Insgesamt wird deutlich, dass TrkA mit Caveolin-1 insbesondere im Bereich des Zellkörpers und der Fortsätze erster Ordnung assoziiert ist. Da sich TrkA aber auch in den feiner verästelten Fortsätzen befindet, was die Doppelmarkierung von TrkA und Caveolin-1 nicht darstellt, ist anzunehmen, dass eine Überlappung bis in feinere Fortsatzverästellungen erfolgt. 


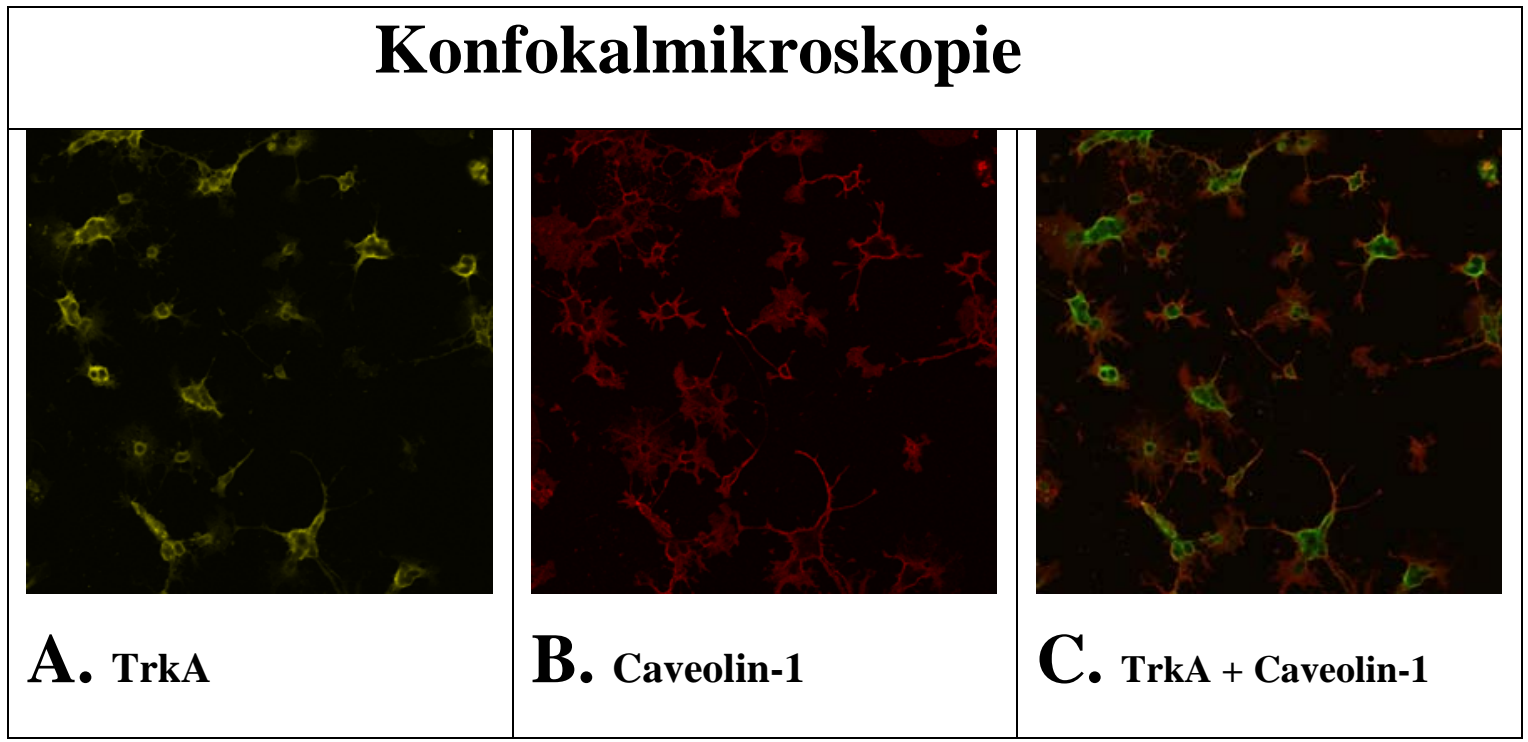

Abb. 21: Darstellung der Caveolin-1 und TrkA-Expression in OL mittels konfokaler Lasermikroskopie. In (A) wurde die Expression von TrkA mit einem polyklonalen Kaninchen anti-TrkA IgG Primärantikörper und einem grünfluoreszierenden sekundären Antikörper immunzytochemisch dargestellt. Die Anfärbung von Caveolin-1 erfolgte mit einem monoklonalen Maus anti-Caveolin IgM sowie einem rotfluoreszierenden Alexa Fluor 546 Ziege anti-Maus IgM (B), sodass aufgrund der unterschiedlichen Antikörperklassen (Isotypen) eine Doppelfärbung möglich war und (A) und (B) übereinander gelegt werden konnten (C), Vergrößerung 200 fach.

\subsection{Darstellung der Interaktion von Caveolin-1 und TrkA mittels Coimmunpräzipitation}

Eine immunzytochemische Colokalisation von zwei Komponenten sagt letztlich noch nichts über eine eventuelle Interaktion aus (HUANG et al., 1999).

Daher wurde mittels Coimmunpräzipitation überprüft, ob Caveolin-1 und TrkA auf Proteinebene direkt miteinander assoziieren. Dazu wurde ein "Catch and Release-Kit" von Upstate verwendet, was diese Methodik optimiert. Über spezielle Immunpräzipitationssäulen wurden Caveolin-1 und TrkA mithilfe ihrer jeweils spezifischen Antikörper immunpräzipitiert. Danach wurden beide Immunpräzipitate in einem ECL Western Blot analysiert. Dabei gelang es im Caveolin-1 Immunpräzipitat TrkA, zusammen mit den MAPK Erk1 und Erk2 nachzuweisen (Abb. 22 A1, B1). Dagegen enthielt das Immunpräzipitat von TrkA Caveolin-1 (Abb. 22 A3), was zeigt, dass Caveolin und TrkA in Schweine-OL miteinander assoziiert sind. Zusätzlich wurde 
nicht an den Caveolin-1 Antikörper gebundenes Zellmaterial in einem Elutionsschritt von der Immunpräzipitationssäule gewaschen und separat analysiert. In diesem konnten ebenfalls TrkA und die MAPK Erk1/Erk2 detektiert werden (Abb. 22 A2, B2), was deutlich macht, dass nur ein Teil von TrkA/MAPK mit Caveolin-1 assoziiert ist.

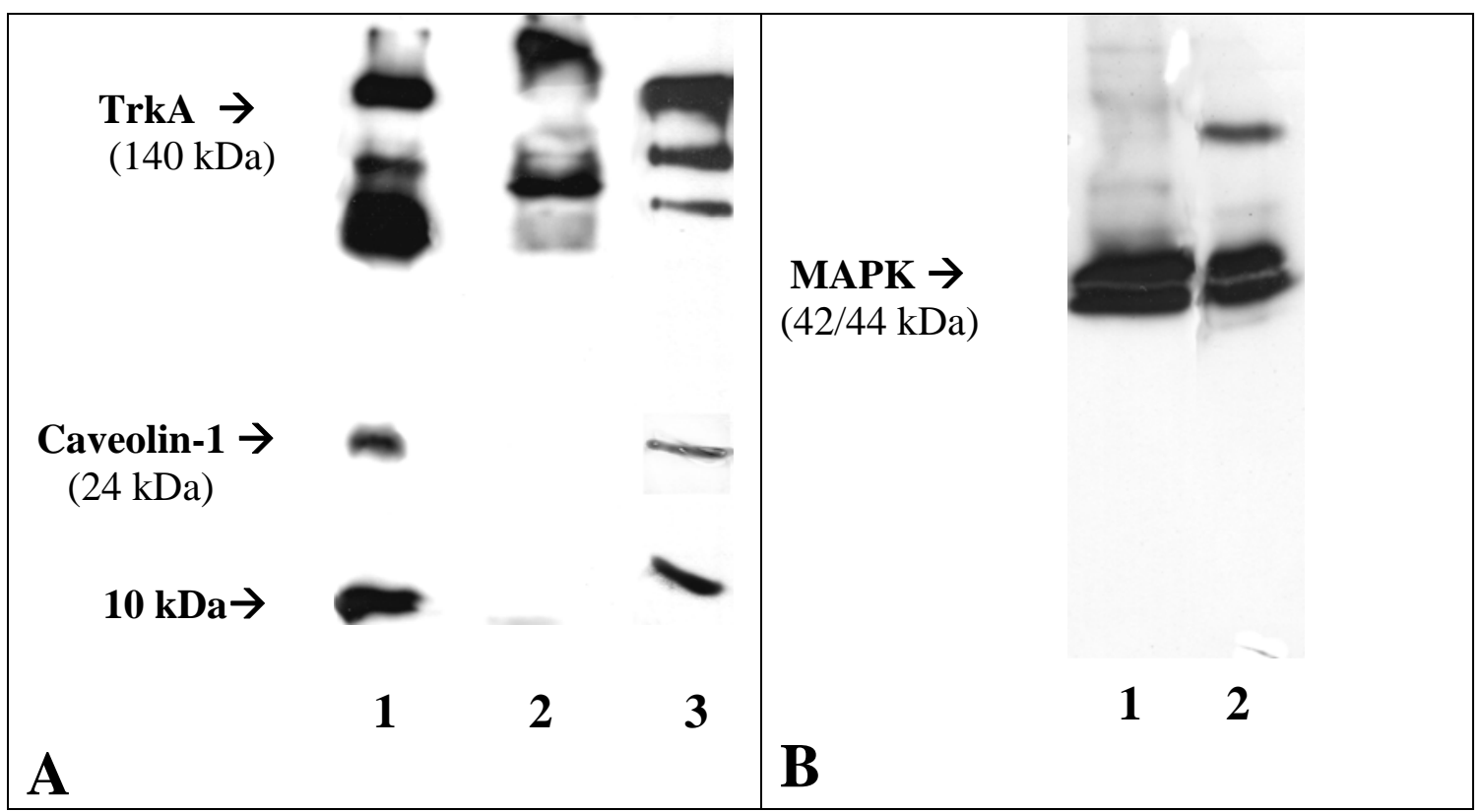

Abb. 22: Coimmunpräzipitation von Caveolin-1 und TrkA (A). Im Caveolin-1 Immunpräzipitat wurden neben TrkA (A1) die MAPK Erk1 und Erk2 (B1) nachgewiesen. Zudem konnte im TrkA Immunpräzipitat Caveolin-1 detektiert werden (A3), was ein direktes Assoziieren dieser Proteine deutlich macht. Bei dem niedermolekularen mit anti-Caveolin-1 anfärbbaren Protein (10 kDa) handelt es sich um ein Abbauprodukt des 24 kDa Caveolins. Zur Kontrolle wurde in den Spuren (A2, B2) das nicht-gebundene Zellmaterial, welches sich in der Elution des Caveolin-1Immunpräzipitates befand, aufgetragen. Es zeigt nicht mit Caveolin-1 assoziiertes TrkA und Erk1/Erk2.

\subsection{Elektronenmikroskopische Darstellung von Caveolae in Schweine-OL}

CMD (caveolinhaltige Mikrodomänen) können einerseits in ihrer Morphologie flach sein oder andererseits als Caveolae auftreten, die in ihrer klassischen Form kolben- oder birnenförmig sind. Bis heute war unklar, ob Schweine-OL in ihrer Plasmamembran auch diese kolbenförmigen Caveolae-typischen Membraneinstülpungen aufweisen. 
Allerdings ist die klassische Kolbenform nicht die einzige Erscheinungsform von Caveolae, da diese relativ polymorph sind und ihr morphologisches Aussehen neben der klassischen Kolbenform auch geschlossen, tubulär oder traubenförmig sein kann (MATVEEV et al., 2000). Einige dieser Erscheinungsformen wurden auch in SchweineOL gefunden, wie eine Flaschenhals-, geschlossene- und abgeflachte Form (Abb. 23 AC).

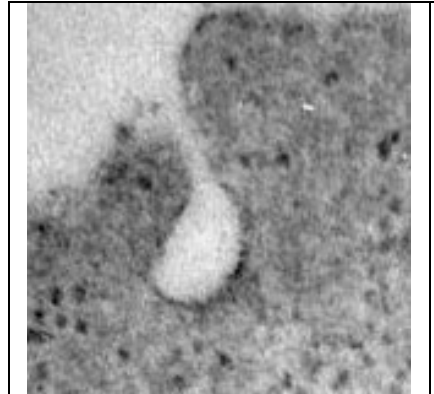

A

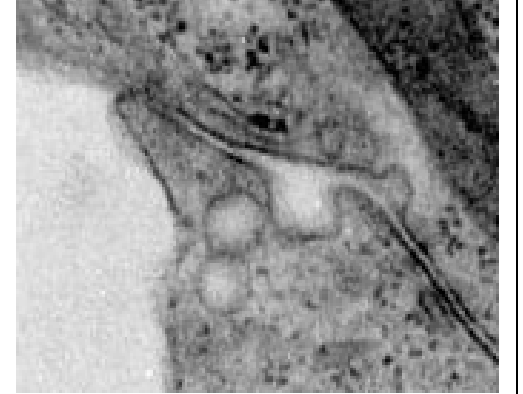

B

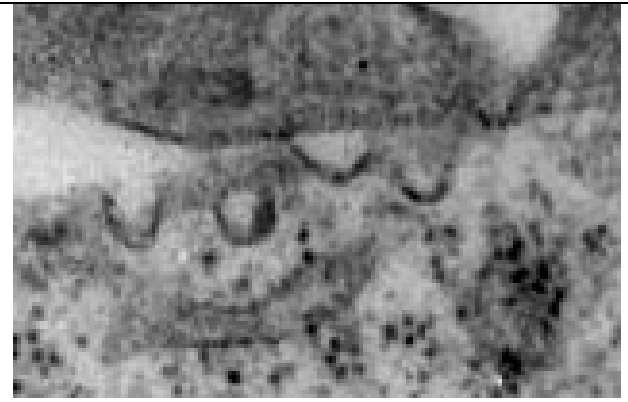

C

Abb. 23: Elektronenmikroskopische Darstellung der unterschiedlichen morphologischen Erscheinungsformen von Caveolae. In (A) erkennt man die typische Flaschenhals-Form, in $(B, C)$ die geschlossene Vesikel-Form sowie in $(C)$ die abgeflachte Erscheinungsform.

Abb. 24 zeigt zwei Arten von Plasmamembraneinstülpungen. Zum einen Caveolae in ihrer für sie typischen kolbenförmigen Erscheinung mit einem Durchmesser von 70-80 nm (weißer Pfeil), zum anderen einen von der Größe und Morphologie ähnlichen, jedoch anders ummantelten Vesikeltyp. Caveolae sind in ihrem Mantel gestreift ("striated“), während der andere Vesikeltyp aufgrund seiner Morphologie als "Stachelsaumvesikel" oder im Englischen als "Honey Comb" bezeichnet wird und als charakteristisches Protein Clathrin enthält. OL besitzen also mindestens zwei verschiedene Endozytosevesikeltypen, wobei der letztere in dieser Arbeit nicht weiter thematisiert wird. 


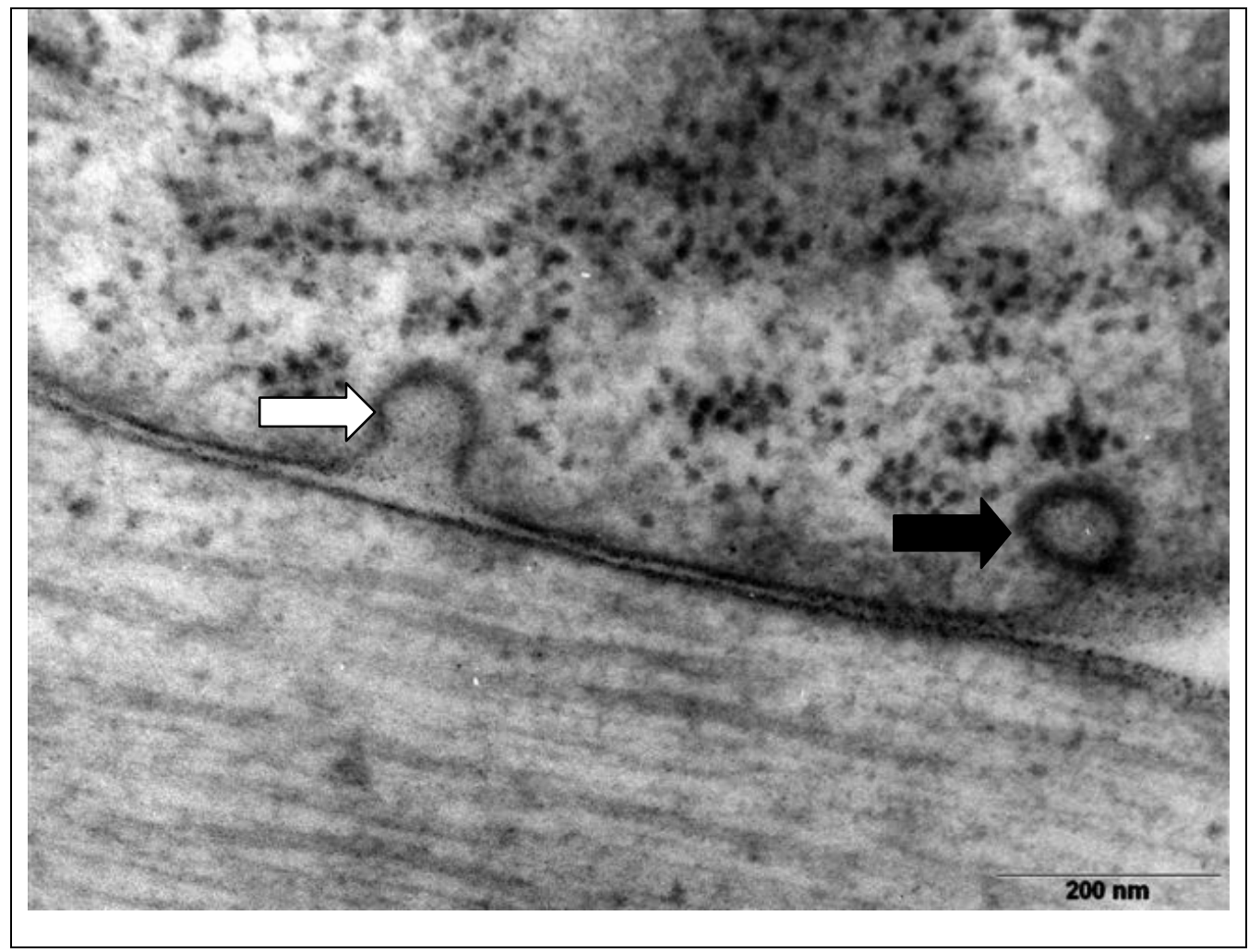

Abb. 24: Elektronenmikroskopische Darstellung einer Caveola in der Plasmamembran eines Schweine-OL mit kolbenförmiger Morphologie. Der weiße Pfeil markiert eine zwischen 70 und $80 \mathrm{~nm}$ große Caveola in ihrer typischen kolbenförmigen, gestreiften Erscheinung; hingegen deutet der schwarze Pfeil auf eine Clathrin ummantelte "Grube" (clathrin coated pit), die ebenfalls in Schweine-OL vorkommt, sich aber deutlich von einer Caveola unterscheidet. Unterhalb des spaltförmigen Zwischenraums erkennt man die quergestreiften Mikrotubuli eines Zellfortsatzes.

\subsection{Veränderungen der Caveolin-1-Expression und des Cholesterin-Levels mit zunehmender Kulturdauer von Schweine-OL}

Unklar war, ob Komponenten der CMD wie Caveolin-1 und Cholesterin bei OL eine "feste Größe“ darstellen oder ob sie sich bei zunehmender Kulturdauer unter Standardbedingungen in ihrer Expression verändern. Zwischen dem 8. und dem 16. DIV findet die Hauptfortsatzausbildung der Zellen statt. Unter StandardKulturbedingungen kommt es nach 11-16 DIV zu einem Anstieg der Caveolin-1Expression und des Cholesterin-Levels (Abb. 25 A1, A2, B). Sobald das 
Hauptfortsatzwachstum abgeschlossen ist, bleibt die Menge an Caveolin-1 und Cholesterin pro mg Protein relativ konstant.

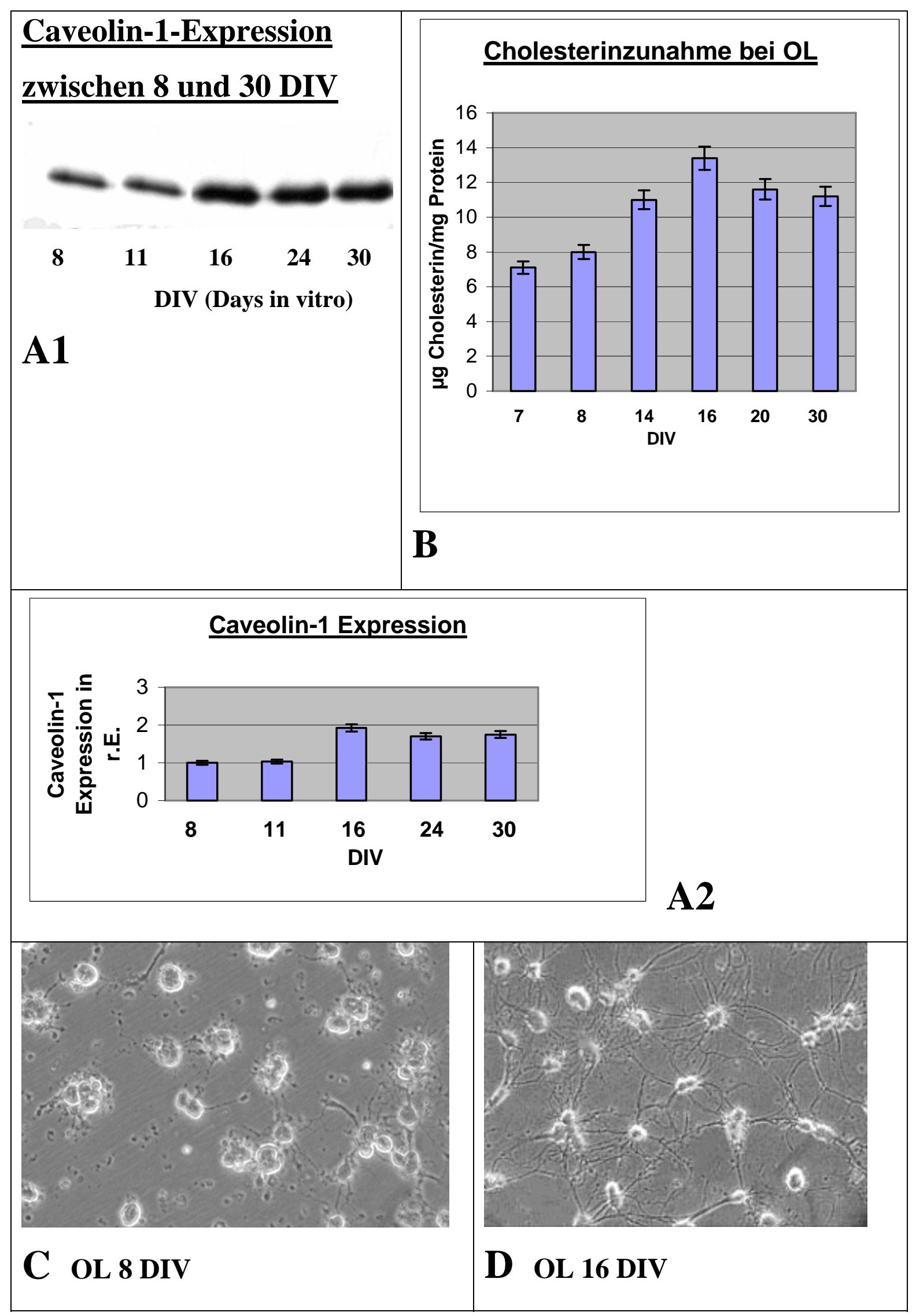


Abb. 25: Darstellung der Caveolin-1-Expression und des Cholesterin-Levels in OL zwischen 8 und 30 DIV (A1, B). Der Nachweis von Caveolin-1 erfolgte durch einen polyklonalen Kaninchen anti-Caveolin IgG. Es wurden jeweils $5 \mu \mathrm{g}$ der lysierten Proteinproben aufgetragen, und mittels ECL Western Blot wurde die Caveolin-1Expression detektiert (A1). Die Hauptfortsatzbildung von OL unter Kulturbedingungen setzte am 8. DIV ein und war nach ungefähr 16. DIV abgeschlossen (C, D). Am Ende des Hauptfortsatzwachstums kam es zu einem deutlichen Anstieg der Caveolin-1Expression und des Cholesterin-Levels (A1, B). Die Proteinbanden in A1 wurden mittels Scion Image quantifiziert (A2).

\subsection{Isolation von CMD aus Schweine-OL}

Bei der Fragestellung, ob Caveolin mit TrkA interagiert, musste desweiteren ein Isolationsverfahren gefunden werden, bei dem man CMD in einem möglichst hohen Reinheitsgrad erhält. Um einen Einfluss auf die NGF/TrkA-Signalkaskade wahrscheinlich zu machen, sollte außerdem gezeigt werden, dass Caveolin-1, TrkA und andere Signalproteine der oben angeführten Signalkaskade in CMD exprimiert werden. Da das Fortsatzwachstum von Schweine-OL vom 8.-16. DIV andauert (3.8), war der 8. DIV der ideale Zeitpunkt für Zellstimulationen sowie für die Isolation von CMD.

\subsubsection{Isolation von CMD nach der Methode von Lisanti mittels detergenshaltiger Saccharose-Dichtegradientzentrifugation}

Um Caveolin-angereicherte Membranen aus Zellen zu isolieren, macht sich diese Methode die charakteristische Eigenschaft von CMD zu Nutze, bei $4^{\circ} \mathrm{C}$ unlöslich in nicht-ionischen Detergentien (z.B. 1\%iges Triton X-100) zu sein. Diese auch als DIMs (Detergent-insoluble Membranes) bezeichneten CMD, reicherten sich nach 22stündigem Zentrifugieren des Triton X-100 haltigen Saccharose-Dichtegradienten bei $39000 \mathrm{rpm}$ und $4^{\circ} \mathrm{C}$ aufgrund ihrer geringen Dichte im oberen Drittel des Gradienten an. Nach Fraktionierung des Dichtegradienten in zwölf $1 \mathrm{ml}$ Fraktionen ergab die Analyse mittels Western Blots eine Anreicherung der CMD in den Fraktionen 4-6, wofür die Caveolin-1-Verteilung innerhalb der 12 Fraktionen spricht, da Caveolin-1 in den Fraktionen 4-6 deutlich angereichert war (Abb. 26). Dagegen enthielten die Fraktionen 7-12 einen mengenmäßig geringeren Anteil an Caveolin-1. Im Gegensatz zu 
den Fraktionen 4-6 war Caveolin-1 in diesen Fraktionen Triton X-100-löslich, was darauf hindeutet, dass Caveolin-1 auch außerhalb von lipidreichen Mikrodomänen lokalisiert sein könnte.

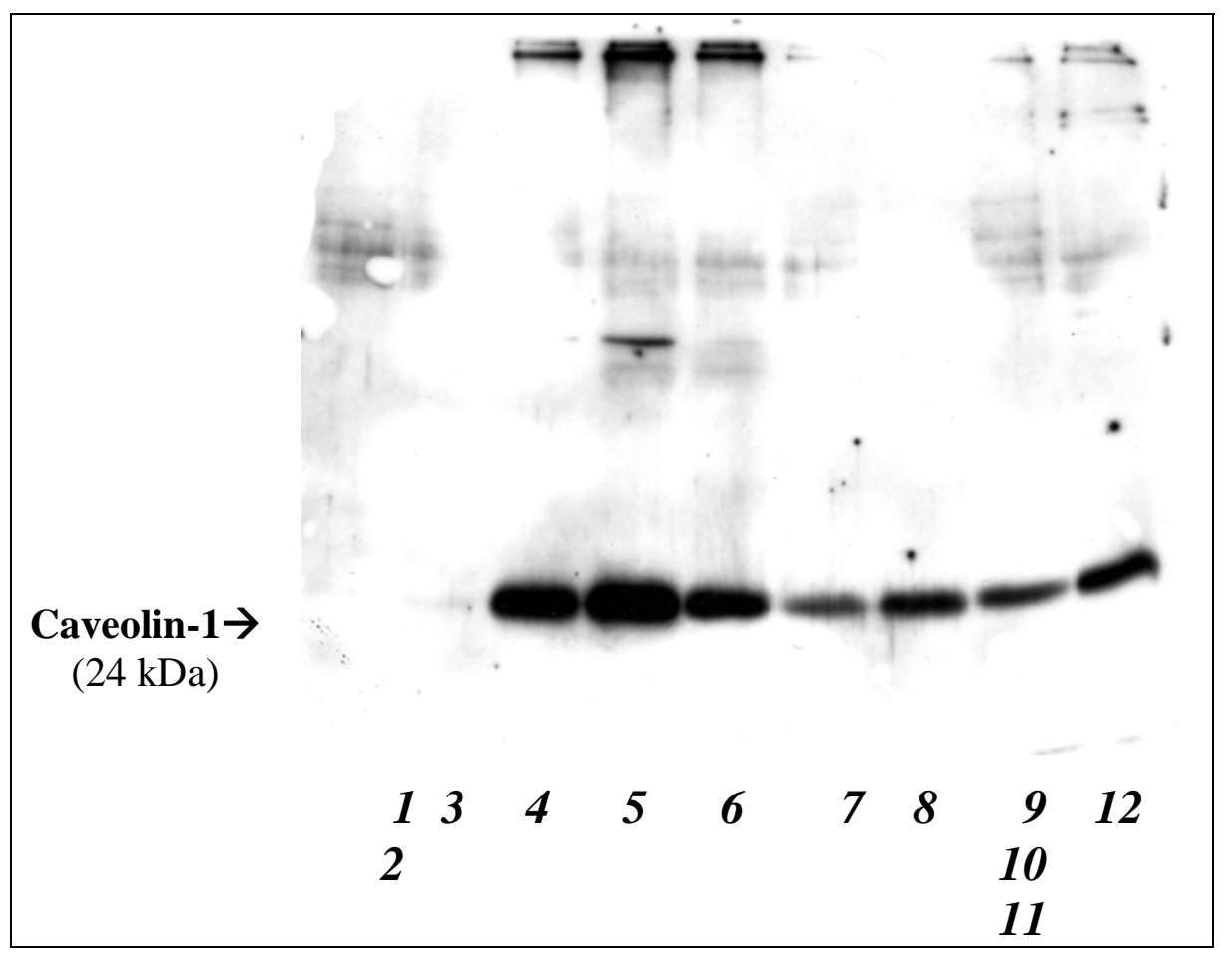

Abb. 26: Isolation von Caveolin-1 mit einem 1\%-igen Triton X-100 SaccharoseDichtegradienten. Der Dichtegradient wurde nach 22-stündiger Zentrifugation in zwölf $1 \mathrm{ml}$ Fraktionen unterteilt. Aufgrund der geringen Proteinmenge wurden Fraktionen 1 und 2 sowie 9, 10 und 11 gepoolt. In einem Immunoblot wurde die Caveolin-1 Verteilung in den 12 Fraktionen dargestellt. Der Hauptanteil von Caveolin-1 befand sich dabei in den Fraktionen 4-6.

\subsubsection{Isolierung von CMD mittels Detergens-freier Saccharose- Dichtegradientenzentrifugation}

Um die Verwendung von nicht-ionischen Detergentien wie Triton X-100, die mit Artefakten der Lipidzusammensetzung einhergehen (PIKE 2003), zu umgehen, wurde auf eine Detergens-freie Methode von Song zur Isolierung von CMD zurückgegriffen (SONG et al., 1996). Hierbei erfolgte der Aufschluss der Zellen in NatriumcarbonatPuffer bei einem pH-Wert von 11. Der relativ hohe pH-Wert diente zur Entfernung peripherer Membranproteine (PIKE 2003). Eine Detergens-freie Isolation scheint wesentlich schonender, da Rezeptor Tyrosinkinasen bisher nicht in Triton X-100 
resistenten Membranen gefunden wurden (PIKE 2005) und innerhalb von Caveolae bzw. CMD nur mithilfe der Natriumcarbonat-Methode detektierbar sind (CHANG et al., 1994; SMART et al., 1995).

Nach Fraktionierung des Dichtegradienten in zwölf $1 \mathrm{ml}$ Fraktionen ergab die Analyse mittels Western Blots ebenfalls eine Anreicherung der CMD in den Fraktionen 4-6 (Abb. 27), wofür die Caveolin-1 Verteilung innerhalb der 12 Fraktionen mit einem Hauptanteil in den Fraktionen 4-6 spricht. Auffällig war zudem, dass die Fraktionen 712 deutlich weniger Caveolin enthielten als bei der Triton X-100-Methode. Außerdem gelang es den Neurotrophinrezeptor TrkA in den CMD-Fraktionen 4-6 anzureichern, was auf eine Assoziation von TrkA mit CMD/Caveolin-1 hindeutet.

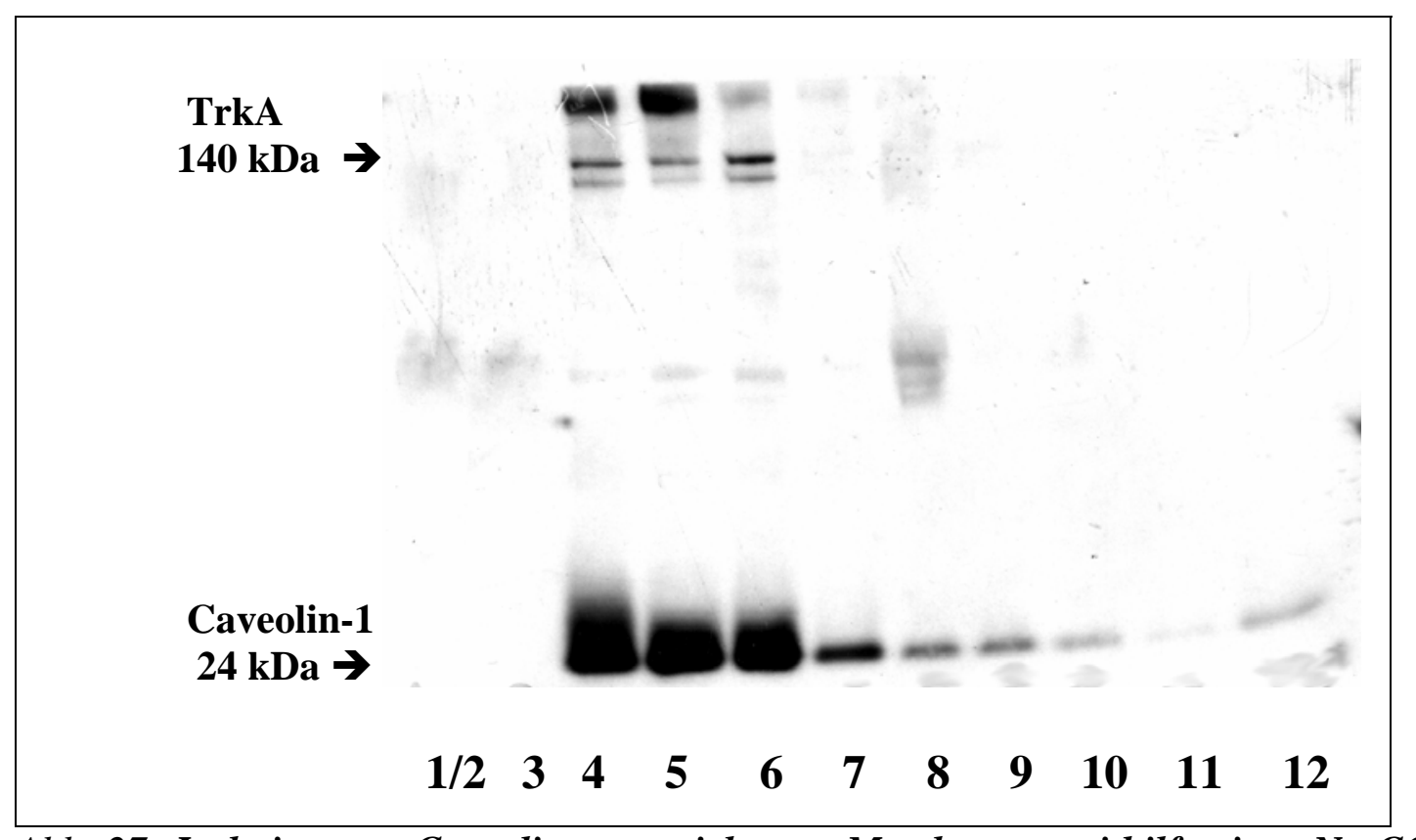

Abb. 27: Isolation von Caveolin-angereicherten Membranen mithilfe eines $\mathrm{Na}_{2} \mathrm{CO}_{3}$ Saccharose-Dichtegradienten. Nach 22-stündiger Zentrifugation wurde der Dichtegradient in zwölf $1 \mathrm{ml}$ Fraktionen unterteilt. Die CMD befanden sich in einem verstreuten, unlöslichen Proteinband in der Interphase zwischen 5\%-iger und 35\%-iger Saccharose. Aufgrund der geringen Proteinmenge wurden die Fraktionen 1 und 2 gepoolt. In einem Immunoblot wurde die Caveolin-1- und TrkA-Verteilung innerhalb der 12 Faktionen dargestellt. Dabei befand sich der Hauptanteil von Caveolin-1 und TrkA in den CMD-angereicherten Fraktionen 4-6. 


\subsubsection{Verteilung des CMD-Markerproteins Flotillin}

Flotillin ist ein Markerprotein für CMD (BICKEL et al., 1997; EVANS et al., 2003). Daher wurde in einem weiteren Western Blot die Verteilung von Flotillin untersucht, wobei die Fraktionen 4-6, 7-9 und 10-12 vor dem Beladen des SDS-Polyacrylamidgels gepoolt wurden. Dabei war das CMD-spezifische Markerprotein Flotillin vor allem in den Fraktionen 4-6 angereichert (Abb. 28), was zeigt, dass sich die Hauptproteinbestandteile der CMD innerhalb dieser drei Fraktionen vorkommen.

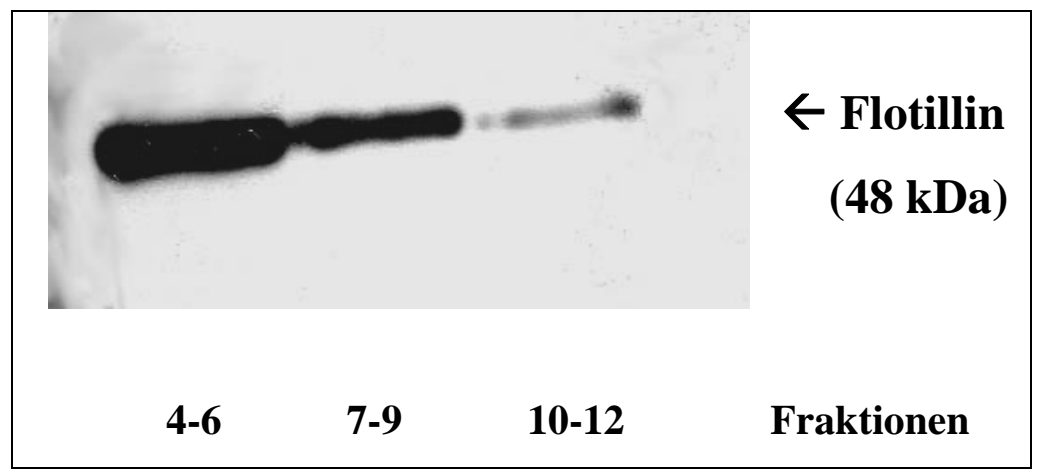

Abb. 28: Detektion des CMD-Markerproteins Flotillin. Der Western Blot zeigte, dass es zu einer Anreicherung von Flotillin in den CMD-Fraktionen 4-6 kam.

\subsubsection{Verteilung von Cholesterin}

Aus der Literatur ist bekannt, dass CMD reich an Cholesterin, Sphingomyelin und Glykolipiden sind. Daher wurden in einem weiteren Experiment die 12 Fraktionen des $\mathrm{NaCO}_{3}$-Saccharose-Dichtegradienten auf ihren Cholesteringehalt hin untersucht.

Nach einem 30-minütigem Inkubationsschritt bei $37^{\circ} \mathrm{C}$ im Mikroplatten-Reader, wurde durch Messung der Optischen Dichte (OD) bei 570-590 nm die Cholesterinkonzentration der 12 Fraktionen bestimmt. Anhand dieses Versuches wurde deutlich, dass sich nahezu 2/3 des gesamten Cholesterins der eingesetzten 50x10 ${ }^{6}$ Zellen in den Fraktionen 4-6 befanden (Abb. 29). Dies zeigt, dass ein großer Teil des gesamten Cholesterins in der Plasmammembran der Zellen und dort innerhalb von CMD lokalisiert ist. 


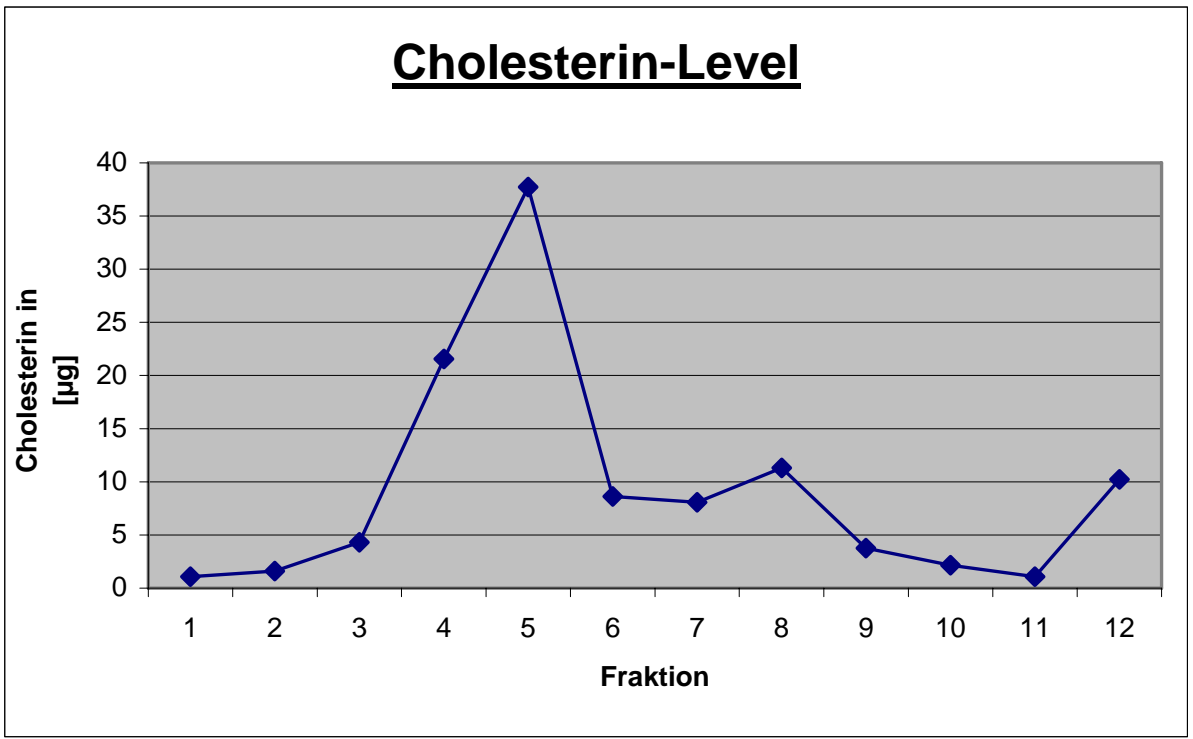

Abb. 29: Vergleich des Cholesteringehaltes der 12 Fraktionen. Nahezu 2/3 des gesamten Cholesterins reicherten sich in den CMD-Fraktionen 4-6 an, was wiederum verdeutlicht, dass über $60 \%$ des in der Plasmamembran enthaltenen Cholesterins in CMD enthalten ist.

\subsubsection{Nachweis der Neurotrophinrezeptoren TrkA, $p 75^{\mathrm{NTR}}$ und von Signal-} proteinen wie p21 Ras in den CMD-angereicherten Fraktionen 4-6

Der Nachweis von Rezeptoren und Signalproteinen, die bei der NGF/TrkASignalkaskade eine Rolle spielen, erfolgte mittels Western Blot. Auf diese Weise gelang es die beiden Neurotrophin Rezeptoren TrkA und p75 ${ }^{\mathrm{NTR}}$, die MAPK Erk1 und Erk2 sowie p21 Ras innerhalb der unter 3.9.2 isolierten CMD-angereicherten Fraktionen 4-6 zu detektieren (Abb. 30). In dieser Abb. wurden zwecks Vereinfachung mehrere Proteinbanden aus verschiedenen Western Blots zu einer Übersicht zusammengestellt (Abb.30B).

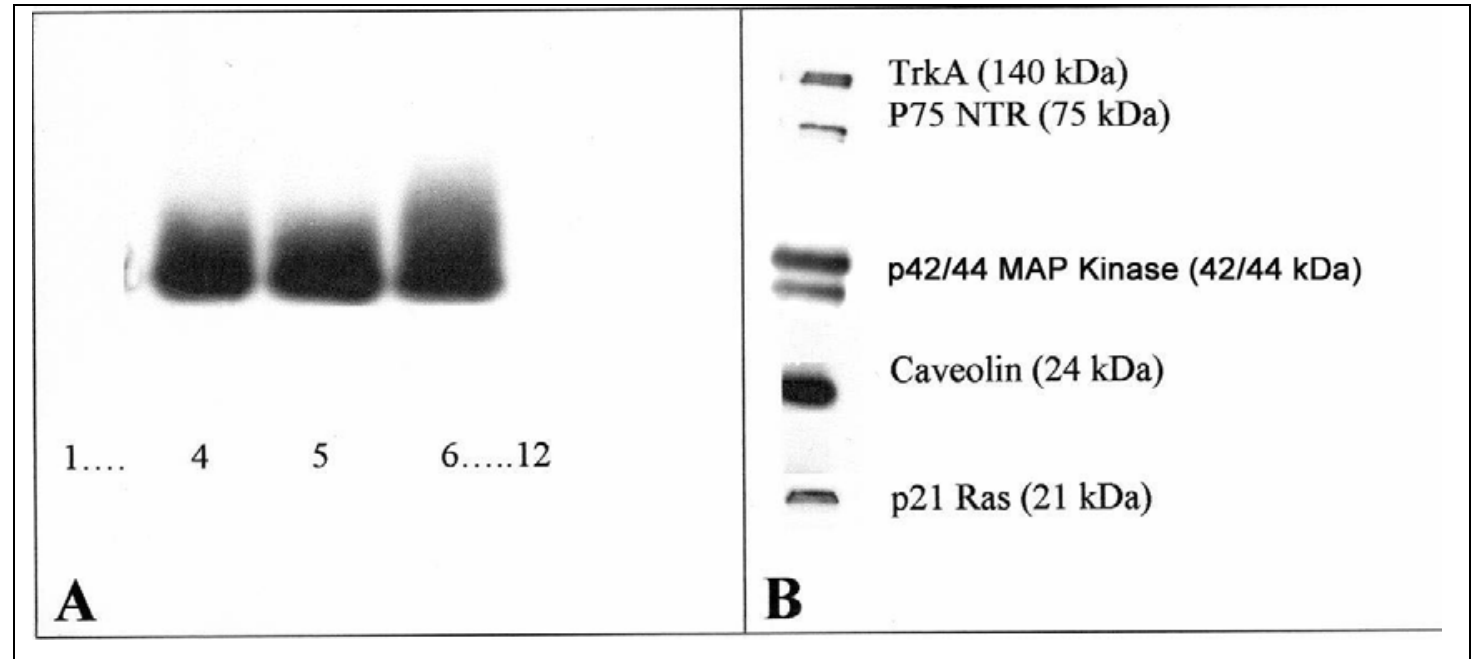


Abb. 30: Nachweis von Signalproteinen und Rezeptoren, die bei der NGF/TrkASignaltransduktion eine Rolle spielen, innerhalb der unter 3.9.2 erhaltenen CMDangereichterten Fraktionen 4-6. Zwecks besserer Verständlichkeit wurden die Proteinbanden aus verschiedenen Western Blots kombiniert und gemeinsam in einer Abb. dargestellt (B). Die CMD-angereicherten Fraktionen 4-6 enthielten neben den beiden Neurotrophinrezeptoren TrkA und $p 75^{N T R}$ weitere Komponenten der NGF/TrkASignaltransduktion, wie die MAPK Erk1 und Erk2 sowie p21 Ras.

\subsubsection{Isolation von CMD aus der Plasmamembran mithilfe von MACS}

Ein Großteil von Caveolin-1 ist unter normalen Bedingungen in der Plasmamembran lokalisiert (ROTHBERG, et al., 1992), daneben findet man aber Caveolin-1 auch im Endoplasmatischen Reticulum und im Golgi-Apparat (KURZCHALIA et al., 1992). Bei der Isolierung CMD mittels Saccharose-Dichtegradientenzentrifugation handelt es sich um eine Standardmethode, bei der allerdings nicht exakt zwischen caveolinhaltigen Membranabschnitten aus der Plasmamembran und anderen Zellorganellen (GolgiApparat oder dem Endoplasmatischen Reticulum) unterschieden werden kann. Abb. 31 zeigt beispielsweise, dass auch die Fraktionen 4-6 ein 60 kDa ER-Markerprotein (Disulfid Isomerase) enthielten.

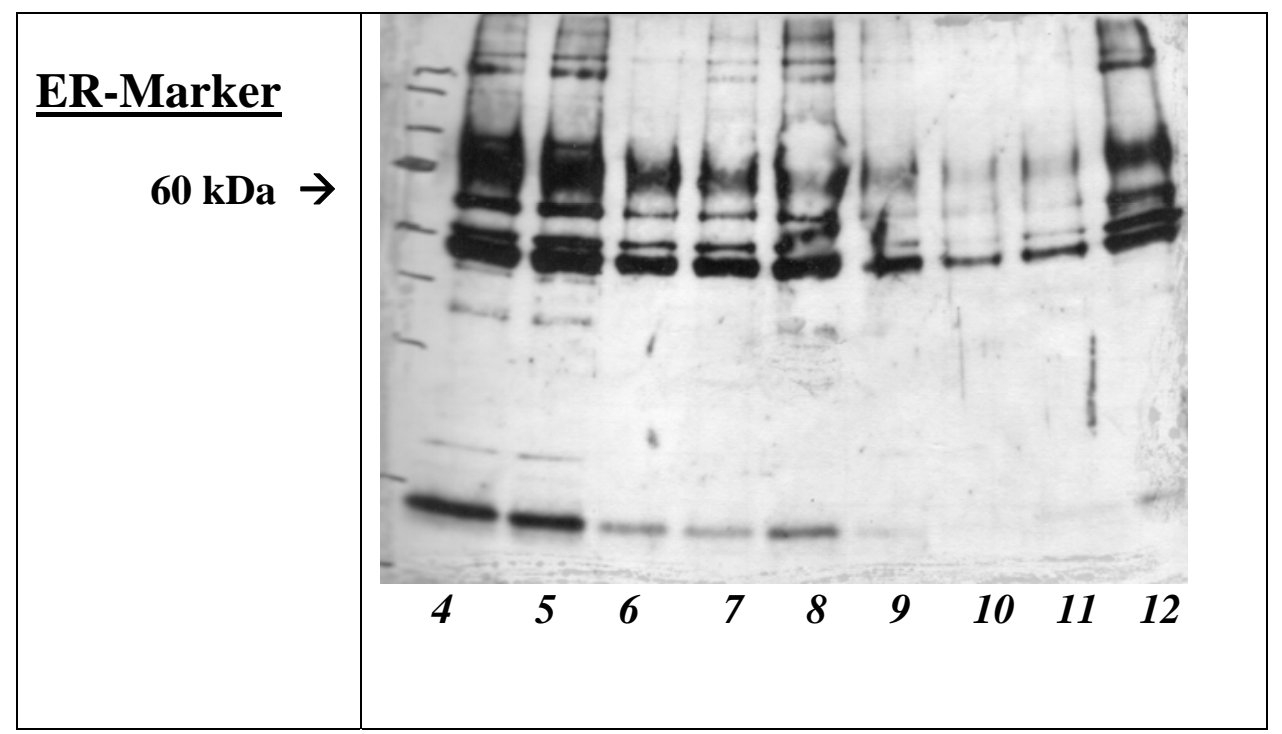

Abb. 31: Detektion des ER-Markerproteins Disulfid Isomerase in den Fraktionen 412 des $\mathrm{Na}_{2} \mathrm{CO}_{3}$-Saccharose-Dichtegradienten. Die Spezifität der $60 \mathrm{kDa}$ Bande konnte durch Weglassen des primären Antikörpers gezeigt werden. Die übrigen Banden sind unspezifisch. 
Daher wurde von uns eine weitere Methode zur Anreicherung von CMD aus einer reinen Plasmamembranfraktion entwickelt. Die Plasmamembran wurde mithilfe von MOSP und einem Beads-gekoppelten sekundären Antikörper über MACS-Säulen isolieren. Diese Plasmamembranfraktion (Abb. 32) wurde danach in 1\%-igem Triton X100 Puffer (bei $4^{\circ} \mathrm{C}$ ) gelöst.

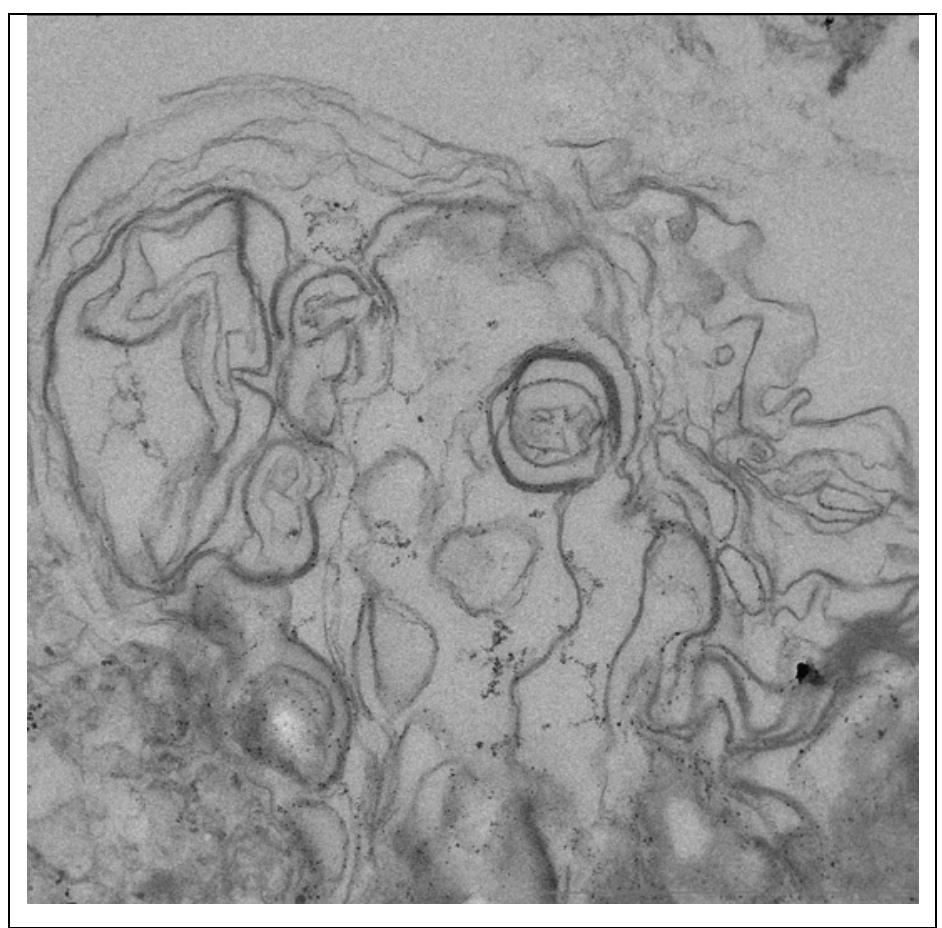

Abb. 32: Transelektronenmikroskopische Aufnahme der Plasmamembranfraktion. Diese wurde mithilfe eines MOSP-Antikörpers und MACS-Technologie isoliert. Die kleinen schwarzen Punkte entsprechen von ihrer Größe $(<5 \mathrm{~nm})$ den verwendete Beads.

In einem Western Blot wurden Caveolin-1 und TrkA in der Triton X-100-löslichen und Triton X-100-unlöslichen Fraktion nachgewiesen (Abb. 33). Dies könnte ein Indiz dafür sein, dass es in der Plasmamembran von OL zwei verschiedene Modifikationen von Caveolin-1 und TrkA gibt, die sich hinsichtlich ihrer Löslichkeit bei $4^{\circ} \mathrm{C}$ in Triton $\mathrm{X}$ 100 unterscheiden. Die chemischen Eigenschaften von CMD machen es wahrscheinlich, dass Detergens-unlösliches Caveolin-1 und TrkA in lipidreichen Mikrodomänen lokalisiert sind. Triton X-100-lösliches Caveolin-1 oder TrkA kommt dementsprechend außerhalb von CMD vor. Die Zerstörung der CMD durch Methyl-ß-Cyclodextrin führte zu einer deutlichen Abnahme von Caveolin-1/TrkA in der Triton X-100-unlöslichen Fraktion. Eine Kontrolle, bei der MOSP weggelassen wurde, zeigte die Spezifität des zweiten, Beads-gekoppelten Antikörpers. 


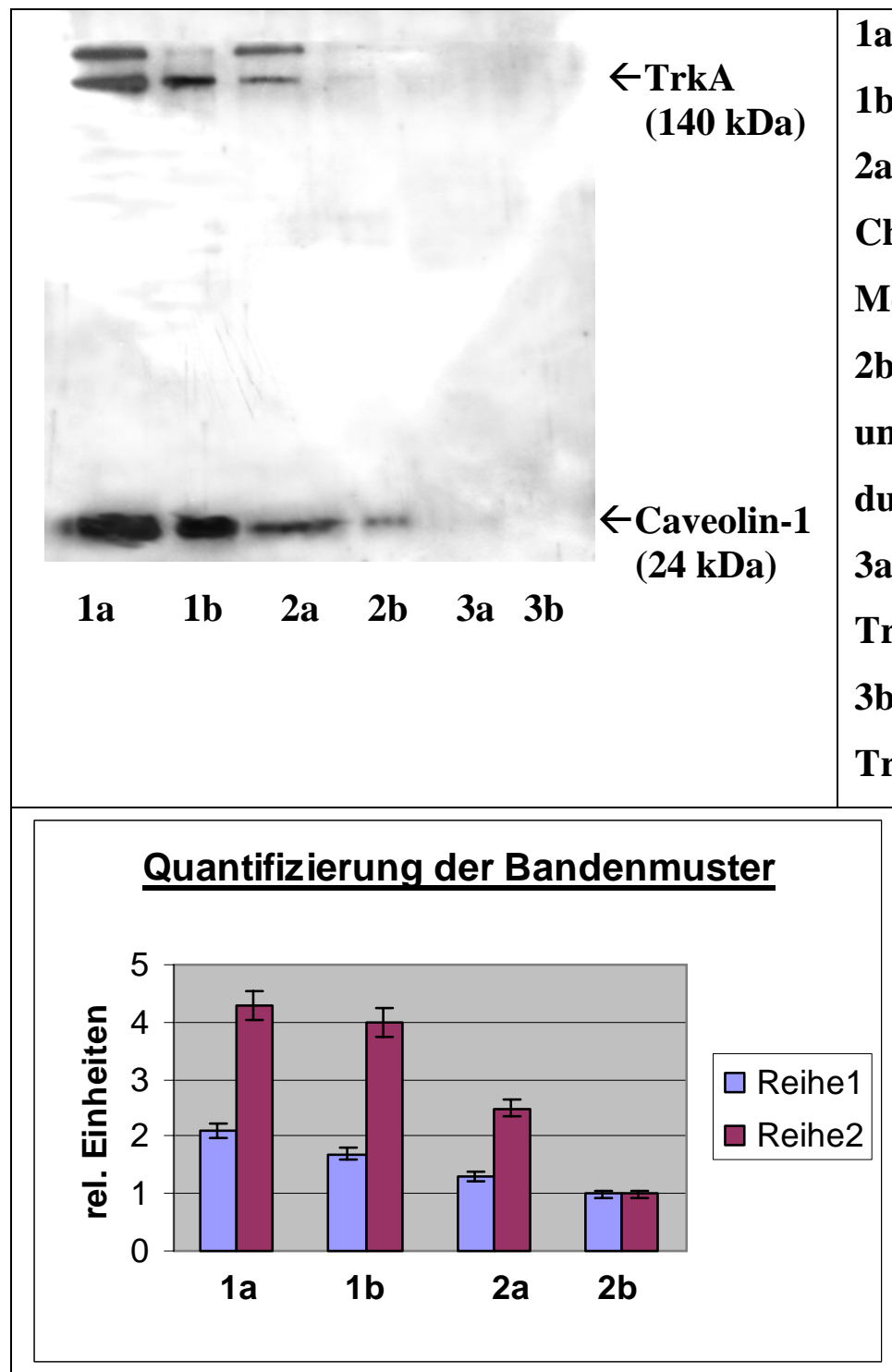

Reihe 1) Quantifizierung des TrkA-Bandenmusters

Reihe 2) Quantifizierung des Caveolin-1-Bandenmusters

Abb. 33: Detektion von Plasmamembran Caveolin-1 und TrkA bei $4^{\circ} \mathrm{C}$ in der Triton $X$-100-löslichen (soluble) und unlöslichen (insoluble) Fraktion. Die Probe $(1 a+b)$ wurde aus unbehandelten OL gewonnen. Dagegen wurden die OL-Kulturen in Probe $(2 a+b)$ für 40 min mit $10 \mathrm{mM}$ Methyl-ß-Cyclodextrin präinkubiert, um den Cholesteringehalt zu senken und Lipid Rafts zu zerstören. Die Spezifität des sekundären Beads-gekoppelten Antikörpers wurde gezeigt, indem der Plasmamembran spezifische MOSP-Antikörper ausgespart wurde. Das Detergens-unlösliche Caveolin-1 und TrkA innerhalb der Plasmamembran stammte wahrscheinlich aus CMD; das Triton X-100lösliche hingegen nicht. Eine weitere Aufreinigung der Detergens-unlöslichen Fraktion über einen Saccharose-Dichtegradienten scheiterte aufgrund von Materialknappheit. 


\subsection{CMD/Caveolin-1-Interaktionen mit NGF/TrkA}

\subsubsection{Einfluss von NGF auf die Caveolin-1-Expression in Schweine- OL}

Der Nachweis von TrkA in CMD der Plasmamembran zeigt zunächst nur, dass aufgrund der Lokalisation eine räumliche Nähe von TrkA zu Caveolin-1 vorhanden ist. Die mittels Coimmunpräzipitation dokumentierte Assoziation von TrkA mit Caveolin-1 beweist das Interagieren dieser beiden Proteine miteinander. Als nächstes stellt sich daher die Frage, auf welchen Ebenen eine solche Interaktion stattfindet.

\subsubsection{Untersuchung der Caveolin-1-spezifischen mRNA-Synthese in Schweine-}

\section{OL nach Stimulation mit NGF}

Mithilfe von RT-PCR sollte untersucht werden, ob sich eine NGF-Exposition von OL auf die Expression der Caveolin-1-mRNA auswirkt. Nach 8 DIV wurden die SchweineOL mit NGF (100 ng/ml) behandelt. Die Stimulierung wurde nach $48 \mathrm{~h}$ gestoppt und die aus der isolierten mRNA hergestellte cDNA wurde mittels PCR amplifiziert und auf einem 1,5\%-igen Agarosegel aufgetrennt. Dabei konnte eine Steigerung der Expression der Caveolin-1-spezifischen mRNA nach 48-stündiger NGF-Stimulation nachgewiesen werden (Abb. 34). Um das Vorhandensein gleicher cDNA-Mengen in der stimulierten und nicht stimulierten cDNA-Probe zu kontrollieren, wurde bei der RT-PCR GAPDHspezifische cDNA parallel amplifiziert (Abb. 34 A2, B2).

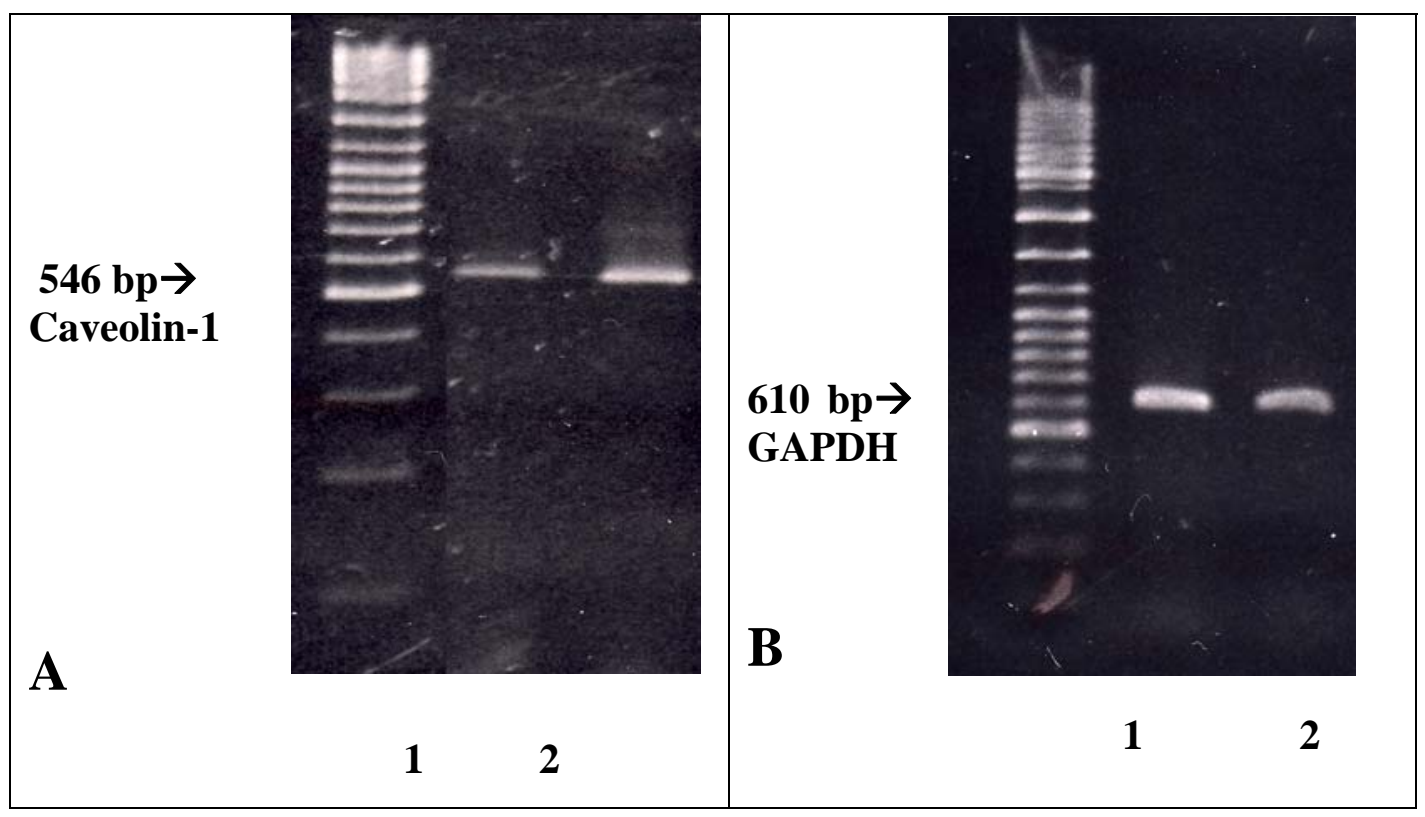




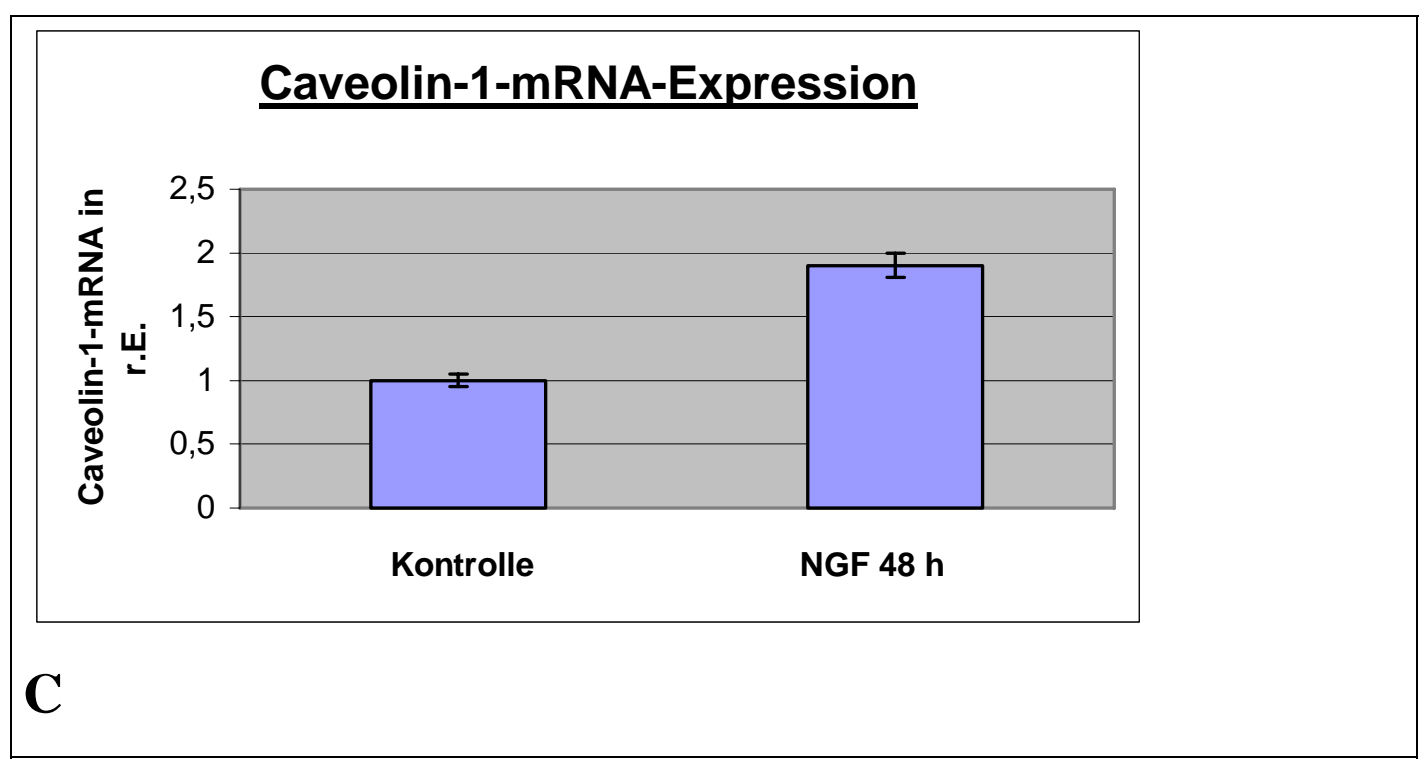

Abb. 34: Detektion der Caveolin-1-spezifischen mRNA mittels RT-PCR. Schweine-OL wurden nach 8 DIV für $48 \mathrm{~h}$ mit NGF (100 ng/ml) stimuliert. Vergleicht man die Caveolin-1 RT-PCR Amplifikate von unstimulierten (A1) und stimulierten OL (A2), so erkennt man eine Hochregulation der Caveolin-1-spezifischen mRNA nach Exposition mit NGF für 48 h. Die GAPDH Kontrollamplifikate dienten zum Vergleich der cDNAMenge in den PCR-Ansätzen; beide Ansätze enthielten in etwa die gleiche Menge an cDNA (B1, B2).

\subsubsection{Beeinflussung der Caveolin-1-Proteinexpression durch NGF}

Schweine-OL wurden für 48 h und 72 h mit NGF stimuliert und ihre Zelllysate in einem Western Blot hinsichtlich der Caveolin-1-Expression analysiert (Abb. 35). Dabei erkennt man eine klare Korrelation zwischen der Fortsatzausbildung und der Caveolin1-Expression, die bei gleicher Proteinmenge stark ansteigt. Die Quantifizierung der Bandenintensitäten ergab, dass sich nach 48-stündiger NGF-Stimulation die Caveolin-1Expression fast verdoppelte. Dieser Effekt stieg nach $72 \mathrm{~h}$ auf das Dreifache im Vergleich zur unbehandelten Kontrolle an. 


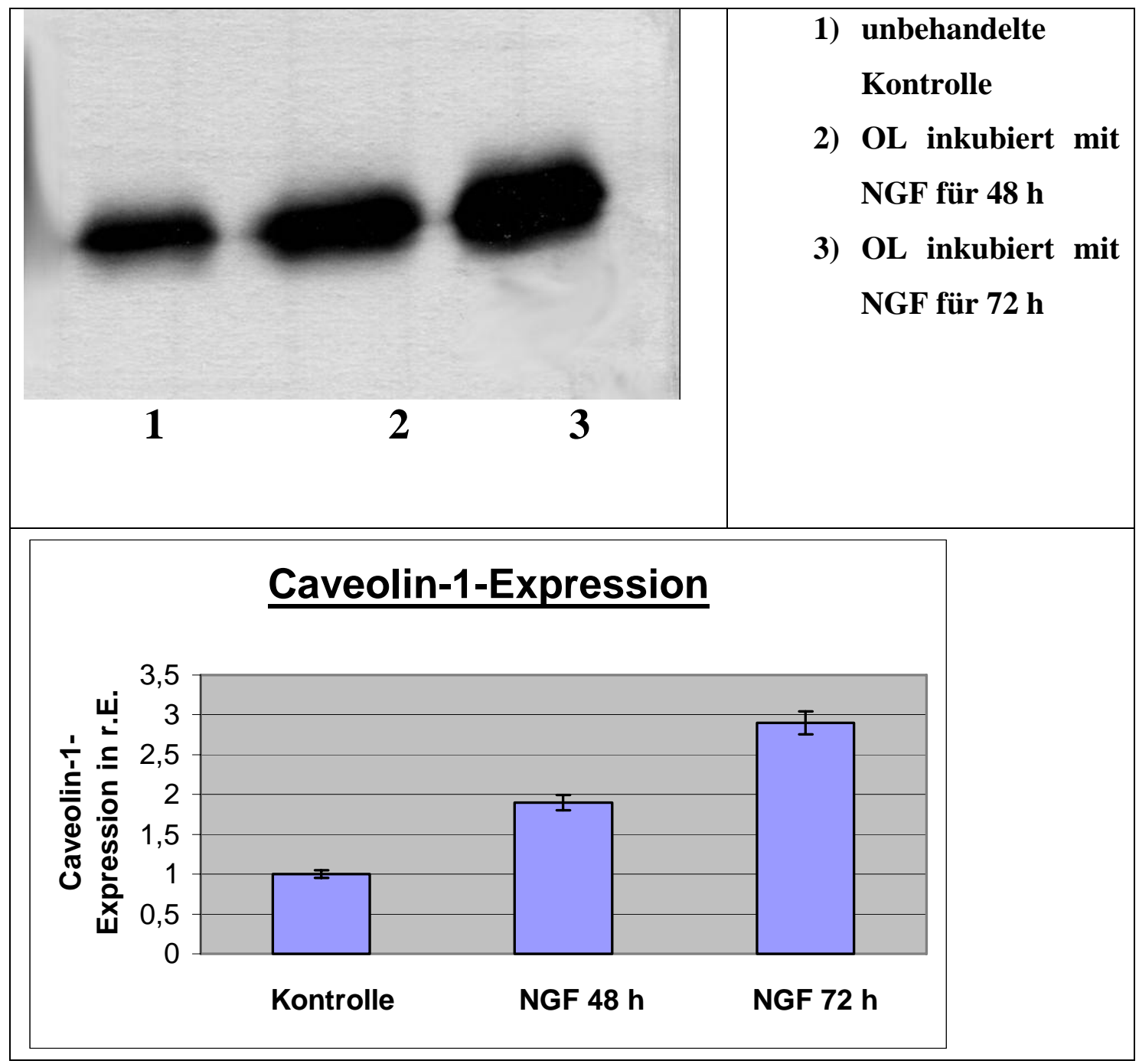

Abb. 35: Detektion der Caveolin-1-Expression nach Stimulation mit NGF (100 $\mathbf{n g} / \mathbf{m l})$

für $48 \boldsymbol{h}$ und 72 h. Der Caveolin-1-Expression von unbehandelten und mit NGF stimulierten Schweine-OL wurde mittels ECL-Western Blots detektiert. Alle Proben enthielten die gleiche Gesamtproteinmenge. Die Quantifizierung der Bandenintensität ergab, dass sich die Caveolin-1-Expression nach 48-stündiger NGF-Exposition nahezu verdoppelte, bzw. nach $72 \mathrm{~h}$ verdreifachte.

\subsection{Inhibitorische Einflüsse von Caveolin-1 auf die NGF Signaltransduktion}

Eine verstärkte Caveolin-1-Expression durch NGF kann prinzipiell auf die NGF/TrkA Signalkaskade positive wie negative Auswirkungen haben. Fördernd wirkt sich die Caveolin-1-Expression auf die Bildung neuer CMD aus, dagegen kann Caveolin-1 auch zu einer Abschwächung der NGF/TrkA Signalkaskade führen. 


\subsubsection{MAPK-Aktivität von 8 Tage kultivierten und von 30 Tage kultivierten OL unter NGF}

Der NGF-induzierte Signalpfad ist von ausschlaggebender Bedeutung für die Fortsatzbildung adulter OL (ALTHAUS et al., 1992b) und hat einen stimulierenden Einfluss auf die MAP-Kinasen p44 Erk1 und p42 Erk2 (Extracellular Signal-regulated Kinases). Bei gleich bleibender TrkA-Expression nimmt die MAPK-Aktivität nach Stimulation mit NGF in 30 Tage kultivierten Schweine-OL im Vergleich zu 8 kultivierten OL deutlich ab (Abb. 36A, B, C). Die Quantifizierung der Proteinbanden mit Scion Image ergab, dass die MAPK-Aktivität in 8 Tage alten OL-Kulturen nach 30minütiger NGF-Stimulation um das 2,5-Fache ansteigt (Abb. 36 D). Dagegen beträgt die Zunahme in 30 Tage alten OL-Kulturen unter den gleichen Bedingungen lediglich 1,5 relative Einheiten.

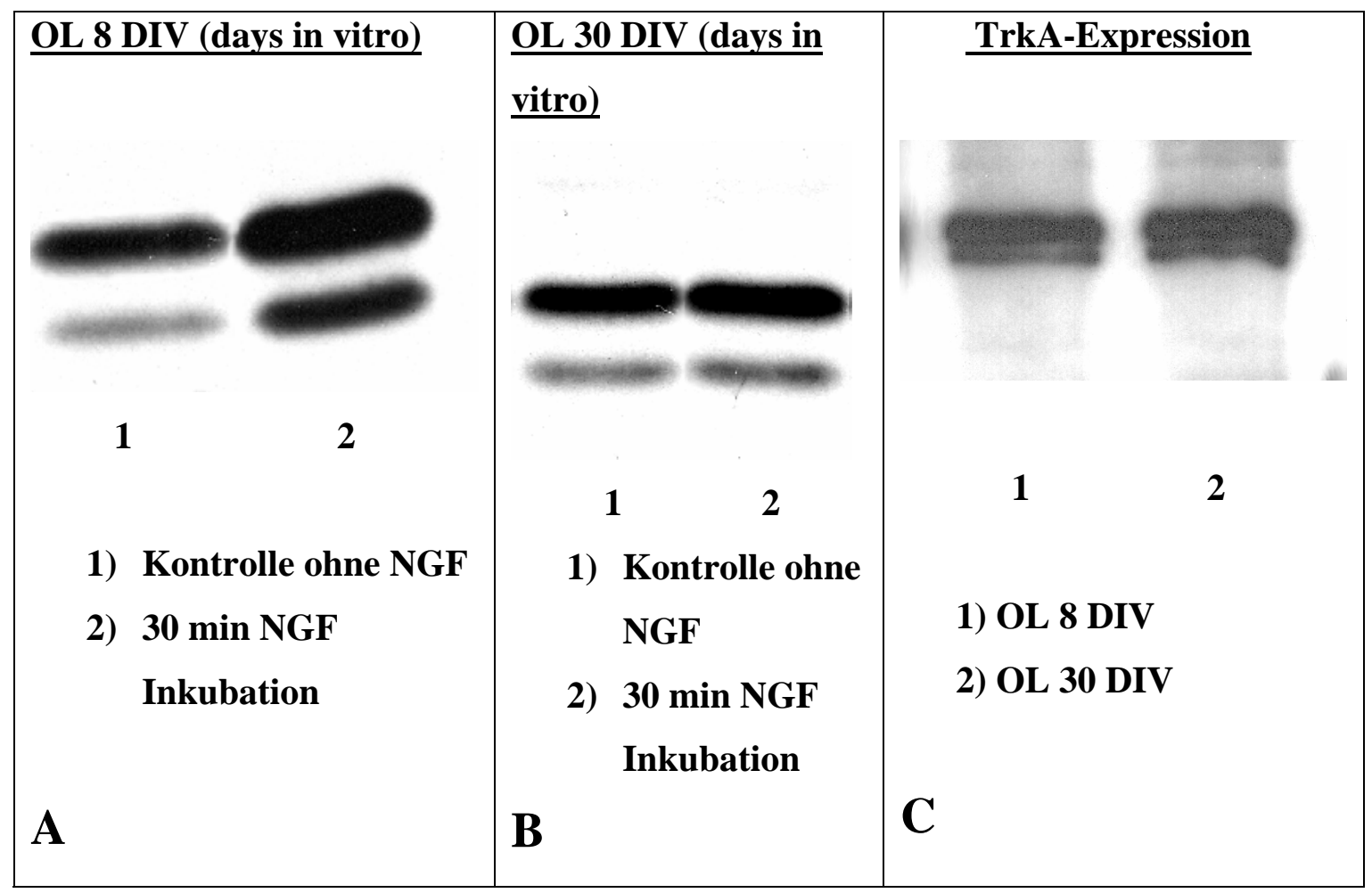




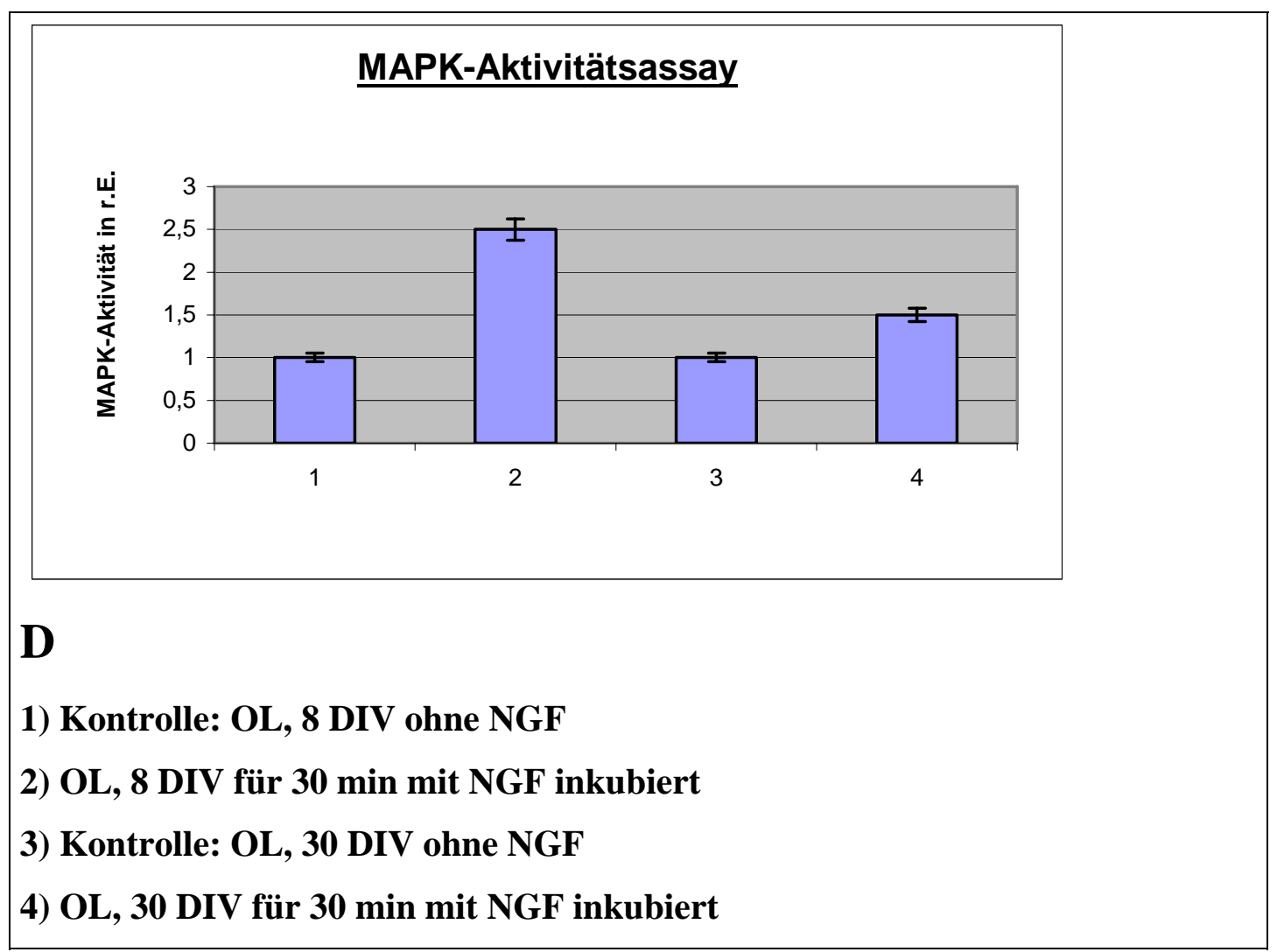

Abb. 36: Abnehmende NGF-Antwort bei 30 Tage kultivierten OL, deren Fortsatzwachstum zu diesem Zeitpunkt abgeschlossen ist. Die Aktivierung der MAPK nach 30-minütiger NGF-Stimulation von 8 Tage kultivierten Schweine-OL (A) wurde mit jener von 30 Tage kultivierten (B) in Relation gesetzt. Die TrkA-Expression blieb in diesem Zeitraum konstant. Alle Proben enthielten die gleiche Proteinmenge. Die Quantifizierung der Bandintensitäten mittels Scion Image ergab eine deutliche Reduktion der NGF-induzierten MAPK-Aktivität von langzeitkultivierten OL nach Stimulation mit NGF.

\subsubsection{Einfluss einer erhöhten Caveolin-1-Expression auf die MAPK-} Aktivität

Um die Caveolin-1-Expression zu erhöhen, wurden OL (8 DIV) für 48 h mit NGF stimuliert. Danach wurden die Zellen gewaschen, bekamen frisches MEM-Medium und wurden für $12 \mathrm{~h}$ im Brutschrank inkubiert, bis die MAPK-Aktivität wieder ihr Basisniveau erreicht hat. Für den eigentlichen Versuch wurden die Zellen nun für $4 \mathrm{~h}$ mit NGF behandelt, und im Anschluss wurde die MAPK-Aktivität in einem radioaktiven "In-Gel Kinase Assay“ bestimmt. Als Kontrollen dienten eine unbehandelte Probe, die die MAPK-Basalaktivität zeigte sowie ein weiterer für $4 \mathrm{~h}$ mit 
NGF stimulierter Ansatz, der den Anstieg der MAPK-Aktivität bei normaler Caveolin1-Expression wiedergab. Das Ergebnis in Abb. 37 zeigt in Ansatz 2 eine geringere Steigerung der MAPK-Aktivität nach 4 h, was möglicherweise auf einen erhöhten Caveolin-1-Level zurückzuführen ist, der sich hemmend auf die Aktivierung der MAPK ausgewirkt haben könnte. Im Vergleich zu der nicht mit NGF für 48 h vorbehandelten Probe ging die MAPK-Aktivität nach 4-stündiger NGF-Gabe um ca. 30\% zurück.

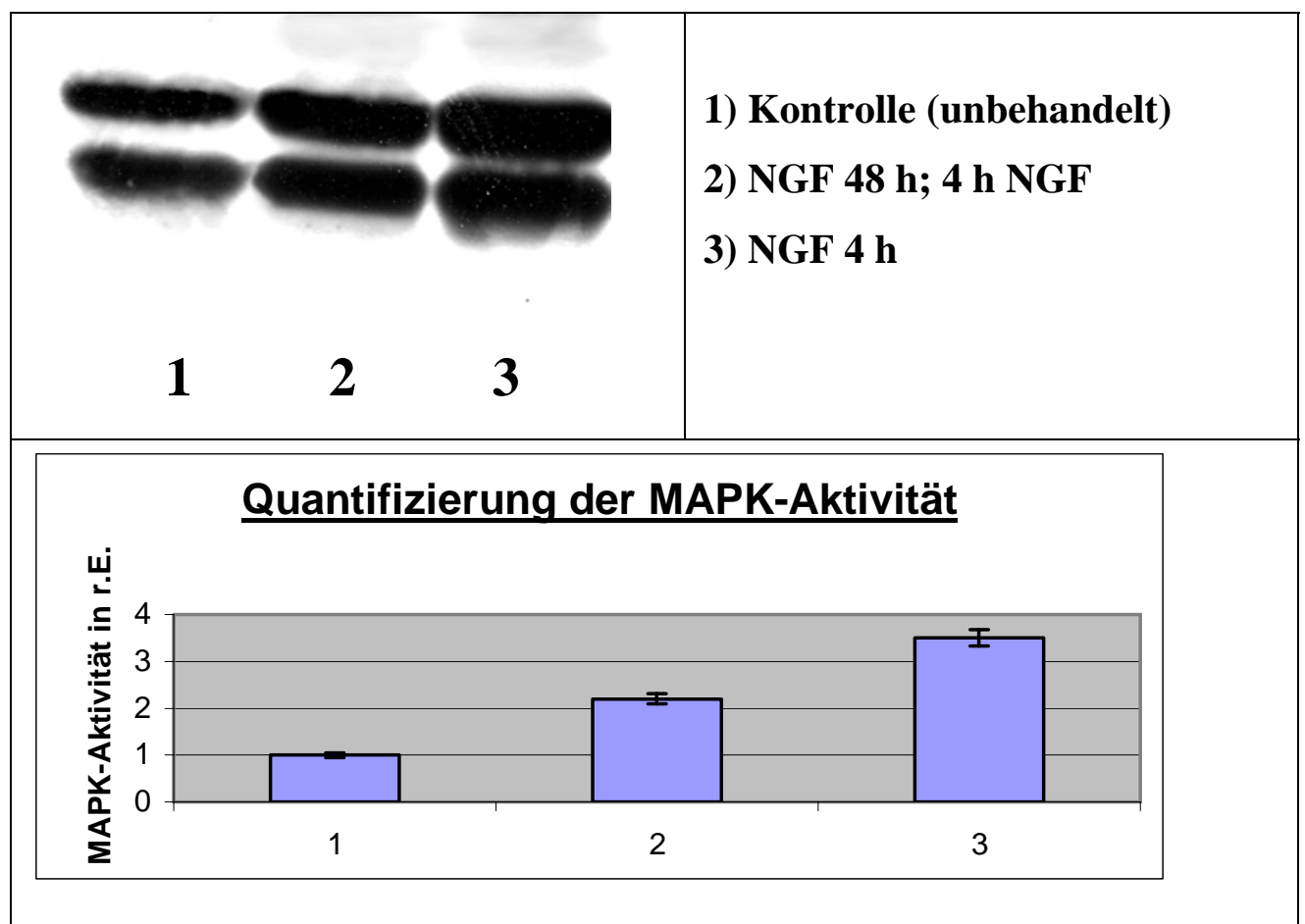

Abb. 37: Inhibition der MAPK-Aktivität in OL mit erhöhter Caveolin-1-Expression. Ansatz 2 wurde für 48 h mit NGF vorinkubiert, um die Caveolin-1-Expression zu steigern. Nach Absetzen von NGF für 12 h, wurden die Zellen erneut mit NGF für $4 \mathrm{~h}$ behandelt. Dabei fiel der Anstieg der MAPK-Aktivität um ca. 30\% geringer aus, als es sonst nach 4-stündiger NGF-Exposition der Fall ist. Dieser Befund könnte aufgrund einer erhöhten Caveolin-1-Expression zustande kommen, die sich möglicherweise inhibierend auf die MAPK-Aktivität ausgewirkt hat.

\subsubsection{Inhibition der MAPK-Aktivität durch Cavtratin}

Caveolin-1 kann über seine CSD (Caveolin-Gerüst-Domäne) Signalkaskaden inhibieren. Eine solche Beeinflussung durch Caveolin-1 sollte nun auch bei der Signalgebung unter NGF untersucht werden. Dazu wurde die CSD als zellgängiges Peptid (Cavtratin) in einer Konzentration von 25 und $50 \mu \mathrm{M}$ auf primärkultivierte 
Schweine-OL gegeben. Nach $1 \mathrm{~h}$ wurde NGF (100 ng/ml) zugegeben, und die Zellen wurden für weitere $4 \mathrm{~h}$ inkubiert. Genauso wurde mit einer negativen Kontrolle, bestehend aus einem funktionslosen NS-(nonsense)Peptid, verfahren. Das Ergebnis dieses MAPK-Assays war eine deutliche inhibitorische Wirkung von Cavtratin auf die MAPK-Aktivität (Abb. 37).

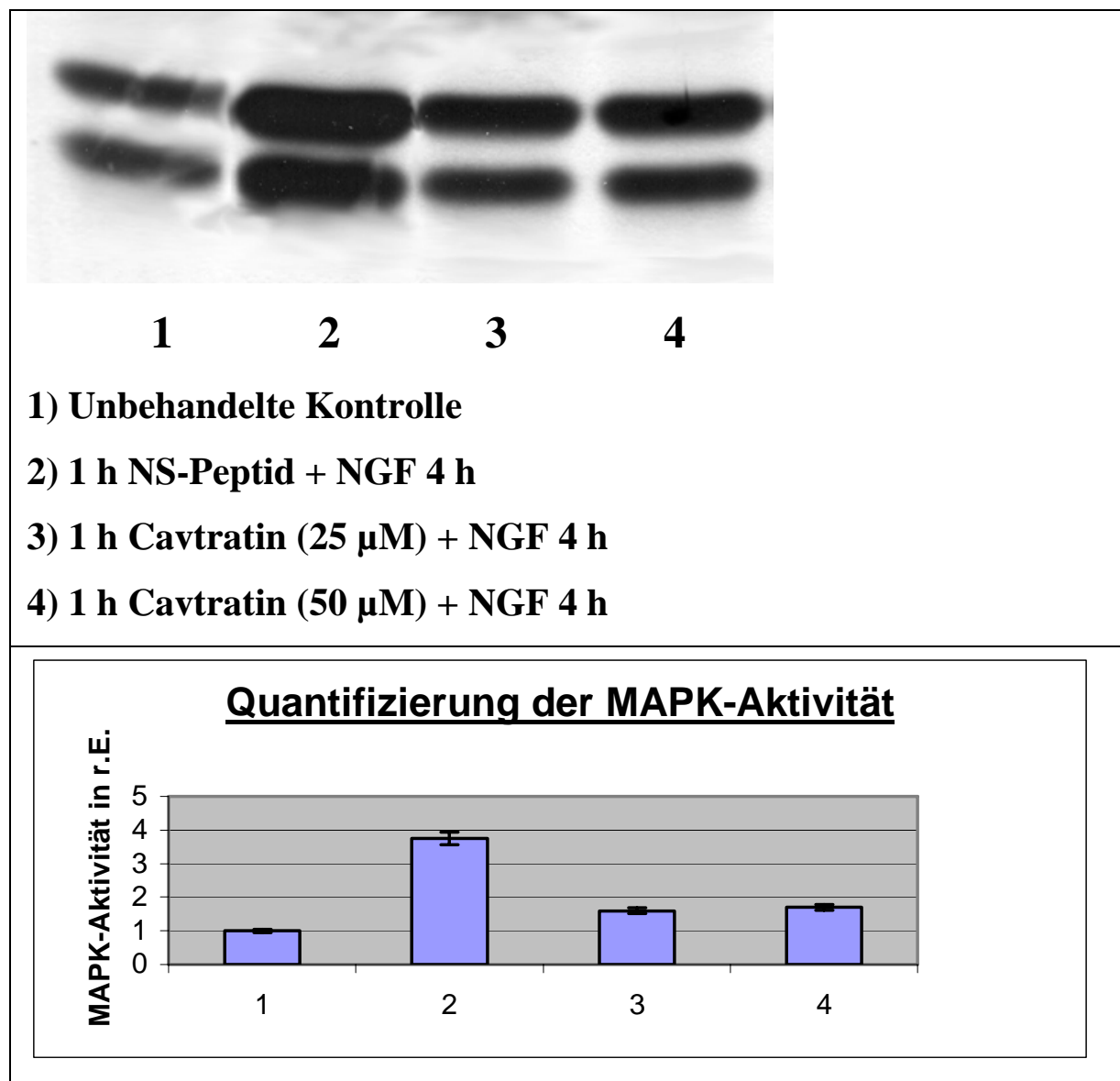

Abb. 38: Inhibitorischer Einfluss von Cavtratin auf die MAPK-Aktivität. Durch diesen Aktivitätsassay konnte gezeigt werden, dass Caveolin-1 über seine CSD die MAPKAktivierung, die in Folge der Stimulation mit NGF eigentlich doppelt so hoch sein müsste, inhibiert.

\subsection{Transfektion von Schweine-OL mit siRNA}

Die RNA-Interferenz dient zur selektiven Reduktion der Genexpression und damit der systematischen Analyse des jeweiligen Genproduktes bzw. des kodierten Proteins. Zuerst musste jedoch gezeigt werden, dass die siRNA zusammen mit dem Transfektionsreagens von Schweine-OL überhaupt aufgenommen wird. Außerdem 
musste untersucht werden, welches Transfektionsreagens am effizientesten und gleichzeitig für die Zellen am schonendsten ist.

\subsubsection{Aufnahme eines fluoreszierenden Transfektionsreagens}

Um die Aufnahme des Transfektionsreagens zu dokumentieren, wurden Schweine-OL mit einem Fluoreszenz-gekoppelten Transfektionsreagens jetSI-Endo Fluor und nicht kodierender siRNA transfiziert. Am darauf folgenden Tag konnte die Aufnahme von jetSI-Endo Fluor bei 400facher Vergrößerung unter UV-Licht im Phasenkontrastmikroskop dokumentiert werden (Abb. 39).

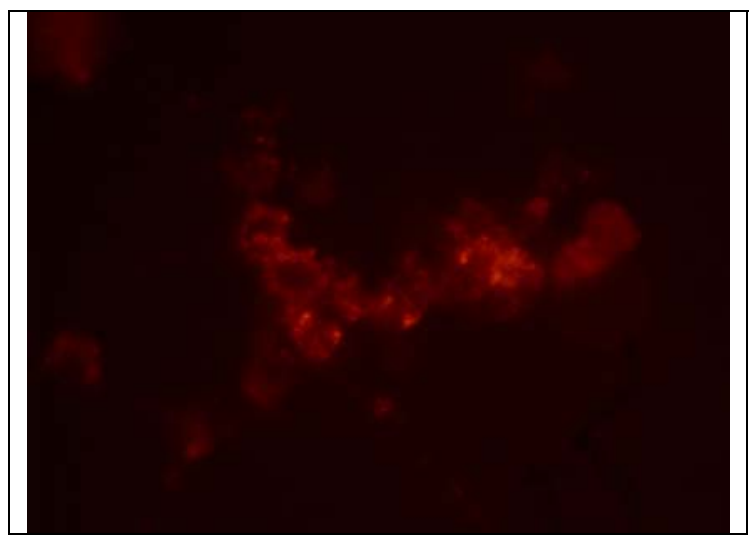

Abb. 39: Aufnahme der fluoreszierenden Transfektionskomplexe bestehend aus jetSIEndo Fluor und nicht kodierender siRNA. (Vergrößerung 400fach)

\subsubsection{Test von verschiedenen Transfektionsreagentien auf ihre Zellverträglichkeit und Transfektionseffizienz}

Mithilfe von Fluoreszenzfarbstoff-markierter, nicht kodierender siRNA wurden 5 verschiedene Tansfektionsreagentien (jetSI-Endo, Oligofectamin, Lipofectamin, Gene Silencer und RNAiFect) hinsichtlich ihrer Transfektionseffizienz und Zellverträglichkeit getestet. Dabei stellten sich einige Unterschiede zwischen den jeweiligen Transfektionsreagentien heraus:

Die Intensität der grünen Fluoreszenz in Abb. 40 korrelierte mit der Transfektionseffizienz. Diese war bei jetSI-Endo am höchsten, weil fast alle Zellen relativ stark fluoreszierten. Die restlichen vier Transfektionsreagentien besaßen eine wesentlich geringe Transfektionseffizienz. Die Transfektion der Kontroll-siRNA erfolgte zum Teil sehr ungleichmäßig wie beim Lipofectamin, das einige Zellen stark 
fluoreszieren ließ, andere dagegen leuchteten kaum. Bei höheren Konzentrationen erwies sich RNAiFect für Schweine-OL als zellschädigend.

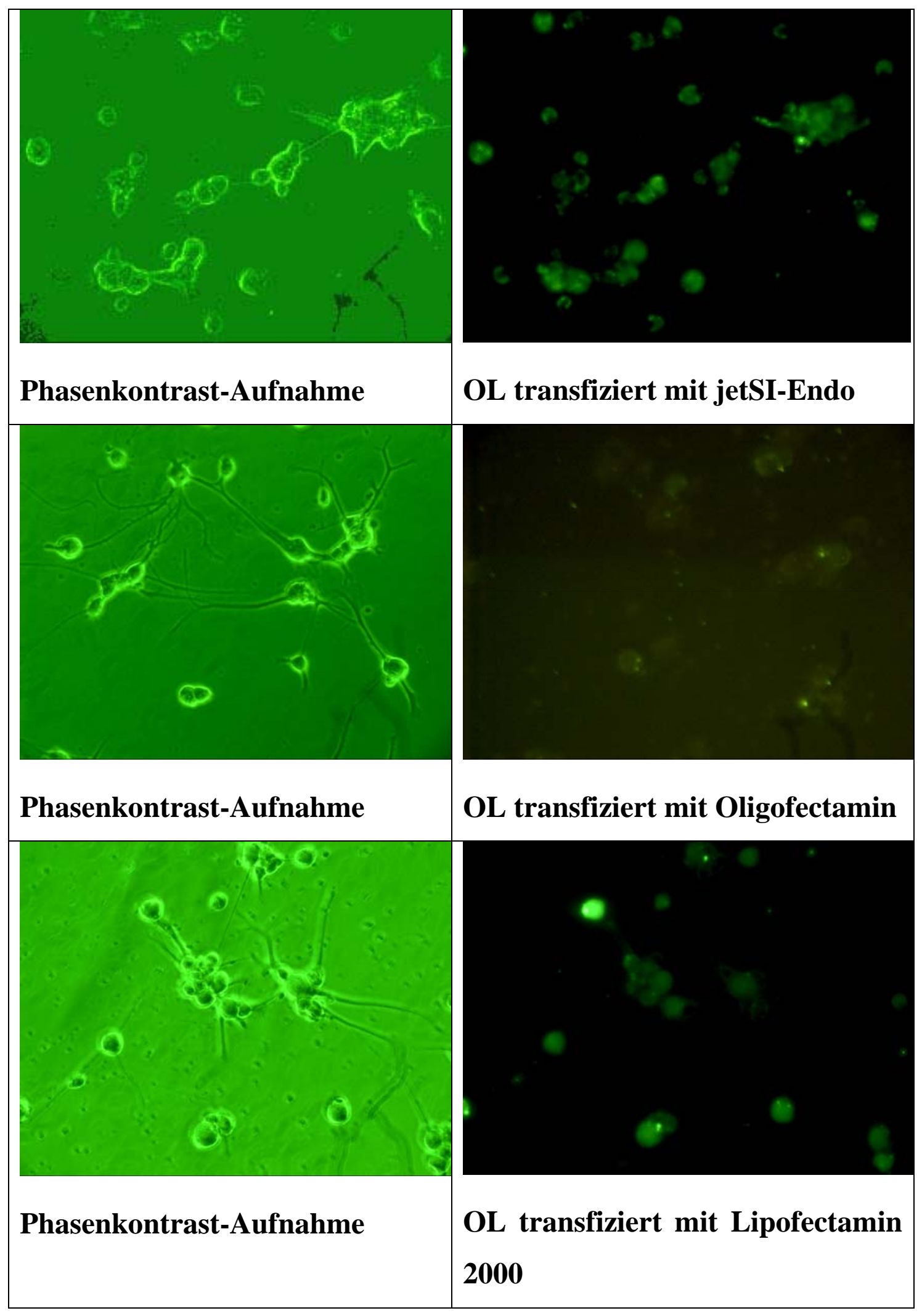



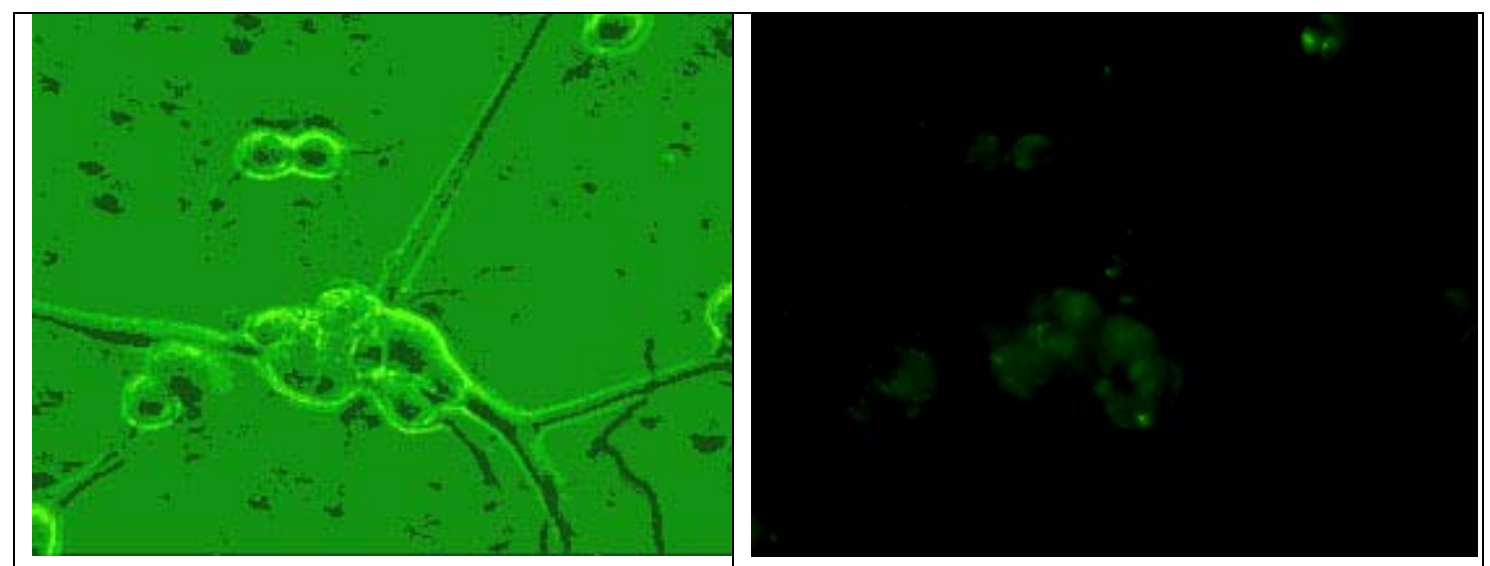

\section{Phasenkontrast-Aufnahme}

\section{OL transfiziert mit Gene Silencer}
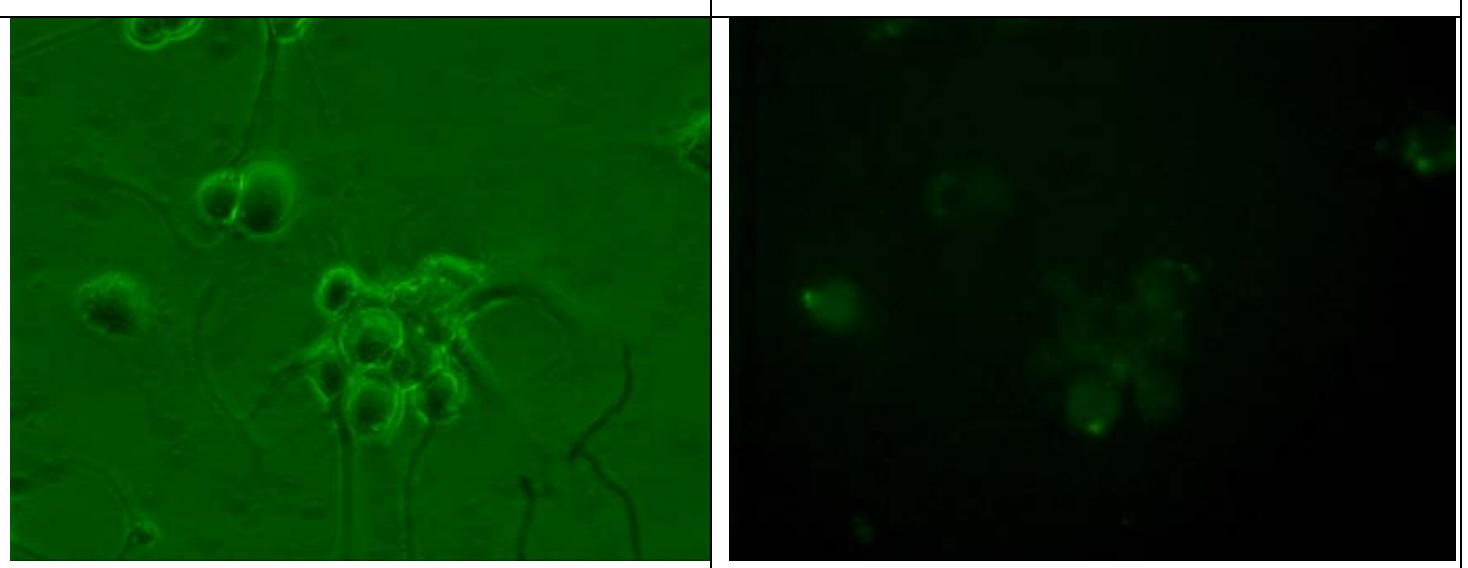

\section{Phasenkontrast-Aufnahme}

\section{OL transfiziert mit RNAiFect}

Abb. 40: Test verschiedener Transfektionsreagentien hinsichtlich ihrer Verträglich-

keit und Transfektionseffizienz. Die Verträglichkeit wurde durch visuelle Betrachtung der transfizierten Zellen im Phasenkontrast-Mikroskop bewertet (linke Spalte). Dagegen wurde die Transfektionseffizienz der jeweiligen Reagentien mithilfe von fluoreszierender siRNA bestimmt, wobei die Intensität der grünen Fluoreszenz und die Transfektionseffizienz miteinander korrelierten (rechte Spalte). Hinsichtlich dieser beiden Parameter erwies sich jetSI-Endo als am besten geeignet. (Vergrößerung 400fach)

\subsubsection{Untersuchung der Zellverträglichkeit von jetSI-Endo in einem MTT-Lebendzellassay.}

Durch den MTT-Lebendzellassay, der die mitochondriale Dehydrogenase-Aktivität in den Zellen misst (MOSMANN 1983), sollte die Zellverträglichkeit von jetSI-Endo bestimmt werden. Dazu wurde die Transfektion mit jetSI-Endo nach 5 h, 10 h und 24 h 
gestoppt und die Anzahl der lebenden Zellen bestimmt. Die Auswertung (Abb. 41) ergab eine relativ geringe Zellsterblichkeit, was die gute Verträglichkeit von jetSI-Endo zeigte.

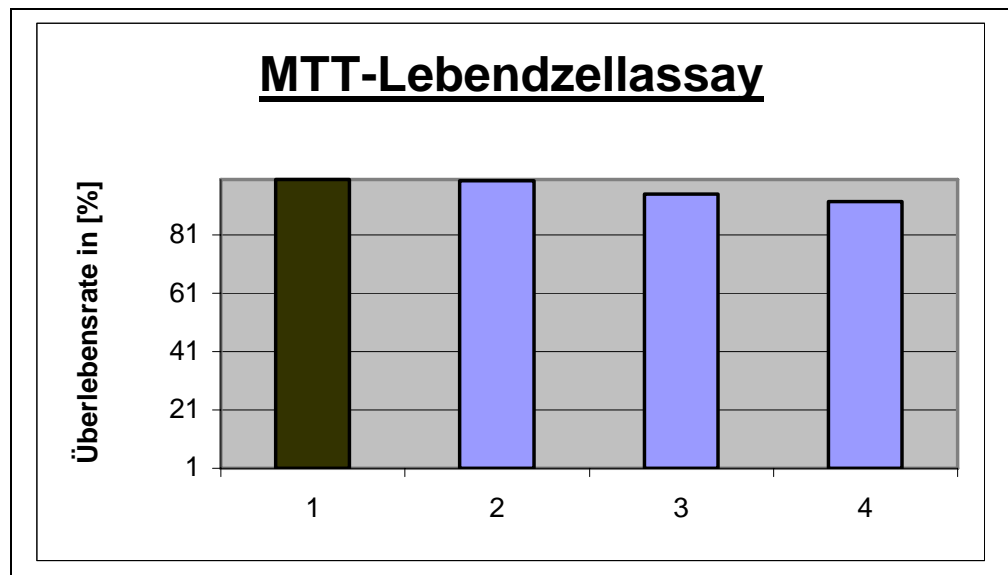

1) unbehandelte Kontrolle $=100 \%$

2) $5 \mathrm{~h}$ nach

Transfektionsende

3) $10 \mathrm{~h}$ nach

Transfektionsende

3) $24 \mathrm{~h}$ nach

Transfektionsende

Abb. 41: Untersuchung der Zellverträglichkeit von jetSI-Endo in einem MTTLebendzellassay. Eine relativ hohe Überlebensrate der transfizierten Zellen dokumentiert die gute Verträglichkeit von jetSI-Endo.

\subsubsection{Transfektion von OL mit MAPK-spezifischer siRNA}

Zur Überprüfung der Transfektionsmethodik wurden OL mit MAPK-spezifischer siRNA transfiziert, die anhand der humanen Gensequenz hergestellt wurde, aber aufgrund der Homologie zur Spezies Schwein dennoch hier verwendet werden konnte. Die Reduktion der MAPK-Expression erfolgte im Wesentlichen innerhalb der ersten 3 DIV nach Transfektionsende. Danach wurden die Zellen für 4 h NGF exponiert, ehe die MAPK-Aktivität in einem "In-Gel Kinase Assay" gemessen wurde. Dieser Versuch bestand zudem noch aus einer unbehandelten Kontrolle sowie einer mit nicht kodierender (NS)-siRNA transfizierten und nach 3 DIV für 4 h mit NGF stimulierten Probe.

Anhand des Rückganges der NGF-induzierten MAPK-Aktivierung wird deutlich, dass die MAPK-Expression in Folge der Transfektion mit MAPK-siRNA herunterreguliert wurde (Abb. 42 (3)). Eine mit NS-siRNA transfizierte Positivkontrolle zeigte dagegen den gewohnten MAPK-Aktivitätsanstieg nach Stimulation mit NGF (Abb. 42 (2)). 


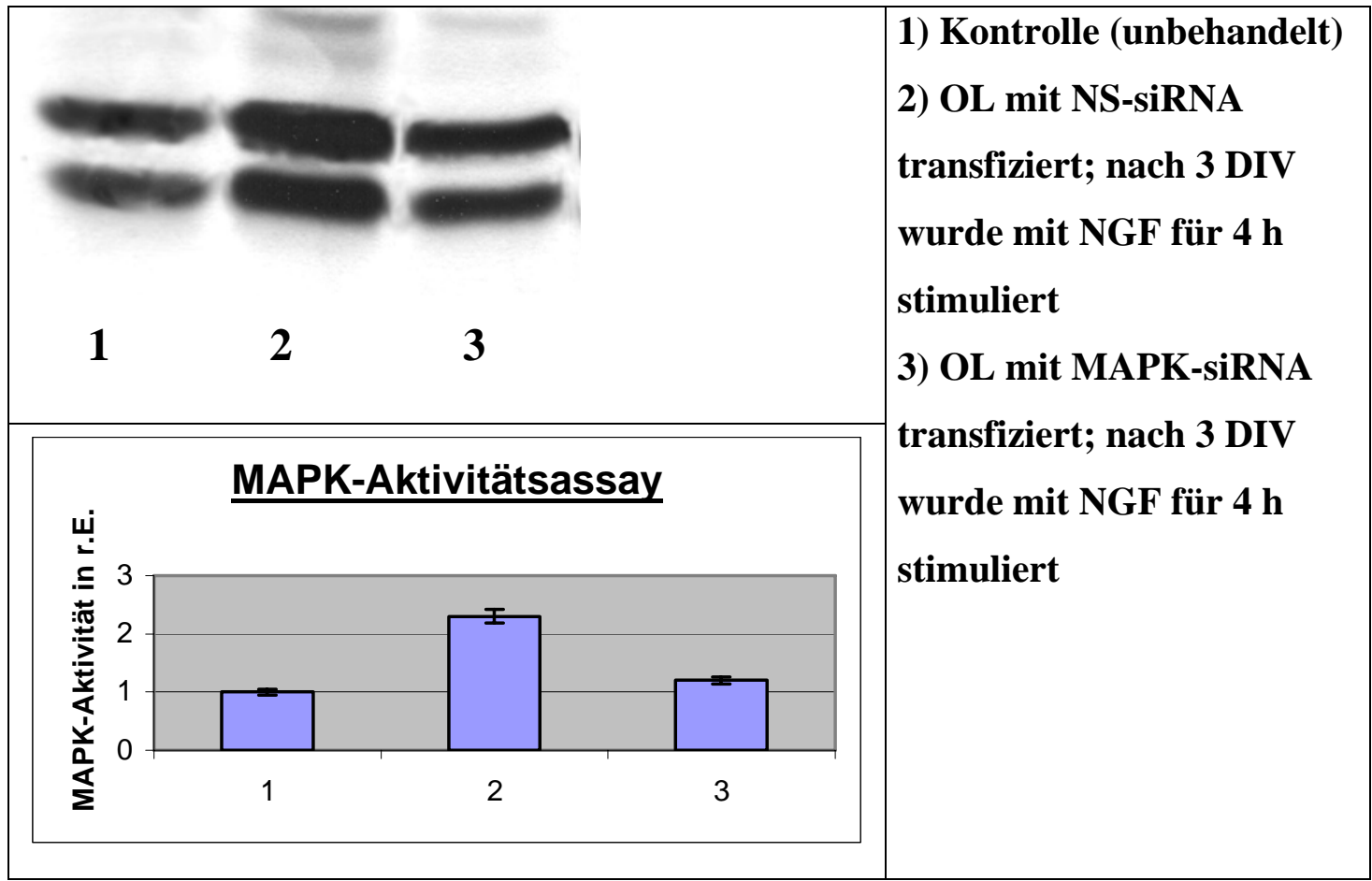

Abb. 42: Abnahme der MAPK-Aktivität nach Transfektion mit MAPK-spezifischer siRNA. OL, die mit MAPK-siRNA transfiziert wurden, wurden nach 3 DIV für 4 h mit NGF behandelt. Danach wurde ihre MAPK-Aktivität in einem radioaktiven "In-Gel Kinase Assay“ bestimmt. Der Rückgang der MAPK-Aktivität nach NGF zeigte im Vergleich zu den mit NS-siRNA transfizierten Zellen, dass eine Herunterregulation der MAPK-Expression mittels MAPK-siRNA offenbar erfolgt war.

\subsection{Reduktion der Caveolin-1-Expression in Schweine-OL durch Transfektion mit Caveolin-1-spezifischer siRNA}

Basierend auf der veröffentlichten Sequenz von Caveolin-1 wurden von Qiagen zwei verschiedene Caveolin-1-siRNAs hergestellt. Diese waren komplementär zur Gensequenz des Caveolin-1-Gens und unterdrückten auf posttranskriptionaler Ebene dessen Expression. Der Transfektionsprozess erfolgte im Brutschrank bei $37^{\circ} \mathrm{C}$ und war nach etwa 5-8 Stunden abgeschlossen. Da der Prozess des "Genstilllegens" einige Zeit benötigt bis er sich auf Proteinebene auswirkt, war ein Effekt erst nach etwa 2-4 Tagen zu erwarten. Innerhalb der Zelle war die siRNA für etwa 5-6 Tage stabil, ehe sie abgebaut wurde. 


\subsubsection{Immunzytochemische Darstellung des durch Transfektion mit Caveolin-1-siRNA herbeigeführten Caveolin-1-Knock-downs}

Zur Überprüfung der Herunterregulation der Caveolin-1-Expression nach Transfektion mit Caveolin-1-spezifischer siRNA wurden die Zellen mit einem monoklonalen Maus anti-Caveolin-1 IgM angefärbt. Die Fluoreszenzintensität ließ Rückschlüsse auf die Expression von Caveolin-1 zu. Vergleicht man nun die mit Caveolin-1-siRNA transfizierten Proben mit den Kontrollzellen, die mit nicht kodierender (NS)-siRNA transfiziert wurden, so erkennt man eine deutliche Abnahme der Fluoreszenz nach 3 DIV (Abb. 43).

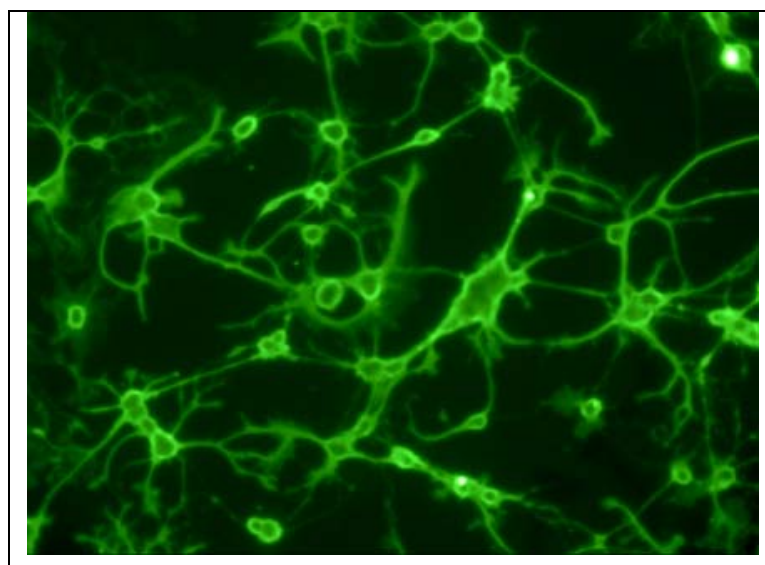

A Kontrollzellen, transfiziert mit NSSiRNA (3 DIV)

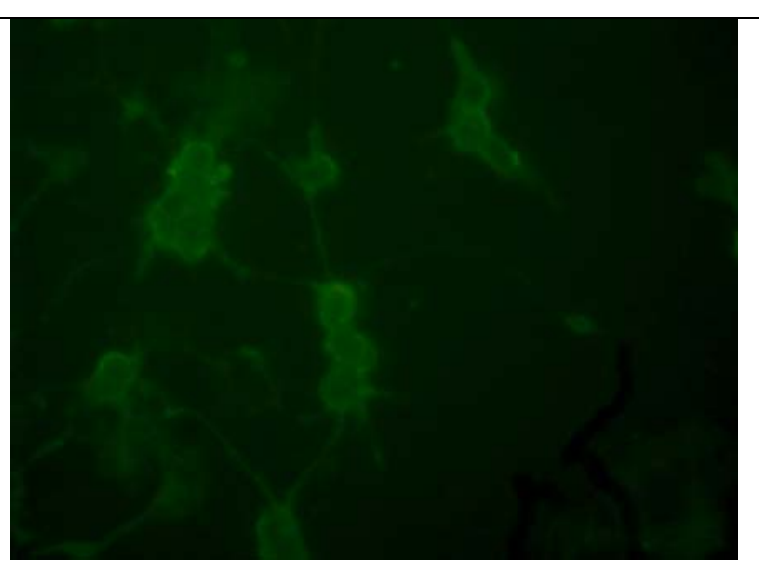

C Kontrolle: Hintergrundfärbung ohne 1. Antikörper

Abb. 43: Darstellung des Caveolin-1-Knock-downs durch immunzytochemische Anfärbung von Caveolin-1. Die Zellen waren zuvor mit Caveolin-1-spezifischer siRNA transfiziert worden und zeigten nach 3 DIV eine geringere Caveolin-1-Expression (B), 
als die Kontrollzellen (A). Diese wurden mit NS-siRNA transfiziert, sodass ihre Caveolin-1-Expression nicht beeinflusst wurde. Zum Nachweis der Spezifität des primären Caveolin-1 Antikörpers wurden in (C) die Zellen lediglich mit dem Fluoreszenz-gekoppelten Sekundärantikörper Alexa Fluor 488 IgM Ziege anti-Maus inkubiert. (Vergrößerung 200fach)

\subsubsection{Nachweis des Caveolin-1-Knock-downs im Western Blot}

Nachdem die erfolgreiche Reduktion der Caveolin-1-Expression mittels siRNA bereits durch immunzytochemische Anfärbung von Caveolin-1 erkennbar war, sollte sie als nächstes auf einem Immunoblot quantifiziert werden.

Getestet wurden zwei verschiedene Caveolin-1-spezifische siRNAs mit unterschiedlicher komplementärer Sequenz zum Caveolin-1-Gen. Zu Vergleichzwecken wurde eine unbehandelte Kontrolle und eine negative Kontrolle, bei der die Zellen mit nicht kodierender NS-siRNA transfiziert wurden, verwendet. Zum Nachweis, dass alle Proben die gleiche Proteinmenge enthielten, wurde neben einer Proteinangleichung mittels Tüpfelprobe die ß-Aktin-Expression der Proben bestimmt. Als Ergebnis dieses Western Blots ist klar hervorzuheben, dass die beiden verwendeten Caveolin-1spezifischen siRNAs funktionstüchtig waren und zu einer deutlichen Herunterregulation von Caveolin-1 nach 3 DIV geführt haben; sie lag in beiden Fällen bei über 60\% (Abb. 44). Dagegen liegt der geringe Unterschied zwischen den unbehandelten Zellen und der Kontrolle innerhalb der Toleranzgrenze, die geringfügigen Schwankungen unterliegt.

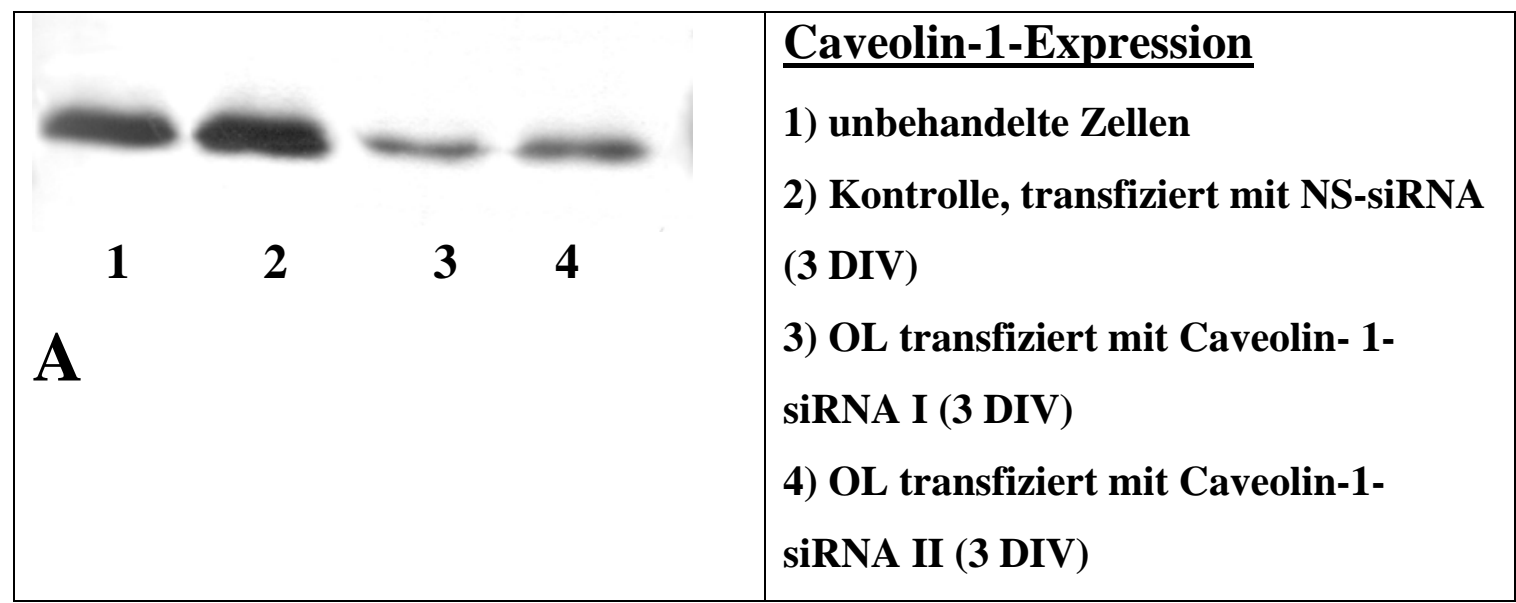




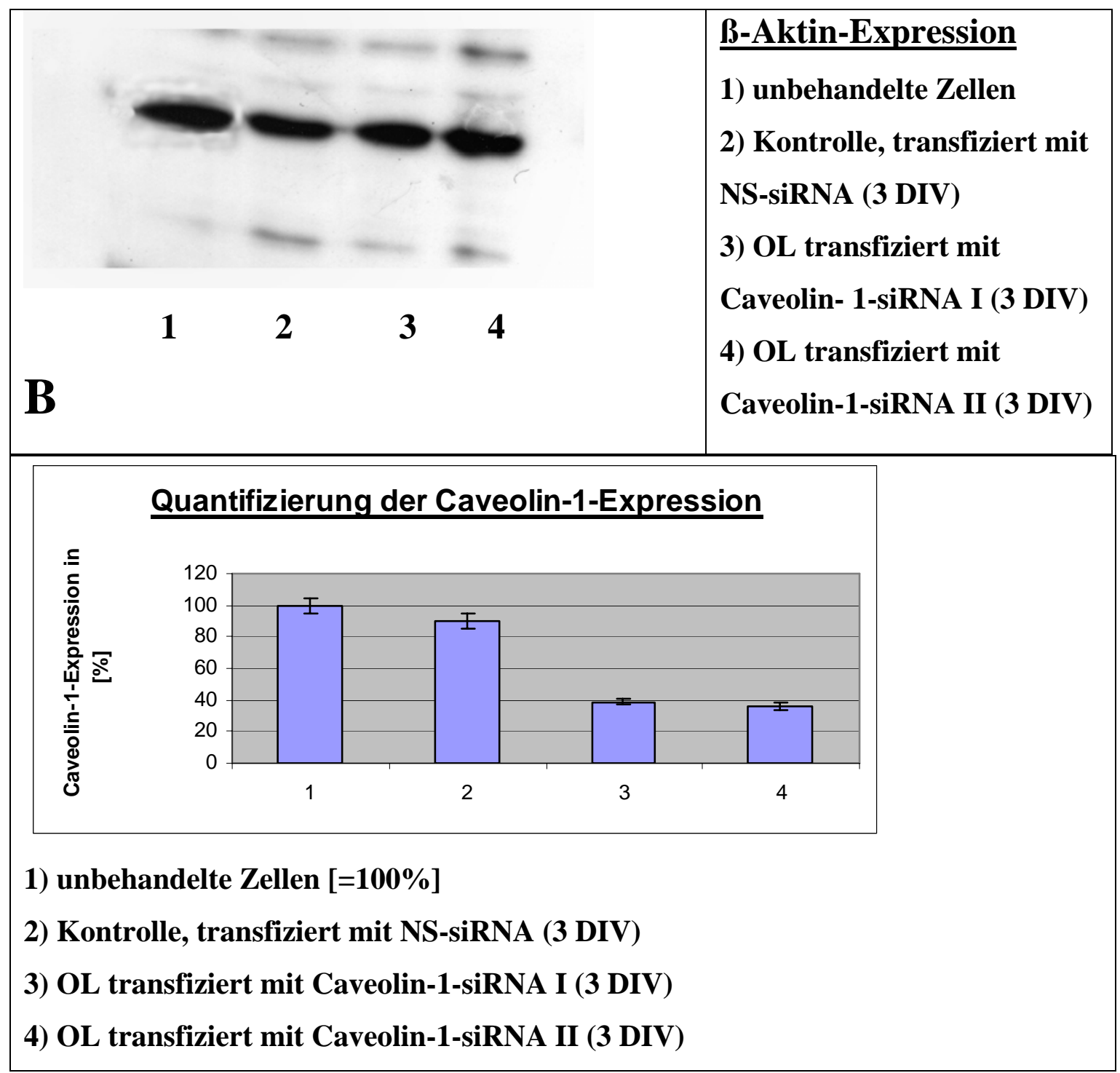

Abb. 44: Reduktion der Caveolin-1-Expression mittels Caveolin-1-spezifischer siRNA im Western Blot. Adulte Schweine-OL wurden mit zwei verschiedenen Caveolin-1spezifischen siRNAs transfiziert. Nach 3 Tagen konnte eine deutliche Abnahme der Caveolin-1-Expression im Vergleich zu den beiden Kontrollansätzen detektiert werden. Eine Proteinangleichung der Zelllysate erfolgte mittels Tüpfelprobe; der Nachweis gleicher Proteinmengen durch die Detektion der ß-Aktin-Expression im Western Blot. Die Quantifizierung der Bandenintensitäten ergab eine ca. 60\%-ige Reduktion der Caveolin-1-Expression. Somit inhibierten beide Caveolin-1-spezifischen siRNAs die Caveolin-1-Expression in etwa gleich gut.

\subsubsection{Morphologische Auswirkungen eines Caveolin-1-Knock-downs}

Anhand der morphologischen Analyse von Schweine-OL sollte geklärt werden, wie sich die Reduktion der Caveolin-1-Expression auf die Fortsatzbildung auswirkt. Dazu 
wurden OL-Kulturen (8 DIV) mit Caveolin-1-spezifischer siRNA transfiziert und danach zwecks Reduktion der Caveolin-Expression für 3 Tage kultiviert.

Im Gegensatz zu den Kontrollzellen, die mit NS-siRNA transfiziert wurden und ein normales Fortsatzwachstum zeigten, besaßen die mit Caveolin-1-spezifischer siRNA transfizierten Zellen deutlich weniger Fortsätze (Abb. 45 A,B). Dieser inhibitorische Effekt der reduzierten Caveolin-1-Expression blieb auch unter NGF erhalten. Im Vergleich zu den mit Caveolin-1-siRNA transfizierten Proben besaßen mit NS-siRNA transfizierte und nach 3 DIV mit NGF stimulierte OL nach 48 h deutlich mehr Fortsätze. Dabei regenerierten die mit NS-siRNA transfizierten OL nach NGF-Gabe ein Netzwerk von stabilen und verzweigten Fortsätzen. Wogegen OL mit reduzierter Caveolin-1-Expression nach Stimulation mit NGF eine Art “Teppich“ oder Geflecht von dünnen Fortsätzen formten.

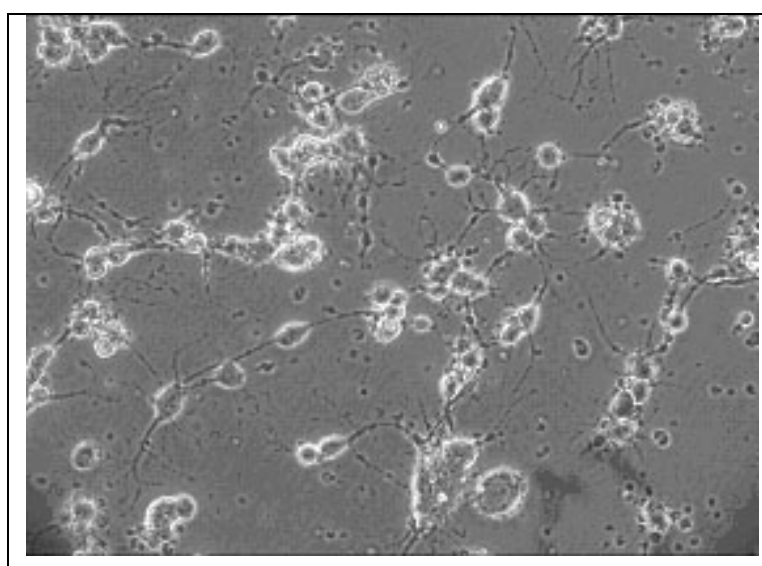

A Kontrolle: OL transfiziert mit NSsiRNA, danach 3 DIV

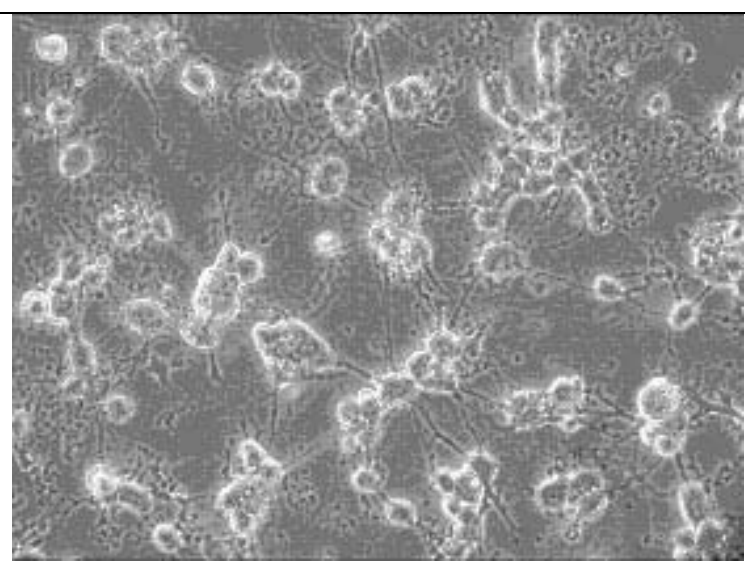

C OL transfiziert mit NS-siRNA, danach 3 DIV; NGF 48 h
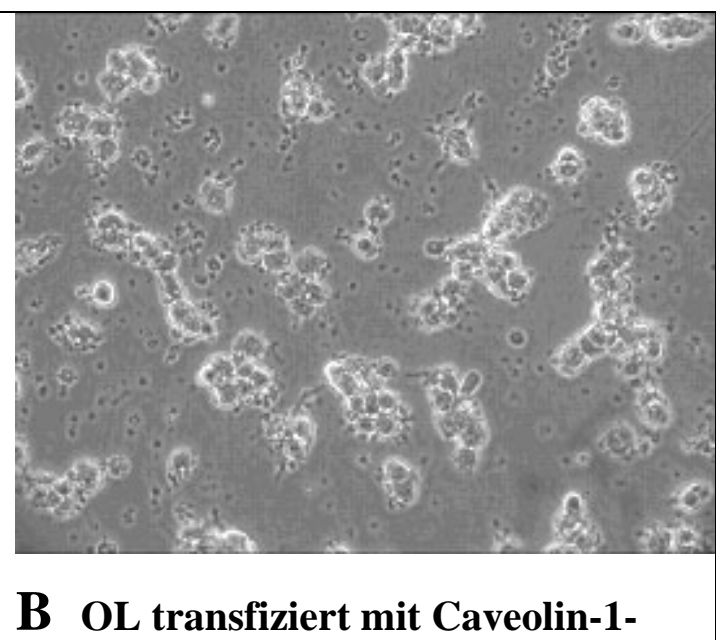
spezifischer siRNA, danach 3 DIV

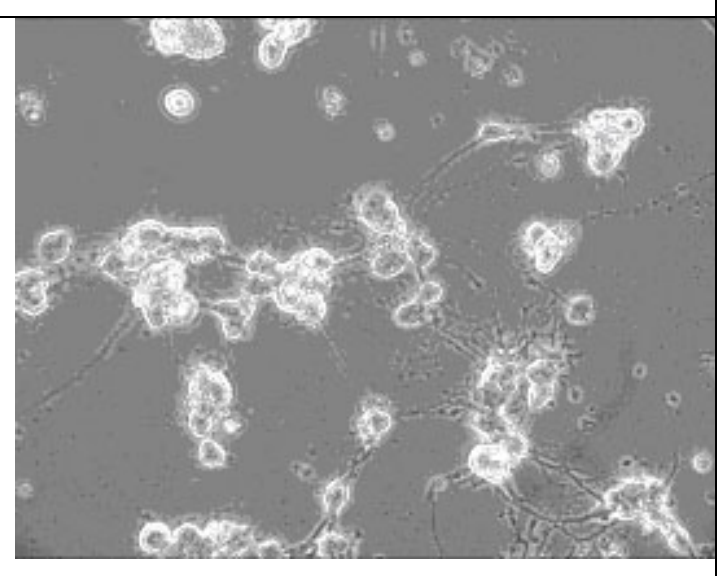

D OL transfiziert mit Caveolin-1spezifischer siRNA, danach 3 DIV; NGF 48 h 


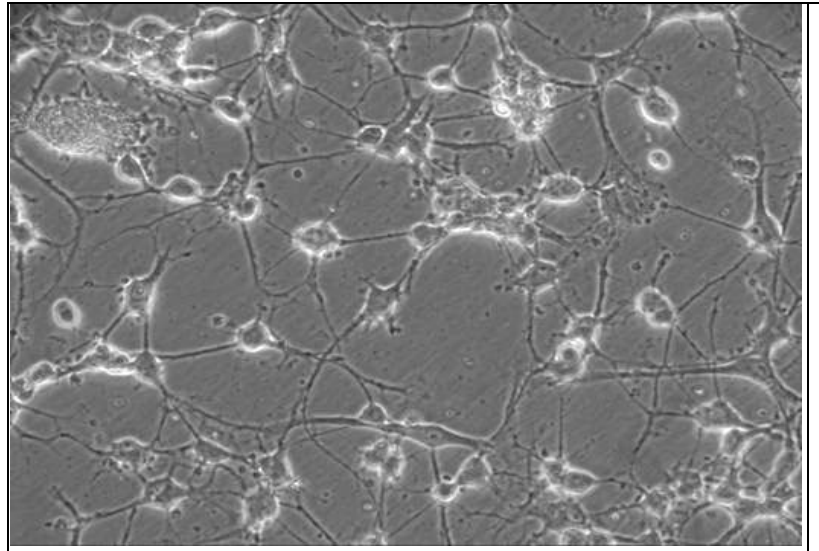

E OL transfiziert mit NS-siRNA, danach 3 DIV, NGF 72 h

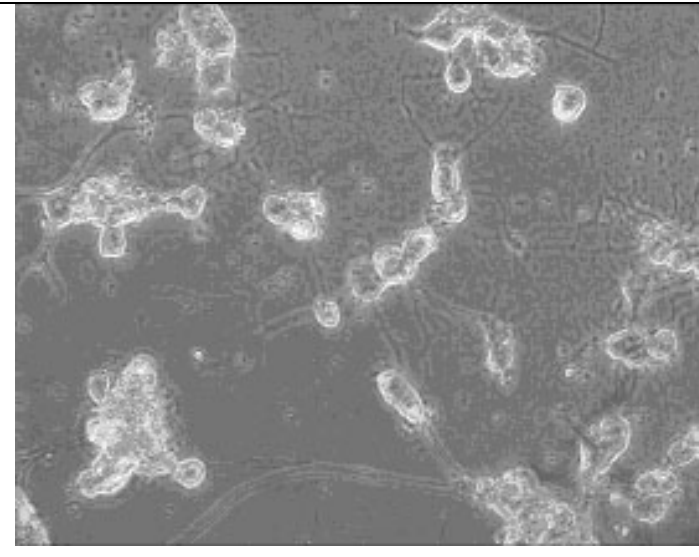

F OL transfiziert mit Caveolin-1spezifischer siRNA, danach 3 DIV; NGF 72 h

Abb. 45: Inhibition der Fortsatzbildung in Schweine-OL, die mit Caveolin-1spezifischer siRNA transfiziert wurden, unter NGF. Kontrollzellen wurden unter den gleichen Bedingungen mit NS-siRNA transfiziert. Nach einer Kulturdauer von 3 Tagen wiesen die mit Caveolin-1-spezifischer siRNA transfizierten OL ein geringeres Fortsatzwachstum auf (B). Im Gegensatz dazu entwickelten sich die Fortsätze der Kontrollzellen normal; sie unterschieden sich dabei kaum von unbehandelten Zellen (A). Verstärkt wurde der Effekt unter NGF, da das NGF-induzierte Fortsatzwachstum durch den Caveolin-1-Knock-down deutlich gebremst wurde (C-F), Vergrößerung 200 fach.

\subsubsection{Auswirkung einer reduzierten Caveolin-1-Expression auf die MAPK-Aktivität von Schweine-OL}

In diesem Versuch wurden OL-Kulturen nach 8 DIV mit Caveolin-1-spezifischer siRNA I und II transfiziert. Zur Detektion der MAPK-Aktivität wurden diese Zellen nach weiteren 3 DIV für $4 \mathrm{~h}$ mit NGF stimuliert und $1 \mathrm{~h}$ vor dem Abernten mit Natrium-Orthovanadat präinkubiert. Danach wurde die MAPK-Aktivität in einem renaturierenden "In-Gel Kinase Assay“ bestimmt. Diese Versuchsreihe bestand zudem noch aus einer unbehandelten Kontrolle, einer mit nicht kodierender NS-siRNA transfizierten und nach 3 DIV für 4 h mit NGF stimulierten Probe sowie einer positiven Kontrolle, die für $4 \mathrm{~h}$ mit NGF stimuliert wurde.

Anhand von Abb. 46 wird deutlich, dass sich eine um ca. 60\% reduzierte Caveolin-1Expression inhibierend auf die MAPK-Aktivität auswirkt. Dagegen besaß die mit NS- 
siRNA transfizierte Probe nach 4-stündiger NGF-Stimulation eine deutlich höhere MAPK-Aktivität, die dem üblichen NGF-Effekt nach 4 h gleich kam. Kontroll-OL wiesen ein Basisniveau an Erk1- und Erk2-Aktivität auf.

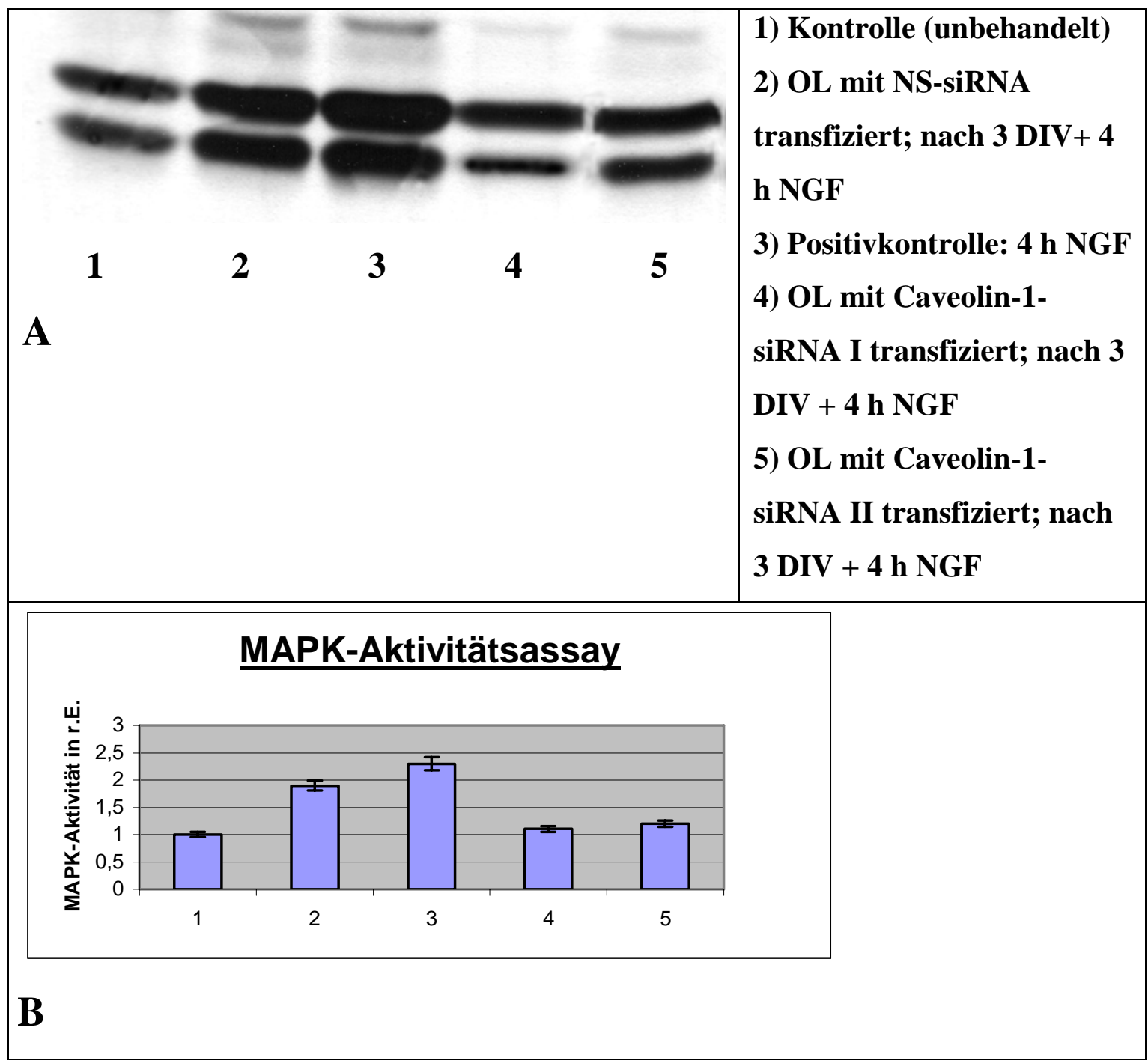

Abb. 46: Bestimmung der MAPK-Aktivität von Schweine-OL mit reduzierter

Caveolin-1-Expression. OL wurden 3 Tage nach Transfektionsende mit den Caveolin1-spezifischen siRNAs I und II für $4 \mathrm{~h}$ mit NGF stimuliert und einem MAPKAktivitätstest unterzogen. Außerdem wurde die MAPK-Aktivität von nicht transfizierten und für $4 \mathrm{~h}$ mit NGF stimulierten sowie von mit NS-siRNA transfizierten Zellen, die nach 3 DIV für 4 h mit NGF Zellen stimuliert wurden, bestimmt. Der um ca. 60\% reduzierte Caveolin-1-Level führte in beiden Proben zu einer deutlich geringeren MAPK-Aktivität, die trotz NGF-Gabe auf Kontrollniveau lag. 


\subsection{Phosphorylierung von Caveolin-1 an Tyrosin-14 (Caveolin pY14) nach Stimulation von Schweine-OL mit NGF}

\subsubsection{Immunzytochemischer Nachweis}

Zur immunzytochemischen Anfärbung der Caveolin pY14 wurden 8-10 Tage alte OLKulturen für $1 \mathrm{~h}$ mit NGF (100 ng/ml) stimuliert. Die Verwendung des Phosphatasehemmers Natrium-Orthovanadat war hierbei essentiell, da Caveolin ansonsten rasch wieder dephosphoryliert wird. Die Caveolin pY14 läuft nicht in allen Zellen gleichzeitig ab, sondern ist an einem bestimmten Zeitpunkt immer nur auf einzelne Zellen oder Zellgruppen beschränkt. Sie wurde mit einem speziellen polyklonalen Maus anti-Caveolin pY14 IgG detektiert. Anhand von Abb. 47 erkennt man, dass sich die Caveolin pY14 auf die gesamte Zelle und ihre Fortsätze erstreckt. Allerdings gibt es stärker und schwächer fluoreszierende Bereiche, die zeigen, dass die Caveolin pY14 nicht gleichmäßig und homogen innerhalb der Zelle abläuft.

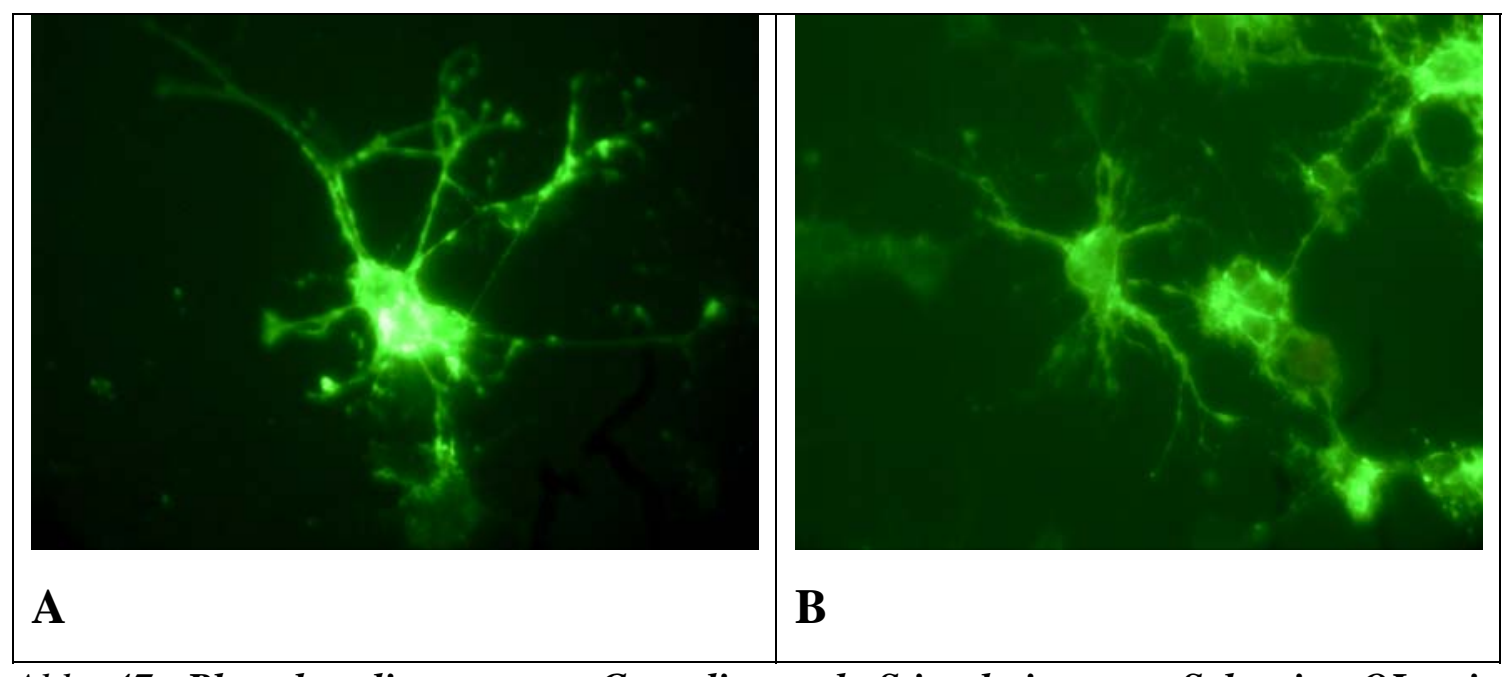

Abb. 47: Phosphorylierung von Caveolin nach Stimulation von Schweine-OL mit NGF (100 ng/ml) für 1 h. Die Detektion erfolgte mithilfe eines polyklonalen Maus antiCaveolin pY14 IgG und eines sekundären Alexa Fluor 488 Ziege anti-Maus IgG. (A) zeigt die Phosphorylierung einer einzelnen Zelle 400-fach vergrößert. Man erkennt, dass sich die Phosphorylierung auf den gesamten Zellkörper und die Fortsätze erstreckt und zum Teil punktförmig verstärkt ist; (B) zeigt einen Ausschnitt, in dem mehrere Zellen gleichzeitig phosphoryliert werden. 


\subsubsection{Quantifizierung der Caveolin pY14 nach Stimulation von Schweine-OL mit NGF}

Zur Quantifizierung der Caveolin pY14 unter NGF wurden Schweine-OL für 10 min, 1 h, 3 h, und 6 h mit NGF (100 ng/ml) stimuliert. Abb. 48 zeigt von jedem Ansatz einen solchen etwa 200 Zellen umfassenden Ausschnitt und vermittelt so einen Überblick über die Caveolin pY14 mit und ohne NGF. Dagegen liefert Abb. 49 etwas genauere Daten, weil in ihr pro Ansatz 3x200 Zellen ausgezählt wurden, um daraus die mittlere prozentuale Anzahl der fluoreszierenden/phosphorylierten Zellen bezogen auf die gesamten ausgezählten Zellen zu ermitteln. Diese Quantifizierung zeigte, dass die Caveolin pY14 bereits nach 10-minütiger NGF-Exposition stark anstieg. Nach 6stündiger NGF Stimulation fluoreszierten nahezu viermal so viele Zellen.

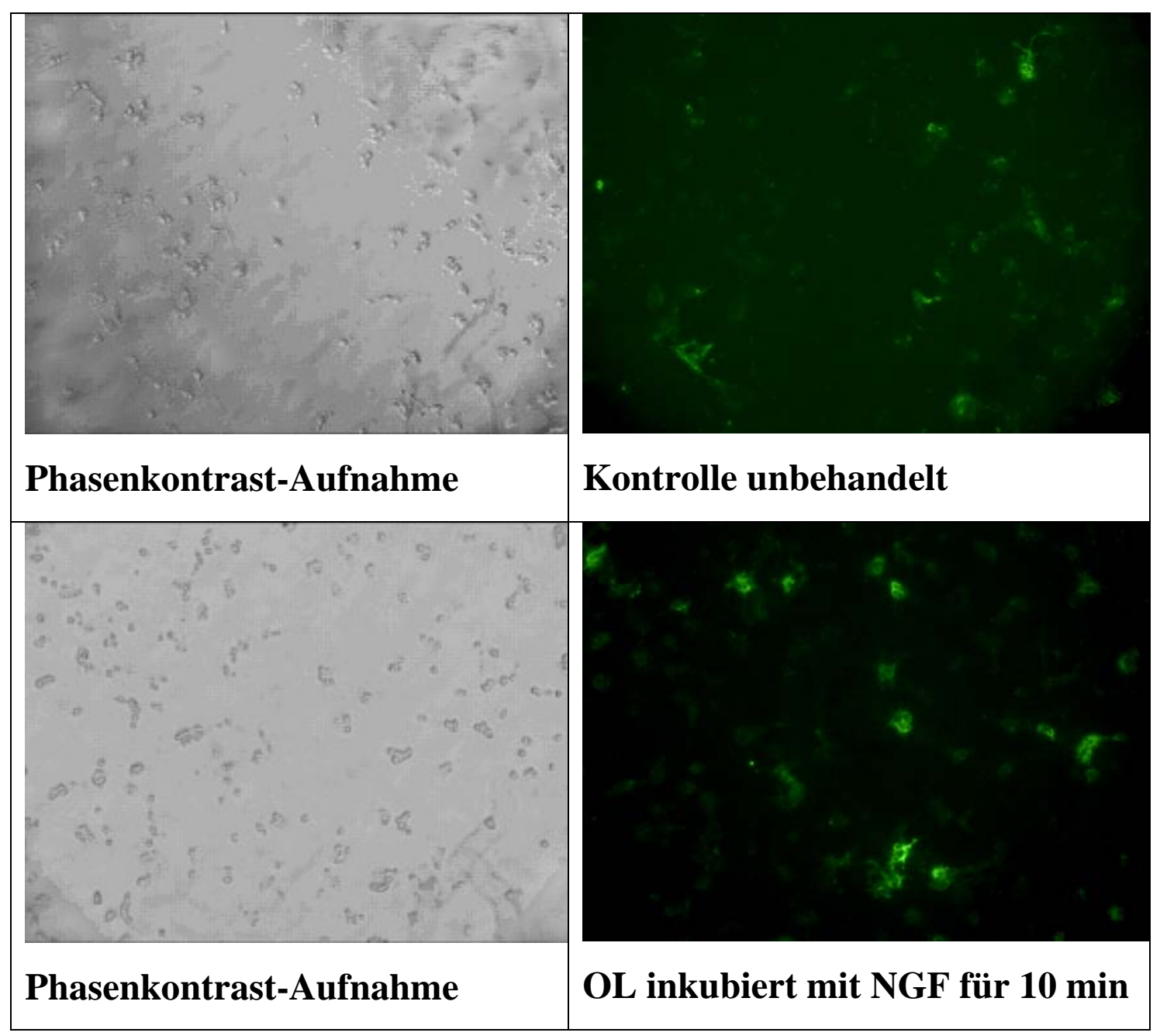




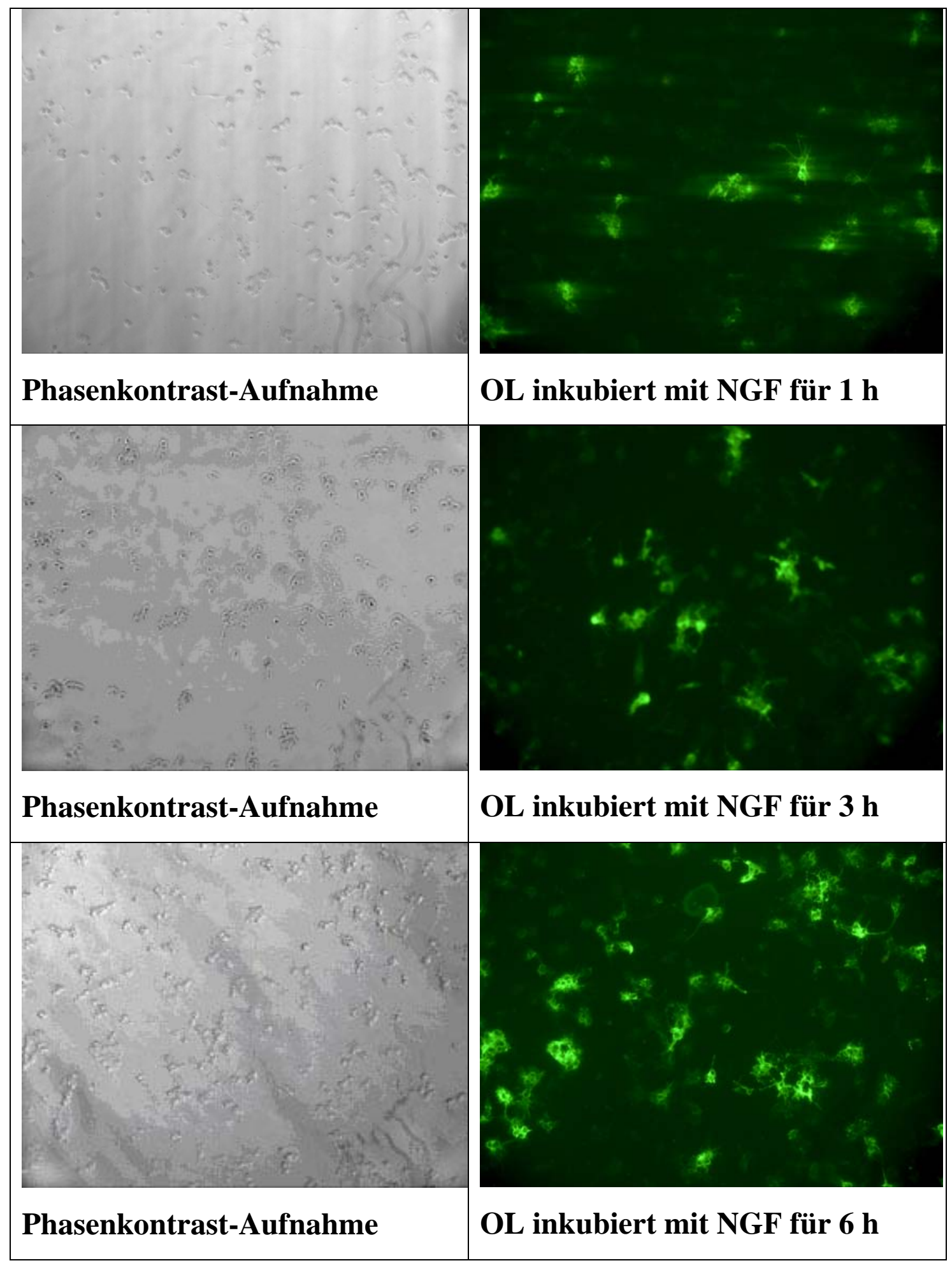

Abb. 48: Darstellung der Caveolin pY14 mit und ohne NGF. Die Phasenkontrast-

Aufnahmen wurden bei 100facher Vergrößerung aufgenommen und zeigen einen Ausschnitt von etwa 200 Zellen. Durch diese Form der Darstellung kann man grob das Verhältnis von phosphorylierten Zellen und nicht phosphorylierten Zellen abschätzen. Bei den mit NGF behandelten Kulturen waren die Caveolin phosphorylierten Zellen zahlreicher, als bei der unbehandelten Kontrolle. 


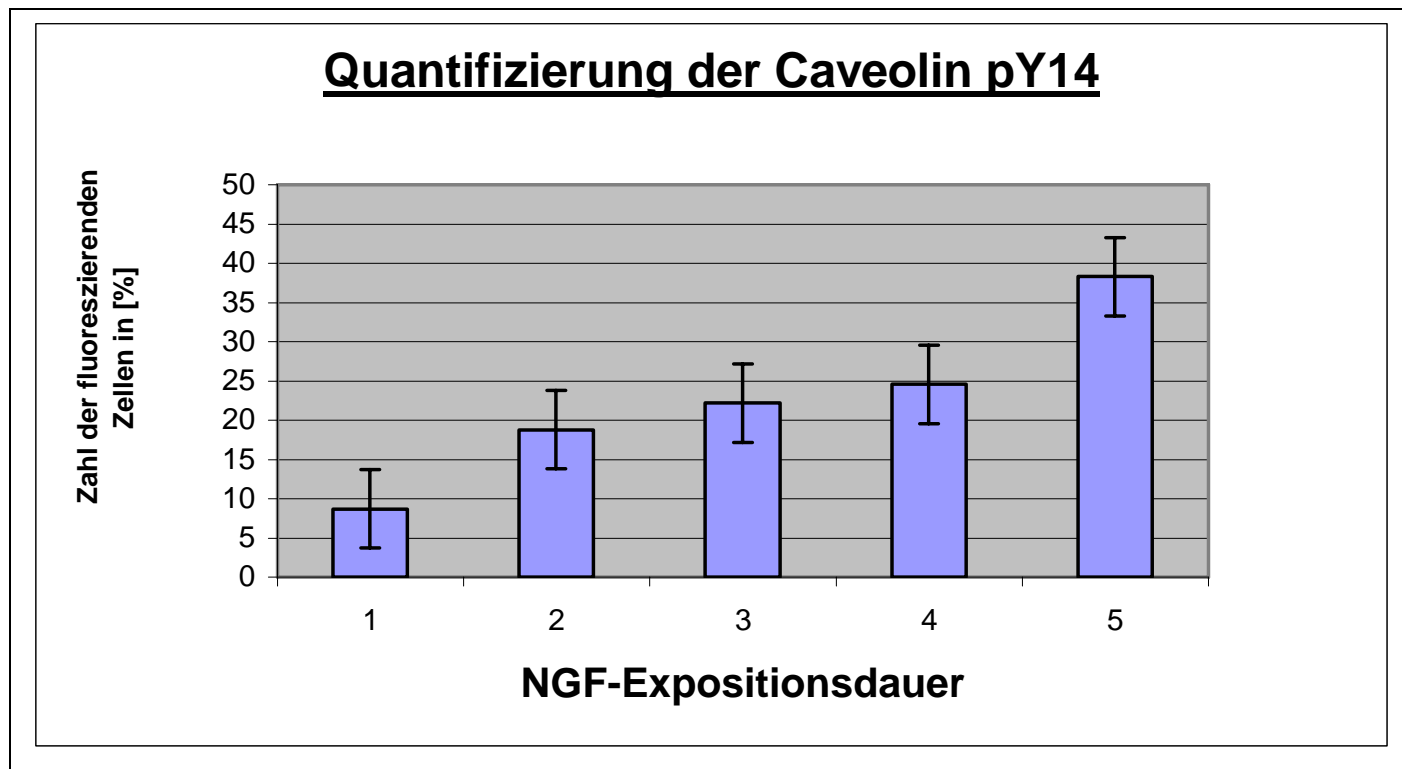

1) unbehandelte Zellen

2) OL inkubiert mit NGF für 10 min

3) OL inkubiert mit NGF für $1 \mathrm{~h}$

4) OL inkubiert mit NGF für $3 \mathrm{~h}$

5) OL inkubiert mit NGF für $6 \mathrm{~h}$

Abb. 49: Quantifizierung der Caveolin pY14 unter NGF. Die Graphik zeigt von ca. $3 \times 200$ ausgezählten Zellen die Anzahl der fluoreszierenden Zellen in [\%]. Man erkennt einen klaren Anstieg der Caveolin phosphorylierten Zellen nach Exposition mit NGF, deren Zahl sich bereits nach 10 min verdoppelt hatte und über einen Zeitraum von $6 \mathrm{~h}$ auf nahezu das Vierfache anstiegt. Um höhere statistische Aussagekraft zu erlangen, wurde diese Quantifizierung an zwei unterschiedlichen Zellpräparationen durchgeführt.

\subsubsection{Nachweis der NGF-induzierten Caveolin pY14 mittels Western Blot}

Nach der immunzytochemischen Darstellung der Caveolin pY14 erfolgte ein weiterer Nachweis mittels ECL Western Blot. Insgesamt wurden drei Ansätze untersucht. Neben der unbehandelten Kontrolle wurden Schweine-OL für 10 min und 6 h mit NGF (100 $\mathrm{ng} / \mathrm{ml}$ ) stimuliert. In Abb. 50 konnte ein signifikanter Anstieg der Caveolin pY14 nach NGF-Gabe dokumentiert werden. Der Western Blot ergab wie die immunzytochemische Färbung (3.14.2), dass die Caveolin pY14 im geringen Maße auch in unbehandelten Zellen vorkommt. 


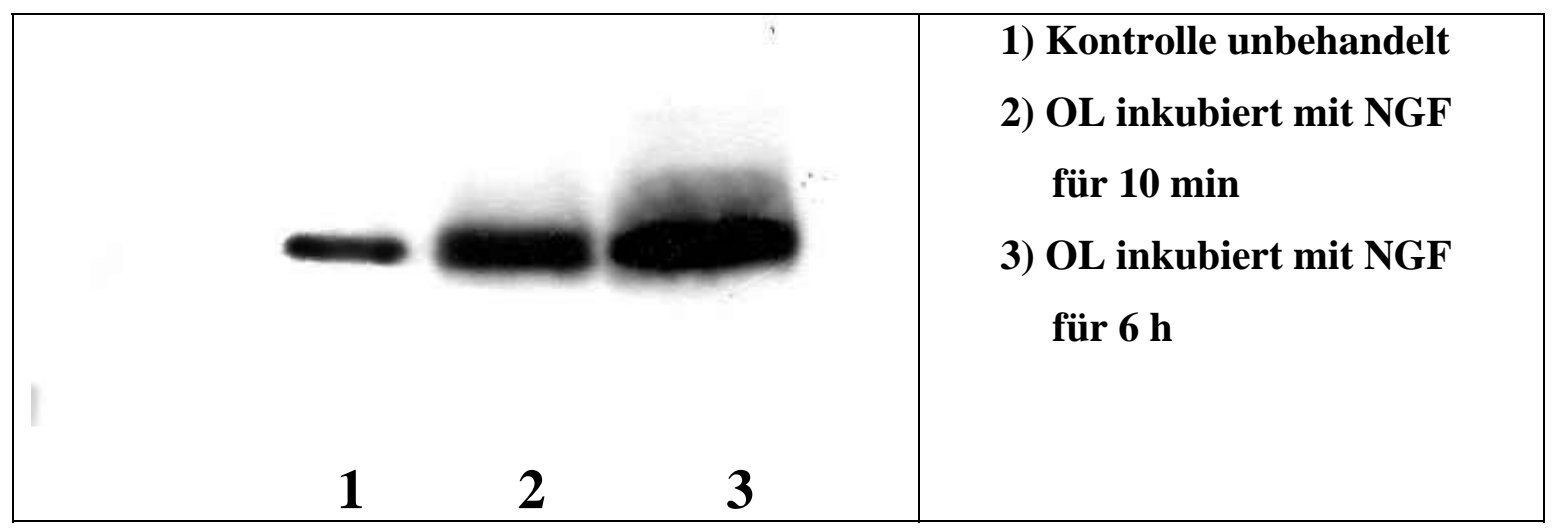

Abb. 50: Darstellung der Caveolin pY14 mittels ECL Western Blot. Die Detektion erfolgte mithilfe eines polyklonalen Maus anti-Caveolin pY14 IgG und zeigte eine Zunahme der Caveolin pY14 nach Gabe von NGF. Die Caveolin pY14 ist nur ein relativ kurzzeitiges Ereignis und trat unter NGF bereits nach 10 min auf. Daher ist eine Präinkubation mit Natrium-Orthovanadat für mindestens $1 \mathrm{~h}$ essentiell. Ein weiterer Anstieg der Caveolin pY14 wurde nach 6 h beobachtet.

\subsubsection{Inhibition der NGF-induzierten Caveolin-1 pY14 durch PP2 und durch K252a}

Als nächstes wurde die Wirkung der beiden Inhibitoren PP2, einem Src-Kinasespezifischen Inhibitor, und K252a, einem TrkA/Tyrosinkinase Inhibitor, auf die Caveolin pY14 unter NGF untersucht. Zu diesem Zweck wurden die Zellen vor NGFGabe für 30 min mit PP2 $(1 \mu \mathrm{M})$ und K252a $(1 \mu \mathrm{M})$ vorinkubiert. NGF wurde danach für $1 \mathrm{~h}$ ins Medium gegeben. Anhand der Caveolin pY14 Färbung in Abb. 51 erkennt man, dass die Inhibition der Src-Kinase und der Trk-Phosphorylierung zu einem deutlichen Rückgang der Caveolin pY14 unter NGF führten. Die Zahl der phosphorylierten Zellen unter NGF sank in etwa auf das Niveau einer unbehandelten Kontrolle. Dieser Versuch zeigt eine mögliche Abhängigkeit der Caveolin pY14 von Src-Kinasen und der Phosphorylierung von TrkA, wobei sich als nächstes die Frage nach der temporären Abfolge der Caveolin pY14 und der Phosphorylierung von TrkA stellt. 


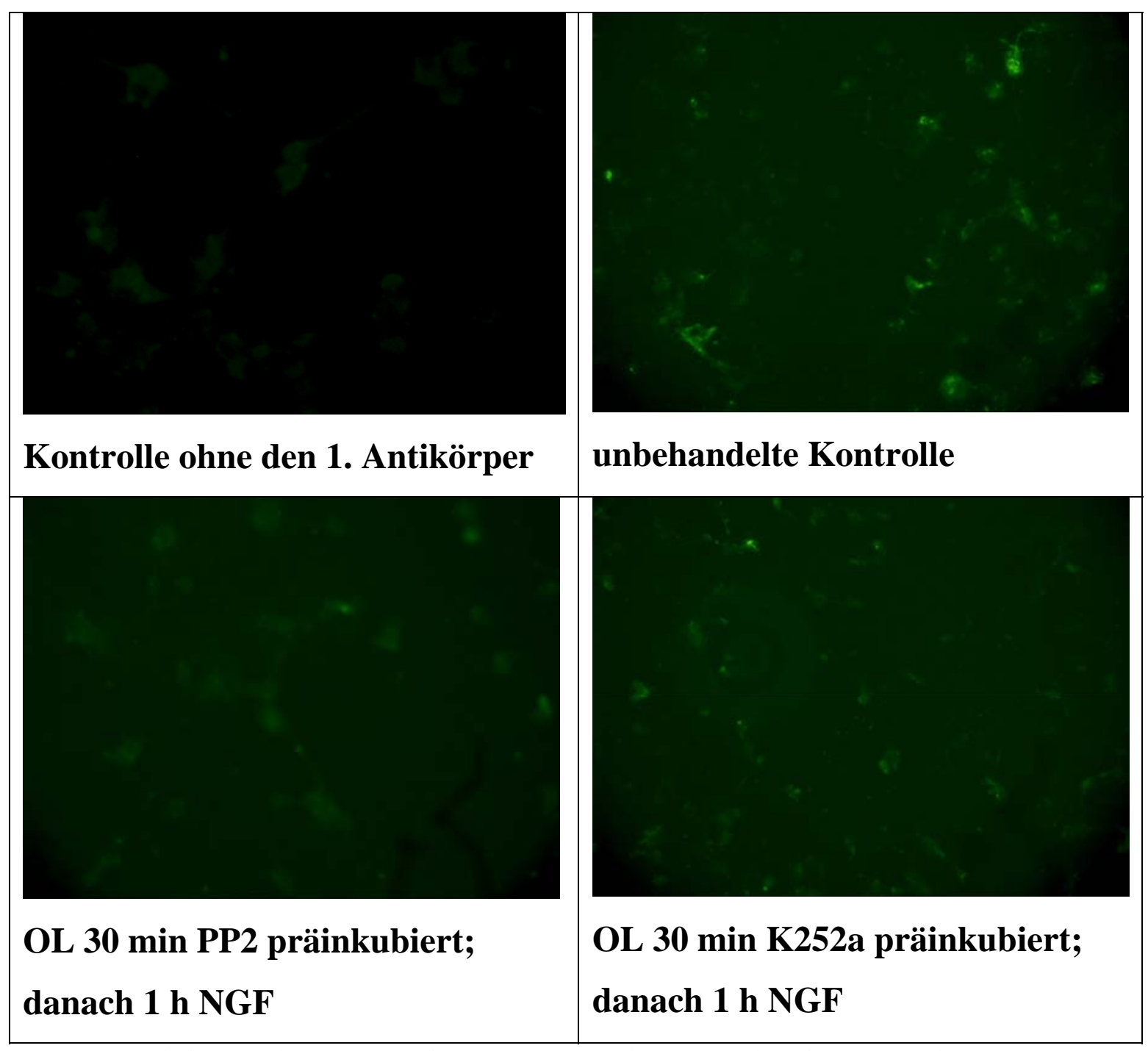

Abb. 51: Inhibition der NGF-induzierten Caveolin pY14 durch PP2 und K252a. Die Zahl der Caveolin pY14 Zellen nach NGF-Gabe ging deutlich in Folge der Inhibition der Src-Kinase und TrkA-Phosphorylierung zurück; hieraus lässt sich eine potentielle Abhängigkeit der Caveolin pY14 von Src-Kinasen und einer TrkA-Phosphorylierung ableiten, Vergrößerung 100fach.

\subsubsection{Anfärbung der Caveolin pY14 und der TrkA-Phosphorylierung}

Aus der NGF-Stimulation von Schweine-OL resultierte eine Phosphorylierung von TrkA und Caveolin pY14. Diese wurde mit einem Kaninchen anti-Phosphor-TrkA IgG detektiert. Mit einer Doppelfärbung sollte untersucht werden, ob die beiden Phosphorylierungen gleichzeitig innerhalb derselben Zelle erfolgen. Die Detektion der beiden Phosphorylierungen erfolgte schließlich mithilfe der Sekundärantikörper Alexa Fluor 546 Ziege anti-Maus IgG und Alexa Fluor 488 Ziege anti-Kaninchen IgG. Mit dieser Doppelfärbung gelang die gleichzeitige Detektion der Caveolin pY14 und der 
TrkA-Phosphorylierung in ein und derselben Zelle, was darauf hindeutet, dass beide Phosphorylierungen, im Laufe der NGF-Signalweiterleitung eine Rolle spielen (Abb. $52)$.

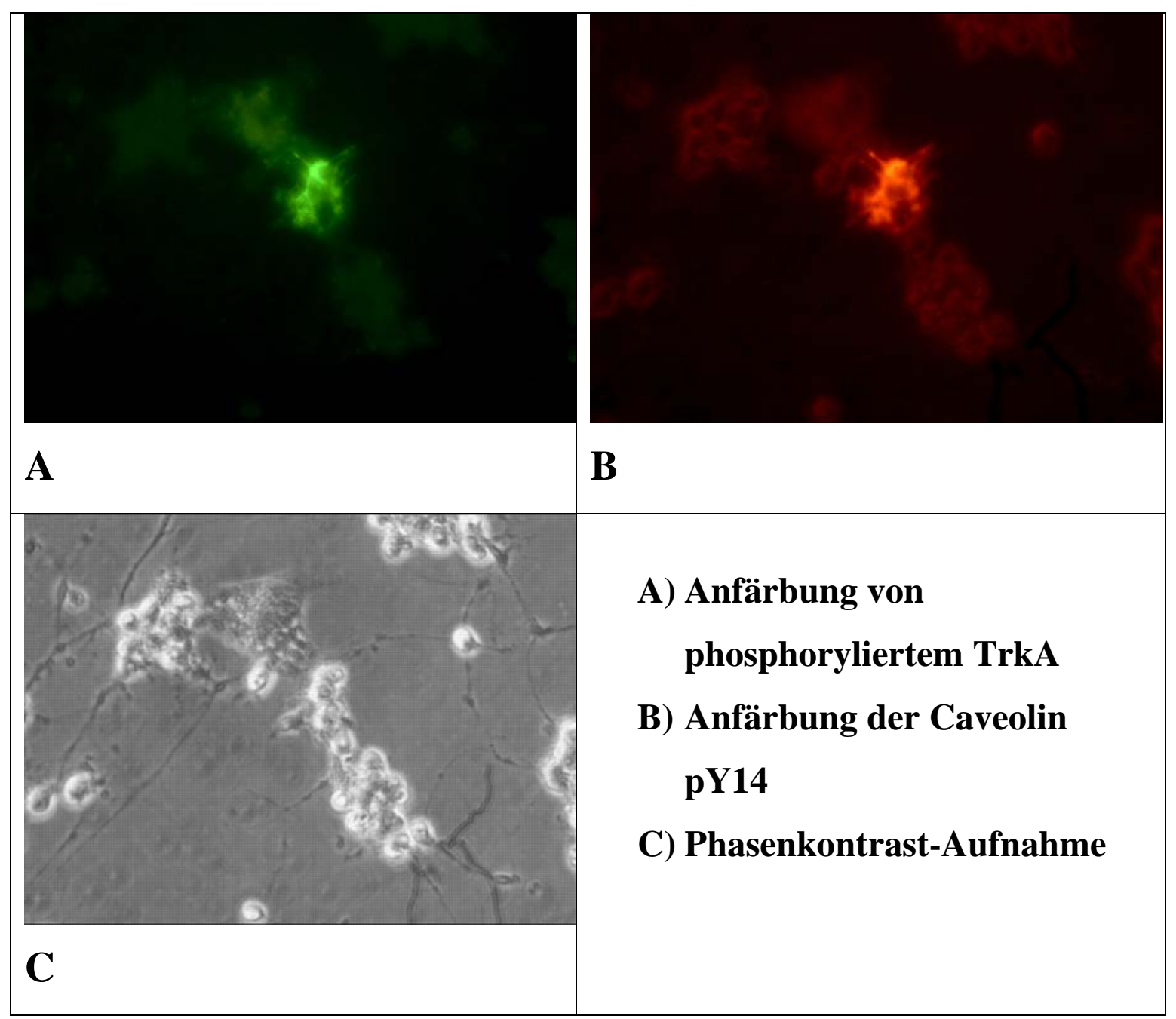

Abb. 52: Detektion der TrkA-Phosphorylierung und der Caveolin pY14 in SchweineOL. Nach 1-stündiger NGF-Stimulation konnte mithilfe dieser Doppelfärbung die gleichzeitige Phosphorylierung von TrkA und Caveolin-1 in derselben Zelle dokumentiert werden. Dies deutet darauf hin, dass bei der NGF-Signalgebung nicht nur die über TrkA ablaufende, sondern auch die über Caveolin eingetretene Phosphorylierung als zusätzlicher Faktor von Bedeutung ist.

Um auszuschließen, dass die beiden fluoreszierenden Sekundärantikörper miteinander kreuzreagieren, wurde TrkA mithilfe eines polyklonalen Kaninchen anti-TrkA IgG angefärbt. Neben dem rotfluoreszierenden spezifischen Alexa Fluor 546 Ziege antiKaninchen IgG wurden die Zellen zusätzlich mit dem unspezifischen und grünfluoreszierenden Alexa Fluor 488 Ziege anti-Maus IgG inkubiert. Dabei kam es 
zwischen den beiden sekundären Antikörpern zu keinerlei Kreuzreaktionen, da der unspezifische, grünfluoreszierende Ziege anti-Maus IgG lediglich eine schwache Hintergrundfärbung hinterließ (Abb. 53).

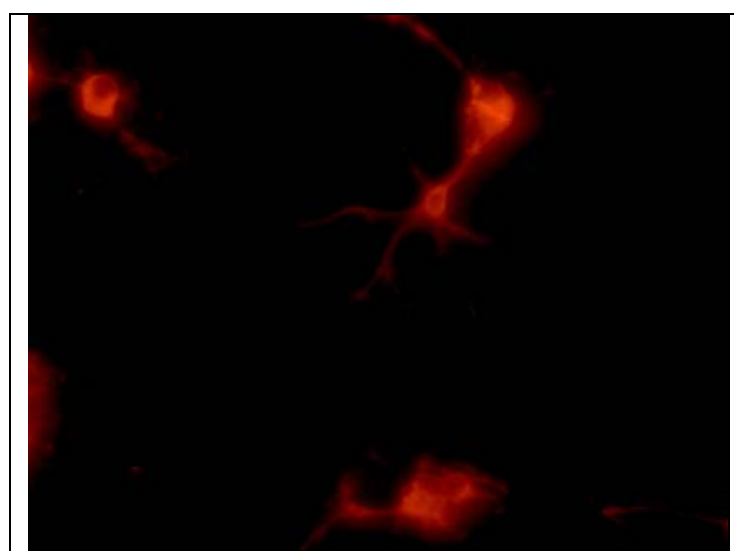

A

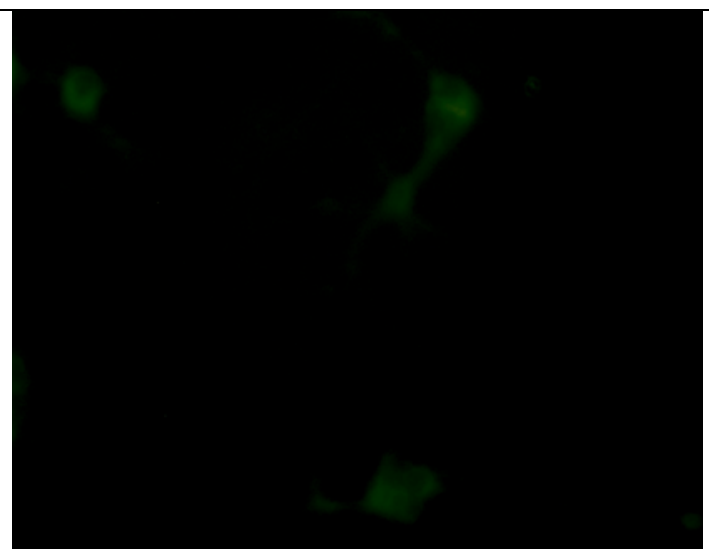

B

Abb. 53: TrkA-Kontrollfärbung in Schweine-OL. Hierdurch sollte gezeigt werden, dass die beiden sekundären Antikörper nicht miteinander kreuzreagieren. Zu diesem Zweck wurde TrkA mit einem polyklonalen Kaninchen anti-TrkA IgG, einem spezifischen Ziege anti-Kaninchen IgG (A) und dem unspezifischen Ziege anti-Maus IgG (B) angefärbt. Die ausbleibende Grünfärbung bewies, dass mögliche Artefakte durch Kreuzreaktion der beiden Sekundärantikörper unwahrscheinlich sind, Vergrößerung 400fach.

\subsection{Einfluss von Cholesterin auf die Signalgebung in Schweine-OL unter NGF}

Als wichtiger Bestandteil von CMD sollte in den folgenden Versuchen geklärt werden, welche Rolle Cholesterin bei der NGF-Signaltransduktion spielt.

\subsubsection{Aufnahme von Cholesterin}

Um den Effekt von exogenem Cholesterin auf die Fortsatzbildung von Schweine-OL näher untersuchen zu können, wurde zwecks Wasserlöslichkeit an PEG-gebundenes Cholesterin verwendet. Immunzytochemisch wurde die Cholesterin-Aufnahme durch Fluorescein-gekoppeltes PEG (FPEG)-Cholesterin $(1 \mu \mathrm{M})$ dokumentiert (ISHITSUKA 
et al., 2005). Nach 15 min reicherte sich das FPEG-Cholesterin zunächst in der Plasmamembran an (Abb. 54 A1, A2), ehe es 24 h später zu einer Aggregation von FPEG-Cholesterin im Bereich des Golgi-Apparates bzw. des Endoplasmatischen Reticulums kam (Abb. 54 B1, B2). Erkennbar war dies an einer Zunahme der Fluoreszenzintensität innerhalb der Zelle.

Als nächstes sollte die Cholesterin-Aufnahme quantifiziert werden. Dazu wurden OL (8 DIV) für 24 h mit PEG-600 Cholesterin behandelt. Die Aufnahme des Cholesterins wurde in einem Cholesterintest mit und ohne Zugabe von PEG-600-gekoppeltem Cholesterin gemessen. Anhand von Abb. $54 \mathrm{C}$ ist zu erkennen, dass sich der GesamtCholesterinspiegel nach Gabe von PEG-600 Cholesterin in 24 h durchschnittlich um über 50\% erhöht; dagegen hatte PEG-600 alleine keinen Einfluss auf den CholesterinLevel der Zellen.

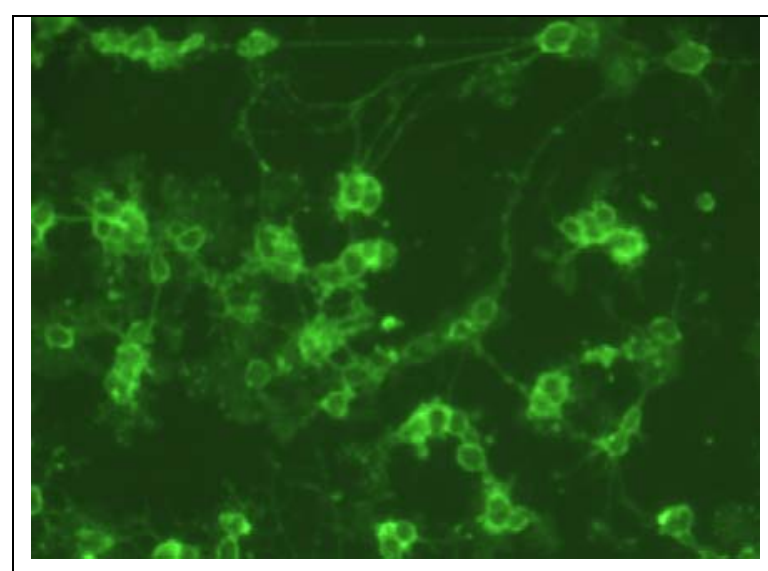

A1 Cholesterinaufnahme nach $15 \mathrm{~min}$

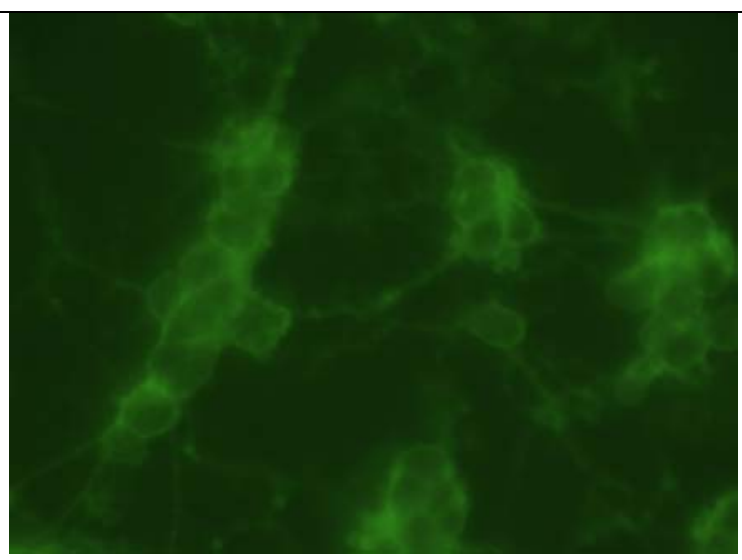

A2 Cholesterinaufnahme nach 15 min

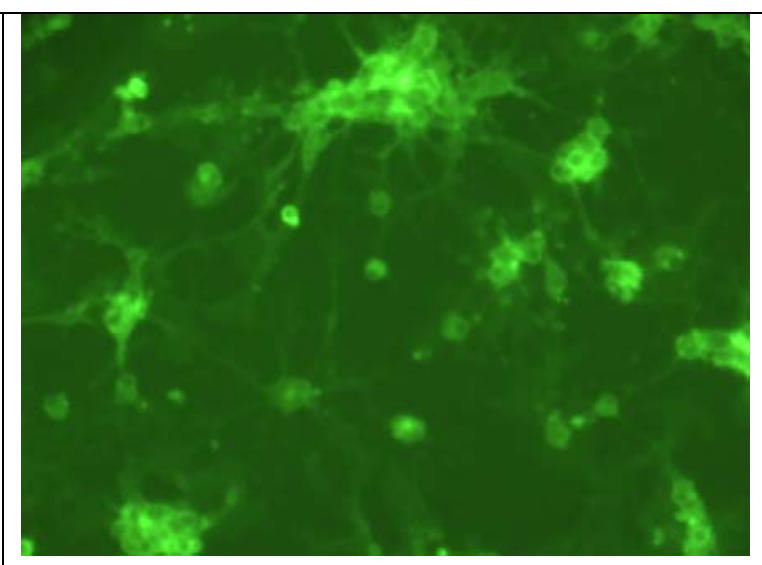

\section{B1 Cholesterinaufnahme nach $24 \mathrm{~h}$}

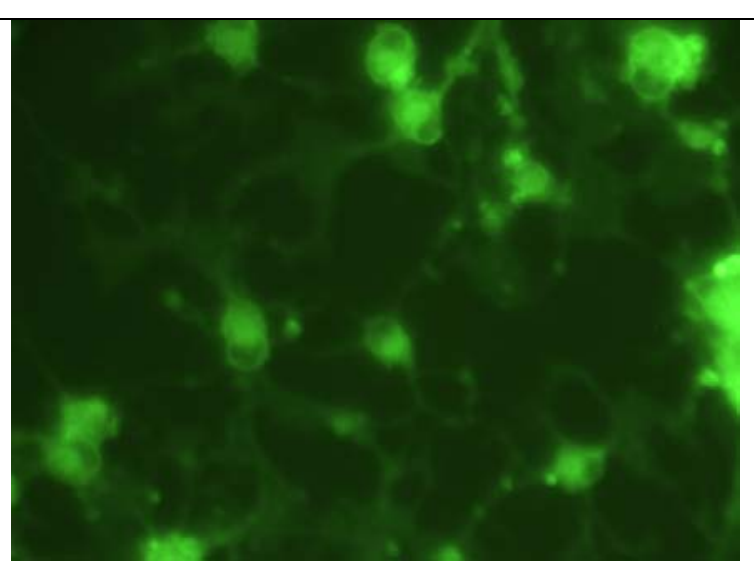

B2 Cholesterinaufnahme nach $24 \mathrm{~h}$ 


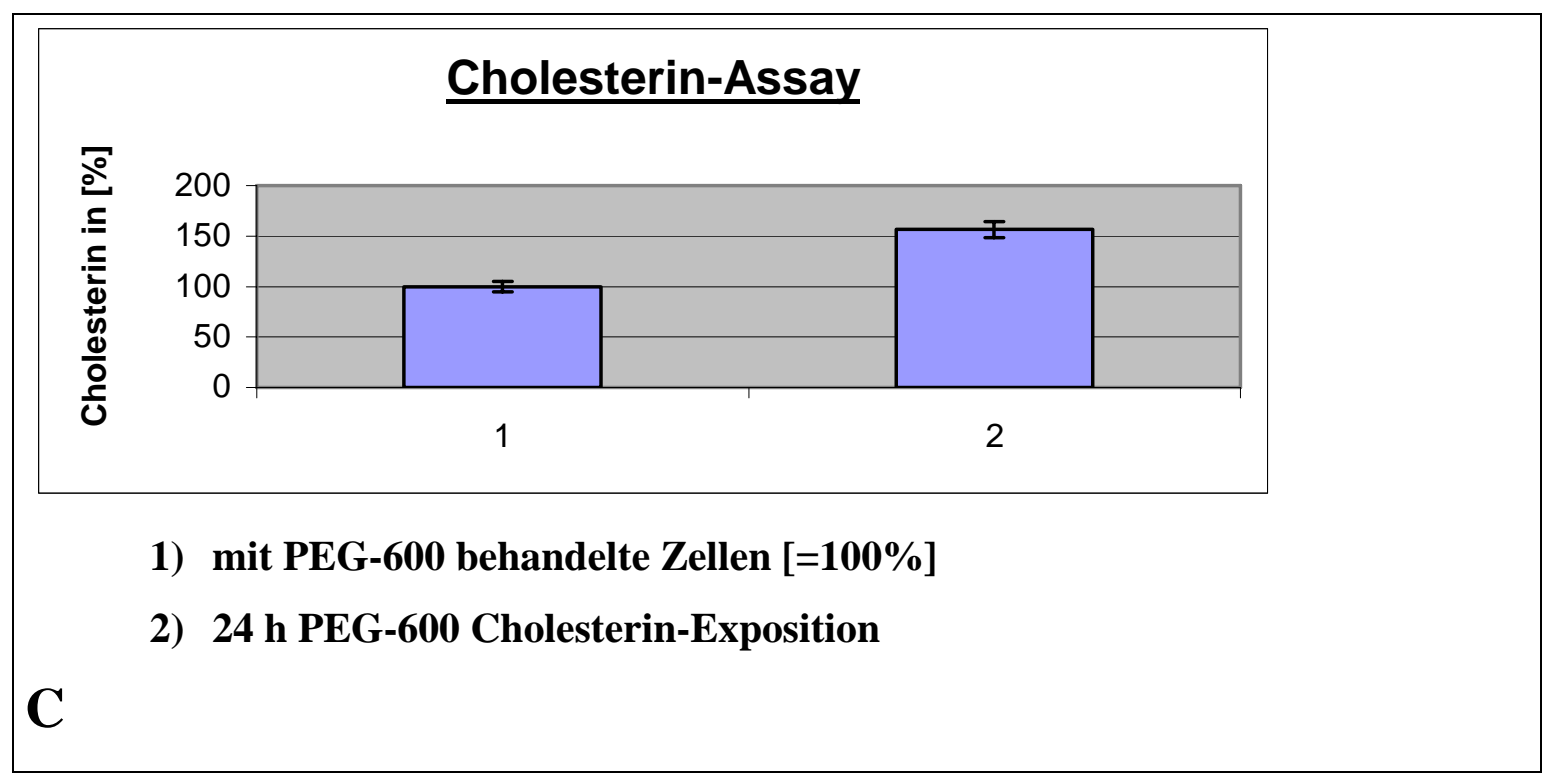

Abb. 54: Cholesterinaufnahme von adulten Schweine-OL. Immunzytochemische Darstellung der FPEG-Cholesterinaufnahme nach 15 min (A1, A2) und 24 h (B1, B2) bei einer Vergrößerung von 200fach (A1, B1) bzw. 400fach (A2, B2). Das FPEGCholesterin sammelte sich nach 15 min in der Plasmamembran an (A1, A2), erkennbar anhand des fluoreszieren Randbereiches. Nach etwa 24 h kam es zu einer Aggregation des FPEG-Cholesterin im Golgi-Apparat bzw. im Endoplasmatischen Reticulum (B1, B2). In (C) wurde zwecks Quantifizierung die Cholesterinaufnahme nach 24 h mithilfe eines Cholesterin Detection Kits (Amplex Red Assay) bestimmt. Dabei stieg nach 24stündiger Cholesterin-Exposition der intrazelluläre Cholesterin-Level um durchschnittlich 56\% im Vergleich zur mit PEG-600 behandelten Kontrolle an.

\subsubsection{Morphologische Charakterisierung von Schweine-OL nach Gabe von PEG-600 Cholesterin}

Zunächst wurde PEG-600 Cholesterin in einer Konzentration von $100 \mu \mathrm{g} / \mathrm{ml}$ auf Schweine-OL (8 DIV) gegeben. Nach 48 h wurde die Fortsatzbildung der OL als morphologisches Kriterium bei der Bewertung eines möglichen Einflusses von Cholesterin herangezogen. Dabei wirkte sich die Gabe von PEG-600 Cholesterin im Vergleich zu den mit PEG-600 behandelten Kontrollzellen positiv auf das Fortsatzwachstum aus, denn mit Cholesterin behandelte Kulturen bildeten nach $48 \mathrm{~h}$ wesentlich mehr Fortsätze als die Kontrolle aus (Abb. 55). Mit PEG-600 behandelte Kontrollzellen unterschieden sich morphologisch kaum von unbehandelten Zellen, was zeigt, dass PEG-600 alleine keine Wirkung auf OL hat. 


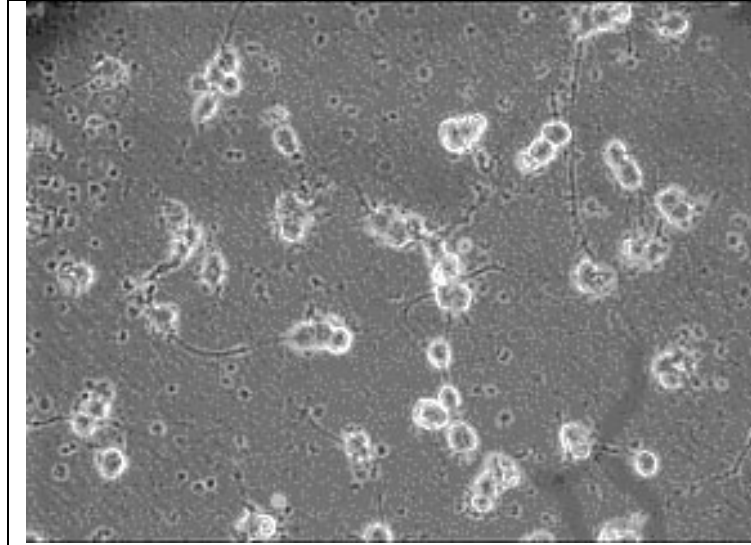

A Kontrolle 48 h PEG-600

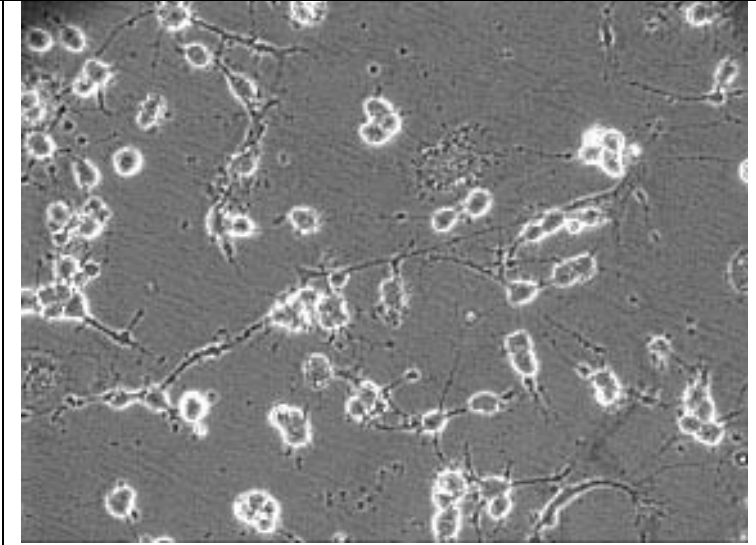

B 48 h PEG-600 Cholesterin

Abb. 55: Einfluss von exogenem PEG-600 Cholesterin auf die Fortsatzbildung von Schweine-OL. Vergleicht man die PEG-600 Kontrolle (A) mit der PEG-600 Cholesterin stimulierten Probe (B), so scheint Cholesterin die Fortsatzbildung zu begünstigen, Vergrößerung 200 fach.

\subsubsection{Kombination von PEG-600 Cholesterin und NGF}

In einem weiteren Experiment sollte untersucht werden, wie sich die gleichzeitige Gabe von NGF und PEG-600 Cholesterin auf die Fortsatzbildung von Schweine-OL auswirkt. Schweine-OL wurden dazu mit 100 ng/ml NGF und 100 g/ml PEG-600 Cholesterin für $24 \mathrm{~h}$ stimuliert. Die Kombination von NGF und Cholesterin wirkte sich dabei positiv auf die Fortsatzbildung aus, denn schon nach $24 \mathrm{~h}$ wiesen die Zellen, die mit Cholesterin und NGF behandelt wurden, wesentlich mehr Fortsätze auf (Abb. 56), als jene mit NGF. NGF alleine benötigt etwa $48 \mathrm{~h}$ für ein bedeutendes Fortsatzwachstum. Dieses ließ sich durch den Zusatz von Cholesterin beschleunigen. 


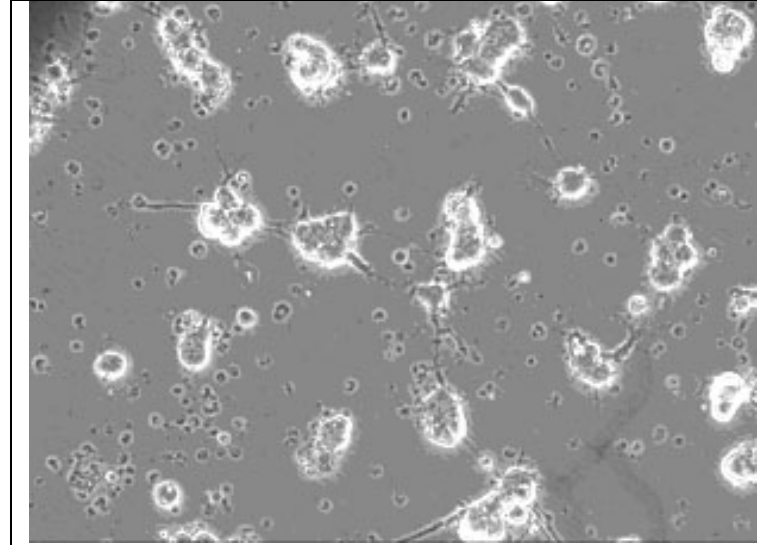

A OL nach Inkubation mit NGF für $24 \mathrm{~h}$

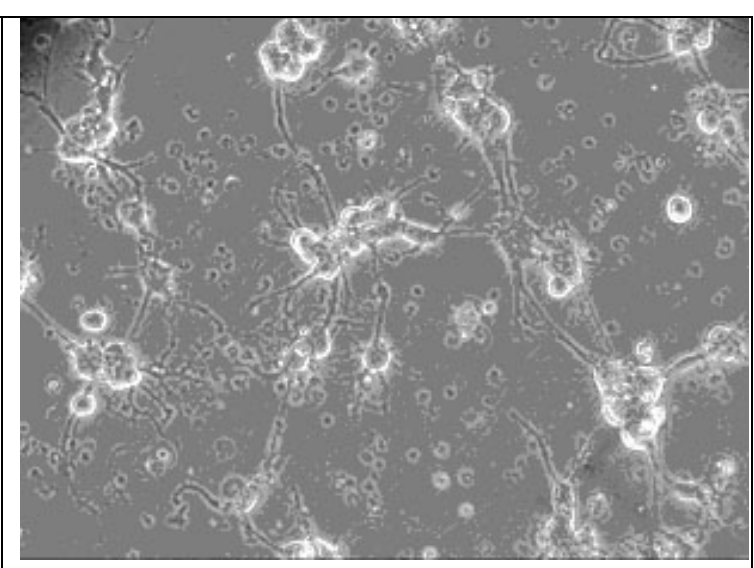

B OL nach Inkubation mit

Cholesterin und NGF für $24 \mathrm{~h}$

Abb. 56: Morphologischer Vergleich des Fortsatzwachstums von NGF und NGF in Kombination mit PEG-600 Cholesterin. Diese Kombination hat einen additiven Effekt auf das Fortsatzwachstum von OL, da bereits nach 24 h ein deutlicher Unterschied zu NGF alleine erkennbar ist.

\subsubsection{Wirkung von PEG-600 Cholesterin auf die Expression von Caveolin-1}

Durch morphologische Analyse konnte ein positiver Einfluss von Cholesterin auf die Fortsatzbildung von Schweine-OL beobachtet werden. Zudem resultierte aus der NGFinduzierten Fortsatzbildung eine Erhöhung der Caveolin-1-Expression. In einem weiterführenden Experiment wurde nun der Caveolin-1-Level von Zellen (8 DIV) untersucht, die für $48 \mathrm{~h}$ mit Cholesterin $(100 \mu \mathrm{g} / \mathrm{ml})$ inkubiert wurden. Anhand eines Western Blots konnte ein leichter Anstieg der Caveolin-1-Expression detektiert werden (Abb. 57). Dieser war allerdings deutlich geringer als nach 48-stündiger NGF Inkubation.

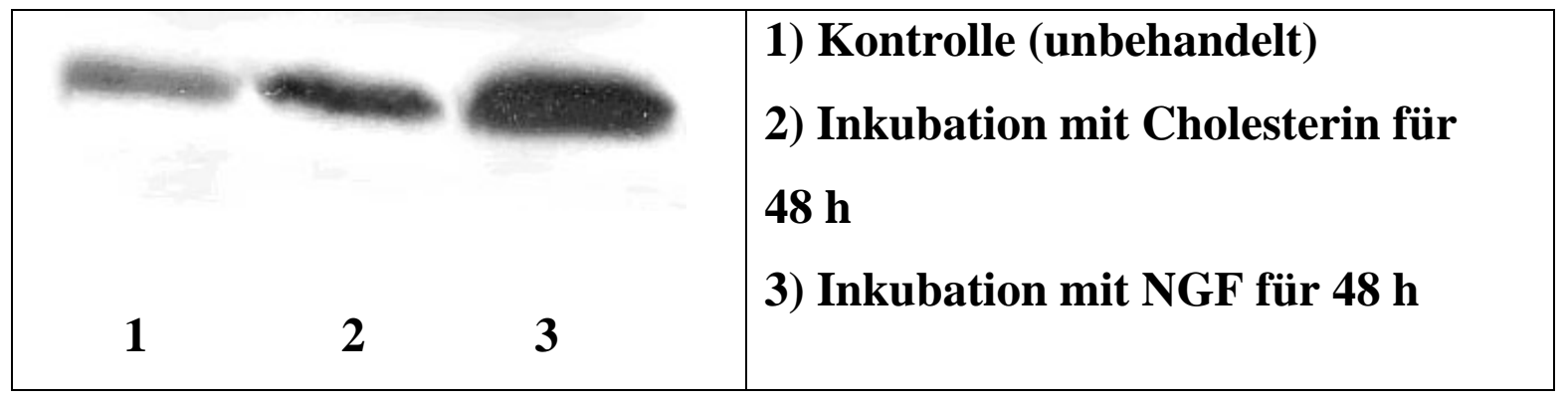




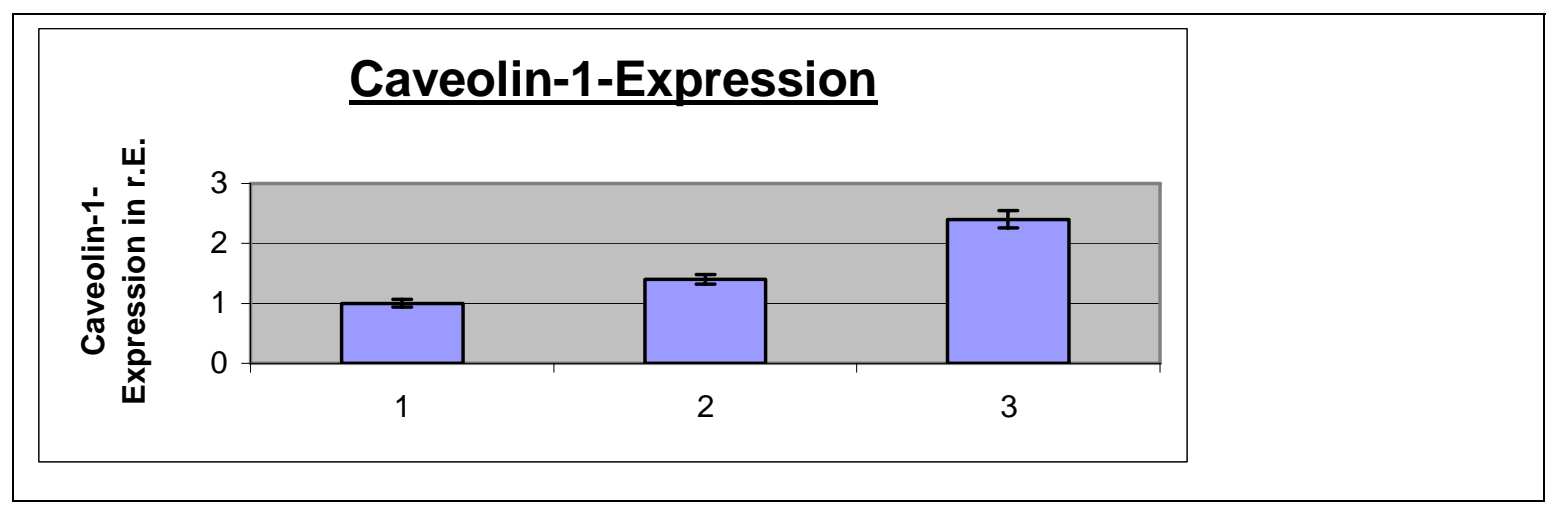

Abb. 57: Steigerung der Caveolin-1-Expression nach Behandlung von OL mit exogenem PEG-600 Cholesterin. Die Cholesterin-bedingte Erhöhung der Caveolin-1Expression (2) lag deutlich unter der NGF induzierten Erhöhung (3).

\subsubsection{Einfluss der Kombination von Cholesterin und NGF auf die MAPK-Aktivität}

Da die Kombination von Cholesterin und NGF einen additiven Effekt auf die Fortsatzbildung hatte, wurde dieser Effekt in einem renaturierenden "In-Gel Kinase Assay“, bei dem die Aktivierung der MAPK Erk1 und Erk2 bestimmt wird, untersucht. Die Auswertung des MAPK-Aktivitätsassays bestätigte diese Hypothese. Eine 24stündige Präinkubation mit PEG-600 Cholesterin erwies sich als wirkungsvoll, da der gewohnte Anstieg der MAPK-Aktivität nach NGF-Stimulation hierdurch übertroffen wurde (Abb. 58). Die Effekte von Cholesterin und NGF schienen sich bei der Aktivierung der MAPK zu addieren.

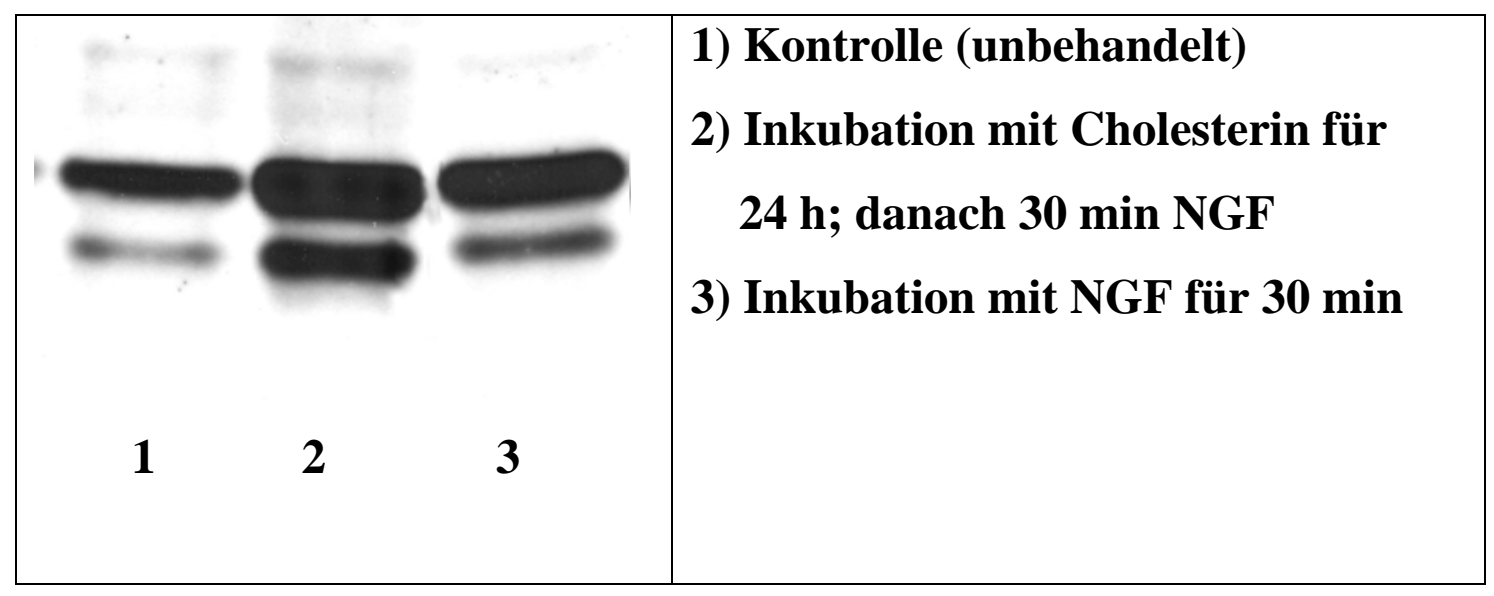




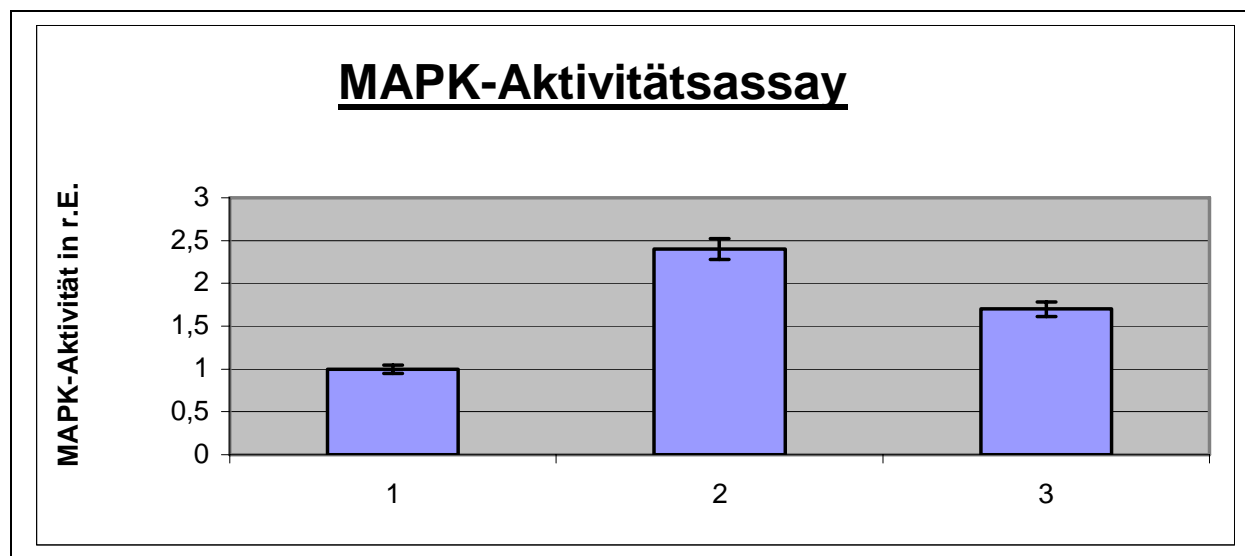

Abb. 58: Einfluss der Kombination von PEG-600 Cholesterin und NGF auf die MAPK-Aktivität. Die Präinkubation mit Cholesterin $(100 \mu \mathrm{g} / \mathrm{ml})$ ließ die Aktivität der MAPK nach 30-minütiger NGF-Stimulation stärker ansteigen (2), als mit NGF allein ohne Cholesterin (3). Unbehandelte Kontroll-OL wiesen eine Grundaktivität von Erk1 und Erk2 auf, die den Unterschied zu den stimulierten Proben deutlich werden lässt (1).

\subsubsection{Reduzierung des Cholesterin-Levels mithilfe von Methyl-ß- Cyclodextrin}

In einer zeitabhängigen Versuchsreihe wurde die Cholesterinabnahme in Schweine-OL nach Gabe von Methyl-ß-Cyclodextrin [10 mM] ins Zellmedium gemessen. Dabei veränderte sich der Cholesterin-Level in den ersten 10 min nur geringfügig; erst nach 30-40 min kam es zu einer deutlichen Cholesterinabnahme von über 40\% (Abb. 59).

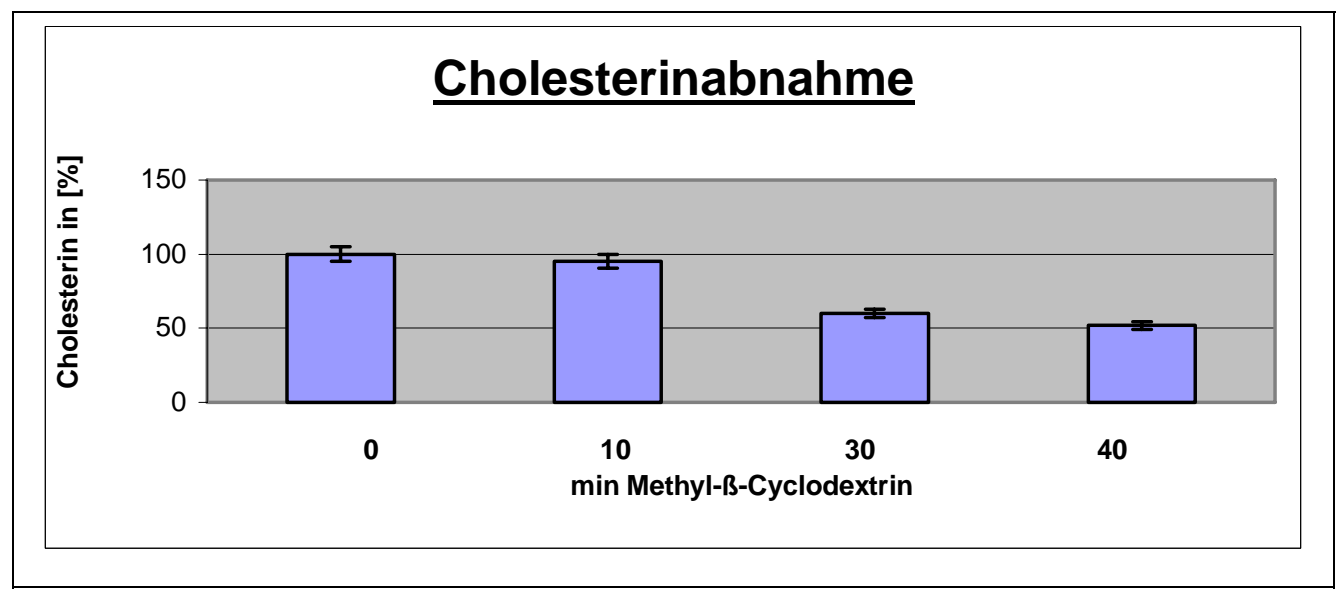

Abb. 59: Abnahme des Cholesterin-Levels nach Inkubation mit Methyl-ßCyclodextrin (10 mM). Der unbehandelten Kontrolle wurde der Wert 100\% zugeordnet. Nach 40-minütiger Methyl-ß-Cyclodextrin Inkubation wurde der Cholesteringehalt der Zellen um über $40 \%$ reduziert. 


\subsubsection{Morphologische Auswirkungen eines durch Methyl-ß- Cyclodextrin herbeigeführten Cholesterinmangels}

Für Versuche, bei denen OL über einen längeren Zeitraum mit Methyl-ß-Cyclodextrin inkubiert wurden, war eine Methyl-ß-Cyclodextrin Konzentration von $10 \mathrm{mM}$ zu hoch, da diese Konzentration spätestens nach 1,5 h zum Ablösen der Zellen vom Plattenboden geführt hätte. Daher wurden OL-Kulturen (8 DIV) für 3 DIV mit 3 mM Methyl-ßCyclodextrin behandelt. Der ausgelöste Cholesterinmangel bewirkte, dass die Zellen ihre Fortsätze einzogen und nach 2-3 Tagen zu großen Zellhaufen verklumpten (Abb. 60B). Dieser Effekt war reversibel, denn das Entfernen von Methyl-ß-Cyclodextrin durch einen Mediumwechsel, bei gleichzeitiger Gabe von PEG-600 Cholesterin, führte zum Auflösen der Zellhaufen (Abb. 60C-E). Auf diese Weise ließen sich die Zellen innerhalb von einer Woche beinahe vollständig regenerieren (Abb. 60E).

Um nachzuweisen, dass es sich nach Auflösung der Zellhaufen nach wie vor um adulte OL handelt, wurden diese einer MOSP-Färbung unterzogen, an deren Ende man sie klar als solche identifizieren konnte.
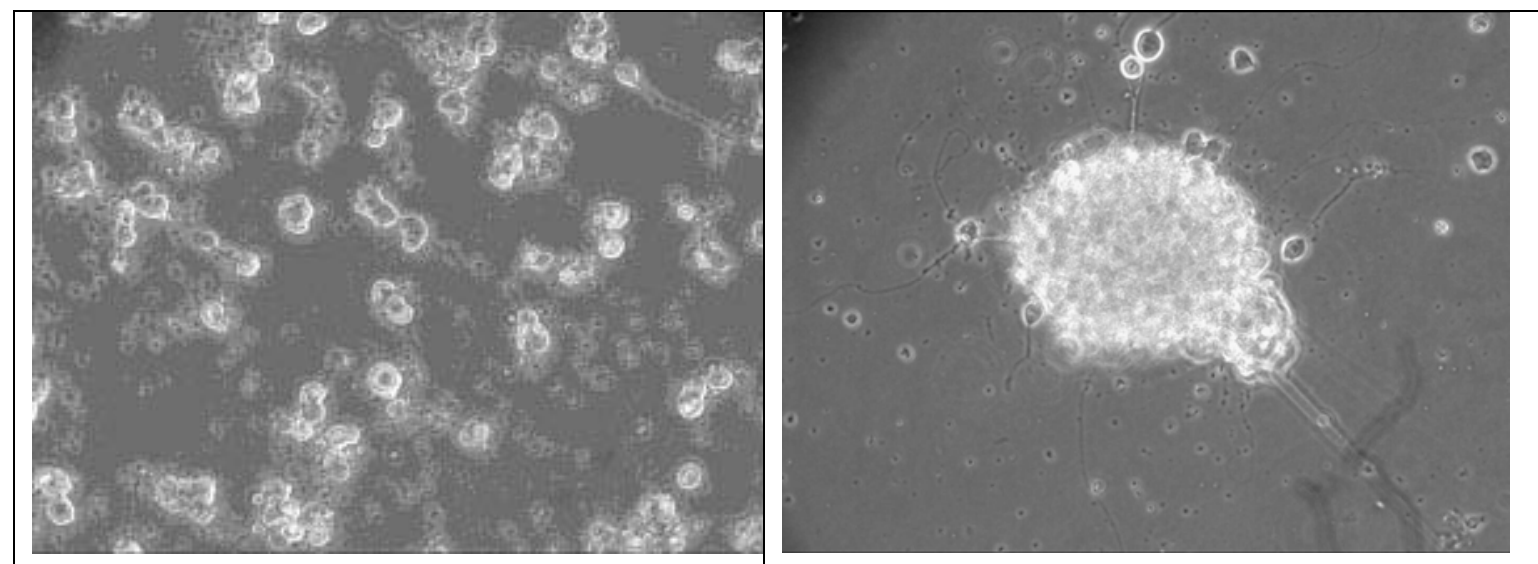

A Inkubation für 24 h mit Methyl-ßCyclodextrin [3 mM]

B Inkubation für 3 Tage mit Methyl-ßCyclodextrin [3 mM] 


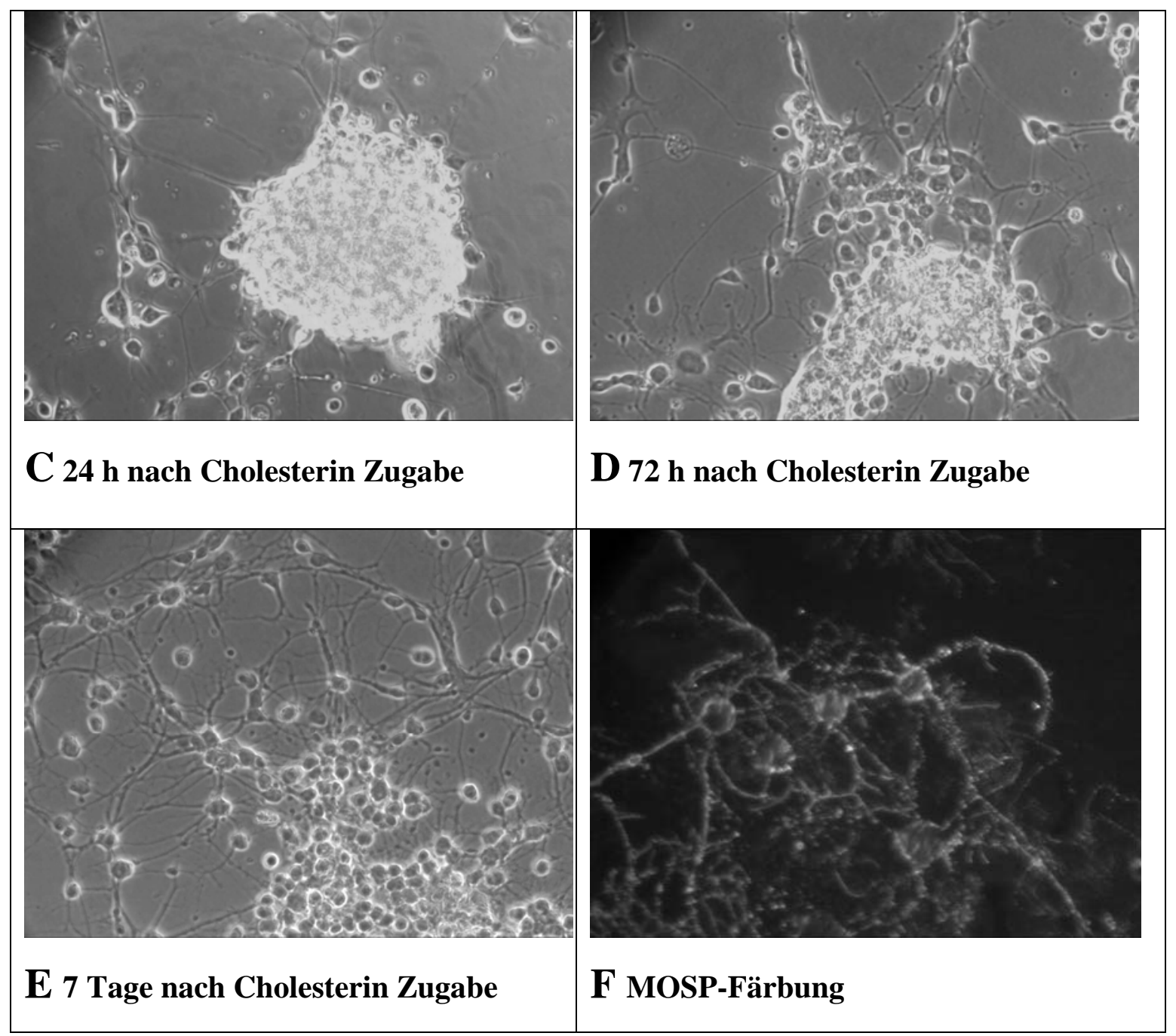

Abb. 60: Morphologische Auswirkungen eines Cholesterinmangels. Durch Methyl- $\beta$ Cyclodextrin [3 mM] wurde bei OL (8 DIV) ein Cholesterinmangel ausgelöst. Die Zellen zogen darauf ihre Fortsätze ein und lagerten sich mit anhaltender Kulturdauer zu einzelnen Zellhaufen zusammen. Diese Zellhaufen lösten sich durch Wegnahme von Methyl-ß-Cyclodextrin und den Zusatz von Cholesterin $(100 \mu \mathrm{g} / \mathrm{ml})$ wieder auf und regenerierten vollständig. Die abschließende MOSP-Färbung diente der Identifikation adulter OL.

\subsubsection{Auswirkung eines Cholesterinmangels auf die MAPK-Aktivität nach NGF-Stimulation}

Um den Cholesterinspiegel in den Zellen zu senken, wurde ein Ansatz mit $10 \mathrm{mM}$ Methyl-ß-Cyclodextrin sowie ein weiterer Ansatz mit (2-Hydroxypropyl)-ßCyclodextrin (10 mM) für 40 min präinkubiert. Außerdem wurde eine unbehandelte und eine für 4 h mit NGF (100 ng/ml) stimulierte Probe eingesetzt. Die Auswertung des 
MAPK-Assays (Abb. 61) zeigte, dass die MAPK-Aktivität nach 4-stündiger NGFStimulation bei den Zellen mit Cholesterinmangel bedeutend niedriger war. Dies war bei beiden Cyclodextrin-Modifikationen zu beobachten.

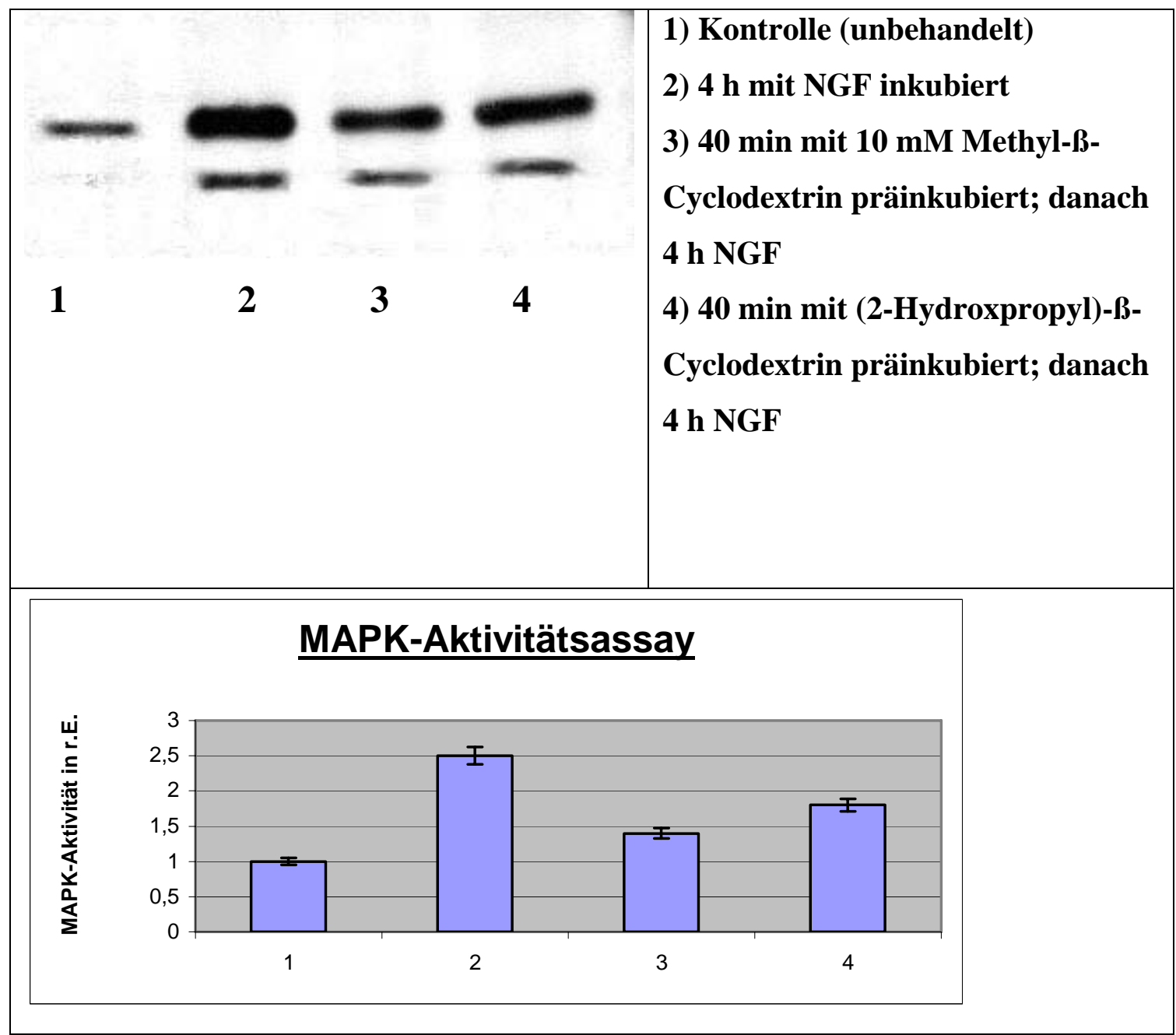

Abb. 61: Auswirkung eines Cholesterinmangels auf die NGF-induzierte Aktivierung der МАРК. Hierbei diente die Intensität der MAPK-Aktivität als Indikator für die Fortsatzbildung. Durch den Cholesterinmangel wurde die MAPK-Aktivität unter NGF deutlich abgeschwächt. Dies ließ sich bei beiden Cyclodextrin-Modifikationen beobachten. 
3.15.9 Bestimmung des Cholesterin-Levels von Schweine-OL, die mit NGF stimuliert wurden

Die in Schweine-OL enthaltene Cholesterinmenge wurde in diesem Versuch in Abhängigkeit zur NGF-Expositionsdauer betrachtet. Dafür wurden 8 Tage alte Primärkulturen für die Dauer von 24 h, 48 h und 96 h mit NGF (100 ng/ml) stimuliert. Anschließend wurde der Gesamtcholesteringehalt der Zellen bestimmt. Dieser nahm mit zunehmender NGF-Expositionsdauer allmählich ab und lag nach 96-stündiger NGF Stimulation ca. 20\% unter dem Kontrollwert, der mit 100\% angegeben wurde.

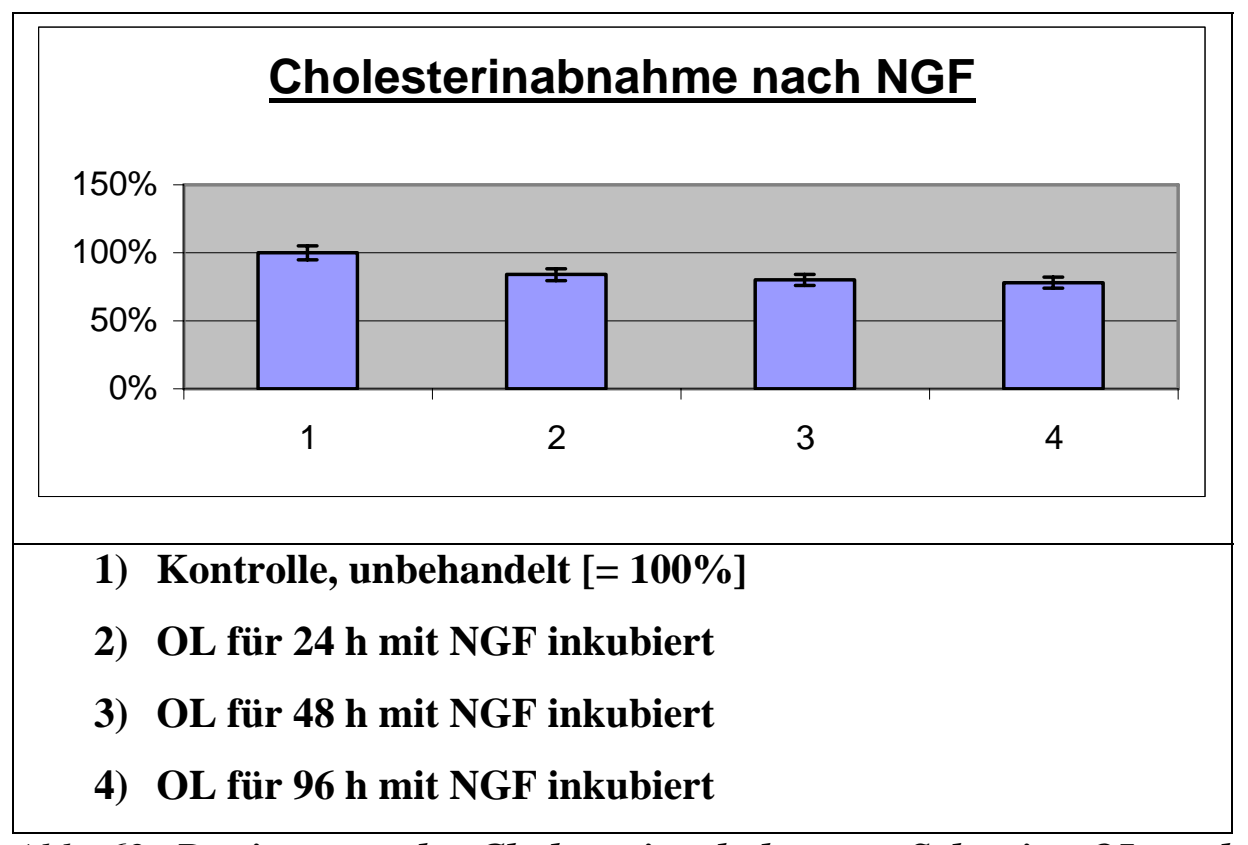

Abb. 62: Bestimmung des Cholesteringehaltes von Schweine-OL nach zunehmender NGF-Expositionsdauer. Der Cholesteringehalt einer unbehandelten Kontrolle diente als Bezugswert [100\%]. Stimuliert man Schweine-OL mit NGF, so führt dies zu einer anhaltenden Senkung des zellulären Cholesterinspiegels nach 96 h um ca. 20\%.

\subsubsection{Beeinflussung des Cholesterin-Levels durch einen mittels siRNA herbeigeführten Caveolin-1-Knock-down}

Caveolin-1 besitzt eine erhöhte Bindungsaffinität zu Cholesterin und kann als Cholesterin-Carrier den zellulären Cholesterin Ein- und Ausstrom modulieren.

Von Schweine-OL, die mit Caveolin-1-spezifischer siRNA transfiziert worden waren, wurde nach 24 h, 48 h, 72 h und 96 h der Gesamtcholesteringehalt bestimmt. Die 
Zunahme wurde prozentual auf eine mit nicht kodierender NS-siRNA transfizierte Kontrolle bezogen. Dabei stieg der Cholesterin-Level in den Ansätzen mit reduzierter Caveolin-1-Expression deutlich an. Nach 96 h lag er ungefähr 56\% über der Kontrolle (Abb. 63).

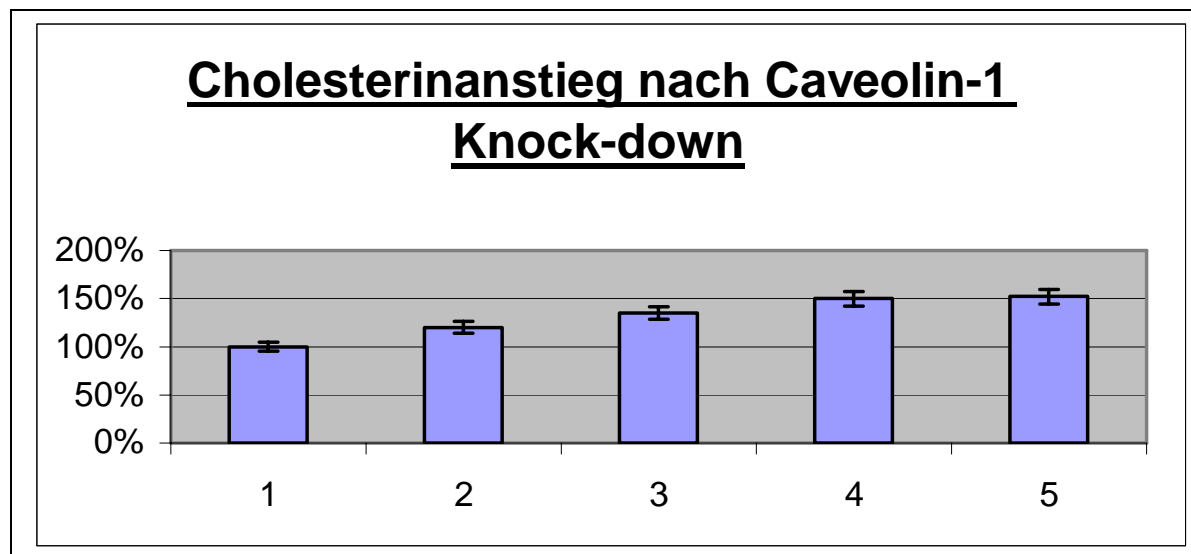

1) Kontrolle: Zellen wurden mit NS-siRNA transfiziert [ $=100 \%$ ]

2) 24 h nach Transfektion mit Caveolin-1-siRNA

3) $48 \mathrm{~h}$ nach Transfektion mit Caveolin-1-siRNA

4) 72 h nach Transfektion mit Caveolin-1-siRNA

5) 96 h nach Transfektion mit Caveolin-1-siRNA

Abb. 63: Cholesterinbestimmung von Schweine-OL, deren Caveolin-1-Expression mittels siRNA deutlich herunterreguliert worden war. Eine Reduzierung der Caveolin1-Expression führte zu einer Zunahme des Cholesterin-Levels. 96 h nach erfolgter Transfektion mit Caveolin-1-spezifischer siRNA stieg der Cholesterin-Level um 56\% an. 


\section{Diskussion}

\subsection{Detektion von Caveolin in adulten Schweine-OL}

Mit der Expression von Caveolin im Gehirn bzw. in neuralen Zellen hat sich bis zu Beginn dieser Arbeit nur eine relativ kleine Anzahl von Veröffentlichungen beschäftigt (GALBIATI et al., 1998; BILDERBACK et al., 1999; HUANG et al., 1999; PEIRO et al., 2000). Dabei wurde Caveolin im Kortex, Cerebellum und in Neuronen, Astrozyten sowie in PC12-Zellen, einer Tumorzelllinie der Nebenniere, detektiert (CAMERON et al., 1997; GALBIATTI et al., 1998). Erstmalig konnte in dieser Arbeit die Expression von Caveolin in adulten Schweine-OL mit einer immunzytochemischen Zellanfärbung und mittels Western Blot dokumentiert werden. Bei einer Subfraktionierung des OLMyelins ließ sich Caveolin zudem innerhalb von Myelinfraktionen nachweisen, überraschenderweise am stärksten in der Pelletfraktion, die sich aus den parainodalen Loops rekrutieren könnte. Von den bei Caveolin bekannten Subtypen und Isoformen (SCHERER et al., 1995; LI et al., 1996c) konnte im Gegensatz zu PC12-Zellen und Astrozyten, die neben Caveolin-1 auch Caveolin-2 enthalten (GALBIATI et al., 1998), in Schweine-OL lediglich Caveolin-1 detektiert werden. Schweine-OL bilden von Caveolin-1 beide Isoformen $\alpha$ und $\beta$ aus; diese werden von zwei verschiedenen mRNAs translatiert (KOGO et al., 2000, 2004). Der Anteil von Caveolin-1 $\alpha$ überwog dabei in Schweine-OL deutlich. Es ist jedoch noch nicht genau geklärt, inwieweit sich diese beiden Isoformen funktionell unterscheiden. Beim Untersuchen der unterschiedlichen CMD-Erscheinungsformen entdeckte Fujimoto mithilfe von Transmissionselektronenmikroskopie (TEM), dass in humanen Fibroblasten das Verhältnis der beiden Caveolin1 Isoformen zueinander in Abhängigkeit vom äußeren Erscheinungsbild der CMD variieren kann. Invaginierte Caveolae, die eine Sonderform von CMD darstellen, enthalten mehr von der Caveolin-1 $\alpha$ Isoform; wogegen in abgeflachten CMD beide Isoformen enthalten sind (FUJIMOTO et al., 2000; STAN 2005). Allerdings lassen sich aus dieser Beobachtung keine generellen Rückschlüsse für Schweine-OL ziehen, bei denen die abgeflachte CMD-Erscheinungsform überwiegend vorkommt, da die äußere Erscheinungsform von CMD von weiteren Faktoren abhängt. 


\subsubsection{Morphologische Erscheinungsformen von CMD}

Ursprünglich wurden Caveolae, die eine Spezialform von Lipid Rafts sind, aufgrund ihres Aussehens als "schmale, nicht Clathrin-ummantelte Plasmamembraneinstülpungen“ beschrieben (PALADE 1953; YAMADA 1955). Anderson und seine Mitarbeiter waren die ersten, die herausfanden, dass caveolinhaltige Membranabschnitte, in dieser Arbeit als CMD benannt, nicht zwangsläufig eingestülpt sein müssen (ROTHBERG et al., 1990; CHANG et al., 1992), da solche Abschnitte dynamische Mikrodomänen sind, die ihr Aussehen permanent ändern und somit polymorph sind. Einige dieser morphologischen Erscheinungsformen von CMD wurden in primärkultivierten Schweine-OL elektronenmikroskopisch dokumentiert. Von den bekannten Erscheinungsformen (MATVEEV et al., 2001; STAN, 2005) konnten in dieser Arbeit alle Formen, von der Flaschenhals- oder Kolbenform bis zu den geschlossenen Formen (closed, detached), detektiert werden; ihre Größe lag bei 70-80 nm. Flache CMD hätten sich nur immunelektronenmikroskopisch darstellen lassen, was aber hier auf technische Schwierigkeiten stieß. Von ihrem Vorkommen wird aber aufgrund der mittels konfokaler Lasermikroskopie gezeigten hohen Caveolin-1Expression in der Plasmamembran Gradienten-isolierter CMD ausgegangen. Im TEM lassen sich zwar an der Plasmamembran klassische, kolbenförmige invaginierte Caveolae darstellen, deren Verteilungsmuster würde aber zu einer punktförmigen Darstellung von Caveolin und nicht zu einer homogenen Expression von Caveolin in der Plasmamembran führen. Von daher ist anzunehmen, dass ein großer Teil des Caveolins der Plasmamembran in caveolinhaltigen Mikrodomänen (CMD), d.h. nichtinvaginiert oder kolbenförmig geformt, lokalisiert ist, weshalb in dieser Arbeit Caveolae sozusagen als Sonderform von CMD betrachtet werden. Der andere Teil des exprimierten Caveolins befindet sich dagegen außerhalb von Mikrodomänen. Über die Funktion des frei vorliegenden Caveolins ist bis heute noch nichts bekannt; es könnte eventuell als Vorrat zur Wiederauffüllung endozytierter CMD dienen. 


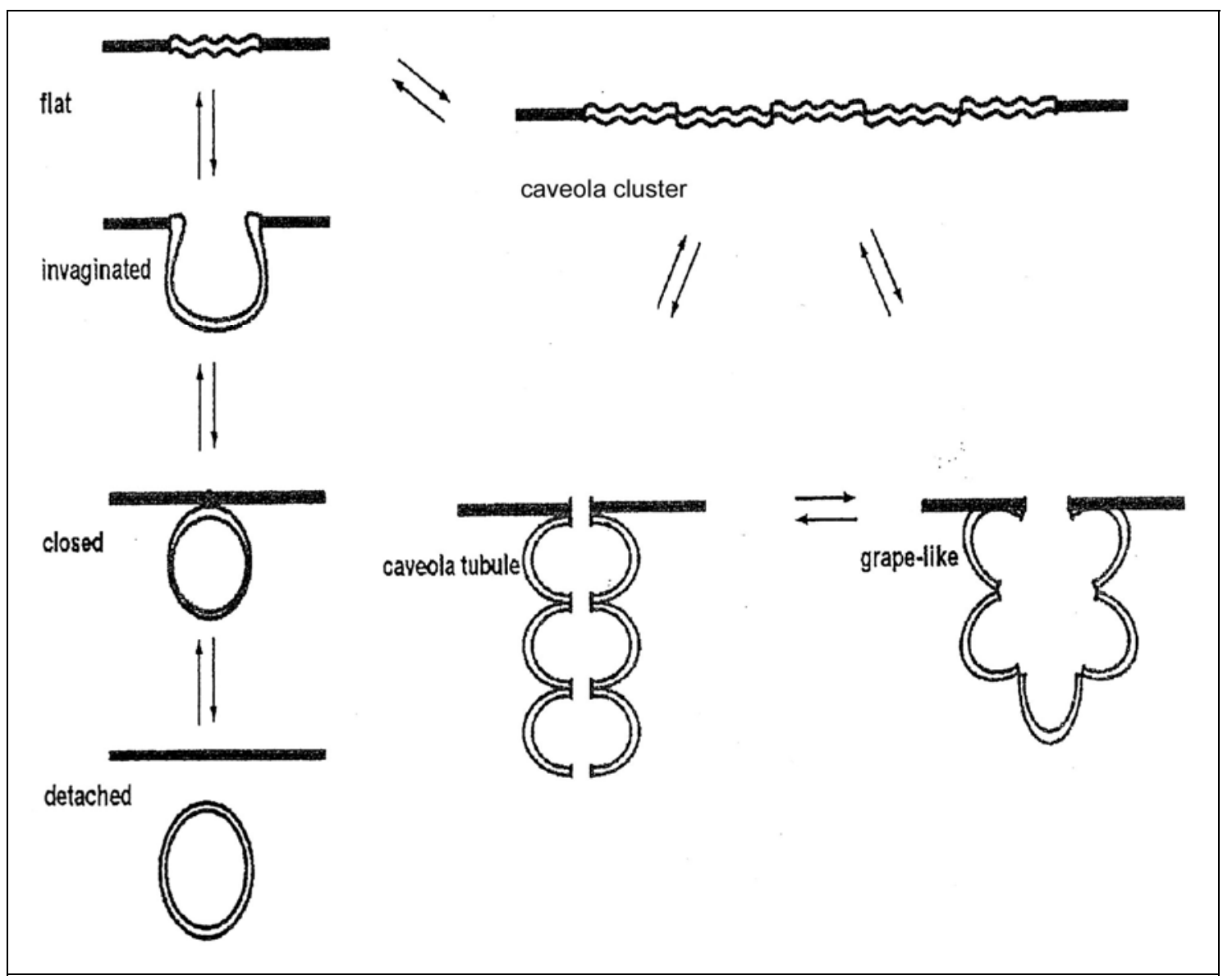

Abb. 64: Darstellung der polymorphen Erscheinungsformen von Caveolae. Da es sich bei Caveolae um dynamische Mikrodomänen handelt, ändert sich ihre Morphologie permanent. Ihr Aussehen kann daher von der Kolbenform abweichen und zudem eine flache, geschlossene, röhren- oder traubenförmige Gestalt annehmen (MATVEEV et al., 2001).

Bei der Frage, welche der in Abb. 64 dargestellten Erscheinungsformen eine caveolinhaltige Mikrodömäne annimmt, könnten folgende Parameter von Bedeutung sein, auf die nachfolgend näher eingegangen wird:

1) Expression der verschieden Caveolin-Subtypen

2) Caveolin pY14

3) Cholesteringehalt der Zellen

4) Zelltyp-bedingte Abhängigkeit

Einige Arbeitsgruppen schreiben dem CMD-Gerüstprotein Caveolin eine entscheidende Funktion zu, von der die Struktur der CMD abhängt (SMART et al., 1996). Eine Coexpression der beiden Caveolin-Subtypen 1 und 2 führt zur Ausbildung von Caveolin-heterooligomeren Komplexen, die in verstärktem Maße zur Bildung der 
klassisch-kolbenförmigen Caveolae beitragen (FUJIMOTO et al., 2000). Die Phosphorylierung von Caveolin-2 an den Serinresten 23 und 36 reguliert nach Sowa die Caveolin-1-abhängige Ausbildung des kolbenförmigen "Caveolar-Coats“ (SOWA et al., 2003). Dies könnte ein möglicher Grund dafür sein, dass Schweine-OL, die kein oder eine nicht nachweisbare Menge an Caveolin-2 besitzen, mehr abgeflachte CMD ausbilden als kolbenförmige Caveolae.

Zudem scheint eine Phosphorylierung von Caveolin-1 an Tyr. 14 zu einem Abflachen der CMD zu führen (NOMURA et al., 1999). Dies könnte durch eine zunehmende Verlagerung von Cholesterin aus den CMD heraus, die im Zuge der Caveolin pY14 auftritt, begründet sein (FIELDING 2006). Demnach ist das Zusammenspiel von Caveolin-1 und Cholesterin ein weiterer Faktor, der für die Erscheinungsform von CMD verantwortlich ist. Eine hohe Caveolin-Expression ermöglicht beispielsweise eine Cholesterin-Akkumulation und kann in diesem Fall die Ausbildung der klassischen kolbenförmigen Caveolae begünstigen (SMART et al., 1994; MATVEEV et al., 2000). Die Relevanz des Cholesterins, das eine wichtige Komponente von CMD ist und somit bei der Genese von CMD eine Rolle spielt (ROTHBERG et al., 1990; CHANG et al., 1992), wird anhand von Versuchen, bei denen ein Cholesterinmangel ausgelöst wird, deutlich. Eine Wegnahme des zellulären Cholesterins durch Reagentien wie Nystatin, Filipin oder Methyl-ß-Cyclodextrin führt zu einer Beeinträchtigung der CaveolarStruktur und damit zu einem verstärkten Abflachen oder Verlust von CMD (MATVEEV et al., 2000; WESTERMANN et al., 2005). Außerdem ist die Ausprägung der Caveolar-Morphologie vom Zelltyp, d.h. von weiteren Faktoren abhängig, da einzelne Zelltypen häufig charakteristische Erscheinungsformen besitzen. Zum Beispiel findet man die T-tubuläre-Form verstärkt in Muskelzellen (PARTON et al., 1997), die Caveolin-3 enthalten. Dagegen bilden Endothelzellen röhrenähnliche CaveolarStrukturen (UEHARA et al., 1999; VASILE et al., 1999) und Adipozyten den traubenähnlichen Typus aus (SCHERER et al., 1994; KANDROR et al., 1995). Aufgrund der Diversität an Erscheinungsformen und Vesikeltypen dient neben der Größe auch die Ummantelung der Vesikel als wichtiges Identifikationsmerkmal. Caveolae besitzen eine relativ dünne "gestreifte“ Vesikel-Ummantelung, mit deren Hilfe man sie von der Clathrin-ummantelten Vesikel-Form unterscheiden kann. Diese "Clathrin coated pits“ kommen ebenfalls in Schweine-OL vor. 


\subsection{Isolationstechniken zur Isolierung von CMD}

Zur Charakterisierung von CMD aus der Plasmamembran wurden diese zunächst mithilfe zweier Standard-Methoden aus adulten Schweine-OL isoliert. Entscheidende Eigenschaften von CMD sind die geringe Dichte und die Unlöslichkeit in nichtionischen Detergentien wie in 1\%-igem Triton X-100 bei $4^{\circ} \mathrm{C}$ (BROWN et al., 1992). Deshalb werden die CMD häufig auch als "Detergent-insoluble Membranes“ (DIMs) oder als "Detergent-insoluble glycolipid-rich Membranes“ (DIGs) bezeichnet (SMART et al., 1999). Diese ursprünglich von Lisanti beschriebene Methode, bei der das ZellHomogenat über einen diskontinuierlichen 5-35\%-igen Saccharose-Dichtegradienten aufgetrennt wird, lieferte erste Ergebnisse bezüglich der Anreicherung von MembranDomänen aus MDCK-Zellen (SARGIACOMO et al., 1993; LISANTI et al., 1994b). Die isolierten DIMs enthielten neben Caveolin eine ganze Reihe von Signalmolekülen wie beispielsweise GTP-bindende Proteine und Src-ähnliche Kinasen. Mit dieser Methode gelang es CMD aus adulten Schweine-OL in den "low density“-Fraktionen (Fraktionen 4-6) des Gradienten anzureichern, was an der hohen Expression ihres Marker- und Strukturproteins Caveolin-1 zu erkennen war. Allerdings bringt die Verwendung von Triton X-100 auch Nachteile mit sich, da es die Struktur nativer Proteine und Membranen verändern kann und somit die Bildung von intramembranösen Artefakten begünstigt. Einige Kritiker gehen sogar soweit, die Existenz von Lipid Rafts unter in vivo Bedingungen anzuzweifeln und bezeichnen sie als Artefakte, die nur in vitro vorkommen (PIERCE 2004). Die Verwendung Triton X-100 verwandter Detergentien wie Brij 96, 98 oder Lubrol WX lieferte zudem widersprüchliche Ergebnisse bezüglich der Lokalisation einiger Proteine in Lipid Rafts (ECKERT et al., 2003; SKWAREK 2004). Außerdem wurde postuliert, dass die niedrige Temperatur von $4^{\circ} \mathrm{C}$ zusammen mit Triton-X-100 das Verhalten von Membranen zu stark beeinflusst (DREVOT 2002); Drevots Auffassung nach sollten alternative Detergentien wie Brij 96, 98 oder Lubrol WX bei $37^{\circ} \mathrm{C}$ angewendet werden. Andere Autoren behaupten dagegen, dass jede Art von Detergens Lipid/Protein-Aggregate in ihrer nativen Form verändern würde (CHAMBERLAINE 2004); außerdem ist nach Pike eine Isolierung von Rezeptor-Tyrosinkinasen und damit von TrkA mit dieser Detergenshaltigen Methode nicht möglich (PIKE 2003). Wegen dieser kritischen Betrachtung wurde für die Isolation von CMD eine Detergens-freie Methode angewendet, die von Song und seinen Mitarbeitern entwickelt wurde (SONG et al., 1996). Diese bestand 
darin, den Aufschluss der Zellen in Natriumcarbonat-Puffer bei einem pH-Wert von 11 durchzuführen. Dabei dient der hohe $\mathrm{pH}$-Wert zur Entfernung von peripheren Membranproteinen (PIKE 2003). Hierbei wurde die postnukleäre, homogenisierte und sonifizierte Zellsuspension über einen diskontinuierlichen 5-40\%-igen SaccharoseDichtegradienten aufgetrennt. Die Zellfraktionierung lieferte vergleichbare Ergebnisse wie bei der Detergens-haltigen Isolation, denn die CMD reicherten sich ebenfalls als "light scattering band" in den "low-density" Fraktionen 4-6 an. Allerdings hatte die Natriumcarbonat-Methode deutliche Vorteile gegenüber der Triton-X-100-Methode: Zum einen war die Anreicherung von Caveolin-1, das wahrscheinlich mit der Menge an CMD korrelierte höher, was wiederum die Detektion weiterer Signalkomponenten innerhalb der CMD-Fraktion erleichterte. Zum anderen war die Detergens-freie Isolation wesentlich schonender, da z.B. Trks und prenylierte Proteine nur mithilfe der Natriumcarbonat-Methode detektierbar sind, nicht aber mit der Triton X-100-Methode (CHANG et al., 1994; SMART et al., 1995; PIKE 2003), bei der eine Detektion von TrkA innerhalb der CMD-Fraktion nicht gelang, was die Anwendung der alternativen Methode erforderlich machte. Außerdem befand sich im Vergleich zu den übrigen Fraktionen ein Großteil des Caveolar-Markerproteins Flotillin und etwa 60\% des gesamten Cholesterins in den CMD angereicherten Fraktionen, woraus ersichtlich wurde, dass es sich tatsächlich auch um CMD in den Fraktionen 4-6 handelte. Durch hochauflösende Immunfluoreszenzstudien von lebenden Zellen wurde durch Verwendung des Fluoreszenz-Resonanz-Energie-Transfers (FRET) gezeigt (VARMA et al., 1998), dass es sich bei den in der "low-density" Fraktion angereicherten Mikrodomänen nicht um biophysikalische Artefakte handelt, die aus der Isolierung resultieren, sondern um einen nativen Zustand der Mikrodomänen. Allerdings offenbarte auch diese Isolations-Methode eine Schwäche. Diese bestand darin, dass diese Methodik nicht ausreichte, um CMD gezielt aus der Plasmamembran zu isolieren. Die von den "Erfindern“ dieser Methode genutzten Endothelzellen exprimieren Caveolin-1 fast ausschließlich in ihrer Plasmamembran (SMART et al., 1994, 1996; OSTERMEYER et al., 2001; WILLIAMS, 2004). Dagegen exprimieren OL Caveolin-1 in der Plasmamembran, im Endoplasmatischen Reticulum (ER) und im Golgi-Apparat. Der Nachweis des ER-Markerproteins Disulfid Isomerase in den CMD-angereichten Fraktionen bestätigte dies. Deshalb musste von uns eine weitere Methode zur Anreicherung von CMD, die ausschließlich aus der Plasmamembran stammen, entwickelt werden. Dazu wurden Plasmamembranen mit MOSP und MACS- 
Technologie aus Schweine-OL isoliert. Aus dieser aufgereinigten PlasmamembranFraktion wurden nun die Detergens-löslichen Bestandteile mittels Triton X-100 extrahiert. Hierzu gehörten vor allem CMD und nicht-caveolinhaltige Lipid Rafts. Eine weitere Aufreinigung über einen Saccharose-Dichtegradienten scheiterte an dieser Stelle aufgrund von Materialknappheit. Durch Anfertigung eines Western Blots wurde Caveolin-1 sowohl in der Detergens-löslichen, als auch in der unlöslichen Fraktion detektiert, was bedeuten könnte, dass ein Teil des in der Plasmamembran exprimierten Caveolins in CMD bzw. in den übrig bleibenden Plasmamembranbestandteilen, bestehend aus nicht-caveolinhaltigen Lipid Rafts sowie nicht näher gekennzeichneten Membranabschnitten, organisiert ist (WAUGH et al., 2001); der andere Teil liegt dagegen außerhalb von Mikrodomänen in der Plasmamembran von OL vor.

Man hätte auch versuchen können Caveolin direkt mithilfe eines Maus anti-Caveolin IgM zu markieren und danach über MACS-Säulen zu separieren. Allerdings hatten Vorversuche gezeigt, dass Caveolin nur zum Teil in Triton X-100 unlöslich ist; außerdem wäre hierbei eine Unterscheidung zwischen Plasmamembran-Caveolin und Caveolin aus zellulären Organellen nicht möglich gewesen.

\subsection{Regulation der NGF/TrkA-Signaltransduktion in CMD}

\subsubsection{Interaktion von Caveolin-1 und TrkA}

Von besonderem Interesse war das Vorkommen von TrkA innerhalb der CMDangereicherten Fraktionen 4-6, und es stellte sich die Frage, ob TrkA und Caveolin-1 direkt miteinander interagieren oder ob beide Proteine lediglich gemeinsam innerhalb von Mikrodomänen lokalisiert sind und einander nicht weiter beeinflussen. Konfokale Lasermikroskopie hatte gezeigt, dass Caveolin-1 und TrkA in Bereichen der oligodendroglialen Plasmamembran colokalisiert sind. Dabei war die Expression beider Proteine nicht nur am gesamten Zellkörper, sondern auch in den Fortsätzen zu beobachten. Außerdem wurden Caveolin-1 und TrkA bei der Isolation von Plasmamembranen aus OL in der CMD-angereicherten Detergens-unlöslichen Fraktion nachgewiesen, was für eine gemeinsame Organisation beider Proteine in CMD spricht. Um herauszufinden, ob Caveolin-1 und TrkA miteinander interagieren, wurden sie coimmunpräzipitiert. Hierbei konnten Caveolin-1 und TrkA im jeweils anderen Immunpräzipitat mittels Western Blot detektiert werden. Außerdem befanden sich die 
MAPK Erk1 und Erk2 innerhalb des Caveolin-1-Immunpräzipitates, was auf eine direkte Modulation der NGF/TrkA-Signalkaskade durch Caveolin-1 hindeutet.

Mit der Interaktion von Caveolin-1 und TrkA beschäftigten sich in der Literatur bislang nur sehr wenige Arbeiten. Bilderback, Huang und Peiro lieferten diesbezüglich erste Ansätze. Die Expression des hochaffinen NGF-Rezeptors TrkA innerhalb von Caveolae wurde von Huang und Peiro anhand von PC12-Zellen gezeigt (HUANG et al., 1999; PEIRO et al., 2000). Bilderback ging methodisch weiter und wies mithilfe von Coimmunpräzipitationen eine Interaktion von Caveolin mit TrkA sowie mit p $75^{\mathrm{NTR}}$ nach (BILDERBACK et al., 1999); die Interaktion von Caveolin mit $\mathrm{p} 75^{\mathrm{NTR}}$ soll an dieser Stelle nur erwähnt werden, ihre Bedeutung ist jedoch in dieser Arbeit nicht weiter von Interesse.

Geht man nun tatsächlich von dieser Interaktion zwischen Caveolin und TrkA aus, so stellt sich als nächstes die Frage, welche Bedeutung diese Interaktion hat und inwiefern sie zur Regulation einer Signalkaskade beitragen kann.

\subsubsection{CMD/Caveolin-1 als Plattform für die NGF/TrkA-Signalkaskade}

Inzwischen wurden über 30 Moleküle u.a. Membranrezeptoren, -transporter oder Signalproteine, die in der Signalgebung eine Rolle spielen, innerhalb von CMD identifiziert (SMART et al., 1999; CERESA et al., 2000). Von den RezeptorTyrosinkinasen wie beispielsweise der EGF-, PDGF-, VEGF- und Insulin-Rezeptor sowie einer Reihe weiterer Enzyme, wie Mitogen-aktivierte Proteinkinasen, NOSynthasen wurde berichtet, dass sie mit Caveolin interagieren (PIKE 2005).

Die Tatsache, dass bei der Charakterisierung der CMD-angereicherten "low-density“Fraktionen 4-6, neben Caveolin-1 auch die beiden Neurotrophin Rezeptoren TrkA und p75 ${ }^{\mathrm{NTR}}$, MAPK (Erk1 und Erk2) sowie p21 Ras detektiert wurden, spricht für eine Assoziation dieser Moleküle mit CMD und lässt auf eine ähnliche Rolle von CMD bei der NGF-Signalkaskade schließen. Diese könnte wie folgt aussehen:

Die Bindung des Wachstumsfaktors NGF führt zur Dimerisierung von TrkA, wodurch es zu einer Autophosphorylierung von TrkA und zur Bindung von Raft-Proteinen an TrkA kommt (TSUI-PIERCHALA et al., 2002) (Abb. 65). Die Phosphorylierungsstellen dienen bei der Signaltransduktion als Andockstellen für Adapter- und Signalmoleküle wie SHC (Src homologous and collagen-like protein) und PLC $\gamma$ (Phospholipase C $\gamma$ ). Wahrscheinlich läuft die Bildung solcher Signalkomplexe 
bevorzugt innerhalb von CMD ab, die gewissermaßen als Plattform für die Signaltransduktion dienen und für die Ausbildung von stabilen Signalkomplexen förderlich sind. Auf diese Weise wird die Weiterleitung des Signals intensiviert.

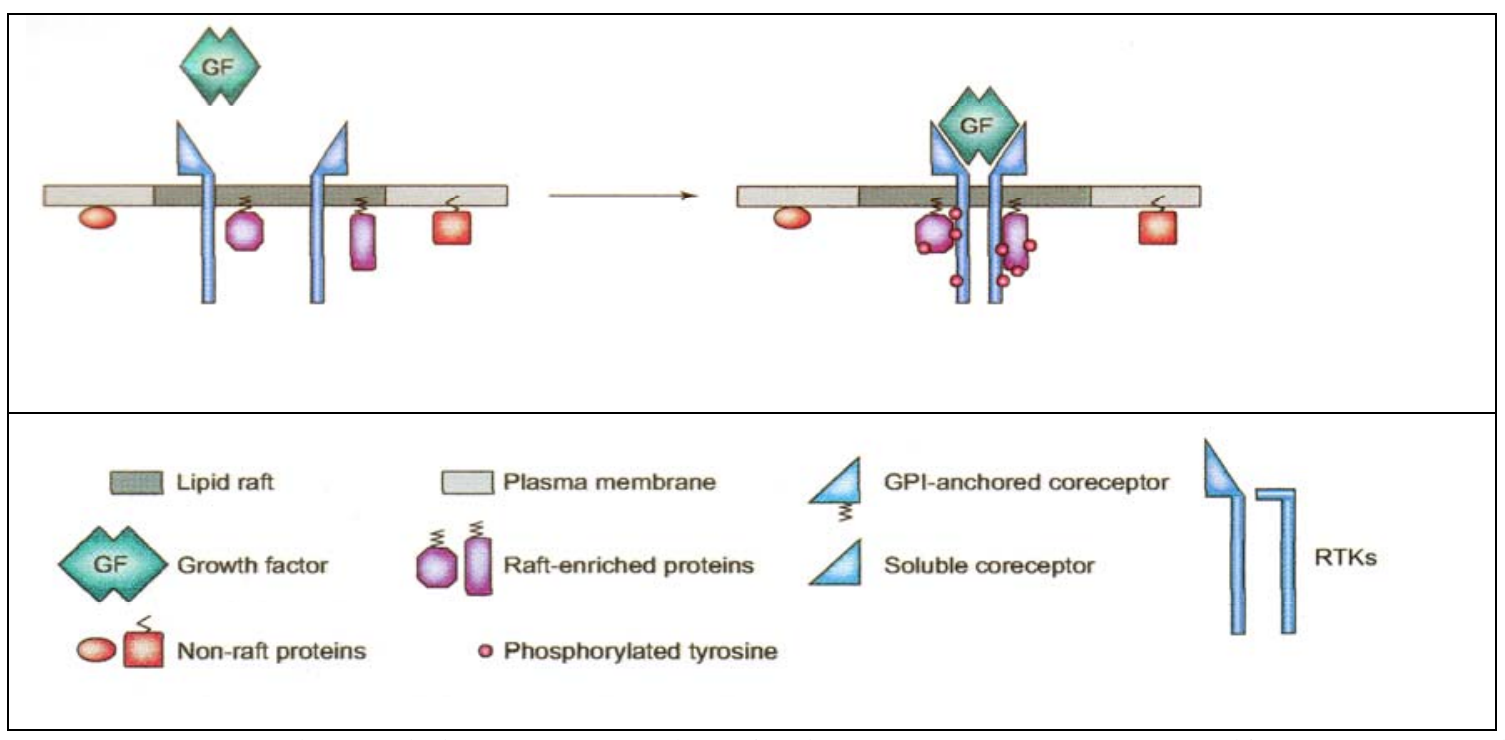

Abb. 65: Signaltransduktion in Lipid Rafts bzw. CMD, einer Spezialform von Lipid Rafts. Aus der Bindung eines Wachstumsfaktors (z.B. NGF) resultiert eine Dimerisierung der Rezeptor Tyrosinkinasen (z.B. TrkA) sowie eine Autophosphorylierung des Rezeptors. Im Laufe dieses Aktivierungsprozesses kommt es zur Anlagerung von Raft-Proteinen (z.B. SHC oder PLC $\gamma$ ) an den Rezeptor, wodurch die Signalgebung moduliert werden kann. (TSUI-PIERCHALA et al., 2002).

Im Gegensatz zum EGF-Rezeptor, der nach Aktivierung die Rafts verlässt (WAUGH et al., 1999), bleibt TrkA permanent in CMD der OL assoziiert; somit ist die Lokalisation von TrkA Ligand-unabhängig (HUANG et al., 1999; PIKE 2003).

Allerdings befindet sich nur ein Teil von TrkA in CMD der Plasmamembran. Die Tatsache, dass ca. $50 \%$ von TrkA in Triton $\mathrm{X}-100$ bei $4^{\circ} \mathrm{C}$ löslich sind, weist darauf hin, dass nicht das gesamte TrkA in CMD lokalisiert ist, da Triton X-100 ( $\left.4^{\circ} \mathrm{C}\right)$ lösliches TrkA außerhalb von CMD organisiert sein sollte. Geht man davon aus, dass die Dimerisierung von TrkA besonders effektiv in CMD stattfindet, würde eine nicht CMDorganisierte Lokalisation für die Signaltransduktion wesentlich ineffektiver sein. Werden CMD etwa durch Zusatz von Methyl-ß-Cyclodextrin in ihrer Organisation zerstört, kommt es in der Tat zu einer reduzierten TrkA-Antwort auf NGF. Unter diesen Vorraussetzungen nimmt die Menge an Triton X-100-löslichem Caveolin-1/TrkA zu und die Aktivität der MAPK ab. Nach Huang sind in PC12-Zellen etwa 40\% von TrkA 
unlöslich und somit in CMD lokalisiert (HUANG et al., 1999). Ein Behandlung der Zellen mit dem Cholesterin-bindenden Reagens Filipin führte zu einer Verlagerung von TrkA im Dichtegradienten aus den CMD-angereicherten Fraktionen 4-6 in die Fraktionen 7-11 (HUANG et al., 1999).

Die genaue Ursache, warum nur ein Teil von TrkA/Caveolin-1 innerhalb von CMD organisiert ist, ist bis heute noch unklar. Innerhalb der Plasmamembran könnte TrkA im Zuge der Rezeptor-Recyclisierung übergangsweise außerhalb von CMD exprimiert werden bzw. könnte die Signalweiterleitung nicht CMD-gekoppelt über frei vorliegendes TrkA verlaufen.

\subsection{NGF-bedingte Einflüsse auf Caveolin-1/CMD}

\subsubsection{Hochregulation der Caveolin-1-Expression durch NGF}

Ein weiteres Argument für eine Abhängigkeit der NGF/TrkA-Signalgebung von Caveolin-1/CMD lieferte die Untersuchung des regulatorischen Einflusses von NGF auf die Caveolin-1-Genexpression. Die Stimulation von Schweine-OL mit NGF führte zu einer 2-3-fachen Hochregulation von Caveolin-1, die auf mRNA- sowie auf Proteinebene nach $48 \mathrm{~h}$ gezeigt werden konnte.

Eine ähnliche Beobachtung über eine Erhöhung der Caveolin-Expression machte Galbiati an PC12-Zellen, wenn sie für vier Tage mit NGF behandelt wurden (GALBIATI et al., 1998).

Der Grund für die gesteigerte Caveolin-1-Expression unter NGF könnte ein negativer regulatorischer Rückkopplungsmechanismus sein, über den eine Zelle die unkontrollierte Ausweitung ihrer Signaltransduktion verhindert. Als Beispiel hierzu wäre die Funktion des Caveolins als Suppressorprotein bei der Entstehung von Tumoren zu nennen. Entartete Kebszellen verfügen nämlich über keine bzw. nur über eine geringe Caveolin-1-Expression (RAZANI et al., 2001).

Ebenfalls denkbar wäre, dass eine erhöhte Caveolin-1-Expression mit einer größeren Anzahl an CMD verbunden ist (FAN 1983; LEE et al., 2005), wodurch die Signalweiterleitung von TrkA innerhalb von CMD optimiert und ausgeweitet werden kann. Zum Beispiel spielt Caveolin-1 im PNS nach Mikol eine wichtige Rolle bei der Signalgebung, die zur Myelinisierung von Schwann Zellen führt; und zwar steigt die Caveolin-1-Expression in Schwann Zellen während der Myelinisierung an, dagegen 
nimmt sie beim Demyelinisierungsprozess wieder ab (MIKOL et al., 1999, 2002). Bei Betrachtung aller Ergebnisse scheint es jedoch in Schweine-OL bezüglich der vorhandenen Caveolin-Menge eine Art "Schwellenwert“ zu geben: Liegt die Caveolin1-Konzentration innerhalb eines "Toleranzbereiches“, so erreicht die Intensität der Signalgebung ihr Optimum. Wird dieser Bereich unterschritten, funktioniert die Signalweiterleitung aufgrund einer zu geringen Anzahl von CMD nicht optimal. Dagegen kann Caveolin-1 bei Überschreitung dieses Schwellenwertes auch als Suppressor wirken.

\subsubsection{NGF-induzierte Caveolin-1 Phosphorylierung an Tyrosin-14 (Caveolin pY14)}

Caveolin-1 ist an der Organisation von Signalkomplexen beteiligt und kann zudem direkt in Signalkaskaden involviert sein, indem es als Substrat für Tyrosin- und Serin/Threoninkinasen dienen kann. Eine dieser Phosphorylierungsstellen von Caveolin-1 befindet sich am aminoterminalen Ende an Tyrosin-14. Allerdings besitzt nur die Caveolin-1 $\alpha$-Isoform diese Phosphorylierungsstelle, da der $ß$-Form die ersten 30 AS an diesem Terminus fehlen. Durch einen spezifischen Antikörper, der speziell gegen Caveolin-phosphoryliertes Tyrosin-14 gerichtet ist, konnte in Schweine-OL nach NGFGabe eine ca. 4-5 fache Zunahme der Caveolin pY14 detektiert werden; unbehandelte Zellen wurden dagegen nur auf einem geringen Grundlevel phosphoryliert. Die Caveolin pY14 setzte nach 10 min ein und erstreckte sich auf die gesamte Zelle und ihre Fortsätze. Allerdings existieren stärker und schwächer fluoreszierende Bereiche, die zeigen, dass die Caveolin pY14 nicht gleichmäßig und homogen innerhalb der Zelle abläuft. In der Plasmamembran und in den Bereichen, wo es zum Zell-Zell-Kontakt kommt, findet eine Akkumulation der Caveolin pY14 statt (LEE et al., 2000). Zu den beiden Hauptauslösern von Caveolin pY14 gehören zellulärer Stress und die Stimulation mit Wachstumsfaktoren (LI et al., 1996a; LEE et al., 2000; VOLONTE et al., 2001). Auch hierbei wurde eine geringe Caveolin pY14 in unbehandelten Zellen beobachtet (NOMURA et al., 1999). Da Caveolin-1 eine Rolle bei der Insulin(KIMURA et al., 2002) und der EGF-Signalgebung spielt, wurde von Lee die Caveolin pY14 in diesen beiden Signalkaskaden, die ebenfalls Tyrosinkinase Rezeptor-gesteuert sind, näher durchleuchtet (LEE et al., 2005). Anhand einer Fibroblasten-Zelllinie, die mit Insulin behandelt wurde, entdeckte Lee eine Phosphorylierungszunahme von 
Caveolin-1 (LEE et al., 2005). Nach Corley-Mastick tritt die Caveolin pY14 bei Gabe von Insulin nach nur einer Minute auf (CORLEY-MASTICK 1995) und erreicht 5 min später ihr Maximum. Bei der Stimulation des EGF-Rezeptors in Epithelzellen beobachtete Orlichenko nach 20-minütiger EGF-Behandlung eine 8-10 fache Zunahme der Caveolin pY14 (ORLICHENKO et al., 2005).

Beide Arbeitsgruppen stimmen darin überein, dass in ihren jeweiligen Zellmodellen cSrc-Kinasen für die Phosphorylierung von Caveolin-1 verantwortlich sind. Die Phosphorylierung erfolgt innerhalb von CMD, wo Caveolin pY14 danach mit Signalmolekülen wechselwirken kann. Um eine rasche Dephosphorylierung durch Tyrosinphosphatasen (CASELLI et al., 2001; LEE et al., 2006) zu verhindern, war eine Behandlung der Zellen mit Natrium-Orthovanadat essentiell.

Innerhalb der Zelle wurden c-Src-Kinasen bereits innerhalb von CMD nachgewiesen (LEE et al., 2005). Die Zugabe von PP2, einem effektiven Src-Kinase-Inhibitor, führte auch in Schweine-OL zu einer Hemmung der Caveolin pY14 unter NGF. Das zeigt die Zelltyp unabhängige Bedeutung von c-Src-Kinase für die Caveolin pY14.

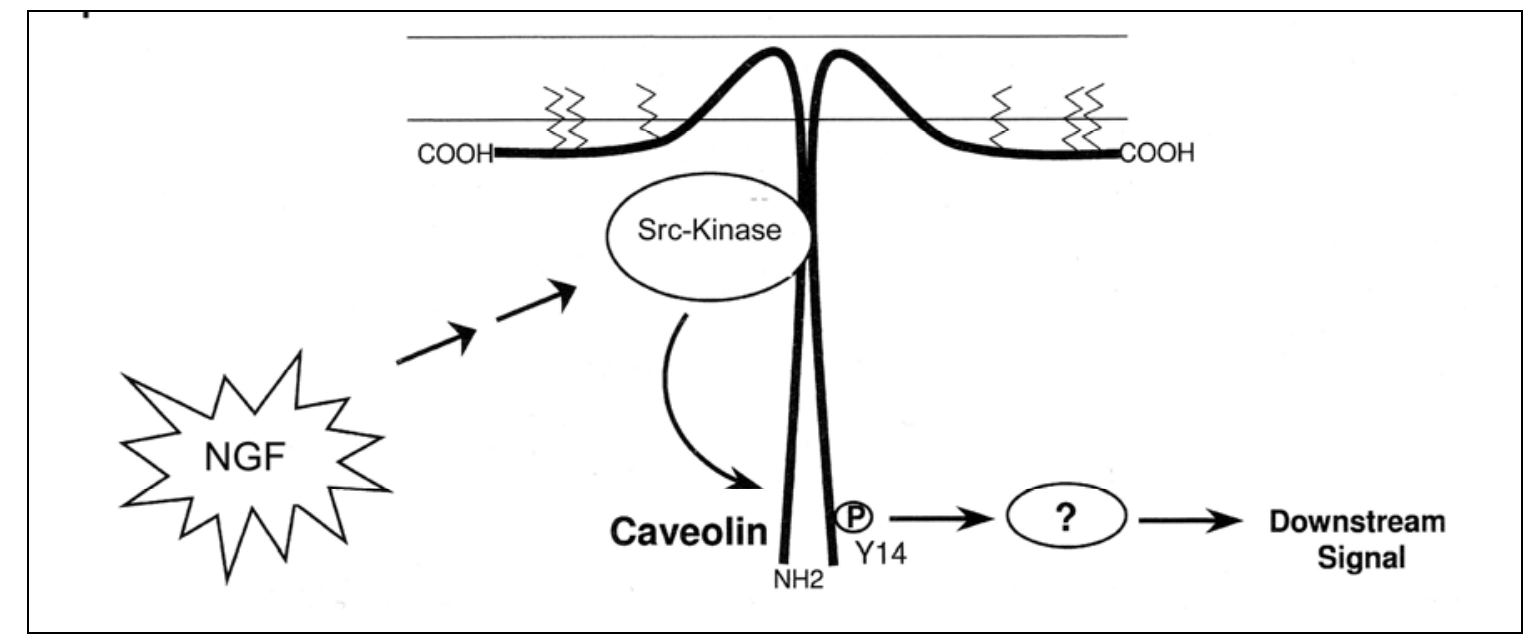

Abb. 66: NGF-induzierte Caveolin pY14. Bereits nach 10-minütiger NGF Stimulation tritt in OL eine verstärkte Caveolin pY14 via c-Src-Kinase auf. Im weiteren Verlauf der Signalgebung könnte die Caveolin pY14 als Andockstelle für modulare Bindedomänen wie SH2 (Src Homologieregion 2)- und PTB-Domänen (Phosphotyrosin Bindungsdomänen) von Signalproteinen dienen (modifiziert nach FIELDING "Lipid Rafts and Caveolae").

Phosphoryliertes Caveolin könnte als Andockstelle für modulare Bindedomänen wie SH2 (Src Homologieregion 2)- und PTB-Domänen (Phosphotyrosin Bindungsdomänen) von Signalproteinen dienen (SARGIACOMO et al., 1995; LI et al., 1996a). 
In diesem Zusammenhang entdeckte Lee eine erhöhte Bindungsaffinität von Grb7 (growth factor receptor-binding protein 7), einem SH2-Domänen Adapterprotein, zu Caveolin pY14 (LEE et al., 2005). Dieses ist wiederum mit zahlreichen anderen Signalproteinen assoziiert und somit ein Baustein in der Signaltransduktion.

Letztendlich kann jedoch über die genaue Funktion, die die Caveolin pY14 bei der Signalgebung ausübt, nur spekuliert werden, da es außer einigen Anhaltspunkten noch zu wenige Studien darüber gibt.

\subsubsection{Zusammenhang zwischen der Phosphorylierung von TrkA und der Caveolin pY14}

Die Stimulation von Schweine-OL mit NGF führt zur Phosphorylierung von TrkA, einem Initialschritt in der NGF-Signaltransduktion, bei der phosphoryliertes TrkA (PTrkA) als Andockstelle für Adapter- und Signalmoleküle dient. Eine Doppelanfärbung der Caveolin pY14 und Phosphorylierung von TrkA sollte darüber Aufschluss geben, ob die Caveolin pY14 sich unmittelbar an die c-Src-Aktivierung anschließt oder ob sie erst nach einiger Verzögerung in Folge weiterer Signalkaskaden zustande kommt. Eine eventuelle Kreuzreaktion der sekundären Antikörper und die damit verbundene Artefaktbildung wurden durch eine Kontrollfärbung ausgeschlossen. Die Doppelfärbung ergab, dass beide Phosphorylierungen in Schweine-OL NGF-induziert sind und im engen zeitlichen Zusammenhang stehen. Sie sind aller Voraussicht nach Bestandteil bei der NGF/TrkA-Signalgebung. Die Autophosphorylierung von TrkA konnte durch das Stausporin-Derivat K252a blockiert werden, was zu einer Inhibition der Fortsatzbildung führte (ALTHAUS et al., 1997a). K252a hemmt zwar auch andere Kinasen, ist aber in der eingesetzten Konzentration von $1 \mu \mathrm{M}$ spezifisch für TrkA (TAPLEY et al., 1992). Interessanterweise führte die Gabe von K252a auch zu einer Hemmung der Caveolin pY14, was auf eine Abhängigkeit von der TrkA Phosphorylierung hindeutet.

\subsection{Caveolin als Negativregulator: Treten altersbedingte Effekte auch in Schweine-OL-Kulturen auf?}

Eine Ursache für neurale Erkrankungen, die im zunehmenden Alter auftreten, könnte der zunehmende Abbau von Myelin sein (BARTZOKIS 2004). Tsui-Pierchala fand heraus, dass der Komplex aus NGF und phosphoryliertem TrkA (P-TrkA) in älteren 
Neuronen wesentlich langsamer wieder dephosphoryliert wird, als in jüngeren (TSUIPIERCHALA et al., 1999).

Bei der Frage, ob eine altersbedingte Abschwächung der NGF/TrkA-Signalkaskade in OL und die zunehmende Degenerierung der Myelinscheiden älterer Neurone, die mit einer Veränderung in der Myelinstruktur verbunden ist (PETERS et al., 2000), mit einer erhöhten Caveolin-Expression einhergehen, wurden primäre Schweine-OL für 30 Tage kultiviert. Danach wurde die Intensität ihrer NGF-Antwort in einem MAPKAktivitätsassay mit der von 8 Tage lang kultivierten Zellen verglichen. Dabei ging die Fähigkeit der langzeitkultivierten OL auf NGF mit einer Erhöhung der MAPK-Aktivität zu reagieren deutlich zurück. Eine mögliche Ursache hierfür könnte der Befund sein, dass die Caveolin-1-Expression im Laufe des Fortsatzwachstums der OL-Kulturen anstieg; die TrkA-Expression blieb dagegen während dieser Zeit beinahe unverändert. Die Caveolin-Expression könnte auch bei humanen OL eine Rolle spielen, da humane OL auf NGF zwar mit einer verbesserten Fortsatzbildung reagierten; die jedoch gegenüber der Reaktion von Schweine-OL deutlich verzögert war (ALTHAUS et al., 2001). Hierbei könnte das Alter der Zellen von Bedeutung sein, da die Schweine-OL von jungen Tieren (einem Jünglingsalter im humanen Bereich entsprechend) isoliert wurden, während die humanen OL bei Operationen von 40-50 jährigen Patienten mit Temporallappenepilepsie gewonnen wurden. Eine Untersuchung der CaveolinExpression bei älteren humanen OL steht aber zurzeit noch aus. Um eine inhibitorische Regulation durch Caveolin zu detektieren, wurden Schweine-OL (8 DIV) für 48 h mit NGF stimuliert, was zu einem deutlichen Anstieg der Caveolin-1-Expression führte. Danach wurde NGF für 12 h entfernt, sodass die Aktivität der MAPK von den Zellen wieder herunterreguliert werden konnte. Gibt man nun erneut NGF auf die Zellen und vergleicht den MAPK-Aktivitätsanstieg nach $4 \mathrm{~h}$ mit dem von zuvor unbehandelten OL (8 DIV), so kam es zu einer ca. 30\%-igen Abnahme der MAPK-Aktivität, die wahrscheinlich auf die erhöhte Caveolin-1-Expression zurückzuführen ist.

In diesem Zusammenhang beschreibt Bilderback, dass PC12-Zellen, die mit Caveolin-1 transfiziert wurden, nicht mehr in der Lage waren auf NGF mit der Ausbildung von Zellfortsätzen zu antworten. Er schloss daraus auf eine direkte Interaktion von Caveolin-1 und TrkA, durch die das Fortsatzwachstum supprimiert wird (BILDERBACK et al., 1999).

Eine ähnliche Beobachtung wurde in gealterten Fibroblasten gemacht, wo eine Überexpression von Caveolin-1 sich abschwächend auf die EGF-Signalkaskade 
auswirkte (VOLONTE et al., 2002), obgleich die Expression vom EGF-Rezeptor nicht vom Normalen abwich (PARK et al., 2000). Eine in vitro herbeigeführte CaveolinÜberexpression in jungen Fibroblasten hatte das gleiche Ergebnis zur Folge (SHIRAHA et al., 2000). Über die möglichen Gründe ist bis heute nur wenig bekannt. Es existieren lediglich einige Vermutungen, wie dieses Ergebnis zu erklären ist:

Beispielsweise entdeckte Wheaton in gealterten humanen Fibroblasten mit erhöhter Caveolin-1-Expression einen zunehmenden Verlust von Caveolae und machte diesen für die Abschwächung der Tyrosinkinase-Aktivität verantwortlich. Caveolin-1 befand sich nämlich zunehmend außerhalb von Caveolae (WHEATON et al., 2001). Eine andere Hypothese macht in alten Fibroblastenzellen eine verstärkte Interaktion zwischen Caveolin und dem EGF-Rezeptor für eine abgeschwächte Erk1/2Phosphorylierung nach EGF-Stimulation verantwortlich (PARK et al., 1999).

All diese Lösungsansätze führen schließlich zu der Frage, ob Caveolin-1 eine reaktive Domäne besitzt, über die eine mögliche Inhibition/Regulation von Signalkaskaden erfolgen kann.

\subsubsection{Inhibition des NGF/TrkA-Signalweges durch die Caveolin-1- Gerüst (Scaffolding)-Domäne}

Da es sich bei Caveolin-1 um ein Suppressor-Protein handelt, das am Beispiel der Tumor-Suppression oder der Inhibition der eNOS (endothelial nitric oxide synthase) Signalkaskade gezeigt wurde, stellt sich als nächsten die Frage nach dem Mechanismus einer solchen Inhibition. In diesem Zusammenhang wird die 21 AS-große Caveolin-1Gerüst (Scaffolding)-Domäne (CSD) von Aminosäure 82-101 als ein Abschnitt beschrieben, der in die katalytische Aktivität von Kinasen eingreift. Die Bindungsspezifität kommt wahrscheinlich durch viele aromatische Aminosäuren innerhalb dieser Region zustande (COUET et al., 1997).

Um eine direkte Regulation der NGF-Signalkaskade durch die CSD zu untersuchen, wurde die CSD in Form eines zellgängigen Peptids (Cavtratin) auf primärkultivierte Schweine-OL gegeben. Dabei konnte eine deutliche Reduktion der MAPK-Aktivität nach Stimulation mit NGF beobachtet werden, die Cavtratin als negativen Regulator für die NGF-Signalgebung ausmacht. Verglichen mit einer Kontrolle, bei der die Zellen mit einem funktionslosen NS-(nonsense) Peptid behandelt wurden, nahm die MAPKAktivität unter NGF in den mit Cavtratin behandelten OL um ca. 50\% ab. Die 
Möglichkeit von Caveolin-1 über seine CSD die MAPK-Aktivität zu hemmen, scheint somit ein wichtiger Regulationsmechanismus bei der NGF-Signalgebung zu sein, der vor allem bei langzeitkultivierten OL, deren Caveolin-1-Expression nach abgeschlossenem Fortsatzwachstum erhöht ist, zum Tragen kommt. Dieser Befund deckt sich mit den Ergebnissen anderer Arbeitsgruppen, die beispielsweise eine selektive Hemmung von eNOS (Endothel Nitrit-Oxid-Synthase) durch CSD beobachteten (VENEMA et al., 1997; FERON et al., 1998; BUCCI et al., 2000; GRATTON et al., 2003; BERNATCHEZ et al., 2005). Bernatchez fand heraus, dass nicht die gesamte CSD, sondern lediglich sechs AS spezifisch für die Hemmung von eNOS sind (BERNATCHEZ et al., 2005). Couet bezeichnet daher die CSD als "universalen Kinase-Inhibitor“ (OKAMOTO et al., 1998; COUET et al., 2001). Caveolin-1 kann z.B. über seine CSD die Aktivität von Src Tyrosinkinasen (c-Src/Fyn) (LI et al., 1996b) oder p42/44 MAPK supprimieren und dadurch nachfolgende Signalkaskaden in ihrer Aktivität abschwächen. Außerdem inhibiert die CSD die Aktivität von G-Proteinen, indem sie den Austausch von GDP und GTP hemmt. Auf diese Weise erfolgt eine Inhibition von Proteinkinase C (TOYA 1998).

In der Onkologie fungiert Caveolin als Tumorsuppressorprotein (RAZANI et al., 2001b) und schützt dadurch den Organismus vor entartetem Zellwachstum. Dies zeigt, wie wichtig eine Caveolin-1-bedingte Suppression von überschießenden Wachstumssignalen für das Überleben eines Organismus (SHATZ et al., 2004) sein kann. Daher wird Caveolin auch als "survival-promoting protein“ bezeichnet (NASU et al., 1998).

\subsection{Auswirkungen eines durch Transfektion mit Caveolin-1- spezifischer siRNA herbeigeführten Caveolin-1-Knock-downs auf die Fortsatzbildung von OL}

In zahlreichen Zellmodellen wirkte sich eine Überexpression von Caveolin-1 negativ auf die Signalgebung aus, da Caveolin-1 eine Suppressorfunktion ausübt. Daher sollte nun untersucht werden, wie sich ein Caveolin-1-Mangel, ausgelöst durch Transfektion mit doppelsträngiger siRNA, auf die NGF/TrkA-Signalgebung auswirkt.

Das Transfektionsreagens jetSI-Endo erwies sich in einem zuvor durchgeführten Test mit Fluoreszenz-gekoppelter siRNA von fünf getesteten Transfektionsreagentien am 
effektivsten. Die erfolgte Caveolin-1-Abnahme wurde immunzytochemisch durch eine Caveolin-Färbung dokumentiert und auf einem ECL Western Blot quantifiziert; sie lag bei über $60 \%$.

Interessanterweise waren dabei Auswirkungen eines Caveolin-1-Mangels auf die Zellen morphologisch zu beobachten; und zwar formten OL mit erniedrigter Caveolin-1Expression weniger Fortsätze als jene, die mit NS-siRNA transfiziert wurden und über eine normale Fortsatzbildung verfügten. Der durch Caveolin-1-Knock-down herbeigeführte Effekt war unter NGF noch auffälliger, denn nach 48-stündiger NGFStimulation war das Fortsatzwachstum der Zellen mit herunterregulierter Caveolin-1Expression im Vergleich zu den Kontrollen deutlich herabgesetzt. OL mit Caveolin-1Mangel formten nach Stimulation mit NGF eine Art "Teppich“ oder Geflecht von dünnen Fortsätzen; wogegen die mit NS-siRNA transfizierte Kontrolle nach NGF-Gabe ein Netzwerk von stabilen und verzweigten Fortsätzen regenerierte. Zudem zeigten beide Ansätze Unterschiede in der Intensität der NGF-induzierten MAPK-Aktivität, die ein Indikator für die Fortsatzbildung ist. Es wurde deutlich, dass sich eine reduzierte Caveolin-1- Expression inhibierend auf die MAPK-Aktivität auswirkte.

\subsubsection{Caveolin-1 als förderndes und hemmendes Regulativ der NGF/TrkA Signalkaskade?}

Zwei Interpretationsmöglichkeiten ergeben sich aus den unter (4.5.1.) und (4.6.) aufgeführten und zunächst gegensätzlich erscheinenden Ergebnissen:

Einerseits kann Caveolin-1 bei Überexpression als negativer Regulator über seine CSD die katalytische Aktivität von TrkA und damit den gesamten Ablauf der NGF/TrkASignalkaskade unterdrücken. Auf der anderen Seite wirkt sich das Fehlen von Caveolin1, dass wahrscheinlich mit einer reduzierten Anzahl von CMD verbunden ist (GRIFFONI et al., 2000), inhibierend auf die NGF/TrkA-Signalkaskade aus, da nur ein Teil der TrkA-Rezeptoren in CMD lokalisiert sind und dort aktiviert werden. CMD können also auch die Aktivierung von TrkA sowie die Anlagerung weiterer Signalproteine und damit die Signalweiterleitung begünstigen. Es scheint jedoch bei der Caveolin-1-Expression eine Art Schwellenwert zu geben, der darüber entscheidet ob eine positive oder negative Regulation der Signalgebung erfolgt.

Bislang gibt es in der Literatur dazu keine vergleichbaren Resultate an OL. Bezüglich der Caveolin-1-Herunterregulation mittels siRNA erreichte Gonzalez eine 90\%-ige 
Reduktion in BAEC (bovine aortic endothel)-Zellen (GONZALEZ et al., 2004). Dabei trat jedoch keine Veränderung bei der Phosphorylierung der MAPK Erk1 und Erk2 auf. Caveolin Knock-out Mäuse sind zwar grundsätzlich lebensfähig, allerdings besitzen diese Mäuse keine funktionellen Caveolae (ZHAO et al., 2002; PARK et al., 2003) und ihre Lebenserwartung ist deutlich verkürzt. Die Liste der Organstörungen ist lang, u.a. resultierte aus dem Fehlen von Caveolin eine erhöhte Anfälligkeit der Mäuse für Krebs, Diabetes, Atherosklerose, muskuläre Dystrophie, einen gestörten Fettstoffwechsel sowie eine eingeschränkte Lungenfunktion (HNASKO et al., 2003). Wahrscheinlich können in vivo andere Transportvesikel (z.B. Clathrin-ummantelte Vesikel) einige Aufgaben von Caveolae wie beispielsweise die Endozytose übernehmen, wodurch sich die Defekte teilweise kompensieren lassen (LAY 2005).

\subsection{Regulation der NGF-Signalkaskade durch die CMD- Komponente Cholesterin}

Cholesterin ist nicht nur ein wichtiges Strukturelement in der Plasmamembran und im Myelin, sondern es spielt auch als Komponente von CMD eine Rolle bei der Signalgebung (MARTIN et al., 2005). Die Wechselwirkungen zwischen Caveolin-1 und Cholesterin wurden erstmals von Rothberg erwähnt. Er beobachtete, dass Zellen, die mit Cholesterin-bindenden Reagentien (z.B. Filipin, Nystatin) behandelt wurden, ein morphologisches Abflachen der Caveolae zeigten (ROTHBERG et al., 1992). Die Palmitoylierung von Caveolin-1 an den Positionen 143 und 156 ermöglicht die direkte Bindung an Cholesterin (FIELDING 1995).

Cholesterin ist mit einem Lipidanteil von 30\% ein wichtiger Bestandteil des ZNS. Da Cholesterin nicht durch die Blut-Hirn-Schranke gelangt, muss die Synthese im ZNS endogen erfolgen. Zu den Hauptproduzenten von Cholesterin im ZNS gehören gliale Zellen, von denen auch OL befähigt sind Cholesterin selber zu synthetisieren.

Außerdem können OL in vitro nach Gabe von PEG-600 Cholesterin für 24 h ihren intrazellulären Cholesteringehalt um über 50\% erhöhen. Durch Exposition mit Fluorescein-gekoppeltem PEG-Cholesterin ließ sich die Cholesterinaufnahme in primären Schweine-OL nachvollziehen. Dabei reicherte sich Cholesterin nach 15 min zunächst in der Plasmamembran an. Etwa 24 h später kam es zu einer Aggregation von Cholesterin im cytosolischen Bereich; wahrscheinlich innerhalb des Golgi-Apparates oder des Endoplasmatischen Reticulums. 
Eine Erhöhung des zellulären Cholesterinspiegels in Schweine-OL führte nach $48 \mathrm{~h}$ zu einem Anstieg der Caveolin-1-Expression, wodurch es wahrscheinlich auch zu einer Zunahme von CMD kam. Außerdem begünstigt Cholesterin das Fortsatzwachstum in Schweine-OL, was nach 48-stündiger Cholesterin-Exposition primärer OL zu beobachten war und auf eine effektivere Signalweiterleitung zurückzuführen ist.

Die Regulation der Caveolin-1-Expression durch Cholesterin erfolgt dabei auf Transkriptionsebene über zwei reglatorische Bindungsstellen am Caveolin-1 Promotor. Fielding entdeckte, dass aus einem Ansteigen des zellulären Cholesterinspiegels eine zunehmende Caveolin-1-mRNA-Synthese resultiert; der entgegengesetzte Effekt tritt nach Cholesterin Wegnahme (FIELDING et al., 1994; BIST et al., 1997), die in MDCK-Zellen zu einem Rückgang der Caveolin-Expression sowie zu von Verlust von CMD führt, auf (HAILSTONES et al., 1998).

Gibt man Cholesterin zusammen mit NGF auf primäre Schweine-OL, so ergänzen sich beide Einzeleffekte bei der Förderung des Fortsatzwachstums. Denn nach 24 h besaßen diese Zellen wesentlich mehr Fortsätze als nach alleiniger NGF-Exposition. Der Vergleich der MAPK-Aktivität beider Proben, die ein Indikator für die Intensität des Fortsatzwachstums ist, bestätigte diesen Befund. Wahrscheinlich erleichtert Cholesterin neben der Genese von CMD auch die Dimerisierung und die Autophosphorylierung von TrkA in CMD.

In vitro kann der zelluläre Cholesterinspiegel in Schweine-OL mittels Methyl-ßCyclodextrin um ca. 60\% reduziert werden. Ein über mehrere Tage anhaltender Cholesterinmangel führte dazu, dass die Zellen ihre Fortsätze einzogen und dazu neigten, größere Zellhaufen auszubilden; diese ließen sich durch Cholesteringabe wieder auflösen. Außerdem setzte kurz nachdem die Zellen ihren Cholesterinmangel behoben hatten das Fortsatzwachstum wieder ein.

Eine abrupte Cholesterinreduktion führt zu einer Zerstörung von CMD (THORN et al., 2003). Daraufhin gelangen Signalrezeptoren und Proteine aus den Mikrodomänen in die umliegende Plasmamembran. Erkennbar wird dieses Phänomen daran, dass es nach Methyl-ß-Cyclodextrin-Inkubation der Zellen zu einer Zunahme von Detergenslöslichem TrkA, bzw. nach Pike zu einer Verlagerung der Signalkomponenten aus der “Low density-Fraktion“ in Fraktionen höherer Dichte kommt (PEIRO et al., 2000).

Auf diese Weise ließen sich in vitro Bedingungen schaffen, unter denen sich TrkA vorwiegend außerhalb von CMD befindet. Dabei zeigte sich, dass die Translokation von TrkA aus den CMD heraus die NGF-Signalgebung weniger effizient macht, da die 
Signalweiterleitung innerhalb von CMD offenbar durch die Bildung stabilerer Signalkomplexe begünstigt wird. Eine Abschwächung des Fortsatzwachstums bei Wegnahme von Cholesterin ließ sich direkt anhand der Intensität der MAPKAktivierung nach Gabe von NGF detektieren, die deutlich unter dem normalen Aktivitätsanstieg blieb.

In PC12-Zellen bewirkt die Gabe von Cholesterin-bindenden Reagentien ebenfalls eine Hemmung der MAPK-Aktivität und eine Erschwerung der Autophosphorylierung von TrkA (HUANG et al., 1999; PEIRO et al., 2000).

Diese Ergebnisse stimmen mit anderen Studien, die sich ebenfalls mit CMDassoziierten Wachstumsrezeptoren beschäftigen, überein. Aus einer Cholesterinreduktion resultiert eine deutlich herabgesetzte Rezeptor-Funktion in der Signalgebung. Beispiele sind der PDGF-Rezeptor (LIU 1997) und der Insulin-Rezeptor (IRS) (VAINIO et al., 2002). Die beschriebenen Auswirkungen eines Cholesterinmangels sind nicht auf das ZNS beschränkt. In diesem Zusammenhang beobachtete Mikol, dass es bei einem Cholesterinmangel auch im PNS zu einer Demyelinisierung von Schwann Zellen kommt (MICOL et al., 2002).

Eine gegenteilige Beobachtung wurde beim EGF-Rezeptor beschrieben, der nach Stimulation mit EGF aus CMD heraus verlagert wird. Hier bewirkt die Gabe von Methyl-ß-Cyclodextrin (1-2\%) daher eine Hyperaktivierung der MAPK (FURCHI et al., 1998; CHEN et al., 2001), weil eine Translokation des EGF-Rezeptors aus CMD heraus begünstigt wird. Auf der anderen Seite hemmt die Gabe von Cholesterin die Bindung von EGF und damit die Aktivierung des EGF-Rezeptors (RINGERIKE et al., 2001), der sich im inaktiven Zustand innerhalb von CMD befindet.

Diesen Resultaten zur Folge ist der TrkA-Rezeptor in der Signalgebung dem PDGFund Insulin-Rezeptor wesentlich ähnlicher als dem EGF-Rezeptor.

\subsubsection{Erfolgt eine indirekte Modulation der NGF/TrkA Signalkaskade via Caveolin-1 über die Cholesterin Homöostase?}

Obwohl Cholesterin ein wichtiger Bestandteil von Myelinmembranen ist, der die Myelinbildung begünstigt, ist bis heute nur sehr wenig über den genauen Ablauf des Cholesterin-Stoffwechsels in OL bekannt. Nachdem bislang immer nur eine direkte Regulation der NGF/TrkA durch Caveolin diskutiert wurde, könnte in OL auch ein indirekter Regulationsmechanismus zum Tragen kommen, bei dem Caveolin-1 über 
Regulation der Cholesterin Homöostase die NGF/TrkA-Signalkaskade ebenfalls beeinflussen kann:

Eine direkte Involvierung von Caveolin-1 bei der Regulation des Cholesteringleichgewichtes der Zelle verdeutlicht die Tatsache, dass ein Caveolin-1Knock-down mittels siRNA einen deutlichen Cholesterinanstieg von über 50\% in OL mit sich bringt, was zeigt, dass die Cholesterin Homöostase gestört ist, da offenbar ein wichtiger Transportmechanismus zum Erliegen kam.

Aus einer andauernden NGF-Exposition resultiert wie bereits erwähnt ein drastischer Anstieg der Caveolin-1-Expression; auf der anderen Seite nimmt der zelluläre Cholesterinspiegel deutlich ab. Daher bestünde ein möglicher Regulationsmechanismus darin, dass Caveolin-1 bei Überexpression im verstärkten Maße Cholesterin herunterreguliert, was sich schließlich negativ auf die Signalgebung auswirkt und sie so abschwächt, da ein Cholesterinmangel aller Voraussicht nach mit einer Abnahme von CMD verbunden ist.

Ein vergleichbarer Mechanismus wurde bereits bei NIH3T3-Fibroblasten postuliert (ROY et al., 1999). Hier inhibiert Caveolin unter Reduktion des Cholesterinspiegels in der Plasmamembran die Aktivierung von Raf durch H-Ras. Bei Zugabe von Cholesterin unterbleibt die Hemmung.

\subsection{Quintessenz der Arbeit}

In dieser Arbeit wurde gezeigt, dass die NGF/TrkA-Signalkaskade nicht wie ursprünglich isoliert zu betrachten ist, sondern einhergeht mit einer in Mikrodomänenorganisierten Plasmamembran. Die anfangs aufgestellte Arbeitshypothese, ob eine Interaktion von TrkA mit Caveolin bzw. CMD erfolgt, und ob dadurch eine Modulation der NGF/TrkA-Signalkaskade erkennbar wird, bestätigte sich. Die Bedeutung von caveolinhaltigen Membranabschnitten ist angesichts der bestehenden Organisation von TrkA innerhalb von CMD sowie der inhibitorischen Wirkung der CSD auf die NGF/TrkA-Signalkaskade abhängig von der Überschreitung eines bestimmten Schwellenwertes, ab dem Caveolin-1 als positiver oder negativer Regulator fungiert. Zudem erwies sich die CMD-Komponente Cholesterin als weiterer Faktor für eine optimierte Signaltransduktion unter NGF, da hierdurch eine Autophosphorylierung von TrkA begünstigt wird. 


\subsection{Zusammenfassung der Arbeit}

Caveolinhaltige Mikrodomänen (CMD), die die morphologisch definierte Flaschenhalsform der Caveolae miteinschließen, sind sphingomyelin-, glykosphingolipid- und cholesterinreiche Membranabschnitte innerhalb der eukaryotischen Zellmembran. "CMD“ wird in dieser Arbeit als eine Art Oberbegriff verwendet. Caveolae sind demnach als Sonderform von CMD anzusehen. Der Befund, dass die Anzahl der im TEM dargestellten Caveolae nicht mit der Menge an detektiertem Caveolin-1 korreliert, zeigte, dass neben der kolbenförmigen klassischen Caveolae-Form mindestens noch eine weitere caveolinhaltige Mikrodomänenform existieren musste. Diese wird in der Arbeit als CMD bezeichnet und kommt in Schweine-OL häufiger vor als die klassischen Caveolae. Die Morphologie sowie die physiologischen Aufgaben von CMD sind vielfältig und reichen vom zellulären Transport bis zur Regulation von Signalkaskaden. Hierzu gehören TyrosinkinaseRezeptor-gesteuerte Signalkaskaden, wie z.B. die über PDGFR und EGFR laufenden Signalkaskaden, die vergleichbar mit der von uns dargestellten NGF/TrkASignaltransduktion sind. Daraus ergab sich schließlich die Fragestellung, ob TrkA und andere Komponenten der NGF/TrkA-Signalkaskade in CMD lokalisiert sind und ob es dadurch zu einer Modulation der NGF/TrkA-Signalkaskade kommt. Außerdem sollte der Einfluss der CMD Komponenten Caveolin und Cholesterin auf die NGF/TrkASignaltransduktion untersucht werden.

In dieser Arbeit gelang es Caveolin-1 in Schweine-OL darzustellen; transmissionselektronenmikroskopisch konnten morphologisch Caveolae in ihrer klassischen Kolbenform nachgewiesen werden. Innerhalb der CMD-angereicherten Fraktionen, in denen etwa 60\% des gesamten Cholesterins enthalten sind, wurden die beiden Neurotrophinrezeptoren TrkA und p75 ${ }^{\text {NTR }}$ sowie p21 Ras und die MAPK Erk1 und Erk2 detektiert. Dabei wurde die Bedeutung einer möglichen Interaktion von Caveolin-1 oder TrkA mit p75 ${ }^{\mathrm{NTR}}$ in dieser Arbeit nicht weiter berücksichtigt. Neben dem gemeinsamen Vorkommen innerhalb von CMD, dargestellt durch konfokale Lasermikroskopie, konnte mithilfe von Coimmunpräzipitation eine Interaktion von Caveolin-1 und TrkA nachgewiesen werden, wobei allerdings immer nur ein Teil von TrkA mit CMD/Caveolin-1 assoziiert ist; der Rest befindet sich außerhalb von Mikrodomänen. 
Die Stimulation von Schweine-OL mit NGF führte neben einem gesteigerten Fortsatzwachstum im weiteren Verlauf zu einer deutlichen Hochregulation der Caveolin-1-Expression, die auf mRNA-Ebene und im Western Blot gezeigt werden konnte. Möglicherweise wirkt sich eine höhere Caveolin-1-Expression inhibierend auf die NGF/TrkA-Signaltransduktion aus und ist der Grund dafür, dass ältere Zellkulturen, deren Caveolin-1-Expression erhöht ist, mit einer wesentlich geringeren MAPKAktivität auf NGF antworten als jüngere Kulturen. Da die MAPK-Aktivität mit dem Fortsatzwachstum von OL korreliert, könnte eine abnehmende MAPK-Aktivität ein Indikator dafür sein, dass eine OL-Antwort auf NGF sich durch Hochregulation von Caveolin begrenzen lässt. Die Hemmung erfolgt wahrscheinlich durch die Caveolin-1Scaffolding Domäne (AS: 82-101). Unter NGF führte die Behandlung der Zellen mit der Caveolin-1-Scaffolding Domäne (Cavtratin) ebenfalls zu einer Inhibition der MAPK-Aktivität. Auf der anderen Seite resultierte aus einem mittels siRNA herbeigeführten Caveolin-1-Knock-down, der mit einer reduzierten Anzahl an CMD verbunden ist, ein abgeschwächtes Fortsatzwachstum der Zellen nach Gabe von NGF. Dies ließ sich durch eine abnehmende MAPK-Aktivität in einem “In-Gel Kinase Assay“ bestätigen. Ein weiterer Effekt, der nach NGF-Stimulation auftrat, war eine zunehmende Phosphorylierung von Caveolin an Tyrosin-14. Diese setzte bereits $10 \mathrm{~min}$ nach NGF-Gabe ein und übertraf den geringen Grundlevel an Caveolin pY14 in unbehandelten Zellen. Bemerkenswert war zudem der Befund, dass die Caveolin pY14 und die Phosphorylierung von TrkA in der gleichen Zelle ablaufen und sich durch K252a einem spezifischen Tyrosinkinase Inhibitor hemmen lassen.

Die Behandlung von Schweine-OL mit Cholesterin, einer wichtigen Komponente der CMD, begünstigte die Fortsatzbildung der OL. Bei Kombination mit NGF wurde der bekannte NGF-Effekt auf die Fortsatzbildung durch Cholesterin verstärkt. Dagegen führte die Wegnahme von Cholesterin durch Methyl-ß-Cyclodextrin, die mit einer Zerstörung von CMD einhergeht, zu einem reduzierten Fortsatzwachstum und einer geringeren MAPK-Aktivität unter NGF. Dies bestätigte die Annahme, dass CMD für die NGF/TrkA-Signalgebung relevant sind, da die Komplexbildung mit anderen Signalmolekülen innerhalb der Mikrodomänen begünstigt wird. Caveolin und Cholesterin sind innerhalb von CMD eng miteinander assoziiert. Außerdem fungiert Caveolin als Cholesterin-Carrier vom Endoplasmatischen Reticulum/Golgi-Apparat zur Plasmamembran. In Folge eines Caveolin-1-Knock-downs stieg der Cholesterinspiegel der Zellen an, da ein wichtiges Cholesterin-Transportsystem durch das Fehlen von 
Caveolin-1 zum Erliegen kam. Auf der anderen Seite resultierte aus einem NGFinduzierten Anstieg der Caveolin-1-Expression eine Abnahme des Cholesterinspiegels der Zellen, die über eine erhöhte Ausfuhr von Cholesterin zustande kommen könnte.

Somit weisen alle in dieser Arbeit gesammelten Befunde auf eine Involvierung von CMD sowie ihrer Komponenten Caveolin-1 und Cholesterin in die NGF/TrkASignaltransduktion hin. 


\subsection{Referenzen}

Agrawal H.C., Trotter J.L., Burton R.M., Mitchel R.F. (1973): Evidence for a precursor role of a myelin subfraction. Biochem J 140: 99-109.

Althaus H.H., Montz H., Neuhoff V., Schwartz P. (1984): Isolation and cultivation of mature oligodendroglial cells. Naturwissenschaften 71: 309-315.

Althaus H.H., Schröter J., Spoerri P., Schwartz P., Klöppner S., Rohmann A., Neuhoff V. (1991): Protein Kinase C stimulation enhances the process formation of adult oligodendrocytes and induces proliferation. J Neurosci Res 29: 481-489.

Althaus H.H., Klöppner S., Schmidt-Schultz T., Schwartz P. (1992): Nerve growth factor induces proliferation and enhances fiber regeneration in oligodendrocytes isolated from adult pig brain. Neurosci Lett 135: 219-223.

Althaus H.H., Hempel R., Klöppner S., Engel J., Schmidt-Schultz T., Kruska L., Heumann R. (1997a): Nerve growth factor signal transduction in mature pig oligodendrocytes. J Neurosci Res 50: 729-742.

Althaus H.H., Schmidt-Schultz T., Klöppner S. (1997b): Mature pig astrocytes do not respond to NGF as oligodendrocyte do. In: Jeserich G., Althaus H.H., RichterLandsberg C., Heumann R. (Hrsg.): "Molecular Signalling and Regulation in Glial Cells”, Springer-Verlag: 20-27.

Althaus H.H. and Richter-Landsberg C. (2000): Glial cells as targets and producers of neurotrophins. Int Rev Cytol 197: 203-275.

Althaus H.H., Mursch K., Klöppner S. (2001): Differential response of mature TrkA/p75 ${ }^{\text {NTR }}$ expressing human and pig oligodendrocytes: Aging does it matter? Microscopy Research and Techniques 52: 689-699.

Althaus H.H. (2004): Remyelination in multiple sclerosis: a new role for neurotrophins? Prog Brain Res 146: 415-432. 
Armstrong R.C., Dorn H.H., Kufta C.V., Friedman E., Dubois-Dalq M.E. (1992):

Pre-oligodendrocytes from adult human CNS. J Neurosci 12: 1538-1547.

Armstrong R.C. (1998): Isolation and characterization of immature oligodendrocyte lineage cells. Methods 16: 282-292.

Arvanitis D.N., Wang H., Bagshaw R.D., Callahan J.W., Boggs J.M. (2004): Membrane-associated estrogen receptor and caveolin-1 are present in central nervous system myelin and oligodendrocyte plasma membranes. J Neurosci Res 75: 603-613.

Atger V.M., Moya M., Stoudt G.W., Rodrigueza W.V., Phillips M.C., Rothblat G.H. (1997): Cyclodextrins as catalysts for the removal of cholesterol from makrophage foam cells. J Clin Invest 99: 773-780.

Baker P.A., Shooter E.M. (1994): Disruption of NGF binding to the low affinity neurotrophin receptor $\mathrm{p}^{\mathrm{NTR}}$ reduces NGF binding to TrkA on PC12 cells. Neuron 13: 203-215.

Barbacid M. (1995): Neurotrophic factors and their receptors. Curr Opin Cell Biol 7: 148-155.

Bartzokis G. (2004): Age related myelin breakdown: a developmental model of cognitive decline and Alzheimer?x2019;s disease. Neurobiology of Aging. 25: 5-18.

Bender F., Montoya M., Monardes V., Leyton L., Quest A.F.G. (2002): Caveolae and caveolae-like membrane domains in cellular signaling and disease: identification of downstream targets for the tumor suppressor protein caveolin-1. Biol Res 35: 139-150.

Bernatchez P.N., Bauer P.M., Yu J., Prendergast J.S., He P., Sessa W.C. (2005): Dissecting the molecular control of endothelial NO synthase by caveolin-1 using cellpermeable peptides. Proc Natl Acad Sci 102: 761-766. 
Bickel P.E., Scherer P.E., Schnitzer J.E., Oh P., Lisanti M.P., Lodish H.F. (1997): Flotillin and epidermal surface antigen define a new family of caveolae-associated integral membrane proteins. J Biol Chem 272: 13793-13802.

Bilderback T.R., Grigsby R.J., Dobrowsky R.T. (1997): Association of p75(NTR) with caveolin and localization of neurotrophin-induced sphingomyelin hydrolysis to caveolae. J Biol Chem 272: 10922-10927.

Bilderback T.R., Gazula V.R., Lisanti M.P., Dobrowsky R.T. (1999): Caveolin interacts with TrkA and p75(NTR) and regulates neurotrophin signalling pathways. J Biol Chem 274: 257-63.

Bist A., Fielding P.E., Fielding C.J. (1997): Two sterol regulatory element-like sequences mediate up-regulation of caveolin gene transcription in response to low density lipoprotein free cholesterol. Proc Natl Acad Sci 94: 10693-10698.

Bothwell M. (1995): Functional interactions of neurotrophins and neurotrophin receptors. Ann Rev Neurosci 18: 223-253.

Boutros T., Croze E., Yong V.W. (1997): Interferon-ß is a potent promotor of nerve growth factor production by astrocytes. J Neurochem 69: 939-946.

Bradford M.M. (1976): A rapid and sensitive method for the quantitation of microgram quantities of protein utilizing the principle of protein-dye binding. Anal Biochem. 72: 248-254.

Brian A., Pierchala T., Ginty D.D. (1999): Characterization of an NGF-P-TrkA retrograde-signaling complex and age-dependent regulation of TrkA phosphorylation in sympathetic neurons. J Neurosci 19: 8207-8218.

Brown D.A., Rose J.K. (1992): Sorting of GPI-anchored proteins to glycolipidenriched membrane subdomains during transport to the apical cell surface. Cell 68: 533544. 
Bruce-Keller A.J. (1999): Microglial-neuronal interactions in synaptic damage and recovery. J Neurosci Res 58: 191-201.

Bucci M., Gratton J.P., Rudic R.D., Acevedo L., Roviezzo F., Cirino G., Sessa W.C. (2000): In vivo delivery of the caveolin-1 scaffolding domain inhibits nitric oxide synthesis and reduces inflammation. Nature Med 6: 1362-1367.

Burnette W.N. (1981): Western Blotting: Electrophoretic transfer of protein from sodium dodecyl sulfate-polyacrylamide gels to unmodified nitrocellulose and radiographic detection with antibody and radioiodinated protein A. Anal Biochem 112: 195-203.

Byravan S., Foster L.M., Phan T., Verity A.N., Campagnoni A.T. (1994): Murin oligodendroglial cells express nerve growth factor. Natl Acad Sci 91: 8812-8816.

Calderon R.O., DeVries G.H. (1997): Lipid composition and phospholipid asymmetry of membranes from a schwann cell line. J Neurosci Res 49: 372-380.

Cameron P.L., Ruffin J.W., Bollag R., Rasmussen H. and Cameron S.C. (1997): Identification of caveolin and caveolin-related proteins in the brain. J Neursci 17: 1-12.

Caselli A., Taddei M.L., Manao G., Camici G., Ramponi G. (2001): Tyrosinephosphorylated caveolin is a physiological substrate of the low $\mathrm{M}_{\mathrm{r}}$ protein-tyrosine phosphatase. J Biol Chem 276: 18849-18854.

Ceresa B.P., Schmidt S.L. (2000): Regulation of signal transduction by endocytosis. Curr Opin Cell Biol 12: 204-210.

Chamberlaine L.H. (2004): Detergents as tools for the purification and classification of lipid rafts. FEBS 559: 1-5.

Chang W.J., Rothberg K.G., Kamen B.A., Anderson R.G. (1992): Lowering cholesterol content of MA104 cells inhibits receptor-mediated transport of folate. J Cell Biol 118: 63-69. 
Chang W.J., Ying Y.S., Rothberg K.G., Hooper N.M., Turner A.J., Gambliel H.A., De Gunzburg J., Mumby S.M., Gilman A.G., Anderson R.G. (1994): Purification and characterization of smooth muscle cell caveolae. 126: 127-138.

Chao M.V. (1994): The p75 neurotrophin receptor. J Neurobiol 25: 1373-1378.

Chen X., Resh M.D. (2001): Activation of mitogen-activated protein kinase by membrane-targeted Raf chimeras is independent of raft localization. J Biol Chem 276: 34617-34623.

Cheng L., Esch F.S., Marchionni M.A., Mudge A.W. (1998): Control of schwann cell survival and proliferation: autocrine factors and neuregulins. Mol Cell Neurosci 12: 141-156.

Christian A.E., Haynes M.P., Phillips M.C. Rothblat G.H. (1997): Use of cyclodextrins for manipulating cellular cholesterol content. J Lipid Res 38: 2264-2272.

Cohen G., Ren R., Baltimore D. (1995): Modular binding domains in signal transduction proteins. Cell 80: 237-248.

Cohen R.I., Marmur R., Norton W.T., Mehler M.F., Kessler J.A. (1996): Nerve growth factor and neurotrophin-3 differentially regulate the proliferation and survival of developing rat brain oligodendrocytes. J Neurosci Res 16: 6433-6442.

Cohen A.W., Hnasko R., Schubert W., Lisanti M.P. (2004): Role of caveolae and caveolins in health and disease. Physiol Rev 84: 1341-1379.

Couet J., Li S., Okamoto T., Ikezu T, Lisanti M.P. (1997): Identification of peptide and protein ligands for the caveolin scaffolding domain. Implications for the interaction of caveolin with caveolae-associated proteins. J Biol Chem 272: 6525-6533.

Couet J., Belanger M.M., Roussel E., Drolet M.C. (2001): Cell biology of caveolae and caveolin. Adv Drug Deliv Rev 49: 223-235. 
Das K., Lewis R.Y., Scherer P.E., Lisanti M.P. (1999): The membrane-spanning domains of caveolins-1 and -2 mediate the formation of caveolin hetero-oligomers. Implications for the assembly of caveolae membranes in vivo. J Biol Chem 274: 1872118726.

Daum G., Eisenmann-Tappe I., Fies H.W., Troppmair J., Rapp U.R. (1994): The ins and outs of raf kinases. TIBS 19: 474-480.

Dietzen D.J., Hastings W.R., Lublin D.M. (1995): Caveolin is palmitoylated on multiple cysteine residues: palmitoylation is not necessary for localization of caveolin to caveolae. J Biol Chem 270: 6838-6842.

Dobrowsky R.T., Werner M.H., Castellino A.M., Chao M.V., Hannun Y.A. (1994): Activation of the sphingomyelin cycle through the low-affinity neurotrophin receptor. Science 265: 1596-1599.

Dobrowsky R.T., Carter B.D. (1998): Coupling of the p75 neurotrophin receptor to sphingolipid signaling. Ann N Y Acad Sci 845: 32-45.

Drevot P., Langlet C., Guo X.J., Bernard A.M., Colard O., Chauvin J.P., Lasserre R., He H.T. (2002): TCR signal initiation machinery is pre-assembled and activated in a subset of membrane rafts. EMBO J 21: 1899-1908.

Dubois-Dalcq M., Armstrong R.C. (1992): The oligodendrocyte lineage during myelination and remyelination. In: Martenson R.E. (Hrsg.): Myelin: Biology and Chemistry. CRC Press, Boca Raton, Ann Arbor, London 81-122.

Dyer C.A., Matthieu J.M. (1994): Antibodies to myelin/oligodendrocyte-specific protein and myelin/oligodendrocyte glycoprotein signal distinct changes in the organization of cultured oligodendroglial membrane sheets. J Neurochem 62: 777-787.

Eckert G.P., Igbavboa U., Müller W.E., Wood W.G. (2003): Lipid rafts of purified mouse brain synaptosomes prepared with or without detergent reveal different lipid and protein domains. Brain Res 962: 144-150. 
Engelman J.A., Schlegel A., Parenti M., Okamoto T. and Lisanti M.P. (1998):

Expression of caveolin-1 and -2 in differentiating PC12 cells and dorsal root ganglion neurons: Caveolin-2 is up-regulated in response to cell injury. Proc Natl Acad Sci USA 95: 10257-10262.

Epa W.R., Markovska K., Barett G.L. (2004): The p75 neurotrophin receptor enhances TrkA signalling by binding to Shc and augmentin its phosphorylation. $\mathrm{J}$ Neurochem 89: 344-353.

Evans W.E., Coyer R.L., Sandusky M.F., Van Fleet M.J., Moore J.G., Nyquist S.E. (2003): Characterization of membrane rafts isolated from rat sertoli cell cultures: caveolin and flotillin-1 content. J Androl 24: 812-821.

Fan J.Y., Carpentier J.L., van Obberghen E., Grunfeld C., Gorden P., Orci L. (1983): Morphological changes of the 3T3-L 1 fibroblast plasma membrane upon differentiation to the adipocyte form. J Cell Sci 61: 219-230.

Feron O., Dessy C., Opel D.J., Arstall M.A., Kelly R.A., Michel T. (1998): Modulation of the endothelial nitric-oxide synthase-caveolin interaction in cardiac myocytes. Implications for the autonomic regulation of heart rate. J Biol Chem 273: 30249-30254.

Fielding P.E., Fielding C.J. (1995): Plasma membrane caveolae mediate the efflux of cellular free cholesterol. Biochemistry 34: 14288-14292.

Fielding C.J., Bist A., and Fielding P.E. (1997a): Caveolin mRNA levels are upregulated by free cholesterol and down-regulated by oxysterols in fibroblast monolayers. Proc Natl Acad Sci USA 94: 3753-3758.

Fielding C.J., Fielding P.E. (1997b): Intracellular cholesterol transport. J Lipid Res 38: 1503-1521.

Fielding C.J., Fielding P.E. (2001a): Caveolae and intracellular trafficking of cholesterol. Adv Drug Deliv Rev 49: 251-264. 
Fielding C.J., Fielding P.E. (2001b): Cellular cholesterol efflux. Biochim Biophys Acta 1533: 175-189.

Fielding C.J. (2006): Lipid rafts and caveolae. Wiley-Vch-Verlag.

Fra A.M., Williamson E., Simons K., Parton R.G. (1995): De novo formation of caveolae in lymphocytes by expressing of VIP21-caveolin. Proc Natl Acad Sci 92: 8655-8659.

Frank P.G., Marcel Y.L., Connelly M.A., Lublin D.M., Franklin V., Williams D.L., Lisanti M.P. (2002): Stabilization of caveolin-1 by cellular cholesterol and scavenger receptor class B type I. Biochemistry 41: 11931-11940.

Friedman G.C. and O’Leary D.D.M. (1996): Eph receptor tyrosine kinases and their ligands in neural development. Curr Opin Neurobiol 6: 127-133.

Fujimoto T., Kogo H., Nomura R., Une T. (2000): Isoforms of caveolin-1 and caveolar structure. J Cell Sci 113: 3509-3517.

Furuchi T. and Anderson G.W. (1998): Cholesterol depletion of caveolae causes hyperactivation of extracellular signal-related kinases (ERK). J Biol Chem 273: 2109921104.

Galbiati F., Volonte D., Gil O., Zanazzi G., Salzer J.L., Sargiakomo M., Scherer P.E., Engelman J.A., Schlegel A., Parenti M., Okamoto T., Lisanti M.P. (1998): Expression of caveolin-1 and -2 in differentiating PC12-cells and dorsal root ganglion neurons: Caveolin-2 is up-regulated in response to cell injury. Proc Natl Acad Sci 95: 10257-10262.

Gamble W., Vaughan M., Kruth H.S., Avigan J. (1978): Procedure for determination of free and total cholesterol in micro- or nanogram amounts suitable for studies with cultured cells. J Lipid Res, Volume 19, 1068-1070. 
Gard A.L., Pfeiffer S.E. (1990): Two proliferative stages of the oligodendrocyte lineage (A2B5+O4- and O4+GalC-) under different mitogenic control. Neuron 5: 615625.

Gebicke-Härter P.J., Althaus H.H., Rittner I., Neuhoff V. (1984): Bulk separation and long-term culture of oligodendrocytes from adult pig brain. I. Morphological studies. J Neurochem 42: 357-368.

Glenney J.R. (1989): Tyrosine phosphorylation of a $22 \mathrm{kD}$ protein is correlated with transformation with rous sarcoma virus. J Biol Chem 264: 20163-20166.

Glenney J.R. (1992): The sequence of human caveolin reveals identity with VIP 21, a component of transport vesicles. FEBS Lett 314: 45-48.

Gonzalez D., Dees W.L., Hiney J.K., Ojeda S.R., Saneto R.P. (1990): Expression of ß-nerve growth factor in cultured cells derived from the hypothalamus and cerebral cortex. Brain Res 511: 249-258.

Gonzales E., Nagiel A., Lin A.J., Golan D.E., Michel T. (2004): Small interfering RNA-mediated down-regulation of caveolin-1 differentially modulates signaling pathways in endothelial cells. J Biol Chem 279: 40659-40669.

Gradient R.A., Cron K. C., Otten U. (1990): Interleukin-1 beta and tumor necrosis factor-alpha synergistically stimulate nerve growth factor (NGF) release from cultured rat astrocytes. Neurosci Lett 117: 335-340.

Graf C.A., Conell P.M., van der Westhuyzen D.R., Smart E.J. (1999): SR-BI promotes the selective uptake of HDL cholesterol esters into caveolae. J Biol Chem 274: 12043-12048.

Gratton J.P., Lin M.I., Yu J., Weiss E.D., Jiang Z.L., Fairchild T.A., Iwakiri Y., Grosmann R., Claffey K.P., Cheng Y.C., Sessa W.C. (2003): Selective inhibition of tumor microvascular permeability by cavtratin blocks tumor progression in mice. Cancer Cell 4: 31-39. 
Greene L.A., Kaplan D.R. (1995): Early events in neurotrophin signalling via trk and p75 receptors. Curr Opin Neurobiol 5: 579-587.

Griffoni C., Spisni E., Santi S., Riccio M., Guarnieri T., Tomasi V. (2000): Knockdown of caveolin-1 by antisense oligonucleotides impairs angiogenesis in vitro and in vivo. Biochem Biophys Res Commun 276: 756-761.

Gustavsson J., Parpal S., Karlsson M., Ramsing C., Thorn H., Borg M., Lindroth M., Peterson K.H., Magnusson K.E. Stralfors P. (1999): Localisation of the insulin receptor in caveolae of adipocyte plasma membrane. FASEB J 13: 1961-1971.

Hailstones D., Sleer L.S., Parton R.G., Stanley K.K. (1998): Regulation of caveolin and caveolae by cholesterol in MDCK cells. J Lipid Res 39: 369-379.

Hantzopoulos P.A., Suri C., Glass D.J., Goldfarb M.P., Yancopoulos G.D. (1994): The low affinity NGF receptor, p75, can collaborate with each of the trks to potentiate functional responses to the neurotrophins. Neuro 13: 187-201.

Harder T., Simons K. (1997): Caveolae, DIGs, and the dynamics of sphingolipidcholesterol microdomains. Curr Opin Cell Biol 9: 534-542.

Hardy R., Reynolds R. (1993): Rat cerebral cortical neurons in promary culture release a mitogen specific for early (GD3+/O4-) oligodendoglial progenitors. J Neurosci Res 34: 589-600.

Heese K., Hock C., Otten U. (1998): Inflammatory signals induce neurotrophin expression in human microglial cells. J Neurochem 70: 699-707.

Heilstones D., Sleer L.S., Parton R.G., Stanley K.K. (1998): Regulation of caveolin and caveolae by cholesterol in MDCK cell. J Lipid Res 39: 369-379.

Helms J.B., Zurzolo C. (2004): Lipids as targeting signals: lipid rafts and intracellular trafficking. Traffic 5: 247-254. 
Hempstead B.L., Martin-Zanca D., Kaplan D.R., Parada L.F., Chao M.V. (1991): High-affinity NGF binding requires coexpression of the trk proto-oncogene and the low-affinity NGF receptor. Nature 350: 678-683.

Hempstead B. (2002): The many faces of $\mathrm{p} 75^{\mathrm{NTR}}$. Curr Opin Neurobiol 12: 260-267.

Heumann R. (1994): Neurotrophin signalling. Curr Opin Neurobiol 4: 668-679.

Hnasko R., Lisanti M.P. (2003): The biology of caveolae: lessons from caveolin knockout mice and implications for human disease. Mol Interv 3: 445-464.

Huang C-S., Zhou J., Feng A.K., Lynch C.C., Klumperman J., DeArmond S.J., Mobley W.C. (1999): Nerve growth factor signaling in caveolae-like domains at the plasma membrane. J Biol Chem 51: 36707-36714.

Hutton L.A., de Vellis J., Perez-Polo J.R. (1992): Expression of p75 ${ }^{\mathrm{NGFR}}$, TrkA, and TrkB mRNA in rat C6 glioma and type I astrocyte cultures. J Neurosci Res 32: 375-383.

Hutton L.A., Perez-Polo J.R. (1995): In vitro glial responses to nerve growth factor. J Neurosci Res 41: 185-196.

Hutvagner G. (2005): Small RNA asymmetry in RNAi: Function in RISC assembly and gen regulation. FEBS Lett 579: 5850-5857.

Ishitsuka R., Sato S.B., Kobayashi T. (2005): Imaging lipid rafts. J Biochem 137: 249-254.

Ju H., Zou R., Venema V.J., Venema R.C. (1997): Direct interaction of endothelial nitric-oxide synthase and caveolin-1 inhibits synthase activity. J Biol Chem 272: 1852218525.

Kameshita, I., Fujisawa H. (1989): A sensitive mothod for detection of calmodulindependent protein kinases II activity in sodium dodecyl sulfate-polyacrylamide gel. Anal Biochem 183: 139-143. 
Kandror K.V., Stephens J.M., Pilch P.F. (1995): Expression and compartmentalization of caveolin in adipose cells: coordinate regulation with and structural segregation from GLUT4. J Cell Biol 129: 999-1006.

Kimura A., Mora S., Shigematsu S., Pessin J.E., Saltiel A.R. (2002): The insulin receptor catalyzes the tyrosine phosphorylation of caveolin-1. J Biol Chem 277: 3015330158.

Kogo H., Fujimoto T. (2000): Caveolin-1 isoforms are encoded by distinct mRNAs. Identification of mouse caveolin-1 mRNA variants caused by alternative transcription initiation and splicing. FEBS Lett 456: 119-123.

Kogo H., Aiba T., Fujimoto T. (2004): Cell type-specific occurrence of caveolin-1 alpha and -1 beta in the lung caused by expression of distinct mRNAs. J Biol Chem 279: 25574-25581.

Kramer E.M., Schardt A., Nave K.A. (2001): Membrane traffic in myelinating oligodendrocytes. Microsc Res Tech 52: 656-671.

Kukushkin A.N., Abramova M.V., Svetlikova S.B., Drieva Z.A., Pospelova T.V., Pospelov V.A. (2002): Downregulation of c-fos gene transcription in cells transformed by E1A and cHa-Ras oncogenes: a role of sustained activation of MAP/ERK kinase cascade and of inactive chromatin structure at c-fos promotor. Oncogene 21: 719-730.

Kumar S., de Vellis J. (1996): Neurotrophin activates signal transduction in oligodendroglial cells: expression of functional TrkC receptor isoforms. J Neurosci Res 44: 490-498.

Kurzchalia T., Dupree P., Parton RG, Kellner R, Virta H, Lehnert M, and Simons K. (1992): VIP 21, A 21-kD membrane protein is an integral component of trans-golginetwork-derived transport vesicles. J Cell Biol 118: 1003-1014.

Kurzchalia T.V., Dupree P., Monier S. (1994): VIP21-caveolin, a protein of the transgolgi network and caveolae. FEBS Lett 346: 88-91. 
Kurzchalia T.V., Parton R.G. (1999): Membrane microdomains and caveolae. Curr Opin Cell Biol 11: 424-431.

Lay S.L., Kurzchalia T.V. (2005): Getting rid of caveolins: phenotypes of caveolindeficient animals. Biochim Biophys Acta 1746: 322-333.

Lee H., Volonte D., Galbiati F., Iyengar P., Lublin D.M., Bregman D.B., Wilson M.T., Campos-Gonzalez R., Bouzahzah B., Pestell R.G., Scherer P.E., Lisanti M.P. (2000): Constitutive and growth factor-regulated phosphorylation of caveolin-1 occurs at the same site (Tyr-14) in vivo: identification of a c-Src/Cav-1/Grb7 signaling cassette. Mol Endocrinol 14: 1750-1775.

Lee H., Xie L., Luo Y., Lee S.Y., Lawrence D.S., Wang X.B., Sotgia F., Lisanti M.P. (2006): Identification of phosphocaveolin-1 as a novel protein tyrosine phosphatase 1B substrate. Biochem 45: 234-240.

Lemke G. (1988): Unwrapping the genes of myelin. Neuron 1: 535-543.

Leuschner P.J., Ameres S.L., Kueng S., Martinez J. (2006): Cleavage of the siRNA passenger strand during RISC assembly in human cells. EMBO Rep in press.

Lewin G.R., Barde Y.A. (1996): Physiology of the neurotrophins. Ann Rev Neurosci 19: 289-317.

Li S., Okamoto T., Chun M., Sargiacomo M., Casanova J.E., Hansen S.H., Nishimoto I., Lisanti M.P. (1995): Evidence for a regulated interaction of heterotrimeric G proteins with caveolin. J Biol Chem 270: 15693-15701.

Li S, Seitz R, Lisanti M.P. (1996a): Phosphorylation of caveolin by Src tyrosine kinases: the $\alpha$-isoform of caveolin is selectively phosphorylated by v-Src in vivo. J Biol Chem 271: 3863-3868. 
Li S., Couet J., Lisanti M.P. (1996b): Src tyrosine kinases, G $\alpha$ subunits, and H-Ras share a common membrane-anchored scaffolding protein, caveolin. Caveolin binding negatively regulates the auto-activation of Src tyrosine kinases. J Biol Chem 271: 29182-29190.

Li S., Song K.S., Koh S.S., Kikuchi A., Lisanti M.P. (1996c): Baculovirus-based expression of mammalia caveolin in Sf21 insect cells. A model system for the biochemical and morphological study of caveolae biogenesis. J Biol Chem 271: 2864728654.

Lisanti M.P., Tang Z.T., Sargiacomo M. (1993): Caveolin forms a heterooligomeric protein complex that interacts with an apical GPI-linked protein: implications for the biogenesis of caveolae. J Cell Biol 123: 595-604.

Lisanti M.P., Scherer P., Tang Z.L., Sargiacomo M. (1994a): Caveolae, caveolin and caveolin-rich membrane domains: a signalling hypothesis. Trends Cell Biol 4: 231-235.

Lisanti M.P., Scherer P.E., Vidugiriene J., Tang Z.L., Hermanoski-Vosatka A., Tu Y.H., Cook R.F., Sargiacomo M. (1994b): Characterization of caveolin-rich membrane domains isolated from an endothelial-rich source: implications for human disease. J Cell Biol 126: 111-126.

Lisanti M.P., Tang Z.T., Scherer P., and Sargiacomo M. (1995): Caveolae purification and GPI-linked protein sorting in polarized epithelia. Methods Enzymol 250: 655-668.

Liscovitch M. Lavie Y. (2000): Multidrug resistance: a role for cholesterol efflux pathways? Trends Biochem Sci 25: 530-534.

Liu J., Oh P., Horner T., Rogers R.A., Schnitzer J.E. (1997): Organized endothelial cell surface signal transduction in caveolae distinct from glycosylphosphatidylinositolanchored protein microdomains. J Biol Chem 272: 7211-7222.

Machleidt T., Li W.P., Liu P., Anderson R.G. (2000): Multiple domains in caveolin-1 control its intracellular traffic. J Cell Biol 148: 17-28. 
Marais R., Light Y., Paterson H.F., Marshall C.J. (1995): Ras recruits Raf-1 to the plasma membrane for activation by tyrosine phosphorylation. EMBO J 14: 3136-3145.

Martin S., Parton R.G. (2005): Caveolin, cholesterol, and lipid bodies. Sem Cell Dev Biol 16: 163-174.

Martinez J., Patkaniowska A., Lührmann R., Tuschl T. (2002): Single stranded antisense siRNA guide target RNA cleavage in RNAi. Cell 110: 563-573.

Matveev S., van der Westhuyzen D.R., Smart E.J. (1999): Co-expression of scavenger receptor BI and caveolin-1 is associated with enhanced selective cholesteryl ester uptake in THP-1 makrophages. J Lipid Res 40: 1647-1654.

Matveev S., Li X., Everson W., Smart E.J. (2001): The role of caveolae and caveolin in vesicle-dependent and vesicle-independent trafficking. Adv Drug Deliv Rev 49: 237250.

Mcdonald J.L., Pike L. (2005): A simplified method for the preparation of detergentfree lipid rafts. J Lipid Res 46: 1061-1067.

McTigue D.M., Horner P.J., Stokes B.T., Gage F.H. (1998): Neurotrophin-3 and brain-derived neurotrophic factor induce oligodendrocyte proliferation and myelination of regenerating axons in the contused adult rat spinal cord. J Neurosci 18: 5354-5365.

Mikol D.D., Hong H.L., Cheng H-L., Feldman E.L. (1999): Caveolin-1 expression in schwann cells. Glia 27: 39-52.

Mikol D.D., Scherer S.S., Duckertt S.J., Hong H.L. and Feldman E.L. (2002): Schwann cell caveolin-1 expression increases during myelination and decreases after axotomy. Glia 38: 191-199.

Monier S., Parton R.G., Vogel F., Behlke J., Henske A., Kurzchalia T.V. (1995): VIP21-caveolin, a membrane protein constituent of caveolar coat, oligomerizes in vivo and in vitro. Mol Biol Cell 6: 911-927. 
Monier S., Dietzen D.J., Hastings W.R., Lublin D.M., Kurzchalia T.V. (1996): Oligomerization of VIP21-caveolin in vitro is stabilized by long chain fatty acylation or cholesterol. FEBS Lett 388: 143-149.

Mosmann T. (1983): Rapid colorimetric assay for cellular growth and survival: application to proliferation and cytotoxicity assays. J Immunol Methods 65: 55-63.

Murata M., Peranen J., Schreiner R., Wieland F., Kurzchalia T.V., Simons K. (1995): VIP21/caveolin is a cholesterol-binding protein. Proc Natl Acad Sci 92: 1033910343.

Nasu Y., Timme T.L., Yang G., Bangma C.H., Li L., Ren C., Park S.H., DeLeon M., Wang J., Thompson T.C. (1998): Suppression of caveolin expression induces androgen sensitivity in metastatic androgen-insensitive mouse prostate cancer cells. Nat Med 4: 1062-1064.

Neufeld E.B., Clooney A.M., Pitha J., Dawidowicz E.A., Dwyer N.K., Pentchev P.G., Banchette-Mackie E.J. (1996): Intracellular trafficking of cholesterol monitored with a cyclodextrin. J Biol Chem 271: 21604-21613.

Neuhoff V., Philipp K., Zimmer H.G., Mesecke A. (1979): A simple, versatile, sensitive and volume-independent method for quantitative protein determination which is independent of other external influences. Hoppe Seylers Z Physiol Chem 360: 16571670.

Nishiyama K., Trapp B.D., Ikezu T., Ranshoff R.M., Tomita T., Iwatsubo T., Kanazawa I., Hasiao K.K., Lisanti M.P., Okamoto T. (1999): Caveolin-3 upregulation activates $ß$-secretase-mediated cleavage of the amyloid precursor protein in Alzheimer's disease. J Neurosci 19: 6538-6548.

Noble M., Wolswijk G., Wren D. (1989): The complex relationship between cell division and the control of differentiation in oligodendrocyte-type-2 astrocyte progenitor cells isolated from perinatal and adult rat optic nerves. Prog Growth Factor Res 3: 179-194. 
Nomura R., Fujimoto T., (1999): Tyrosine-phosphorylated caveolin-1: Immunlocalization and molecular characterization. Mol Biol Cell 10: 975-986.

Nystrom F.H., Chen H., Cong L.N., Li Y., Quon M.J. (1999): Caveolin-1 interacts with the insulin receptor and can differentially modulate insulin signaling in transfected Cos-7 cells and rat adipose cells. Mol Endocrinol 13: 2013-2024.

Ohvo-Rekila H., Ramstedt B., Leppimaki P., Slotte J.P. (2002): Cholesterol interactions with phospholipids in membranes. Prog Lipid Res 41: 66-97.

Oka N., Yamamoto M., Schwencke C., Kawabe J., Ebina T., Ohno S., Couet J., Lisanti M.P., Ishikawa Y. (1997): Caveolin interaction with protein kinase C. Isoenzyme-dependent regulation of kinase activity by the caveolin scaffolding domain peptide. J Biol Chem 272: 33416-33421.

Okamoto T., Schlegel A., Scherer P.E., Lisanti M.P. (1998): Caveolins, a family of scaffolding proteins for organizing “preassembled signaling complexes” at the plasma membrane. J Biol Chem 273: 5419-5422.

Orentas D.M., Miller R.H. (1998): Regulation of oligodendrocyte development. Mol Neurobiol 18: 247-259.

Orlichenko L., Huang B., Krueger E., McNiven M.A. (2005): EGF-induced phosphorylation of caveolin-1 at tyrosine 14 stimulates caveolae formation in epithelial cells. J Biol Chem in press.

Ostermeyer A.G., Paci J.M., Zeng Y., Lublin D.M., Munro S., Brown D.A. (2001): Accumulation of caveolin in the endoplasmic reticulum redirects the protein to lipid storage droplets. J Cell Biol 152: 1071-1078.

Palade G.E. (1953): Fine structure of blood capillaries. J Appl Physiol 24: 1424-1436. 
Paratcha G., Ibanez C.F. (2002): Lipid rafts and the control of neurotrophic factor signaling in the nervous system: variations on a theme. Curr Opin Neurobiol 12: 542549.

Park S.C., Yeo E.J., Han J.A., Hwang Y.C., Choi J.Y., Park J.S., Park Y.H., Kim K.O., Kim I.G., Seong S.C., Kwak S.J. (1999): Aging process is accompanied by increase of transglutaminase C. J Gerontol Biol Sci Med Sci 54: 78-83.

Park W.Y., Park J.S., Cho K.A., Kim D.I., Ko Y.G., Seo J.S., Parks S.C. (2000): Up-regulation of caveolin attenuates epidermal growth factor signalling in senescent cell. J Biol Chem 275: 20847-20852.

Park D.S., Cohen A.W., Frank G.W., Razani B., Lee H., Williams T.M., Chandra M., Shirani J., De Souza A.P., Tang B., Jelicks L.A., Factor S.M., Weiss L.M., Tanowitz H.B., Lisanti M.P. (2003): Caveolin-1 null (-/-) mice show dramatic reductions in life span. Biochemistry 42: 15124-15131.

Parton R.G., Way M., Zorzi N., Stang E. (1997): Caveolin-3 associates with developing T-tubules during muscle differentiation. J Cell Biol 136: 137-154.

Parton R.G., Richards A.A. (2003): Lipid rafts and caveolae as portals for endocytosis: new insights and common mechanisms. Traffic 4: 724-738.

Peiro S., Comella J.X., Enrich C., Martin-Zanca D., Rocamora N. (2000): PC12 cells have caveolae that contain TrkA. Caveolae disrupting drugs inhibit nerve growth factor-induced, but not epidermal growth factor induced, MAPK phosphorylation. J Biol Chem. 275: 37846-37852.

Peters A. (1964): Observation on the connexions between myelin sheaths and glial cells in the optic nerve of young rats. J Anat 98: 125.

Peters A., Moss M.B., Sethares C. (2000): Effects of aging on myelinated nerve fibers in monkey primary visual cortex. J Comp Neurol 419: 364-376. 
Pfeiffer S.E., Warrington A.E., Bansal V.S. (1993): The oligodendrocyte and its many cellular processes. Trends Cell Biol 191-197.

Pfrieger F.W. (2003): Cholesterol homeostasis and function in neurons of the central nervous system. Cell Mol Life Sci 60: 1158-1171.

Pierce S.K. (2004): To cluster or not to cluster: FRETting over rafts. Nature Cell Biol 6: 180-181.

Pike L.J. (2003): Lipid rafts: bringing order into the chaos. J Lipid Res 44: 655-666.

Pike L. (2005): Growth factor receptors, lipid rafts and caveolae: An evolving story. Biochem Biophys Acta 1746: 260-273.

Pringle N., Collarini E.J., Mosley M.J., Heldin C.H., Westermark B., Richardson W.D. (1989): PDGF A chain drive proliferation of bipotential (O-2A) glial progenitor cells in the developing rat optic nerve. EMBO J 8: 1049-1056.

Razani B., Lisanti M.P. (2001a): Two distinct caveolin-1 domains mediate the functional interaction of caveolin-1 with protein kinase A. Am J Physiol Cell Physiol 281: $1241-1250$.

Razani B., Schlegel A., Liu J., Lisanti M.P. (2001b): Caveolin-1, a putativ tumour suppressor gene. Biochem Soc Trans 29: 494-499.

Rabizadeh S., Oh J., Zhong L.T., Yang J., Bitler C.M., Butcher L.L., Bredesen D.E. (1993): Induction of apoptosis by the low-affinity NGF receptor. Science 261: 345-348.

Richardson W.D., Smith H.K., Sun T., Pringle N.P., Hall A., Woodruff R. (2000): Oligodendrocyte lineage and the motor neuron connection. Glia 29: 136-142.

Ringerike T., Blystad F.D., Levy F.O., Madshus I.H., Stang E. (2001): Cholesterol is important in control of EGF receptor kinase activity but EGF receptors are not concentrated in caveolae. J Cell Sci 115: 1331-1340. 
Rodriguez-Tebar A., Dechant G., Barde Y.A. (1990): Binding of brain-derived neurotrophic factor receptor. Neuron 4: 487-492.

Rodriguez-Tebar A., Dechant G., Gotz R., Barde Y.A. (1992): Binding of neurotrophin-3 to its neuronal receptors and interactions with nerve growth factor and brain-derived neurotrophic factors. EMBO J 11: 917-922.

Rohde G. (1998): Effekt von NGF auf die Remyelinisation von experimentell demyelinisierten Arealen im Corpus Callosum des Göttinger Miniaturschweines. Dissertation, Tierärztliche Hochschule Hannover.

Rothberg K.G., Ying Y.S., Kamen B.A., Anderson R.G. (1990): Cholesterol controls the clustering of the glycophospholipid-anchored membrane receptor for 5methyltetrahydrofolate. J Cell Biol 111: 2931-2938.

Rothberg K.G., Heuser J.E., Donzell W.C., Ying Y., Glenney J.R., Anderson R.G.W. (1992): Caveolin, a protein component of caveolae membrane coats. Cell 68: 673-682.

Roy S., Luetterforst R., Harding A., Apollini A., Etheridge M., Stang E., Rolls B., Hancock J.F., Parton R.G. (1999): Dominant negative caveolin inhibits H-Ras function by disrupting cholesterol-rich plasma membrane domains. Nat Cell Biol 1: 98105.

Sargiacomo M., Sudol M., Tang Z.L., Lisanti M.P. (1993): Signal transducing molecules and GPI-linked proteins form a caveolin-rich insoluble complex in MDCK cells. J Cell Biol 122: 789-807.

Sargiacomo M., Scherer P.E., Tang Z., Kubler E., Song K.S., Sanders M.C., Lisanti M.P. (1995): Oligomeric structure of caveolin: implications for caveolae membrane organization. Proc Natl Acad Sci 92: 9407-9411.

Scherer P.E., Lisanti M.P., Baldini G., Sargiacomo M., Corley-Mastick C., Lodish H.F. (1994): Induction of caveolin during adipogenesis and association of GLUT4 with caveolin-rich vesicles. J Cell Biol 127: 1233-1243. 
Scherer P.E., Tang Z.L., Chun M.C., Sargiacomo M., Lodish H.F., Lisanti M.P. (1995): Caveolin isoforms differ in their N-terminal protein sequence, subcellular distribution: identification and epitope mapping of an isoform-specific monoclonal antibody probe. J Biol Chem 270: 16395-16401.

Scherer P.E., Lewis R.Y., Volonte D., Engelman J.A., Galbiati F., Couet J., Kohtz D.S., van Donselaar E., Peters J., Lisanti M.P. (1997): Cell-type and tissue-specific expression of caveolin-2. Caveolins 1 and 2 co-localize and form a stable heterooligomeric complex in vivo. J. Biol. Chem 272: 29337-29346.

Schlessinger J., Ullrich A. (1992): Growth factor signalling by receptor tyrosine kinases. Neuron 9: 383-391.

Schwab W., Galbiati F., Volonte D., Hempel U., Wenzel K.W., Funk R.H., Lisanti M.P., Kasper M. (1999): Characterization of caveolins from cartilage: expression of caveolin-1,-2 and -3 in chondrocytes and in alginate cell culture of the rat tibia. Cell Biol 112: 41-49.

Shatz M., Liscovitch M. (2004): Caveolin-1 and cancer multidrug resistance: coordinate regulation of pro-survival protein? Leuk Res 28: 907-908.

Shiraha H., Gupta K., Drabik K., Wells A. (2000): Aging fibroblasts present reduced epidermal growth factor (EGF) responsiveness due to preferential loss of EGF receptors. J Biol Chem 275: 19343-19351.

Silva W.I., Maldonado H.M., Lisanti M.P., De Vellis J., Chrompre G., Mayol N., Ortiz M., Velazquez G., Maldonado A., Montalvo J. (1999): Identification of caveolae and caveolin in C6 glioma cells. Int J Dev Neurosci 17: 705-714.

Simons K., Ikonen E. (1997): Functional rafts in cell membranes. Nature 387: 569572.

Simons K, Toomre D. (2000): Lipid rafts and signal transduction. Nat Rev Mol Cell Biol 1: 31-39. 
Skwarek M. (2004): Recent controversy surrounding lipid rafts. Arch Immunol Ther Exp 52: 427-431.

Smart E.J., Ying Y., Conrad P.A., Anderson R.G.W. (1994): Caveolin moves from caveolae to the golgi apparatus in response to cholesterol oxidation. J Cell Biol 127: 1185-1197.

Smart E.J., Ying Y., Mineo C., Anderson R.G.W. (1995): A detergent-free method for purifying caveolae membrane from tissue cultured cells. Proc Natl Acad Sci 92: 10104-10108.

Smart E.J., Ys Y., Donzell W.C., Anderson R.G.W. (1996): A role for caveolin in transport of cholesterol from endoplasmic reticulum to plasma membrane. J Biol Chem 271: 29427-29435.

Song S.K., Li S., Okamoto T., Quilliam L.A., Sargiacomo L.A., Lisanti M.P. (1996): Co-purification and direct interaction of Ras with caveolin, an integral membrane protein of caveolae microdomains. Detergent-free purification of caveolae microdomains. J Biol Chem 271: 9690-9697.

Song K.S., Tang Z., Li S., Lisanti M.P. (1997): Mutational analysis of the properties of caveolin-1. A novel role for the C-terminal domain in mediating homo-typic caveolin-caveolin interaction. J Biol Chem 272: 4398-4403.

Sowa G., Pypaert M., Fulton D., Sessa W.C. (2003): The phosphorylation of caveolin-2 on serines 23 and 36 modulates caveolin-1 dependent caveolae formation. Proc Natl Acad Sci 100: 6511-6516.

Stan R.V (2002): Structure and function of endothelial caveolae. Microsc Res Tech 57: 350-364.

Stan R.V. (2005): Structure of caveolae. Biochim Biophys Acta 1746: 334-348. 
Stariha R.L., Kikuchi S., Siow Y.L., Pelech S.L., Kim M., Kim S.U. (1997): Role of extracellular signal-regulated protein kinases 1 and 2 in oligodendroglial process extension. J Neurochem 68: 945-953.

Tabernero A., Bolanos J.P., Medina J.M. (1993): Lipogenesis from lactate in rat neurons and astrocytes in primary culture. Biochem J 294: 635-638.

Tapley P., Lamballe F., Barbacid M. (1992): K252a is a selective inhibitor of the tyrosine protein kinase activity of trk family of oncogenes and neurotrophin receptors. Oncogenes 7: 371-381.

Tang Z.L., Scherer P.E., Okamoto T., Song K., Chu C., Kohtz D.S., Nishimoto I., Lodish H.F., Lisanti M.P. (1996): Molecular cloning of caveolin-3, a novel member of the caveolin gene family expressed predominantly in muscle. J Biol Chem 271: 22552261.

Thiele C., Hannah M.J., Fahrenholz F., Huttner W.B. (2000): Cholesterol binds to synaptophysin and is required for biogenesis of synaptic vesicles. Nat Cell Biol 2: 4249.

Thorn H., Stenkula K.G., Karlsson M., Ortegren U., Nystrom F.H., Gustavsson J., Stralfors P. (2003): Cell surface orifices of caveolae and localization of caveolin to the necks of caveolae in adipocytes. Mol Biol Cell 14: 3967-3976.

Towbin H., Staehlin T., Gordon J. (1979): Electrophoretic transfer of proteins from polyacrylamide gels to nitrocellulose sheets: Procedure and some applications. Proc Natl Acad Sci 76: 4350-4354.

Toya Y., Schwencke C., Couet J., Lisanti M.P., Ishikawa Y. (1998): Inhibition of adenylyl cyclase by caveolin peptides. Endocrinology 139: 2025-2031.

Tsui-Pierchala B.A., Ginty D.D. (1999): Characterization of an NGF-P-TrkA retrograde-signaling complex and age-dependent regulation of TrkA phosphorylation in sympathetic neurons. J Neurosci 19: 8207-8218. 
Tsui-Pierchala B.A., Encinas M., Milbrnadt J., Johnson E.M. (2002): Lipid rafts in neuronal signalling and function. Trends Neurosci 25: 412-417.

Uehara K., Miyoshi M. (1999): Tubular invaginations with caveolae and coated pits in the sinus endothelial cells in the rat spleen. Histochem Cell Biol 112: 351-358.

Uittenbogaard A., Ying Y.S., Smart E.J. (1998): Characterization of a cytosolic heatshock protein-caveolin chaperone complex. Involvement in cholesterol trafficking. J Biol Chem 273: 6525-6532.

Uittenbogaard A., Smart E.J. (2000): Palmitoylation of caveolin-1 is required for cholesterol binding chaperone complex formation and rapid transport of cholesterol to caveolae [in process citation]. J Biol. Chem. 275: 25595-25599.

Ullrich A., Schlessinger J. (1990): Signal transduction by receptors with tyrosine kinase activity. Cell 61: 671-678.

Vainio S., Heino S., Mansson J.E., Fredman P., Kuismanen E., Vaarala O., Ikonen E. (2002): Dynamic association of human insulin receptor with lipid rafts in cells lacking caveolae. EMBO Rep 3: 95-100.

Vance J.E., Campenot R.B., Vance D.E. (2000): The synthesis and transport of lipid for axonal growth and nerve regeneration. Biochim Biophys Acta 1486: 84-96.

Varma R., Mayor S. (1998): GPI-anchored proteins are organized in submicron domains at the cell surface. Nature 394: 798-801.

Vasile E., Hong Q., Dvorak H.F., Dvorak A.M. (1999): Caveolae and vesiculovacuolar organelles in bovine capillary endothelial cells cultured with VPF/VEGF on floating matrigelcollagen gels. J Histochem Cytochem 47: 159-167.

Venema V.J., Ju H., Zou R., Venema R.C. (1997): Interaction of neuronal nitric oxide synthase with caveolin-3 in skeletal muscle. Identification of a novel caveolin scaffolding/inhibitory domain. J Biol Chem 272: 28187-28190. 
Verdi J.M., Anderson D.J. (1994): Neurotrophins regulate sequential changes in neurotrophin receptor expression by sympathetic neuroblast. Neuron 13: 1359-1372.

Virdee K., Tolkovsky A.M. (1995): Activation of p44 and p42 MAP kinases is not essential for the survival of rat sympathetic neurons. Europ J Neurosci 7: 2159-2169.

Voinnet O. (2005): Induction and suppression of RNA silencing: insights from viral infections. Nat Rev Genet 6: 206-220.

Volonte D., Galbiati F., Pestell R.G., Lisanti M.P. (2001): Cellular stress induces the tyrosine phosphorylation of caveolin-1 $\left(\mathrm{Tyr}^{14}\right)$ via activation of p38 mitogen-activated protein kinase and c-Src kinase. Evidence for caveolae, the actin cytoskeleton, and focal adhesions as mechanical sensors of osmotic stress. J Biol Chem 276: 8094-8103.

Volonte D., Zhang K., Lisanti M.P., Galbiati F. (2002): Expression of caveolin-1 induces premature cellular senescence in primary cultures of murine fibroblasts. Stressinduced premature senescence upregulates the expression of endogenous caveolin- 1 . Mol Biol Cell 13: 2502-2517.

Waugh M.G., Lawson D., Hsuan J.J. (1999): Epidermal growth factor receptor activation is localized within low-buoyant density, non-caveolar membrane domains. Biochem J 337: 591-597.

Waugh M.G., Minogue S., Anderson J.S., dos Santos M., Hsuan J.J. (2001): Signalling and non-caveolar rafts. Biochem Soc Trans 29: 509-512.

Way M., Parton R. (1995): M-caveolin, a muscle-specific caveolin-related protein. FEBS Lett 376: 108-112.

Westermann M., Steiniger F., Richter W. (2005): Belt-like localization of caveolin in deep caveolae and its re-distribution after cholesterol depletion. Histochem Cell Biol 123: 613-620. 
Wheaton K., Sampsel K., Boisvert F.M., Davy A., Robbins S., Riabowol K. (2001):

Loss of functional caveolae during senescence of human fibroblasts. J Cell Physiol 187: 226-235.

Williams T.M., Lisanti M.P. (2004): The caveolin proteins. Genome Biol 5: 214.

Yamada E. (1955): The fine structure of the gall bladder of the mouse. J Biophys Biochem Cytol: 445-458.

Yamamoto M., Toya Y., Schwencke C., Lisanti M.P., Myers M., Ishikawa Y. (1998): Caveolin is an activator of insulin receptor signaling. J Biol Chem 273: 2696226968.

Yancey P.G., Rodrigueza W.V., Kilsdonk E.P.C., Stoudt G.W., Johnson J., Phillips M.C., Rothblat G.H. (1996): Cellular cholesterol efflux mediated by cyclodextrins. J Biol Chem 271: 16026-16034.

Zhao Y.Y., Liu Y., Stan R.V., Fan L., Gu Y., Dalton N., Chu P.H., Peterson K., Ross J. JR., Chien K.R. (2002): Defects in caveolin-1 cause dilated cardiomyopathy and pulmonary hypertension in knockout mice. Proc Natl Acad Sci 99: 11375-11380. 


\section{Danksagung}

Mein besonderer Dank gilt Herrn Dr. H.-H. Althaus für die freundliche Überlassung des Themas dieser Dissertation sowie die hervorragende Unterstützung und Betreuung meiner Arbeit.

Meinen Kollegen Sabine Klöppner und Steve Klopfleisch danke ich vielmals für ein sehr angenehmes Arbeitsklima während meiner ganzen Zeit und für all die Hilfe und die sehr gute Zusammenarbeit.

Meiner lieben Freundin Sandra Signore danke ich herzlichst für ihre Hilfe beim Korrekturlesen der Arbeit.

Außerdem danke ich dem Diplombiologen Markus Schlomm, meinem besten Freund und ehemaligen Bundeswehrkameraden, für seine Hilfe beim Korrekturlesen der Arbeit.

Ich danke insbesondere meiner Familie, meiner Mutter Ursula Schmitz und meinem Vater Dieter Schmitz sowie meinen Großeltern für all die Unterstützung und Liebe, die sie mir auf meinem Lebensweg mitgegeben haben. 


\section{Lebenslauf}

$\begin{array}{ll}\text { Name: } & \text { Schmitz } \\ \text { Vorname: } & \text { Matthias } \\ \text { Geburtsdatum: } & 02.09 .1975 \\ \text { Geburtsort: } & \text { Hamm } \\ \text { Staatsangehörigkeit: deutsch }\end{array}$

\section{Schulbildung:}

1982-1986: $\quad$ Grundschule Grüner Winkel in Hamm

1986-1995: Beisenkampgymnasium in Hamm

Abschluss : $\quad$ Abitur

Wehrdienst:

1995-1996: $\quad$ Grundwehrdienst in Lippstadt 2. Transportbataillon 801

\section{Studium:}

WS 1996/97: Immatrikulation an der Georg-August-Universität Göttingen

Oktober 1998: $\quad$ Vordiplom in den Fächer: Mikrobiologie, Botanik, anorganische Chemie und physikalische Chemie

Mai 2001: Hauptdiplomprüfung in den Fächer: Genetik, Immunologie, Chemie

bis April 2002: $\quad$ Externe Diplomarbeit in der Abteilung Immunologie mit folgendem Titel: “Induktion profibrotischer Zytokine und extrazellulärer Matrixproteine in Hepatischen Sternzellen (ItoZellen) durch das Anaphylatoxin C5a.“

2002-2006: $\quad$ Promotionsarbeit im Max-Planck-Institut für experimentelle Medizin in der Arbeitsgruppe: Neurale Regeneration. Leiter: Dr. H.-H. Althaus 